\title{
Assessment and evaluation of noise controls on roof bolting equipment and a method for predicting sound pressure levels in underground coal mining
}

Rudy J. Matetic

West Virginia University

Follow this and additional works at: https://researchrepository.wvu.edu/etd

\section{Recommended Citation}

Matetic, Rudy J., "Assessment and evaluation of noise controls on roof bolting equipment and a method for predicting sound pressure levels in underground coal mining" (2006). Graduate Theses, Dissertations, and Problem Reports. 2754.

https://researchrepository.wvu.edu/etd/2754

This Dissertation is protected by copyright and/or related rights. It has been brought to you by the The Research Repository @ WVU with permission from the rights-holder(s). You are free to use this Dissertation in any way that is permitted by the copyright and related rights legislation that applies to your use. For other uses you must obtain permission from the rights-holder(s) directly, unless additional rights are indicated by a Creative Commons license in the record and/ or on the work itself. This Dissertation has been accepted for inclusion in WVU Graduate Theses, Dissertations, and Problem Reports collection by an authorized administrator of The Research Repository @ WVU.

For more information, please contact researchrepository@mail.wvu.edu. 
Assessment and Evaluation of Noise Controls on Roof Bolting Equipment and A Method For Predicting Sound Pressure Levels in Underground Coal Mining

Rudy J. Matetic

\author{
Dissertation Submitted to the \\ College of Engineering and Mineral Resources \\ at West Virginia University \\ in partial fulfillment of the requirements \\ for the degree of
}

Doctor of Philosophy

In Engineering

\author{
Syd Peng, Ph.D., Chair \\ Felicia Peng, Ph.D. \\ Yi Luo, Ph.D. \\ Keith Heasley, Ph.D. \\ Gerald Finfinger, Ph.D. \\ Department of Mining Engineering \\ Morgantown, West Virginia \\ 2006
}

Keywords: Roof Bolting, Drilling, Sound Power, Sound Pressure, Noise Controls, Drill Bits, Drill Steel

Copyright 2006 Rudy J. Matetic 


\begin{abstract}
Assessment and Evaluation of Noise Controls on Roof Bolting Equipment and A Method For Predicting Sound Pressure Levels in Underground Coal Mining
\end{abstract}

Rudy J. Matetic

Over-exposure to noise remains a widespread and serious health hazard in the U.S. mining industries despite 25 years of regulation. Every day, $80 \%$ of the nation's miners go to work in an environment where the time weighted average (TWA) noise level exceeds $85 \mathrm{dBA}$ and more than $25 \%$ of the miners are exposed to a TWA noise level that exceeds $90 \mathrm{dBA}$, the permissible exposure limit (PEL). Additionally, MSHA coal noise sample data collected from 2000 to 2002 show that $65 \%$ of the equipment whose operators exceeded $100 \%$ noise dosage comprise only seven different types of machines; auger miners, bulldozers, continuous miners, front end loaders, roof bolters, shuttle cars (electric), and trucks. In addition, the MSHA data indicate that the roof bolter is third among all the equipment and second among equipment in underground coal whose operators exceed $100 \%$ dosage.

A research program was implemented to: 1) determine, characterize and to measure sound power levels radiated by a roof bolting machine during differing drilling configurations (thrust, rotational speed, penetration rate, etc.) and utilizing differing types of drilling methods in high compressive strength rock media (>20,000 psi). The research approach characterized the sound power level results from laboratory testing and provided the mining industry with empirical data relative to utilizing differing noise control technologies (drilling configurations and types of drilling methods) in reducing sound power level emissions on a roof bolting machine; 2) distinguish and correlate the empirical data into one, statistically valid, equation, in which, provided the mining industry with a tool to predict overall sound power levels of a roof bolting machine given any type of drilling configuration and drilling method utilized in industry; 3) provided the mining industry with several approaches to predict or determine sound pressure levels in an underground coal mine utilizing laboratory test results from a roof bolting machine and 4) described a method for determining an operators’ noise dosage of a roof bolting machine utilizing predicted or determined sound pressure levels. 


\section{TABLE OF CONTENTS}

Title Page

. $\mathrm{i}$

Abstract.

List of Figures.

List of Tables

Nomenclature xiv

Dedication xvii

Acknowledgement xviii

Chapter 1: INTRODUCTION...

Chapter 2: LITERATURE REVIEW. .6

Chapter 3: OBJECTIVE OF RESEARCH .14

Chapter 4: SCOPE AND METHODS OF RESEARCH

4.1. Standard Operating Procedure for Conducting Noise

Measurements (Sound Power) of Roof Bolting Machines

In the Pittsburgh Research Laboratory’s Reverberation

Room.

4.1.1 Preface for Determining Sound Power Level ...................................17

4.1.2 Introduction ............................................................................17

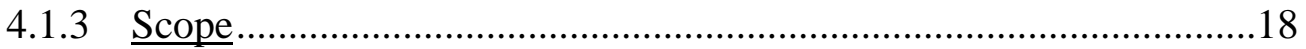

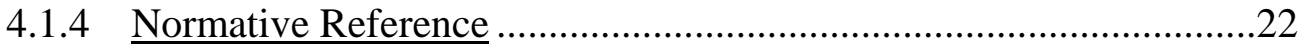

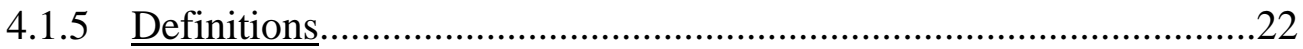

4.1.6 Requirements for a Special Reverberation Test Room......................22

4.1.7 Installation and Operation of Source under Test ..............................24

4.1.8 Measurements in Test Room …...................................................25

4.1.9 Calculation of Sound Power Levels...................................................29

4.1.10 Information Reported for Each Test Condition .................................30

4.2 Modification of Steel Test Fixture for Roof Bolter Testing in the

Reverberation Room ....................................................................................33

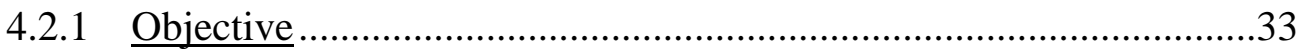

4.2.2 Tests Performed to Assess Sound Power Radiated from Test Fixture .......................................................................................34

4.2.3 Conclusions...................................................................................40

4.3 Sound Power Level Testing in Reverberation Room ................................41

4.3.1 Setting of Thrust Configurations. ...................................................44

4.3.2 Setting Rotational Speed Configurations..........................................47

4.3.3 Determining Penetration Rate or Displacement during Testing ........48

4.3.4 Pulse System and Excel Data Collection Common to Speed And Displacement...........................................................................49

4.4 Rock Media and Strength Property Testing of Drilling Media......................50

4.4.1 Type of Rock Media ......................................................................50

4.4.2 Obtaining Rock Cores of Rock Media...............................................51

4.4.3 Unconfined Compressive Strength of Rock Media ...........................52

$4.5 \quad$ Testing of Differing Bits and Drill Steel.....................................................53

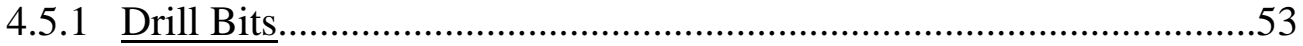

4.5.2 Drill Steel ........................................................................................54 
4.6 Testing of Different Drilling Methods .............................................................55

4.6.1 Dry (Vacuum), Wet and "Mist" System ..........................................55

4.7 Summary of Tests Conducted in the Reverberation Room ............................56

Chapter 5: APPLICATIONS OF SOUND POWER LEVEL MEASUREMENTS

CONDUCTED IN THE REVERBERATION ROOM..............................58

5.1 Drilling Components and Parameters Utilized for Testing..............................58

5.2. Data Collected for Sound Power Level Tests ..................................................59

5.3. Experimental Test Results - Sound Power Levels ........................................72

5.3.1 Round Drill Steel Compared to Hexagonal Drill Steel........................73

5.3.2 One Inch Diameter Compared to One and Three-Eighths Inch

Diameter Drill Bits................................................................................ 80

5.3.3 General Conclusions Regarding Data Collection ...............................83

5.4. Development of a Statistical Model for Determining Sound Power Levels..85

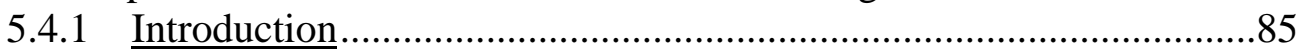

5.4.2 Statistical Accuracy of the Model.......................................................98

5.4.3 Development of Equation for Determining a Sound Power Level...111

Chapter 6: DEVELOPMENT AND UTILIZATION OF MODELS FOR PREDICTING SOUND PRESSURE LEVELS FROM LABORATORY

TESTS

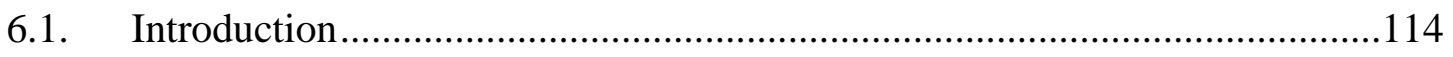

6.2. Model for Predicting Sound Pressure Levels Using Overall Sound

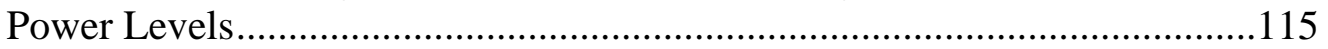

6.2.1 Introduction.....................................................................................115

6.2.2 Predicting Underground Sound Pressure Levels from

Measurements Above Ground .............................................................116

6.2.2.1 Differences between the Room Acoustic Method and Imaging Method ..................................................................116

6.2.2.2 Predicting Sound Levels at a Single Point ..............................118

6.2.2.3 Predicting Sound Levels at Multiple Points.............................119

6.2.2.4 Predicting Sound Levels in the Near-Field.............................124

6.2.3 Limitations of Model Utilizing Overall Sound Power Level..............126

6.3. Model for Predicting Sound Pressure Levels Using Full-Octave

Band Frequency Sound Power Level.........................................................127

6.3.1 Ray-tracing Technique.......................................................................127

6.3.2 Raynoise Computer Program.............................................................127

6.3.3 Absorption Coefficients.......................................................................129

6.3.4 Method for Determining Absorption Coefficients in an Underground

Coal Mine...........................................................................................130

6.3.4.1 Underground Measurements and Testing Parameters ............130

6.3.4.2 Utilizing the Excelparse Program for Calculating OctaveBand Information .....................................................................137

6.3.4.3 Development of an Equivalent Model in Raynoise for

Predicting Sound Pressure Levels............................................141

6.3.5 Predicting Sound Pressure Levels Underground Due to Drilling

Cycle of Roof Bolting Machine ..........................................................158 
6.3.5.1 Full-Octave Band Sound Power Levels from Laboratory Testing ................................................................................158

6.3.5.2 Specific Characteristics of the Roof Bolting Machine ..........159

6.3.5.3 Establishment of a Measurement Grid for the Underground Mine Section .............................................................................161

6.3.5.4 Development of a Command File for Input into Raynoise Program..............................................................................164

6.3.5.5 Sound Pressure Levels Determined from Raynoise

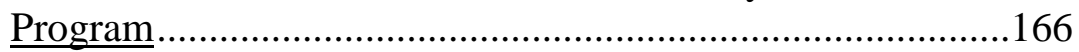

6.3.5.6 Comparing Sound Pressure Levels - Model Prediction vs.Underground Measurements 169

6.3.6 Determining the Noise Dosage a of Roof Bolter Operator from Predicted Sound Pressure Levels ........................................................181

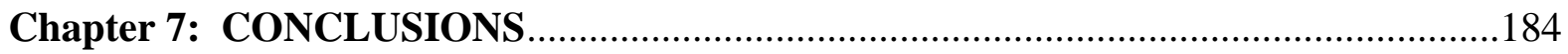

Chapter 8: RECOMMENDATIONS FOR FUTURE RESEARCH .............................188

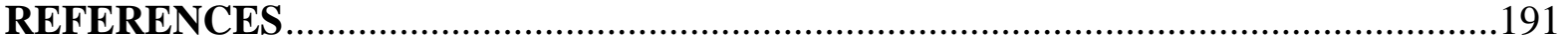




\section{LIST OF FIGURES}

Figure \#

Page

1.1 Analysis of Audiograms for Coal and Metal/Non-Metal Miners

1.2 MSHA Coal Noise Sample Data - Percentage of Equipment Whose Operators Exceeded 100\% Dose

1.3 Noise Testing of Roof Bolter in Reverberation Room

4.1 Sketch of the PRL Reverberation Chamber

One-third Octave Sound Power Levels Determined for a Specific Control Test

4.3 Test Fixture in Reverberation Room

4.4 Location of Test Fixture Support Tubes and Accelerometers

4.5 Estimated Sound Power Level (dBA) and Reduction in

Sound Power Level Before and After Modifications

4.6 Reverberation Room at PRL

4.7 Bruel \& Kjaer Pulse Data Acquisition System

4.8 Joystick on Control Panel

4.9 Drill Mast of Roof Bolting Machine Raised to Test Stand

4.13 Location of String Potentiometer for Determination of Penetration Rate 


\section{LIST OF FIGURES}

Figure \# $\quad$ Page

4.16 Sample of Core Collected from Barre Granite Rock Media 52

4.17 Types of Drill Bits Used During Roof Bolting Operations 53

4.18 Types of Drill Steel Used During Roof Bolting Operations $\quad 54$

4.19 Photograph of “Mist” System Used During Noise Testing 55

$5.1 \quad$ Drill Steels - Round and Hex (1-inch) - Thrust vs. 73

Penetration Rate

5.2 Drill Steels - Round and Hex (1-inch) - Penetration Rate 75 vs. Sound Power Level

5.3 Drill Steels - Round and Hex (1.375-inch) - Thrust vs. 77 Penetration Rate

5.4 Drill Steels - Round and Hex (1.375-inch) - Penetration Rate 79 vs. Sound Power Level

5.5 One-inch vs. 1.375-inch Drill Bit - 81

(Penetration Rate vs. Thrust)

5.6 One-inch vs. 1.375-inch Drill Bit -

(Penetration Rate vs. Sound Power Level)

5.7 One-inch Round Drill Steel - Vacuum and Wet -

Sound Power Levels - 4,949 lbs Thrust, 200 rpm Rotational Speed

5.8 Histogram Representing the Fit Accuracy of Statistical

Run of Model

6.1 Comparison of Imaging and Room Acoustics Method of Predicting Sound Pressure Levels

6.2 Correction Factors for Converting Above Ground Measurements to Underground Sound Pressure Levels (Tunnels) 


\section{LIST OF FIGURES}

Figure \# $\quad \underline{\text { Page }}$

6.3 Correction Factors for Converting Above Ground

Measurements to Underground Sound Pressure

Levels (Flat Rooms)

6.4 Correction Factors for Determining Underground

122

Sound Pressure Levels from Sound Power Measurements

Above Ground (Tunnels)

$6.5 \quad$ Correction Factors for Determining Underground Sound

123

Pressure Levels from Sound Power Measurements Above

Ground (Flat Rooms)

6.6 Correction Factors for Determining Sound Pressure Levels

125

Underground in the Near Field

(Top-Tunnel and Bottom-Flat Room)

6.7 Sound Pressure Level Contour Plot Using the Raynoise

128

Program

6.8 Illustration of Ray Tracing Model for Analyzing the Acoustic

Environment

6.9 Measurement Layout Used for Determining Absorption

Coefficients in an Underground Coal Mine

6.10 Photograph of Calibrated Sound Source Used for

132

Underground Testing

6.11 Photograph of a A Brüel and Kjaer 2260 Investigator

6.12 Measurement Locations for Determining Acoustical

135

Properties Underground

6.13 Screenshot of the Excelparse Program

6.14 Test Layout for First Run in Raynoise Model 142

6.15 Sound Pressure Levels at 1,000 Hz Full-Octave Band 144

6.16 Comparing Calculated vs. Measured Sound Pressure Levels for 146 63-Hz Octave Band 


\section{LIST OF FIGURES}

Figure \# $\quad$ Page

6.17 Comparing Calculated vs. Measured Sound Pressure Levels for 147 125-Hz Octave Band

6.18 Comparing Calculated vs. Measured Sound Pressure Levels for 147 250-Hz Octave Band

6.19 Comparing Calculated vs. Measured Sound Pressure Levels for 148 500-Hz Octave Band

6.20 Comparing Calculated vs. Measured Sound Pressure Levels for 148 1,000-Hz Octave Band

6.21 Comparing Calculated vs. Measured Sound Pressure Levels for 2,000-Hz Octave Band

6.22 Comparing Calculated vs. Measured Sound Pressure Levels for 4,000-Hz Octave Band

6.23 Comparing Calculated vs. Measured Sound Pressure Levels for 8,000-Hz Octave Band

6.24 Comparing Calculated vs. Measured Sound Pressure Levels for 63-Hz Octave Band (Model Run 5)

6.25 Comparing Calculated vs. Measured Sound Pressure Levels for 125-Hz Octave Band (Model Run 5)

6.26 Comparing Calculated vs. Measured Sound Pressure Levels for 250-Hz Octave Band (Model Run 5)

6.27 Comparing Calculated vs. Measured Sound Pressure Levels for 152 500-Hz Octave Band (Model Run 5)

6.28 Comparing Calculated vs. Measured Sound Pressure Levels for 1,000-Hz Octave Band (Model Run 5)

6.29 Comparing Calculated vs. Measured Sound Pressure Levels for 2,000-Hz Octave Band (Model Run 5)

6.30 Comparing Calculated vs. Measured Sound Pressure Levels for 4,000-Hz Octave Band (Model Run 5) 


\section{LIST OF FIGURES}

Figure \# $\quad \underline{\text { Page }}$

6.31 Comparing Calculated vs. Measured Sound Pressure Levels for 154 8,000-Hz Octave Band (Model Run 5)

6.32 AutoCAD drawing of a Roof Ranger II Roof Bolting Machine 160

6.33 AutoCAD drawing of a HDDR Roof Bolting Machine 161

6.34 Measurement Grid Developed for a Roof Bolting Machine 162

6.35 Measurement Grid Developed for a Roof Bolting Machine at 163 a Crosscut

6.36 Measurement Grid Developed for a Roof Bolting Machine at 163 an Intersection

6.37 Screenshot of a Command File for Input into Raynoise Program 165

6.38 Determined Sound Pressure Level Contours in an Underground 166 Coal Mine

$6.39 \quad$ Determined Sound Pressure Levels (Numerical) in an 167 Underground Coal Mine

6.40 Zoom-view of Determined Sound Pressure Levels Near a Roof 168 Bolting Machine

6.41 Roof Bolting Plan at the Underground Coal Mine 169

6.42 Model Simulation for Predicting Sound Pressure Levels 171

6.43 Sound Pressure Level Contours for Model Run 173

6.44 A-Weighted Sound Pressure Levels Near Operator Position $\quad 179$ of Roof Bolting Machine 


\section{LIST OF TABLES}

$\underline{\text { Table \# }}$

Page

4.1 Reverberation Chamber-Surface Area and Volume

4.2 Estimated Values of the Standard Deviation of

21

Reproducibility of Sound Power Levels

4.4 Evaluation Test for the Suitability of the Test Chamber Specific Test (numeric)

5.3 Sound Power Level Testing - Vacuum Drilling Method, 1-inch bit, Hex Drill Steel

5.4 Sound Power Level Testing - Vacuum Drilling Method, 1-3/8-inch bit, Hex Drill Steel 


\section{LIST OF TABLES}

Table \#

Page

5.6 Sound Power Level Testing - Wet Drilling Method (3 gal/min), 64 1-inch bit, Round Drill Steel

5.7 Sound Power Level Testing - Wet Drilling Method (3 gal $/ \mathrm{min}), \quad 65$ 1-inch bit, Hex Drill Steel

5.8 Sound Power Level Testing - Wet Drilling Method (3 gal/min), 66 1-3/8-inch bit, Round Drill Steel

5.9 Sound Power Level Testing - Wet Drilling Method (3 gal/min), 67 1-3/8-inch bit, Hex Drill Steel

5.10 Sound Power Level Testing - Mist Drilling Method (3 qt/min), 68 1-inch bit, Round Drill Steel

$5.11 \quad$ Sound Power Level Testing - Mist Drilling Method (3 qt/min), 69 1-inch bit, Hex Drill Steel

$5.12 \quad$ Sound Power Level Testing - Mist Drilling Method (3 qt/min), 70 1-3/8-inch bit, Round Drill Steel

$5.13 \quad$ Sound Power Level Testing - Mist Drilling Method (3 qt $/ \mathrm{min}), \quad 71$ 1-3/8-inch bit, Hex Drill Steel

5.14 Sound Power Level Contributions of Two Frequency Bands

5.15 Laboratory Data Utilized for Input into the Statistical Model 87

5.16 Regression Coefficients Determined from the Statistical Model 98

5.17 Comparing Laboratory Results to Model Results 100

6.1 One-Third Octave-band Sound Power Levels for Calibrated Noise Source

6.2 Example of the One-Third Octave Data Collected Underground 


\section{LIST OF TABLES}

Table \# $\quad \underline{\text { Page }}$

6.3 Measured Full-Octave Band Sound Pressure Levels 140 from Underground Testing

6.4 Absorption Coefficients Utilized for First Run of 143 Raynoise Model

6.5 Calculated Full-Octave Band Sound Pressure Levels - $\quad 145$

6.6 Calculated Full-Octave Band Sound Pressure Levels - $\quad 155$ Fifth Run of Model

6.7 Differences Relative to the Measured and Calculated 156

Sound Pressure Levels

6.8 Final Absorption Coefficients Determined from Model Runs $\quad 157$

6.9 Full-Octave Band Sound Power Levels from Laboratory Testing 159

6.10 Sound Pressure Level Measurements at Operator Position $\quad 170$ of Roof Bolting Machine

6.11 Full-Octave Band Sound Power Levels - 172

Compressive strength-5,000 psi., hex drill steel, 1-inch bit, rotational speed-500 rpm, Thrust setting-6,363 lbs.

6.12 Sound Pressure Level Results (Numerically) of the Model Run 174

6.13 Noise Dosage (MSHA and NIOSH) of Roof Bolting 183

Machine Operator 


\section{NOMENCLATURE}

$\underline{\text { Symbol }}$

$\alpha$

$\sigma \mathrm{R}$

$\theta$

$\lambda$

A

avthrust

avspeed

C。

$\mathrm{C}$

CL

D

$\mathrm{d}_{\min }$

DUT

ER

FRF

$\mathrm{Hz}$

$\mathrm{kHz}$

L

$L_{p i}$

$L_{p}$

$L_{w}$ $\underline{\text { Description }}$

Sabine or Absorption Coefficent

Standard Deviation of Reproducibility

Temperature

degree Celsius

Wavelength of Sound

Area of Rock Core

in $^{2}$

Average Thrust During Test

lbs

Average Rotational Speed During Test rpm

Unconfined Compressive Strength (Corrected) psi

Unconfined Compressive Strength

psi

Criterion Level

dBA

Diameter of Rock Core

in

Minimum Distance Between Microphones $\mathrm{m}$

Device Under Test

Exchange Rate

dBA

Frequency Response Function

$\mathrm{g} / \mathrm{n}$

Hertz

Kilohertz

Length of Rock Core

in

Sound pressure level at the $i^{\text {th }}$ measurement $d B$ Position

Mean of Sound Pressure Levels

$\mathrm{dB}$

Sound Power Level

$d B$ of $d B A$ 
NOMENCLATURE

\begin{tabular}{|c|c|c|}
\hline Symbol & Description & $\underline{\text { Units }}$ \\
\hline$\overline{L_{v}}$ & Surface Average Velocity Level & $\mathrm{dB}$ or $\mathrm{dBA}$ \\
\hline $\mathrm{L}_{\mathrm{wA}}$ & Average Sound Power Level & dBA \\
\hline $\mathrm{L}_{\mathrm{p}}$ (underground) (Patterson) & A-weighted Sound Pressure Level & dBA \\
\hline $\mathrm{L}_{\mathrm{w}}$ (aboveground) (Patterson) & A-weighted Sound power Level & $\mathrm{dBA}$ \\
\hline MSHA & Mine Safety and Health Administration & \\
\hline MSHA-PEL & MSHA-Permissible Exposure Limit & $\%$ \\
\hline NIOSH & $\begin{array}{l}\text { National Institute for Occupational Safety } \\
\text { and Health }\end{array}$ & \\
\hline NIOSH-REL & NIOSH-Recommended Exposure Limit & $\%$ \\
\hline $\mathrm{N}$ & Newton & lbs \\
\hline $\mathrm{N}_{\mathrm{s}}$ & Number of Source Positions & \\
\hline $\mathrm{P}$ & Load at Failure (rock core) & lbs \\
\hline PRL & Pittsburgh Research Laboratory & \\
\hline PEL & Permissible Exposure Limit & \\
\hline pendepth & Penetration Depth During Test & in \\
\hline penrate & Penetration Rate During Test & $\mathrm{in} / \mathrm{sec}$ \\
\hline $\mathrm{R}^{2}$ & Coefficient of Determination & \\
\hline RTime & Run Time & sec \\
\hline S & Surface Area & $\mathrm{m}^{2}$ \\
\hline $\mathrm{S}_{0}$ & Reference Surface Area & $\mathrm{m}^{2}$ \\
\hline setthrst & Thrust Setting Prior to Drilling & lbs \\
\hline
\end{tabular}




\section{NOMENCLATURE}

Symbol

setspd

SPL

$\mathrm{spdb}$

spdba

TWA

T60

TC

V $\underline{\text { Description }}$

Rotational Speed Setting Prior to Drilling

Sound Pressure Level

Linear Sound Power For Test

A-weighted Sound Power for Test

Time-Weighted Average

Decay Time

Criterion Time

Volume $\underline{\text { Units }}$

rpm

$\mathrm{dB}$ or $\mathrm{dBA}$

$\mathrm{dB}$

dBA

dBA

sec

h or sec

$\mathrm{m}^{3}$ 


\section{DEDICATION}

TO MY DECEASED FATHER AND MOTHER, MY DAUGHTER, MORGAN AND WIFE, DEB

For providing me with the motivation and determination to reach one's full potential 


\section{ACKNOWLEDGEMENTS}

The list of those deserving of mention is extensive and includes dedicated and extraordinary individuals from the National Institute for Occupational Safety and Health (NIOSH) and the West Virginia University (WVU). Each organization, contributed extensively to my ability to conduct the research and complete the dissertation. The individuals who provided substantial insight and direction include Professor Syd Peng, WVU (my Advisor and Committee Chair), Dr. Gerald Finfinger, NIOSH, Mr. Pete Kovalchik, NIOSH and Dr. Güner Gürtunca, NIOSH. Each played an integral role in the research endeavor and continued to provide me with a significant amount of devotion, intelligence and eagerness to mentor me thru this process. 


\section{CHAPTER 1 \\ INTRODUCTION}

Over-exposure to noise remains a widespread and serious health hazard in the U.S. mining industries despite 25 years of regulation. Most other categories of illnesses and injuries associated with mining have improved dramatically, with the exception of hearing loss. The use of heavy equipment, the drilling and cutting of rock and coal, and the confined work environment are the major factors that contribute to high levels of noise exposure during mining operations. Every day, $80 \%$ of the nation's miners go to work in an environment where the time weighted average (TWA) noise level exceeds 85 dBA and more than $25 \%$ of the miners are exposed to a TWA noise level that exceeds 90 dBA, the permissible exposure limit (PEL) (1).

In January 1995, the Physical Agents Effects Branch, located in the National Institute for Occupational Safety and Health (NIOSH), Division of Biomedical and Behavioral Science, Cincinnati, Ohio, began collaboration on a project with the Mine Safety and Health Administration (MSHA) that was designed to determine the prevalence of hearing loss among miners. Two reports were forwarded to MSHA: one for coal miners, and one for metal/non-metal miners (2). After removing potentially invalid audiograms through a quality assurance process, the first report contained an analysis of 17,260 audiograms for 2,871 coal miners, and the second report reviewed 22,488 audiograms on 5,244 metal/non-metal miners. For comparison purposes, hearing thresholds were calculated for a similar-aged population of non-exposed individuals by using Annex A from ISO-1999 (ISO 1990) (3). The noise levels that would be predicted 
to cause the amount of hearing loss observed for the miners were also calculated from the ISO-1999.

The results of these investigations showed that miners developed hearing loss much more quickly than those in the non-occupational noise-exposed database used by ISO-1999, and that the miners experienced a greater severity of hearing loss than would

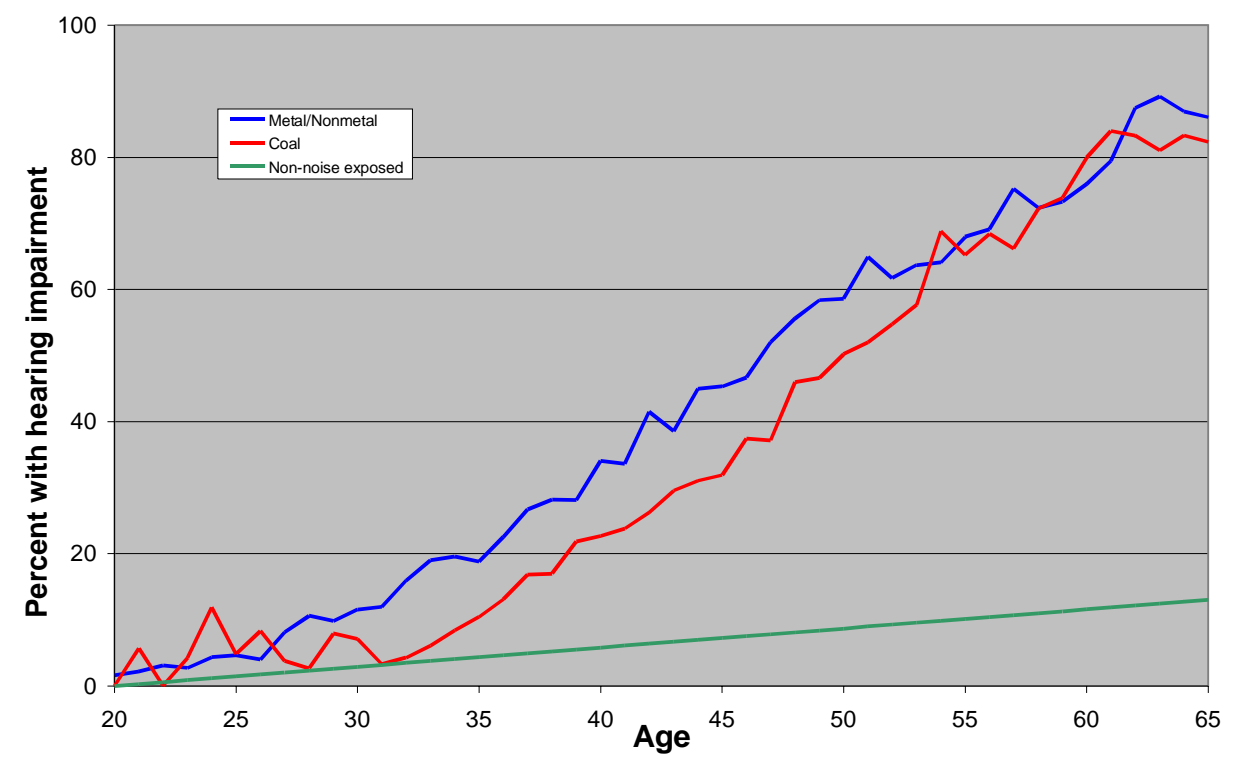

Figure 1.1 Analysis of Audiograms for Coal and Metal/Non-Metal Miners

be expected for non-occupational noise-exposed persons of the same age and gender. Using hearing thresholds at $4000 \mathrm{~Hz}$ as an indicator, coal miners experienced hearing loss $2 \frac{1}{2}$ to 3 times greater than would be expected for persons not exposed to occupational noise. At age 55, 65\% of the coal miners and metal/non-metal miners were found to have a hearing impairment. By comparison, only $10 \%$ of the non-occupationally exposed group had a hearing impairment at age 55 (Figure 1.1) (2). While Noise Induced Hearing Loss (NIHL) is the most common occupational illness in this country, this problem is especially acute among miners. NIOSH has recognized NIHL as one of the 10 leading 
work-related diseases and injuries in the Nation, and has emphasized its importance in the National Occupational Research Agenda (NORA).

Over the past decade, the Mine Safety and Health Administration (MSHA) has worked to develop a revised health standard for occupational noise exposure in coal, metal, and nonmetal mines. In December of 1996, the agency released its Proposed Rule in the Federal Register (30 CFR Parts 56, 57, 62, 70, and 71) (4). Unlike its predecessor, the proposed rule emphasizes the primacy of engineering controls as the strongest defense against excessive exposure to noise and the prevention of NIHL among miners and disallows reliance on personal hearing protection devices (PHPs) as a means of compliance with the standard. Despite the extensive work performed in the 1970's and 80's, NIHL is still a pervasive problem in the mining industries.

A new MSHA noise standard was published on September 13, 1999. This rule closely resembles the existing Occupational Safety and Health Administration (OSHA) Occupational Noise Exposure Standard and Hearing Conservation Amendment (29 CFR 1910.95), and replaced the different standards for occupational noise exposure in coal mines and in metal/non metal mines with a single new standard applicable to all mines. MSHA concluded in a recent survey that if an OSHA-like hearing conservation program was adopted, hypothetically, $78 \%$ of the coal miners surveyed would be required to be in a hearing conservation program (5). Although the proposed noise exposure limits would not totally eliminate the risk of material impairment, it is expected to reduce by twothirds the number of miners currently projected to suffer a material impairment of their hearing. 
Additionally, MSHA coal noise sample data (6) collected from 2000 to 2002 show that $65 \%$ of the equipment whose operators exceeded $100 \%$ noise dosage comprise only seven different types of machines; auger miners, bulldozers, continuous miners, front end loaders, roof bolters, shuttle cars (electric), and trucks. In addition, the MSHA data indicates that the roof bolter is third among all the equipment and second among equipment in underground coal whose operators exceed 100\% dosage (Figure 1.2).

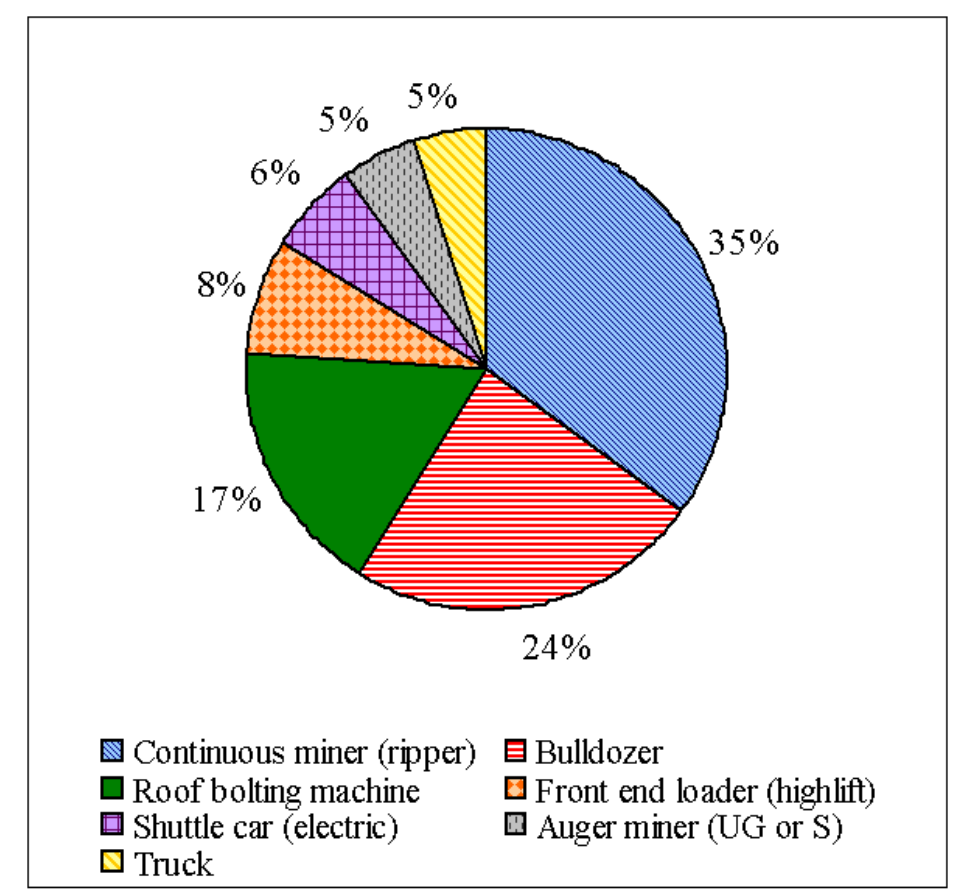

Figure 1.2 MSHA Coal Noise Sample Data - Percentage of Equipment Whose Operators Exceeded 100\% Dose

Lesser elements in the hierarchy of controls for reduction of noise exposure, including administrative practices (e.g. job rotation), and the use of personal hearing protective devices (PHP’s) have been the main sources of noise control in the past, relying on workers to properly wear and maintain their hearing protection. A balanced approach to the prevention of NIHL that includes not only education, surveillance, and 
intervention, but a research emphasis on engineering controls for noise is absolutely necessary. The development and utilization of engineering noise controls represent a permanent solution while the use of PHP's is seen as an interim solution. This research effort focuses on the development and assessment of engineering noise controls for mining equipment, specifically, roof bolters used in underground coal mining. The research will be conducted in a specialized laboratory using a standard roof bolter and a variety of operational conditions and settings representative of the underground coal mining industry as shown in figure 1.3 below. The data collected will provide information related to optimum drilling configurations, related to high compressive strength drilling media (>20,000 psi) for reducing sound power emissions from the machine. Additionally, the research will then persist, using a modeling approach, to predict the sound pressure level an operator is exposed to in an underground coal mine utilizing the sound power level data obtained from the laboratory.

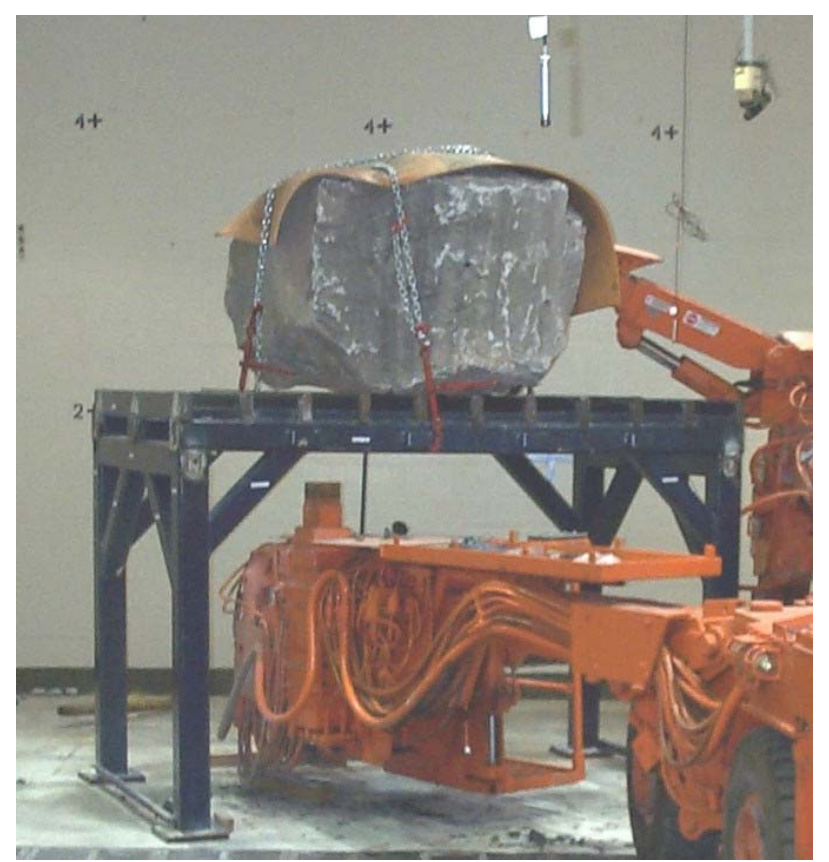

Figure 1.3 Noise Testing of Roof Bolter in Reverberation Room 


\section{CHAPTER 2}

\section{LITERATURE REVIEW}

Recent research focusing on engineering noise controls, specifically, on underground coal mining roof bolters is considerably limited. In 1983, the former Bureau of Mines developed a handbook entitled, "Mining Machinery Noise Control Guidelines, 1983” (7) which documented available noise control information of numerous pieces of mining equipment for dissemination to the mining industry. Several noise treatments were proposed within the handbook related to roof bolting machines in underground coal settings, which included; modifying the dust collection blower or changing to a quieter model; cover or enclose the hydraulic pump and sealing the enclosure around motor and pump-blower drives using the existing cover panels. A major manufacturer of roof bolting equipment, J.H. Fletcher, Inc. has supported most of the recommended controls, however, when the drilling or bolting process occurs with the machine, noise levels experienced by the operator still exceed regulatory limits, therefore overexposing the operator to noise.

NIOSH has performed numerous noise exposure surveys related to roof bolting operators in underground coal mines. The data suggests that $81 \%$ of the samples collected (a total of 16 samples of roof bolter operators), exceeded the MSHA Permissible Exposure Level (8). Additionally, representatives from MSHA conducted a series of environmental noise surveys in 12 underground coal mines (9). Approximately, 2,600 employees were included in the survey. The data suggested that $20 \%$ of all workers which are associated with face operations are exposed to noise levels which are in excess of the prescribed limits (MSHA Permissible Exposure Level). Specifically, 
while monitoring operators of roof bolting machines, the data suggested that noise levels exceeded $90 \mathrm{dBA}$ during drilling and bolting activities, therefore contributing overexposure of noise to these operators.

Recent and prior research associated with noise controls for roof bolting machines utilized in underground coal (rotary) is significantly limited. Numerous attempts have been made to "quiet” percussive type drills (development of differing types of drill rod, utilization of water, etc.), mainly utilized in hard rock mining commodities that could possibly be applicable to rotary roof bolting machines. The noise radiated from percussive type drills can be classified into two different components: airflow noise due to the utilization of compressed air and mechanical noise, which generally is attributed by the impact and rattling of drill components; for example, drill rod noise.

Lesage, et. al (10) addressed an experimental approach to characterize the vibroacoustic behaviour of percussion drill steel rods under real operating conditions and laboratory controlled operating conditions. The contribution of longitudinal and flexural vibration related to noise generation was provided. The testing concluded that the bending waves within the drill steel were mainly responsible for the largest portion of noise radiation and the contribution of longitudinal waves to the noise radiation was found to be negligible.

Champoux, et. al. (11) addressed a method for determining the contribution of both longitudinal and flexural waves related to the radiation of noise associated with percussive type drill steel rods. The authors determined that in order to reduce the noise produced by the steel rod, one must understand significant aspects of the noise generation mechanism (12). A typical cylindrical steel rod was utilized as the test piece and hung 
vertically in a semi-anechoic room. A soft suspension was attached to a steel striking piece solidly attached at the top end of the rod. Being supported by the top, the steel rod was always aligned vertically. First, the vibration behavior of the structure was examined. The use of modal analysis was performed on the structure. Lateral impacts were administered using an impact hammer to exite predominantly the bending modes of the steel. Accelerometers were glued on the rod at several locations and transfer functions were recorded utilizing a two-channel frequency analyzer. The longitudinal modes and the corresponding frequencies were measured by impacting the striking end piece along the rod's longitudinal axis and the response was measured with an accelerometer installed on the striking piece and oriented in the same axis. To determine noise radiation characteristics, a sinusoidal excitation was used initially, and to generate a longitudinal excitation, a 50-pound shaker was attached vertically to the upper part of the rod. However the noise generated by the rod when excited by the shaker was very low. An impact hammer was then used to control the amplitude and location of impact with respect to the rod. The end of the impact handle was attached to a hinge allowing a well controlled rotation along a horizontal axis. The blows of impact were then always applied on the striking end piece of the rod in a direction parallel to the longitudinal axis. The impacts were applied on the longitudinal center line of the rod (axial excitation) and near the edge of the tip of the rod (eccentric excitation). The force amplitude peaks were on the order of 1,000 N (225 lbF). To record the noise, a microphone, located $20 \mathrm{~cm}$ (7.9 inches) from the rod was used. Results of the testing concluded that: 1) imperfection tends to create double peaks for the flexural modes; 2) flexural and longitudinal waves both contribute to the sound radiation; 3) for a given force amplitude, the longitudinal 
mode amplitude appears to be insensitive to impact force location and 4) flexural modes are very sensitive to imperfection of the rod and impact force location.

Stein and Aljoe (13) provided information on noise controls related to percussivetype drills. A concentric drill steel was designed for use as a drilling tool and noise control. The design differed from the typical drill steel because it was constructed of two members rather than the usual one member. The two members consisted of an inner pulse transmission rod and an outer torque transmission tube. The inner rod transmitted percussive energy to the bit just as the conventional steel would, however torque to the bit was eliminated. The other member, the torque tube, provided torque to the bit. The torque tube provided rotation to the bit and acted as a barrier to attenuate noise emitted for the inner rod. Testing of the concentric steel for noise output to the operator provided a $5 \mathrm{dBA}$ reduction as compared to the standard steel.

Visnapu and Jensen (14) researched modifications on standard pneumatic rock drills to reduce the noise of the air exhaust, drill steel resonance noise and noise radiated by the drill body. The drill body was enclosed with a close-fitting case and muffler. The enclosure consisted of a metallic honeycomb skeleton filled with viscoelastic absorber on the inside and a durable outer shell, in which was designed to provide both exhaust and drill body noise muffling and absorption. Noise radiated by the drill steel was attempted to be reduced by utilization of a constrained-layer treatment consisting of a tubular metal cover bonded to the outside of the rod by a viscoelastic filler. The constrained-layer damped steels were prepared by slipping the metal tube over the drill steel, centering the steel in the tube, and then filling the space between the tube with liquid viscoelastic filler. Upon curing of the filler, part of the covering around the collar and shank was removed. 
Tubes with wall thicknesses from 0.049 to 0.065 inch and outside diameters of 1-1/4 to 11/2 inches were bonded to 7/8-inch-diameter drill steels. Two viscoelastic fillers were selected, a two-part-mix urethane rubber, and a syntactic polyurethane foam. Noise testing related to the constrained-layer drill steels demonstrated to be an effective method for reducing drill steel noise. Results displayed a 3-6 dBA reduction when utilizing constrained-layer drill steels in comparison to standard steel.

Bartholomae (15) reported on an in-the-hole drill concept for noise control associated with percussive type drills. The concept eliminated the drill rod as a stress transfer mechanism so that the percussive motor is located just behind the drill bit. The motor is pushed into the borehole thru utilization of the drill pipe, which is used to rotate the percussion motor and drill bit to transmit the drill feed force. The noise reduction principle of the "in-the-hole" drill involved an operational effect. Once the borehole is started, the high energy noise from the percussive tool is contained entirely within the borehole, with the rock mass acting as an acoustic enclosure. This design was significantly different than standard percussive drills, in which the major noise producing components (drill hammer, drill steel, air exhaust) are located outside the borehole. Laboratory testing, for noise related to this concept, displayed that noise levels significantly decreased, 4 dBA (4 ft. into rock). However, mechanical difficulties associated with water leaks, percussion motor, etc. related to the drill eliminated any further testing. Future plans were to address the mechanical problems associated with the new design, since noise level reduction did show promise.

Paraszczak and Planeta (16) reported on the utilization of water-powered jackleg rock drills to be more efficient, faster and more comfortable (noise generation) than 
conventional pneumatic drills. The authors tested a water-powered hand-held drill in comparison to compressed-air jackleg drills in relation to: 1) penetration rate 2) energy consumption and 3) noise level to the operator. The tests concluded that the waterpowered jackleg drill achieved faster penetration rates (approximately 10-30\% higher than the pneumatic drills), along with less energy consumption (12 times less) and lower drilling costs (40\% less). Additionally, a reduced noise level (11 to $25 \mathrm{dBA}$ ) and a reduced vibration level was achieved thru utilization of the water-powered jackleg drill.

Additionally, high pressure water jets to assist rotary drilling operations were examined by Hurel and Cagnioncle (17). The idea associated with this research was to extend the application of rotary drilling to harder and more abrasive rocks, by assisting conventional mechanical bits with high pressure water jets, since, for hard and abrasive rocks, recourse is taken to percussive drilling which involves disadvantages concerning both the level of the cost of the installation and the nuisances it produces (noise, vibration, dust, etc.). Laboratory tests examined the following mining applications: 1) blast hole drilling for driving galleries by the use of explosives and 2) drilling holes for roof bolting. The latter, drilling holes for roof bolting will be addressed due to the relevance to the research proposed. A test bench was set up and coupled with a data acquisition system which enabled the recording of thrust, force, rotation speed, pressure, rate of water flow, drilling penetration rate and energy consumption. The diameter of the roof bolting bits utilized for testing was $22 \mathrm{~mm}$ ( $0.87 \mathrm{inch})$. The testing program was developed to determine the advantages resulting from water jet assistance related to key drilling parameters (thrust, rotation speed, water pressure, etc.). The drilling tests were performed on rocks whose uniaxial compressive strength reached $190 \mathrm{MPa}$ 
(approximately 28,000 psi). Results displayed the following: 1) the increase in flow rate, water pressure, etc. provided an increase in penetration rate, along with a decrease in cutting energy; 2) the water jet assistance was more efficient when the jets come thru the tungsten carbide inserts of the drill bit, allowing the high-pressure jets to act precisely in the area of contact between the rock and the drill bit, consequently acting upon the cutting process initiated by the tungsten carbide insert and 3) the orientation of the jets should be such that one is directed towards the perimeter of the drill bit and the other towards the hole axis. Testing of the water-jet design was also performed in a uranium mine. Three separate sites were chosen underground to verify that the drilling of holes for roof bolting was possible in different roof material in the mine workings. Drilling was performed on rock whose uniaxial compressive strength ranged between 50 and 200 MPa (7250 and 29,000 psi) and the water-pressure jet assistance was set to provide pressures between 220 and $240 \mathrm{MPa}$ (32,000 and 35,000 psi). Results showed that in very hard rock strata, the penetration rate obtained was approximately $1.20 \mathrm{~m} / \mathrm{min}$ (approximately $4 \mathrm{ft} / \mathrm{min}$ ), whereas, in other bands, the penetration rate was measured to provide between 2 and $5 \mathrm{~m} / \mathrm{min}$ ( 6.6 and $16.4 \mathrm{ft} / \mathrm{min}$ ). Overall, the average penetration rate of drilled holes was approximately $1.80 \mathrm{~m} / \mathrm{min}$ (approximately $6 \mathrm{ft} / \mathrm{min}$ ). The penetration rates obtained for this study were comparable to those obtained with rotary percussion hammer drills utilized in the mine working.

This research effort will focus on evaluating and assessing several noise controls to be utilized during drilling activities in high compressive strength media (> 20,000 psi) associated with the roof bolting machine and then, consequently utilizing a modeling approach, predict sound pressure levels to roof bolting machine operators in an 
underground coal mine to examine noise exposure. The ultimate objective of the research is to provide the mining industry with valuable information to minimize or eliminate noise overexposure to roof bolter operators during the drilling portion of the work cycle of the machine. 


\section{CHAPTER 3}

\section{OBJECTIVE OF RESEARCH}

The overall objective of the research is to determine, to characterize and to measure sound power levels radiated by a roof bolting machine during differing drilling configurations (thrust, rotational speed, penetration rate, etc.), along with utilizing a modeling approach for predicting sound pressure levels associated with roof bolter operators during the drilling cycle in high compressive strength rock media (>20,000 psi) utilizing the sound power level laboratory data measured. The determined sound power levels generated during the drilling cycle are of major interest because these levels represent the overall sound power being generated by the machine. These levels, determined from laboratory tests, can then be used to accurately assess the effectiveness of differing noise controls for reducing noise exposure to roof bolter operators. Utilizing sound power results obtained from the laboratory tests, a statistical model could then be developed for predicting sound power levels given differing drilling parameters (thrust, rotational speed, penetration rate, drill steel size and shape, drill bit size and drilling methods (vacuum, wet or mist). Additionally, utilizing the sound power levels related to differing drilling methods and parameters already determined and/or predicted, along with the utilization of knowledge related to the environmental noise characteristics associated with underground coal mining, sound pressure levels being experienced by roof bolter operators could then be determined and/or predicted to determine overall noise exposure using differing drilling configurations. The completion of the research will provide the mining industry with valuable information related to: 1) an understanding on how differing drilling configurations and drilling methods attribute to 
the sound power levels generated from a roof bolting machine while drilling into a high compressive rock media; 2) optimal drilling configurations and drilling methods in reducing sound power levels of the roof bolting machine; 3) a statistically valid equation for determining sound power levels of a roof bolting machine given differing drilling configurations and drilling methods; 4) a method for predicting sound pressure levels at the operator position and multiple locations in an underground mine related to the drilling cycle of a roof bolting machine and 5) a method for determining an operators' noise dosage relative to a roof bolting machine given any type of drilling configuration or drilling method utilized. 


\section{CHAPTER 4}

\section{SCOPE AND METHODS OF RESEARCH}

The first phase of the research study was conducted in the PRL's reverberation room. The objective of the first phase was to conduct a myriad of sound power tests related to differing drilling parameters (thrust, rotational speed, penetration rate, drill steel size and shape, drill bit size) and drilling methods (vacuum, wet or mist) during the drilling cycle of a roof bolting machine in high compressive strength media $(>20,000 \mathrm{psi})$. The laboratory results were then analyzed to provide the mining industry with valuable information related to optimum drilling configurations or parameters to be utilized when drilling into high compressive strength media $(>20,000 \mathrm{psi})$ obtained from sound power levels collected in the laboratory. The second phase of the research was to use the data collected in the first phase of the research, and utilizing a modeling approach, predict the sound pressure levels the operator will experience in an underground coal mine in an effort in reducing noise exposure to the roof bolting operator. Procedures utilized for conducting the laboratory tests in the reverberation room are mentioned below.

\subsection{Standard Operating Procedure for Conducting Noise Measurements (Sound Power) of Roof Bolting Machines in the Pittsburgh Research Laboratory's Reverberation Room}

The following information presented below relates to the method used (utilizing the ISO 3740 series of acoustical standards) for determining sound power values (in 1/3 octave band frequencies) in the reverberation room at the Pittsburgh Research Laboratory (PRL) relative to the specific engineering noise control tests for the roof bolting machine. 


\subsubsection{Preface for Determining Sound Power Levels}

The ISO 3740 series of acoustical standards specify various methods of determining the sound power levels of machines and equipment. The standards detail the acoustical requirements for the measurements appropriate for different test environments. Given the desired classification method for testing related to this research effort, the available test environment; a reverberation chamber, the expected characterization of the noise source; broad-band in frequency, and the desired output; A-weighted, octave and/or third octave sound power, the ISO 3743-2 (18) standard served as the reference standard for the research. The information discussed below relates to each section of the ISO 3743-2 standard and explains the rational behind the decisions made to meet the standard for testing the roof bolting machine in the reverberation room at PRL (19).

\subsubsection{Introduction}

The introduction of the standard lists the general guidelines to assist in selecting the most appropriate ISO 3740 series standard, given the purpose of the test and the testing conditions. The ISO 3743 standard explains conducting engineering grade experiments where A-weighted (replicates the human response of the ear) and octave band sound pressure levels are measured at prescribed microphone locations or along prescribed paths. The measurements are then used to calculate sound power levels. The standard methods are applicable for "small" machines, devices, components, and sub-assemblies, particularly those considered portable. The standard suggests that the device-under-test (DUT) (e.g. roof bolting machine) preferably be less than one percent of the test room volume but the standard does not specifically disallow the testing of larger devices. The ISO 3743-2 specifically documents requirements for testing in a special reverberation chamber, a facility that is available at the NIOSH-PRL and thus the ISO 3743-2 
was considered the appropriate document to specify test procedures, analysis, and instrumentation specifications for this phase of the research study.

\subsubsection{Scope}

This section (scope) of the standard documents the engineering method to determine the sound power of small, movable noise sources in a specifically designed room having a specified reverberation time over the frequency range of interest. There are two test methods available, the direct and comparison method. The comparison method was selected for testing. The methods of the ISO 3743-2 are suitable for the measurement of all types of noise within a specified frequency range. The maximum volume of the device-under-test (DUT) and the lower limit of the frequency range for the test methods depend upon the volume of the test chamber. While the standard states that measurements on sources emitting noise below $200 \mathrm{~Hz}$ may be difficult, this statement assumes reverberation chambers much smaller than the chamber at the PRL. Table 4.1 provides the surface area and volume associated with the reverberation room at PRL. Additionally, Figure 4.1 represents a sketch of the reverberation room at PRL used for testing of the roof bolting machine. 
Table 4.1 Reverberation Chamber-Surface Area and Volume

\begin{tabular}{|c|c|c|c|}
\hline & Length (m) & Width (m) & Height (m) \\
\hline Major chamber dimensions & 18.31 & 10.37 & 6.73 \\
\hline & \multicolumn{2}{|c|}{ Surface Area $\left(m^{2}\right)$} & Volume $\left(\mathrm{m}^{3}\right)$ \\
\hline Front wall & & 69.80 & $1,277.84$ \\
\hline Rear wall & & 78.02 & \\
\hline Right wall & & 123.22 & \\
\hline Left wall & & 132.99 & \\
\hline Floor & & 219.01 & \\
\hline Ceiling & & 189.84 & \\
\hline Chamber door protrusion & & 4.25 & 6.26 \\
\hline Trench & & 15.77 & 1.57 \\
\hline Left wall window & & .43 & 0.07 \\
\hline Left wall entry door & & 1.03 & .32 \\
\hline Right wall entry door & & 1.03 & .32 \\
\hline TOTAL & & 835.39 & $1,286.38$ \\
\hline
\end{tabular}




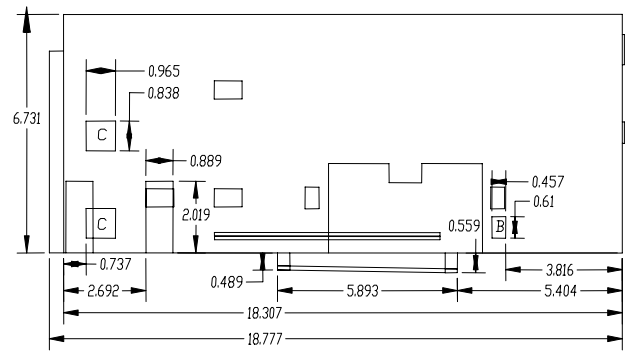

Right Wall of Reverb Room
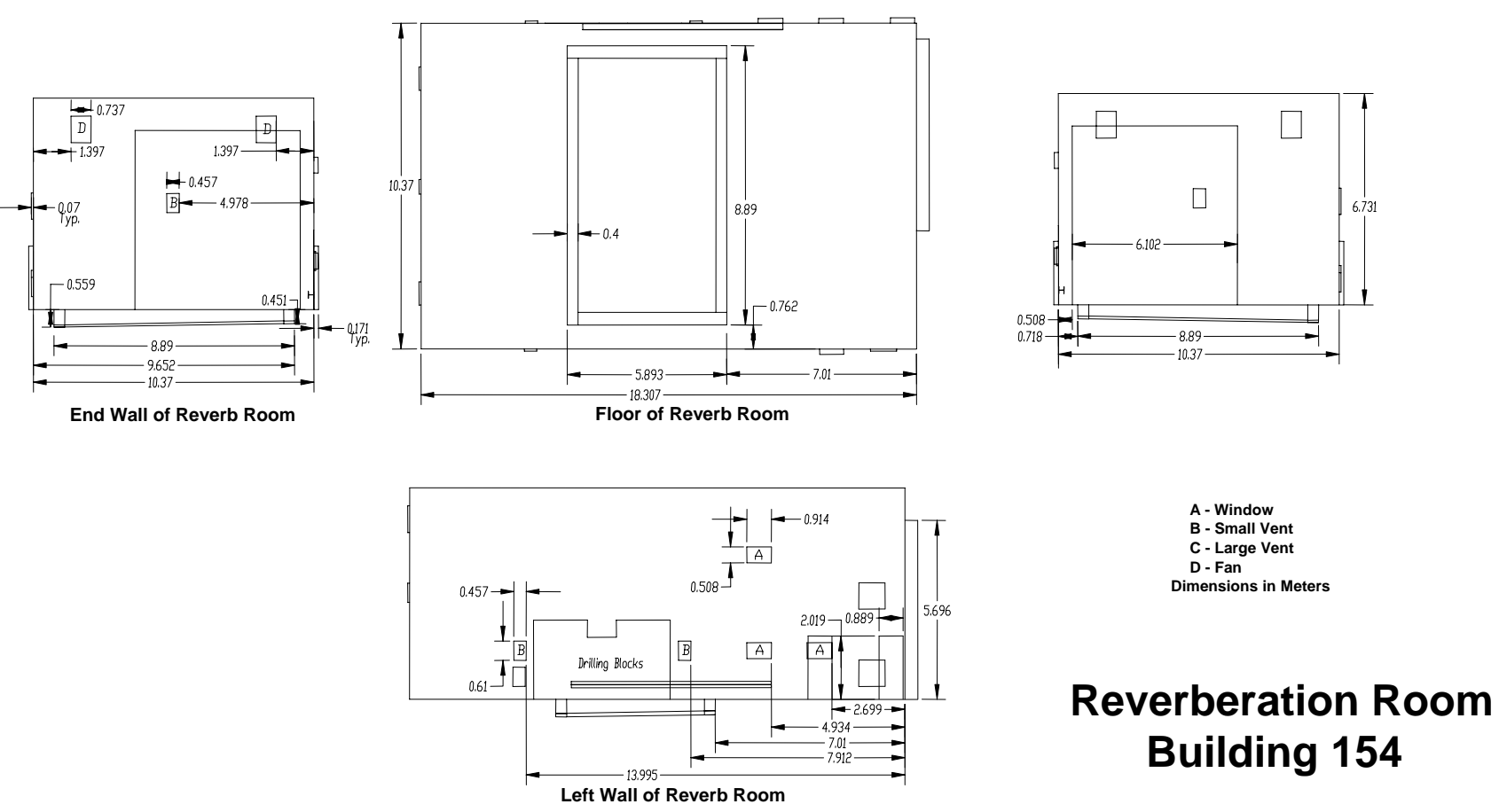

Figure 4.1 Plan view of the Reverberation Room at the PRL 
The ISO 3743-2 standard also addresses measurement uncertainty. These uncertainties arise from several different factors, including environmental conditions and experimental techniques. Given the standard deviations of A-weighted (replicates the human response of the ear) sound power levels calculated from test results generated in the reverberation room utilizing a known noise or sound source, the standard deviations should not exceed those shown in Table 4.2. The cumulative effects of the measurement uncertainty in applying the procedures of ISO 3743-2 are taken into account in the standard deviations of Table 4.2 but they do not include changes in the DUT operating or mounting conditions. The measurement uncertainty depends on the standard deviation of reproducibility $\left(\sigma_{\mathrm{R}}\right)$ listed in Table 4.2 and the degree of confidence required. Given a normally distributed sound power spectrum, there is $90 \%$ confidence that the true sound power of a source lies within the range of $\pm 1.645 \sigma_{R}$ of the measured value and for a $95 \%$ confidence level, within $\pm 1.96 \sigma \mathrm{R}$ of the measured value.

Table 4.2 Estimated Values of the Standard Deviation of Reproducibility of Sound Power Levels

\begin{tabular}{|c|c|}
\hline $\begin{array}{c}\text { Octave Band Center } \\
\text { Frequency (Hz) }\end{array}$ & $\begin{array}{c}\text { Standard Deviation } \\
\text { of Reproducibility } \\
\boldsymbol{\sigma}_{\mathbf{R}}\end{array}$ \\
\hline 125 & 5.0 \\
\hline 250 & 3.0 \\
\hline 500 to 4,000 & 2.0 \\
\hline 8,000 & 3.0 \\
\hline A-weighted & 2.0 \\
\hline
\end{tabular}




\subsubsection{Normative References}

Additional standards used in conjunction with the ISO 3743-2 standard are listed below.

Table 4.3 Normative References.

\begin{tabular}{|l|l|}
\hline \multicolumn{1}{|c|}{ Number } & \multicolumn{1}{c|}{ Title } \\
\hline ISO 3741 & $\begin{array}{l}\text { Acoustics - Determination of sound power levels of noise sources } \\
\text { Precision methods for broad-band sources in reverberation rooms. }\end{array}$ \\
\hline ISO 3743-1 & $\begin{array}{l}\text { Acoustics - Determination of sound power levels of noise sources - } \\
\text { Engineering methods for small, movable sources in reverberant fields - } \\
\text { Part 1: Comparison method for hard walled test rooms. }\end{array}$ \\
\hline ISO 3745 & $\begin{array}{l}\text { Acoustics - Determination of sound power levels of noise sources - } \\
\text { Precision methods for anechoic and semi-anechoic rooms. }\end{array}$ \\
\hline ISO 6926 & $\begin{array}{l}\text { Acoustics - Determination of sound power levels of noise sources - } \\
\text { Requirements for the performance and calibration of reference sound } \\
\text { sources. }\end{array}$ \\
\hline ISO 7574-1 & $\begin{array}{l}\text { Acoustics - Statistical methods for determining and verifying stated } \\
\text { noise emission values of machinery and equipment - Part 1: General } \\
\text { considerations and definitions. }\end{array}$ \\
\hline ISO 7574-4 & $\begin{array}{l}\text { Acoustics - Statistical methods for determining and verifying stated } \\
\text { noise emission values of machinery and equipment - Part 4: Methods for } \\
\text { stated values for batches of machines. }\end{array}$ \\
\hline IEC 225 & $\begin{array}{l}\text { Octave, half octave and third-octave band filters intended for the analysis } \\
\text { of sounds and vibrations. }\end{array}$ \\
\hline IEC 651 & Sound level meters. \\
\hline IEC 804 & Intergrating-averaging sound level meters. \\
\hline IEC 942 & Sound calibrators. \\
\hline
\end{tabular}

\subsubsection{Definitions}

A single definition is listed for a special reverberation test room. It is defined as "A test room meeting the requirements of this part of the ISO 3743-2". These are addressed in Section 4.1.6.

\subsubsection{Requirements for a Special Reverberation Test Room}

Guidelines for the design of a suitable test room, the reverberation time, and surface treatment are discussed within this section. The reverberation chamber walls and floor were designed to have Sabine absorption coefficients (the ratio of the sound energy absorbed by a 
surface of a medium or material to the sound energy incident on the surface) less than 0.16 , meeting the requirements of the standard. Another issue relates to background noise, this ensures that at each microphone the background sound pressure level noise shall be at least four decibels (dB), and preferably ten decibels less than the DUT sound pressure level. Background noise is measured as part of the test procedure and past test results show that it is unlikely a problem will occur. There are also additional criteria listed for temperature and relative humidity. As stated in the standard, with the relative humidity expressed as a $\%$ and the temperature in degrees $\mathrm{C}$, the product

$$
\text { Relative Humidity } \mathrm{x}(\theta+5 \text { degrees } \mathrm{C})
$$

shall not differ by more than $\pm 10 \%$ from the value of the product measured during the measurement of the reverberation time of the test room, where $\theta$ is the temperature in degrees Celsius. The temperature, relative humidity, and barometric pressure sensor data is fed into the data collection system to allow monitoring and recording of environmental data. Additionally, a four step process was utilized for testing the suitability of the test room. A small broad-band calibrated reference noise source was used following the procedures given in the standard ISO 6926 (20). Calibration report data, test data and the allowable difference between the two is provided in Table 4.4 below. The reverberation chamber passed the suitability test. 
Table 4.4 Evaluation Test for the Suitability of the Test Chamber

\begin{tabular}{|c|c|c|c|c|}
\hline $\begin{array}{c}\text { Octave Band } \\
\text { Center Frequency } \\
(\mathbf{H z})\end{array}$ & $\begin{array}{c}\text { Calibration Report } \\
\text { Sound Power Level } \\
(\mathbf{d B})\end{array}$ & $\begin{array}{c}\text { NIOSH Chamber } \\
\text { Test Sound Power } \\
\text { Level (dB) }\end{array}$ & $\begin{array}{c}\text { Allowable } \\
\text { Delta } \\
(\mathbf{d B})\end{array}$ & $\begin{array}{c}\text { Difference } \\
(\mathbf{d B})\end{array}$ \\
\hline 125 & 83.1 & 83.1 & 0.0 & \pm 5 \\
\hline 250 & 84.7 & 84.7 & 0.0 & \pm 3 \\
\hline 500 & 85.4 & 85.4 & 0.0 & \pm 3 \\
\hline 1,000 & 89.1 & 89.1 & 0.0 & \pm 3 \\
\hline 2,000 & 90.1 & 90.1 & 0.0 & \pm 3 \\
\hline 4,000 & 87.8 & 87.9 & 0.1 & \pm 3 \\
\hline 8,000 & 84.3 & 83.6 & 0.7 & \pm 4 \\
\hline
\end{tabular}

\subsubsection{Installation and Operation of Source Under Test}

The acoustical properties of the reverberation chamber and the manner of source operation play a significant role in the sound power emitted by a device. The DUT shall be placed at one or more locations as if it were installed or used normally. If no such location may be found, then the DUT will be installed on the floor with at least one meter in distance between the DUT and the nearest wall. It may be necessary to test the DUT in multiple locations, if needed. Because roof bolter testing requires a rather large drill media, e.g. granite, as well as a large support stand, care must be taken to ensure that these do not radiate significant amounts of sound energy. To prevent this, the support stand, with the exception of its diagonal members and the short horizontal members along the minimum direction of the top of the structure, were filled with sand and two layers of urethane were bonded to the rock support members between the drill media due to a significant amount of vibration testing conducted (21). Finally, an additional layer of urethane was laid between the drill media and chain holding the media in place. All of this served to reduce vibration transmission and noise emission. See Section 4.2 - Modification of Steel Test Fixture for Roof Bolter Testing in the Reverberation Room. 
During the measurements, the device was operated under normal conditions. Test parameters, e.g. rotation speed, thrust, etc., were selected beforehand and held constant before and while acoustical measurements were being made. These conditions were then reported.

\subsubsection{Measurements in Test Room}

The calculation of the approximate sound power level of the DUT is based on measured mean-square values of the sound pressure averages in time over an appropriate number of microphone positions within the test room. Each test shall last approximately 30 seconds. No microphone position shall be closer to room boundaries than $\lambda / 4$ where $\lambda$ is the wavelength of the sound corresponding to the lowest third octave band frequency of interest $(50 \mathrm{~Hz})$. This value is $\mathrm{d}_{\lambda}$ and at $50 \mathrm{~Hz}$, equals 1.72 meters. The minimum distance between any microphone position and the surface of the DUT is then calculated by:

$$
\mathrm{d}_{\min }=0.3 * \mathrm{~V}^{1 / 3}
$$

Where $\mathrm{V}$, is the volume of the reverberation room

Or, for the NIOSH facility, $d_{\min }$ is 3.26 meters. The distance between any two microphone positions shall be at least $\lambda / 2$, where $\lambda$ is defined earlier. At $50 \mathrm{~Hz}, \mathrm{~d}_{\min }$ equals 3.44 meters. 
In summary,

Table 4.5 Minimum Distances of Microphones

\begin{tabular}{|l|c|}
\hline \multicolumn{1}{|c|}{ Condition } & Distance (meters) \\
\hline $\begin{array}{l}\text { Microphone to room boundary } \\
(50 \mathrm{~Hz})\end{array}$ & 1.72 \\
\hline Microphone and surface of DUT & 3.26 \\
\hline Microphone to microphone $(50 \mathrm{~Hz})$ & 3.44 \\
\hline
\end{tabular}

The number of microphone positions and source locations necessary to obtain the specified precision of the sound power levels depend upon the room and noise source properties. For each source, the minimum number of positions required in obtaining the specified standard deviations which are equal to or less than those given in Table 4.2 will be determined by the following. Given a particular DUT location, the sound pressure will be measured at six microphone locations that are spread throughout the reverberation chamber. An estimate of the standard deviation, $\mathrm{s}_{\mathrm{M}}$, in decibels, of the measured sound pressure levels will be established from the following equation.

$$
\mathrm{S}_{\mathrm{M}}=(\mathrm{n}-1)^{-1 / 2}\left[\sum_{i=1}^{n}\left(L_{p i}-L_{p}\right)^{2}\right]^{1 / 2}
$$

where

$L_{p i}$ is the sound pressure level at the $\mathrm{i}^{\text {th }}$ measurement position $(\mathrm{dB})($ reference: $20 \mu \mathrm{Pa})$

$L_{p}$ is the mean value of $\mathrm{L}_{\mathrm{p} 1}, \mathrm{~L}_{\mathrm{p} 2}, \ldots, \mathrm{L}_{\mathrm{p} 6}(\mathrm{~dB})$ (reference : $20 \mu \mathrm{Pa}$ )

$\mathrm{n}$ is the number of microphone positions, six.

The mean value, $L_{p}$ shall be calculated by

$$
L_{p}=10 \log 10\left[(1 / 6) *\left(10^{0.1 L p 1}+10^{0.1 L p 2}+\ldots+10^{0.1 L p 6}\right)\right] \mathrm{dB}
$$

The calculated values for $\mathrm{s}_{\mathrm{M}}$ must be compared to the data listed in Table 4.6 to select a suitable 
combination of the minimum number of microphones, $\mathrm{N}_{\mathrm{m}}$, and source positions, $\mathrm{N}_{\mathrm{s}}$. Because the reverberation chamber is currently instrumented with fifteen microphones, 15 will serve as $\mathrm{N}_{\mathrm{m}}$, as this meets the requirements of the standard. Table 4.6 is used primarily to select, $\mathrm{N}_{\mathrm{s}}$, the minimum number of source positions for testing.

Table 4.6 Minimum Number of Source Locations

\begin{tabular}{|c|c|c|c|c|}
\hline \multirow[b]{3}{*}{$S_{M}(d B)$} & \multirow[b]{3}{*}{$\begin{array}{c}\text { Octave Band Frequency } \\
(\mathrm{Hz})\end{array}$} & \multicolumn{3}{|c|}{ Number of Microphones, $\mathbf{N}_{m}$} \\
\hline & & 3 & 6 & 12 \\
\hline & & \multicolumn{3}{|c|}{$\begin{array}{c}\text { Minimum Number of Sourc } \\
\text { Locations, } N_{s}\end{array}$} \\
\hline $\mathrm{s}_{\mathrm{M}}<2.3$ & $\begin{array}{l}125 \text { to } 8,000 \text { and } \mathrm{A}- \\
\text { weighting }\end{array}$ & 1 & 1 & 1 \\
\hline \multirow{3}{*}{$2.3 \leq \mathrm{s}_{\mathrm{M}} \leq 4$} & 125 & 1 & 1 & 1 \\
\hline & 250,500 , and A-weighting & 2 & 2 & 1 \\
\hline & 1,000 to 8,000 & 2 & 1 & 1 \\
\hline \multirow{4}{*}{$\mathrm{s}_{\mathrm{M}}>4$} & 125 & 3 & 2 & 2 \\
\hline & 250 and A-weighting & 4 & 3 & 2 \\
\hline & 500 & 4 & 2 & 2 \\
\hline & 1,000 to 8,000 & 3 & 2 & 1 \\
\hline
\end{tabular}

The presence of irregularities in the frequency spectrum of an emitted sound can be determined from the values given above. Three ranges of the $s_{M}$ are selected to define the presence of discrete frequencies or narrow bands of noise:

a) if $\mathrm{s}_{\mathrm{M}}>4 \mathrm{~dB}$, a discrete tone may be present in the frequency band in question;

b) If $2.3 \mathrm{~dB} \leq \mathrm{s}_{\mathrm{M}} \leq 4 \mathrm{~dB}$, narrow-band noise components may be present in the frequency band in question;

c) If $\mathrm{s}_{\mathrm{M}}<2.3 \mathrm{~dB}$, the frequency spectrum is probably broadband in nature.

The suspected presence of any narrow-band or discrete frequencies in the spectrum of the emitted sound will then be reported. 
A third octave background noise level is measured at a minimum of twice per day, once in the morning and once in the afternoon. Additional measurements are taken if the background noise changes appreciably during the testing. The most recently collected background data will be included in each test report and will be used for a comparison with the DUT data and reference sound source data to determine the corrections for background noise. As per the 3743-2 standard, if the third octave background noise is less than four decibels below the reference sound source or the DUT, no data shall be reported without clearly stating that that the background noise requirements of the standard have not been met. This is not expected to be an issue for the roof bolter testing as the third octave roof bolter sound pressure levels are expected to greatly exceed the typical background noise levels. The corrections for background sound pressure levels and typical third octave background noise levels are given below in table 4.7 and typical background sound pressure noise levels are shown in table 4.8.

Table 4.7 Corrections for Background Sound Pressure Levels

\begin{tabular}{|c|c|}
\hline $\begin{array}{c}\text { Difference between sound pressure } \\
\text { level measured with sound source } \\
\text { operating and background sound } \\
\text { pressure alone. }\end{array}$ & $\begin{array}{c}\text { Correction to be subtracted from sound } \\
\text { pressure level measured with noise } \\
\text { source operating to obtain sound } \\
\text { pressure level due to noise source alone. }\end{array}$ \\
\hline 4 & 2 \\
\hline 5 & 2 \\
\hline 6 & 1 \\
\hline 7 & 1 \\
\hline 8 & 1 \\
\hline 9 & 0.5 \\
\hline 10 & 0.5 \\
\hline 10 & 0 \\
\hline
\end{tabular}


Table 4.8 Typical Background Noise Sound Pressure Levels

\begin{tabular}{|c|c|c|c|c|c|}
\hline $\begin{array}{c}\text { Third Octave } \\
\text { Band Frequency } \\
(\mathbf{H z})\end{array}$ & \multicolumn{2}{|c|}{$\begin{array}{c}\text { Sound Pressure } \\
\text { Level }\end{array}$} & \multirow{2}{*}{$\begin{array}{c}\text { Third Octave } \\
\text { band Frequency }\end{array}$} & \multicolumn{2}{|c|}{ Sound Pressure Level } \\
& $\mathbf{( d B )}$ & $\mathbf{( d B A )}$ & $\mathbf{H z})$ & $\mathbf{( d B )}$ & $\mathbf{( d B A )}$ \\
\hline 50 & 36.5 & 6.3 & 800 & 29.3 & 28.5 \\
\hline 63 & 38.9 & 12.7 & 1,000 & 33.8 & 33.8 \\
\hline 80 & 43.2 & 20.7 & 1,250 & 27.5 & 28.1 \\
\hline 100 & 35.1 & 16.0 & 1,600 & 23.8 & 24.8 \\
\hline 125 & 44.0 & 27.9 & 2,000 & 22.2 & 23.4 \\
\hline 160 & 32.3 & 18.9 & 2,500 & 21.3 & 22.6 \\
\hline 200 & 32.7 & 21.8 & 3,150 & 18.4 & 19.6 \\
\hline 250 & 35.8 & 27.2 & 4,000 & 15.2 & 16.2 \\
\hline 315 & 31.0 & 24.4 & 5,000 & 12.8 & 13.3 \\
\hline 400 & 33.9 & 29.1 & 6,300 & 11.0 & 10.9 \\
\hline 500 & 31.1 & 27.9 & 8,000 & 10.9 & 9.8 \\
\hline 630 & 27.8 & 25.9 & 10,000 & 10.0 & 7.5 \\
\hline
\end{tabular}

\subsubsection{Calculation of Sound Power Levels}

From the measured one-third octave band sound pressure levels and the calculated third octave band sound pressure levels for frequency bands of interest, the mean overall value, in decibels, shall be calculated by;

$$
\mathrm{L}_{\mathrm{p}}=10^{*} \log \left[(1 / \mathrm{n}) *\left(10^{0.1 \mathrm{Lp} 1}+10^{0.1 \mathrm{Lp} 2}+\ldots .+10^{0.1 \mathrm{Lpn}}\right)\right]
$$

where

$\mathrm{L}_{\mathrm{p} 1}$ is the third octave band level or A-weighted level for the first measurement $(\mathrm{dB})$

$\mathrm{L}_{\mathrm{pn}}$ is the third octave band level or A-weighted level for the $\mathrm{n}^{\text {th }}$ measurement $(\mathrm{dB})$

$\mathrm{n}$ is the total number of measurements for a particular third octave band or with the Aweighted network inserted.

To conduct the comparison method for determining sound power, a Bruel \& Kjaer 4204 reference noise source will be placed on the floor of the test room at least 1.5 meters from any wall. The mean sound pressure level in each third octave band will then be determined and any background noise corrections will be performed if necessary, using the calculation procedure 
provided earlier. Then, the sound power level produced by the DUT will then be determined, $\mathrm{L}_{\mathrm{we}}$, in decibels (reference: $1 \mathrm{pW}$ ) for each third octave band as follows. Subtract the band pressure level produced by the reference noise source, $\mathrm{L}_{\mathrm{pr}}$ (after background noise corrections) from the know sound power level produced by the reference noise source and then add the difference to the band pressure level of the DUT, $\mathrm{L}_{\mathrm{pe}}$, (after corrections for background noise), i.e.;

$$
\mathrm{L}_{\mathrm{we}}=\mathrm{L}_{\mathrm{pe}}+\left(\mathrm{L}_{\mathrm{wr}}-\mathrm{L}_{\mathrm{pr}}\right)
$$

Where

$\mathrm{L}_{\mathrm{pe}}$ is the mean band pressure level of the DUT (dB) (reference: $20 \mathrm{uPa}$ )

$\mathrm{L}_{\mathrm{wr}}$ is the band power level of the reference noise source (dB) (reference: $1 \mathrm{pW}$ )

$\mathrm{L}_{\mathrm{pr}}$ is the mean band pressure level of the reference noise source $(\mathrm{dB})$ (reference: $20 \mathrm{uPa}$ )

\subsubsection{Information to be Reported for Each Test Condition}

The report for each test will state whether or not the reported sound power levels have been obtained in full conformity with the requirements of the ISO 3743-2 standard as mentioned in previous sections. The report for each test will provide the sound power levels in decibels referenced to one $\mathrm{pW}$ (picowatt). Sound level exposure of mining machine operators is determined both by the sound power radiated by the machine and by the acoustic characteristics of the mine environment. The sound power is the quantity of most interest, because this information provides the sound radiated by the machine. Once the sound power is known, the sound pressure level that the operator would experience can be predicted or determined based on the acoustic characteristics of the environment. Sound power gives a direct comparison of noise 
for any machine tested under the same conditions. An example of this data (report summary) for each test to be conducted (testing plan) in the reverberation room for the roof bolter testing is shown below:

Table 4.9 Example of Reported Information for each Sound Power Test

\section{SOUND POWER MEASUREMENT REPORT}

\begin{tabular}{|c|c|c|c|c|c|c|}
\hline \multicolumn{7}{|c|}{ SOUND POWER MEASUREMENT AS PER THE ISO 3743-2 (comparison method) } \\
\hline \multicolumn{3}{|c|}{ TEST SPECIFCATIONS } & \multicolumn{4}{|c|}{ REFERENCE SOURCE SPECIFCATIONS } \\
\hline $\begin{array}{l}\text { DATE } \\
\text { LOCATION } \\
\text { OPERATOR } \\
\text { COMMENTS }\end{array}$ & \multicolumn{2}{|c|}{$\begin{array}{l}\text { 3/20/03 } \\
\text { PRL reverberation room, Bldg } 154 \\
\text { J. Shawn Peterson } \\
\text { none }\end{array}$} & $\begin{array}{l}\text { MANUFACTURER } \\
\text { TYPE } \\
\text { TECHNICAL COMMENTS } \\
\text { SERIAL NUMBER }\end{array}$ & \multicolumn{3}{|c|}{$\begin{array}{l}\text { Bruel \& Kjaer } \\
4204 \\
\text { Last calibrated 12/20/02, certificate } \\
\text { number P101784-1 } \\
955307\end{array}$} \\
\hline \multicolumn{7}{|c|}{ SOURCE SPECIFCATIONS } \\
\hline DEMCE & \multicolumn{2}{|l|}{ roof bolter } & & $\mathrm{x}$ & $\mathbf{Y}$ & \multirow[t]{2}{*}{ Z } \\
\hline TECHNICAL COMMENTS & \multicolumn{2}{|c|}{ none } & LOCATION(S) OF & \multirow[b]{2}{*}{9.0} & \multirow[b]{2}{*}{6.0} & \\
\hline $\begin{array}{l}\text { MANUFACTURER } \\
\text { SERIAL NUMBER }\end{array}$ & \multicolumn{2}{|c|}{$\begin{array}{l}\text { J. H. Fetcher } \\
\text { 93070/20000332 }\end{array}$} & $\begin{array}{l}\text { SOURCE } \\
\text { LOCATION(S) OF }\end{array}$ & & & 1.0 \\
\hline YEAR OF MANUFACTURE & \multicolumn{2}{|c|}{ E 2002} & REFERENCE SOURCE & 12.0 & 4.0 & 0.0 \\
\hline OPERATION CONDITIONS & S normal & & & $\begin{array}{l}12.0 \\
\text { LENGTH(M) }\end{array}$ & $\operatorname{MDTH}(\mathrm{M})$ & HEGHT (M) \\
\hline MOUNTING CONDITIONS & NA & & SOURCE DIMENSIONS & 9.0 & 4.0 & 1.5 \\
\hline \multicolumn{7}{|c|}{ ACOUSTICAL EMMRONMENT } \\
\hline & LENGTH (M) & MDTH(M) HEGHT (M) & & PRE-TEST & \multicolumn{2}{|r|}{ POST-TEST } \\
\hline \multirow[t]{2}{*}{ CHAMBER DIMENSIONS } & 18.3 & $10.4 \quad 6.7$ & AIR TEMPERATURE $\odot$ & 22.3 & & 22.3 \\
\hline & RIGHT & 123.2 & AMBIENT PRESSURE (Pa) & 978.0 & & 978.0 \\
\hline CHAMBER WAL & LEFT & 133.0 & RELATIVE HUMIDITY (\%) & 66.4 & & 66.9 \\
\hline SURFACES (METERS & FRONT & 69.8 & & & & \\
\hline SQUARED) & REAR & 78.0 & & & & \\
\hline & TOTAL & 404.0 & & & & \\
\hline INSTRUMENTATION & & & & & & \\
\hline MANUFACTURER & Bruel \& Kja & & CAUBRATION : DATE & $8 / 9 / 02$ & & \\
\hline NAME & Multi-chann & el Pulse & CAШBRATION : PLACE & Bruel \& Kjaer & & \\
\hline TYPE & $3560 \mathrm{E}$ & & CALIBRATION : METHOD & Calibration pr & rocedure 7 & 04823 \\
\hline SERIAL NUMBER & 2361569 & & & & & \\
\hline TEST PARTICULARS & & & & & & \\
\hline TEST TYPE & & $\dot{3}$ & $\begin{array}{l}\text { ROCK COMPRESSIVE } \\
\text { STRENGTH (psi) }\end{array}$ & & & 23,000 \\
\hline BIT MANUFACTURER & Brady & 9 & THRUST (lbs) & & & 5,280 \\
\hline & & & ROTATION SPEFD (rpm) & & & 300 \\
\hline BIT TYPE & carbide & $\frac{1}{3}$ & WATER PRESSURE (psi) & & & 80 \\
\hline DRIL STEFL TYPE & hexagonal & $\exists$ & WATER FLOW (gal / min) & & 1 & $\exists$ \\
\hline DRIL STEEI SIZE (dia) & 1 inch & 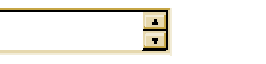 & MST WATER FLOW (qt / n & $\min )$ & 1 & $\ddot{\exists}$ \\
\hline
\end{tabular}


Table 4.10. One-third octave sound power levels determined for a specific test (numeric) OVERALL THIRD OCTAVE SOUND POWER LEVELS

\begin{tabular}{|c|c|c|c|c|c|c|}
\hline Band (Hz) & 100 & 125 & 160 & 200 & 250 & 315 \\
\hline Level (dB re 1 pW) & 103.7 & 106.1 & 108.2 & 109.9 & 109.0 & 106.9 \\
\hline Band (Hz) & 400 & 500 & 630 & 800 & 1000 & 1250 \\
\hline Level (dB re 1 pW) & 109.0 & 110.7 & 110.2 & 110.9 & 109.6 & 109.8 \\
\hline Band (Hz) & 1600 & 2000 & 2500 & 3150 & 4000 & 5000 \\
\hline Level (dB re 1 pW) & 108.3 & \begin{tabular}{l|l|}
107.8 \\
\end{tabular} & 105.1 & 104.6 & 101.6 & 98.5 \\
\hline Band (Hz) & 6300 & 8000 & 10000 & $\mathrm{~A}$ & $\mathrm{~L}$ & \\
\hline Level (dB re 1 pW) & 98.5 & 92.9 & 89.2 & 118.9 & 120.7 & \\
\hline
\end{tabular}

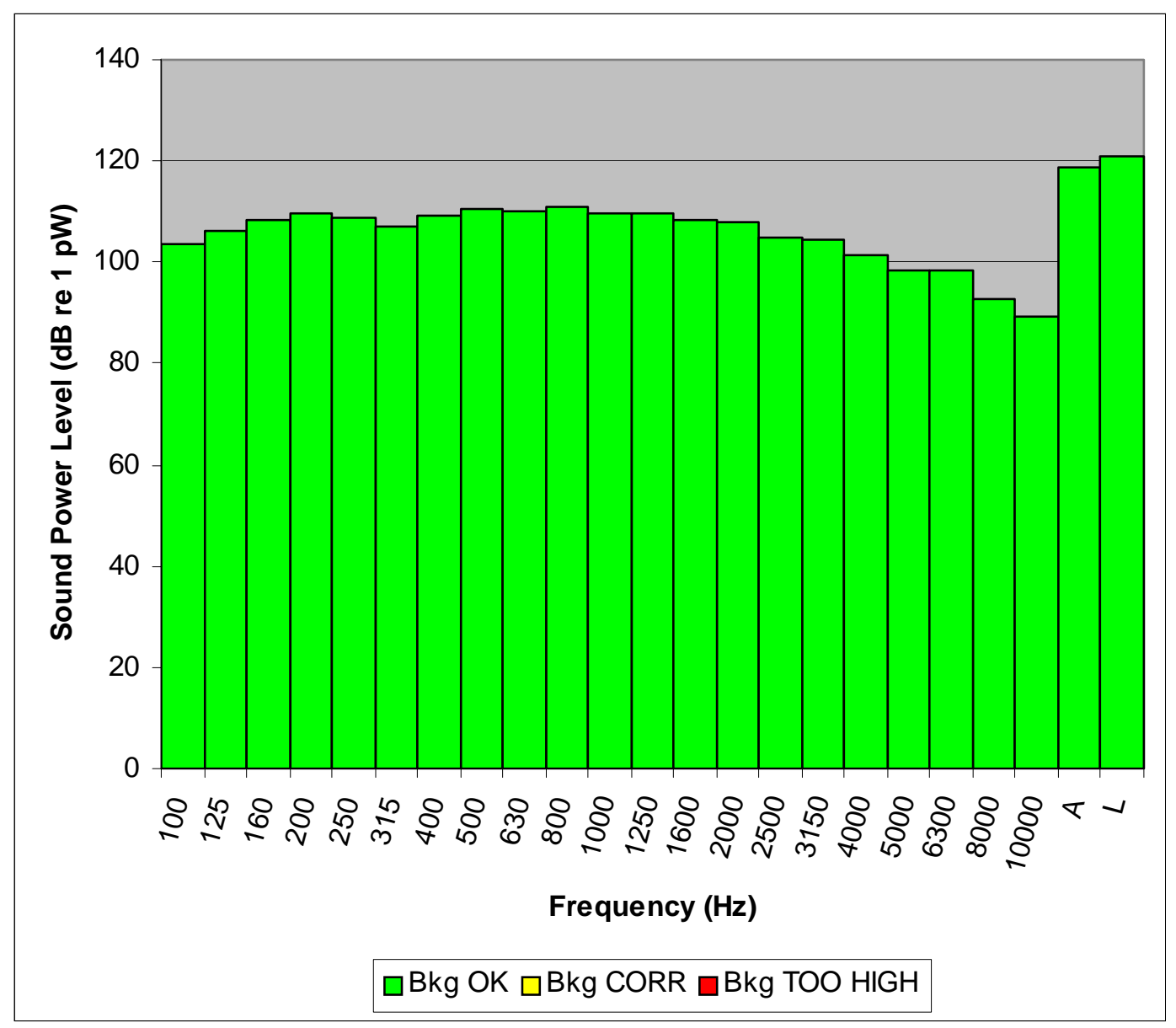

Figure 4.2 One-third Octave Sound Power Levels Determined for a Specific Control Test 


\subsection{Modification of Steel Test Fixture Used for Roof Bolter Testing in the Reverberation Room}

\section{$\underline{4.2 .1 \quad \text { Objective }}$}

The sound power levels radiated by a roof bolting machine were evaluated by drilling into high compressive strength rock media $(>20,000 \mathrm{psi})$ in the reverberation chamber. The rock media was supported on a steel structure that is comprised of rectangular tubes as shown in figure 4.3 .

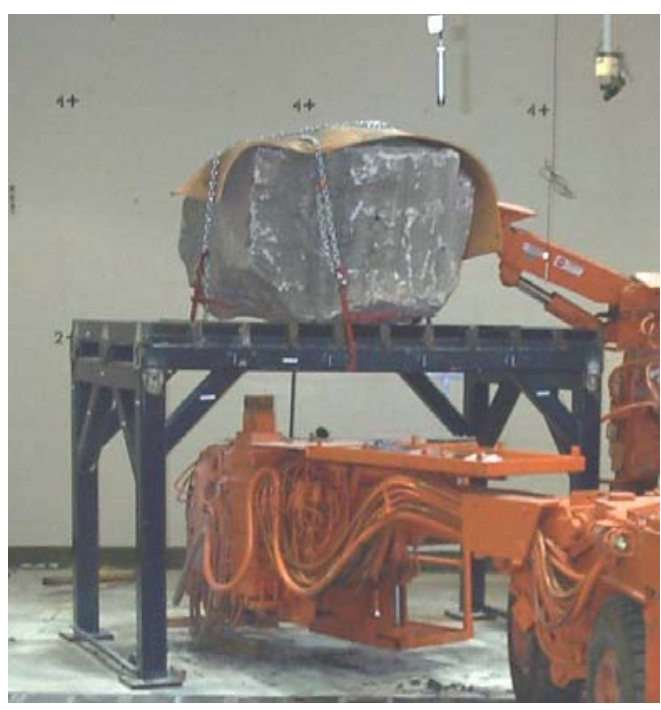

Figure 4.3 Test Fixture in Reverberation Room.

It was necessary to insure that the test fixture did not make a significant contribution to the sound power radiated during actual testing. Initially, the tubes were hollow and the rock was placed directly on the rock support tubes and held in place by a tensioned chain. The objective of the tests performed was to assess the potential sound power radiated by the rock support during drilling as discussed below. Then, modifications to the structure were performed to reduce the sound power radiated by the rock support. The tests performed are described below. 


\subsubsection{Tests Performed to Assess Sound Power Radiated from Test Fixture}

Two types of tests were performed to assess the performance of the rock support structure before any modifications to the fixture were performed (21). First, Frequency Response Function (FRF) measurements were performed at several locations on the test fixture. The rock was placed directly on the rock support tubes and held in place with a tensioned chain. An instrumented impact hammer was used to apply an input force to the structure and accelerometers were used at several locations to measure the vibratory response of the structure. The input was then randomly moved to each accelerometer location to measure FRFs in $g / N$. The accelerometers were located and oriented as follows:

1. Top Horizontal Tube at 34.5 " from the end oriented to measure in the Y direction.

2. Top Horizontal Tube at 34.5 " from the end oriented to measure in the $\mathrm{Z}$ direction (vertical).

3. Middle Horizontal Tube at 34.5 " from the end oriented to measure in the Y direction.

4. Middle Horizontal Tube at 34.5 " from the end oriented to measure in the $Z$ direction (vertical).

5. Rock Support Tube \#7 at 20.5" from the end oriented to measure in the X direction.

6. Rock Support Tube \#7 at 20.5 " from the end oriented to measure in the $\mathrm{Z}$ direction (vertical).

7. Vertical Support Tube at 20.5 " from the top end oriented to measure in the $X$ direction. 
8. Vertical Support Tube at 20.5" from the top end oriented to measure in the Y direction.

Figure 4.4 below displays location of support tubes on the test fixture along with the specific accelerometer locations. 


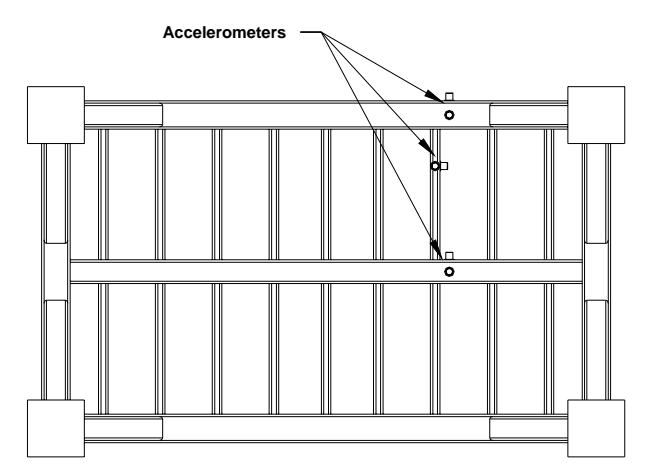

Bottom View

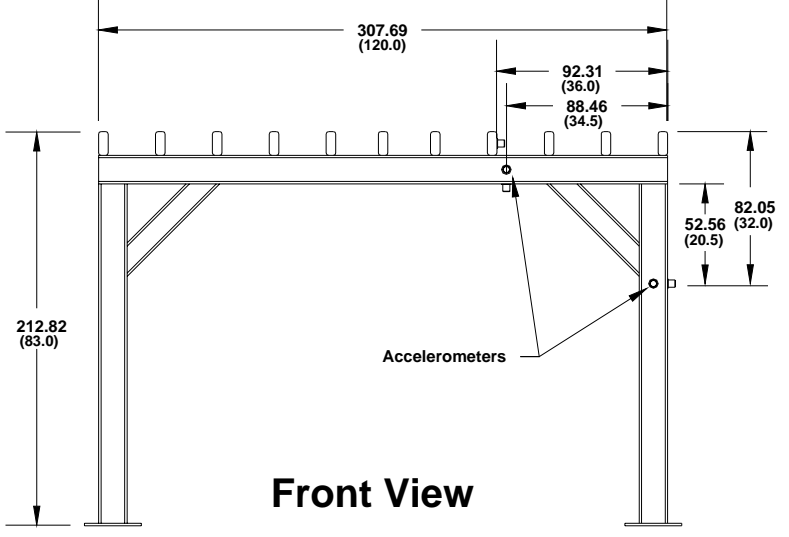

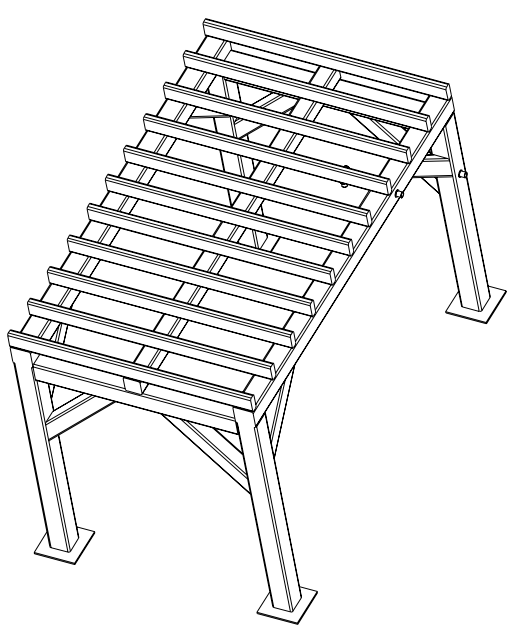

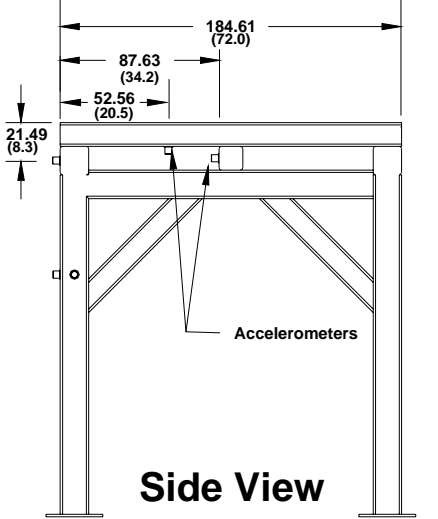

Roofbolter Test Fixture Units $=$ Centimeters (inches)

Figure 4.4 Location of Test Fixture Support Tubes and Accelerometers 
The hollow tubes were then filled with sand, except for the diagonal tubes and the horizontal tubes along the short direction at the top of the structure. This was done for two reasons: convenience and to create an impedance mismatch in the structure to reduce vibration transmission. In addition to filling the tubes, two layers of a urethane material were bonded to the rock support tubes to break direct contact between the rock and the structure. Finally, a layer of urethane was placed between the rock and the chain.

After measuring the FRFs in $\mathrm{g} / \mathrm{N}$, software was used to integrate the FRFs to provide the data into units of velocity per unit force: $\mathrm{mm} / \mathrm{s} / \mathrm{N}$. Velocity-based (mobility) FRFs are better suited to judging noise radiation because the sound power radiated by an object is related to the surface averaged mean square velocity. After measuring the velocity-based (mobility) FRFs, a hole was drilled and the accelerations were measured at each of the accelerometer locations. An A-weighting filter was applied to the digital data in the time domain and the signals were integrated to obtain the A-weighted vibration velocity at each accelerometer location.

Software was then used to compute the $1 / 3$-octave spectra with slow time weighting and RMS averaging for each time history. Finally, the A-weighted sound power radiated by the test fixture while drilling was calculated based on the data before and after the modifications using ISO/CD 7849 (22). The A-weighted sound power was used instead of the linear sound power because A-weighting is the frequency weighting that closely approximates the frequency response of the human ear. The influences of low and high frequencies are reduced in comparison to midrange frequencies because people are most sensitive to midrange sounds. Therefore, the sound power can be calculated from:

$$
L_{w}=\overline{L_{v}}+10 \log \left(\frac{S}{S_{0}}\right)
$$

where 
$\overline{L_{v}} \quad$ is the surface average velocity level with a reference of $50 \mathrm{~nm} / \mathrm{s}$

$\mathrm{S} \quad$ is the surface area

$\mathrm{S}_{0} \quad$ is the reference surface area of $1 \mathrm{~m}^{2}$.

The above equation was derived assuming a radiation efficiency of 1 and standard atmospheric conditions. It was unlikely that the radiation efficiency would be 1 at all frequencies, however, since the interest is the maximum sound power that can be radiated, this assumption would skew the estimate to the conservative side. Figure 4.5 shows the estimate of the sound power radiated by the test fixture before and after the modifications. The figure shows that the most significant sound power radiated by the fixture before the modifications is in the 1600 and $2000 \mathrm{~Hz}$ 1/3-Octave bands. The figure also shows that with the modifications, the highest 1/3-Octave A-weighted sound power level would be in the 1600 and $2000 \mathrm{~Hz} 1 / 3$-Octave bands. However, the modifications reduced the sound power level radiated to under $60 \mathrm{dBA}$ (30 dB) in all bands. Since it was likely that the drill will radiate much higher sound power levels, the fixture would not be a significant factor. 


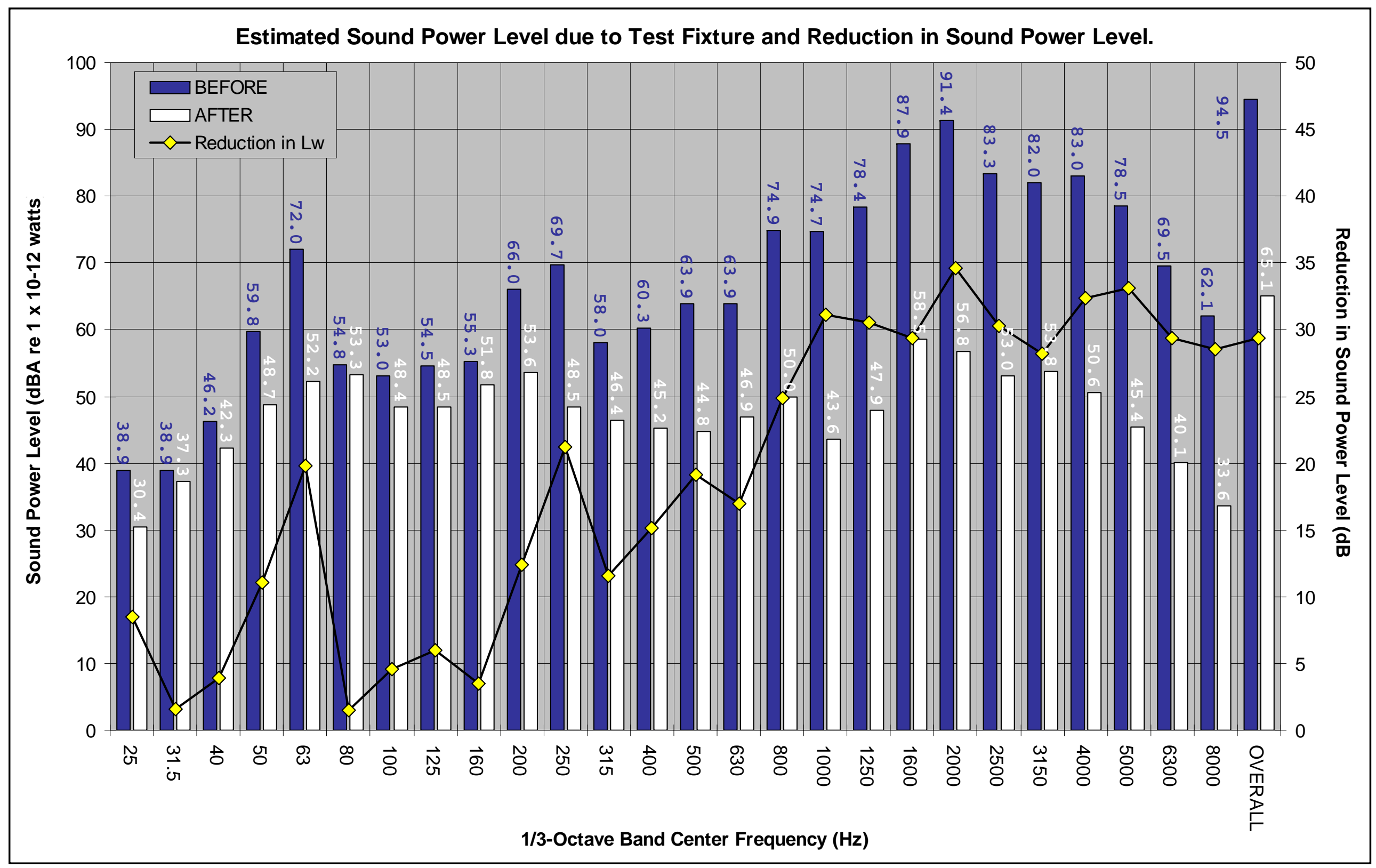

Figure 4.5 Estimated A-weighted Sound Power Level and Reduction in Estimated Sound Power Level Before and After Modification 


\section{$\underline{4.2 .3 \text { Conclusions }}$}

Velocity based FRFs indicated that filling the test fixture with sand significantly increased the damping of the structure. Subsequent recordings of accelerations at several locations showed that the vibration was significantly reduced for drilling conditions due to the added sand and isolating the rock from the test fixture. The procedure for estimating the sound power radiated from a structure using vibration data was followed to estimate the sound power level radiated by the fixture during drilling before and after the modifications. Before the modifications, the estimated sound power level radiated by the fixture exceeded $90 \mathrm{dBA}$ in the $2000 \mathrm{~Hz}$ 1/3-octave band. After the modifications, the estimated sound power level for all 1/3octave bands was below $60 \mathrm{dBA}$. Since the sound power level radiated by the roof bolting machine was expected to be much higher (more than $20 \mathrm{dBA}$ ) than $60 \mathrm{dBA}$, the test fixture was no longer a significant contributor to the sound power determined in the reverberation room, therefore sound power levels determined, will only be attributed to the activity of the roof bolting machine. 


\subsection{Sound Power Level Testing in Reverberation Room}

Sound power level testing was conducted in the reverberation room. Sound power level determination in a reverberant field is one of several methods available to calculate the noise emission of equipment and the reverberation room at the PRL has a unique facility which facilitates these measurements (figure 4.6).

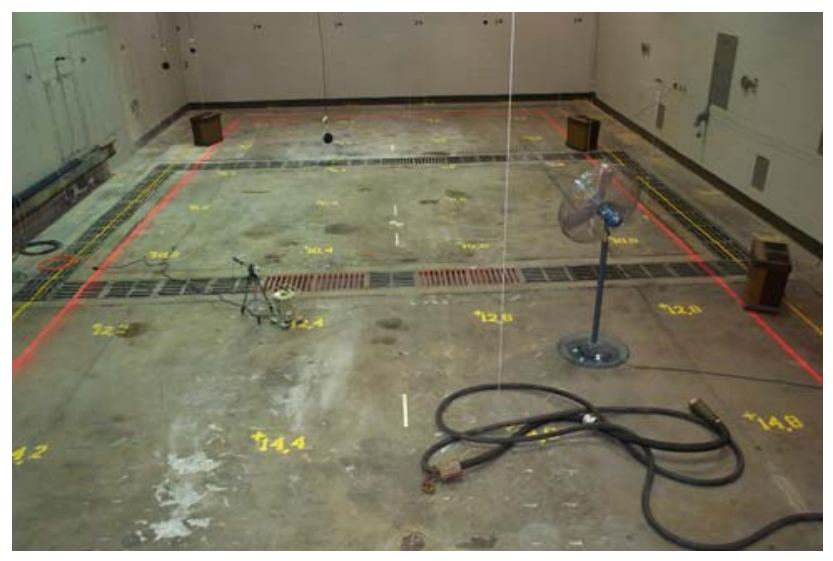

Figure 4.6 Reverberation Room at PRL

Further, a state of the art data collection, analysis, and reporting system is in place and allows for high throughput, i.e., a significant amount of testing may be conducted, from data collection to a detailed test report, within a short period of time (figure 4.7).

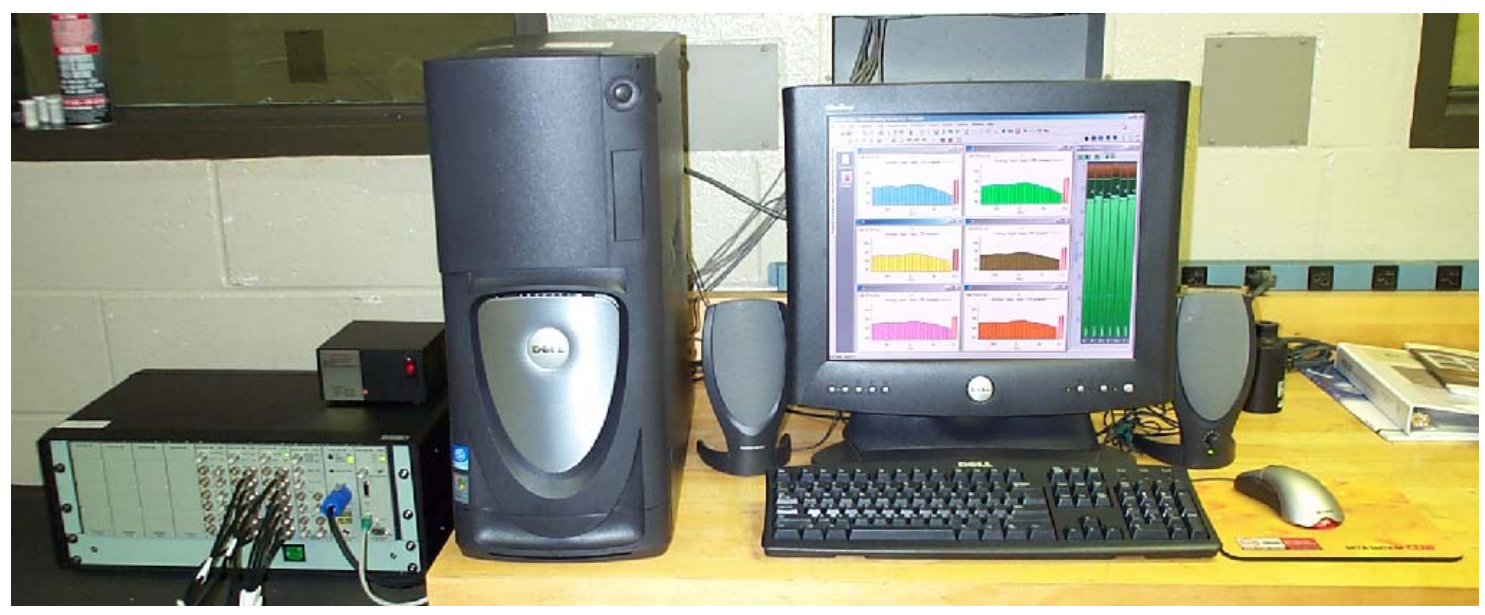

Figure 4.7. Bruel \& Kjaer Pulse Data Acquisition System 
As mentioned previously, the sound power level data collected, will be related to differing drilling parameters (thrust, rotational speed, penetration rate, drill steel size and shape, drill bit size) and drilling methods (vacuum, wet or mist) associated with the roof bolting machine during drilling operations in high-compressive strength $(>20,000 \mathrm{psi})$ rock media. The reverberation room was used to determine the sound power generated by the roof bolting machine in relation to the type of drilling procedure utilized for drilling a bolt hole. Numerous tests were performed to determine the effectiveness of each possible noise control related to the overall sound power generated for each testing condition. Table number 4.11 below demonstrates the different tests conducted (rotational speeds and thrust configurations) for dry, wet and mist system drilling methods in high compressive strength rock media ( $>20,000 \mathrm{psi})$, along with the specific data collected for each test configuration. Additionally, the following sections illustrate how the selected drilling parameters (thrust, rotational speed and penetration rate) were set and determined for the differing testing conditions. 


\begin{tabular}{|c|c|c|c|c|c|c|c|}
\hline $\begin{array}{l}\text { Vacuum, } \\
\text { Mist }\end{array}$ & et or & Kennameta & & & Test Da & lected Duri & Sound Powe \\
\hline Manual & & Carbide & & & & & \\
\hline Granite & & 1 or 1.375 & & & & & \\
\hline SET P & INTS & AVE & AGE & SOUN & R LEVEL & PENE & IION \\
\hline (lbs) & (rpm) & (Ibs) & (rpm) & (dB) & $(\mathrm{dBA})$ & (in) & (in/sec) \\
\hline setthrst & setspd & avthrust & avspeed & spdb & spdba & pendepth & penrate \\
\hline & 200 & & & & & & \\
\hline & 300 & & & & & & \\
\hline 2,121 & 400 & & & & & & \\
\hline & 500 & & & & & & \\
\hline & 600 & & & & & & \\
\hline & 200 & & & & & & \\
\hline & 300 & & & & & & \\
\hline 2,828 & 400 & & & & & & \\
\hline & 500 & & & & & & \\
\hline & 600 & & & & & & \\
\hline & 200 & & & & & & \\
\hline & 300 & & & & & & \\
\hline 3,535 & 400 & & & & & & \\
\hline & 500 & & & & & & \\
\hline & 600 & & & & & & \\
\hline & 200 & & & & & & \\
\hline & 300 & & & & & & \\
\hline 4,242 & 400 & & & & & & \\
\hline & 500 & & & & & & \\
\hline & 600 & & & & & & \\
\hline & 200 & & & & & & \\
\hline & 300 & & & & & & \\
\hline 4,949 & 400 & & & & & & \\
\hline & 500 & & & & & & \\
\hline & 600 & & & & & & \\
\hline & 200 & & & & & & \\
\hline & 300 & & & & & & \\
\hline 5,656 & 400 & & & & & & \\
\hline & 500 & & & & & & \\
\hline & 600 & & & & & & \\
\hline & 200 & & & & & & \\
\hline & 300 & & & & & & \\
\hline 6,363 & 400 & & & & & & \\
\hline & 500 & & & & & & \\
\hline & 600 & & & & & & \\
\hline
\end{tabular}




\subsubsection{Setting of Thrust Configurations}

The thrust setting on the bolting machine was set utilizing the following steps displayed below:

1) Verify the required thrust pressure required for the specific test configuration.

2) Determine the existing thrust setting.

a. Push the enable button on the operator joystick (figure 4.8), then push the joystick forward, causing the drill head to move up and contact the center beam of the test fixture. The mast should be located in a position which will allow the drill head to fully contact the center beam of the test fixture (figure 4.9).

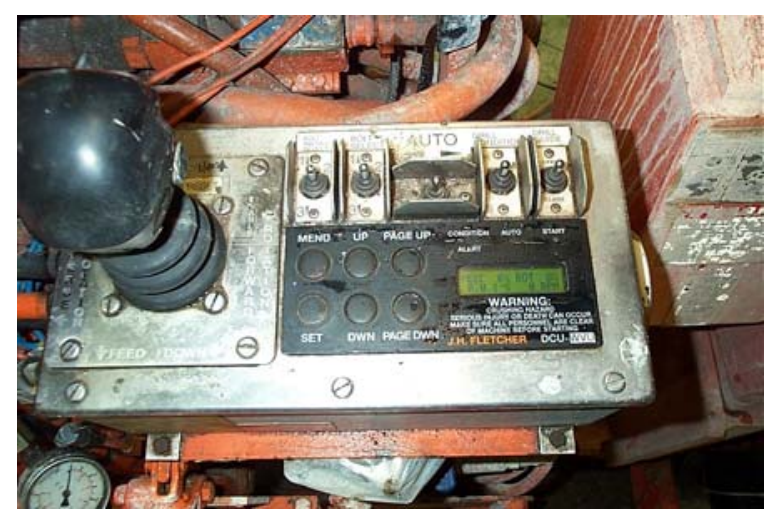

Figure 4.8 Joystick on Control Panel 


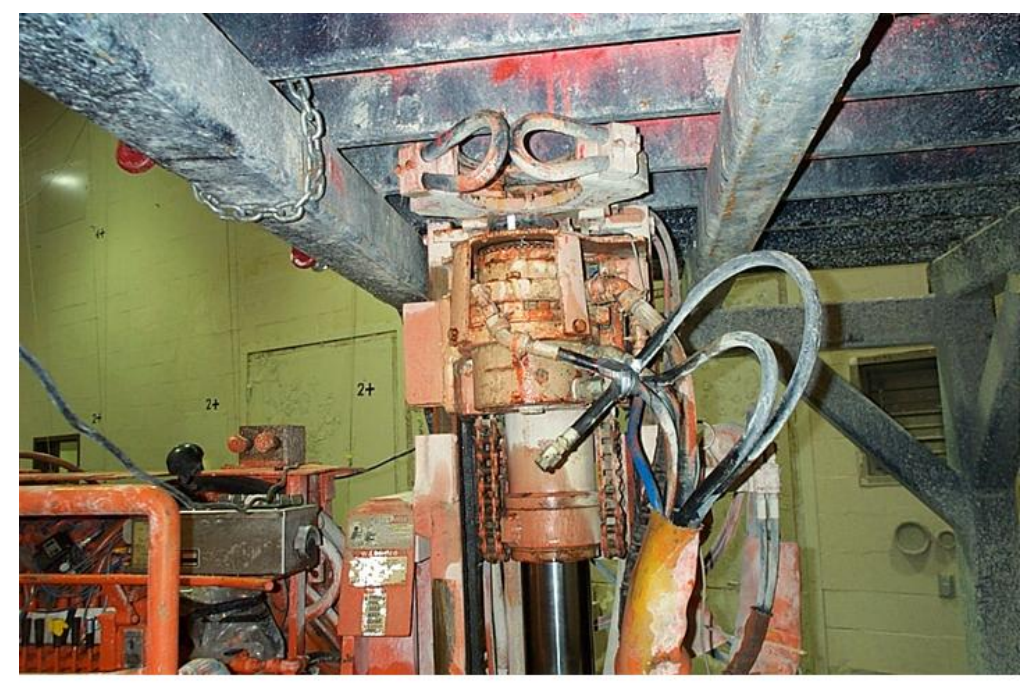

Figure 4.9 Drill Mast of Roof Bolting Machine Raised to Test Stand

b. While continuing to push forward on the operator joystick, examine the thrust pressure gauge located to the left of the hydraulic controls. Note the pressure. 


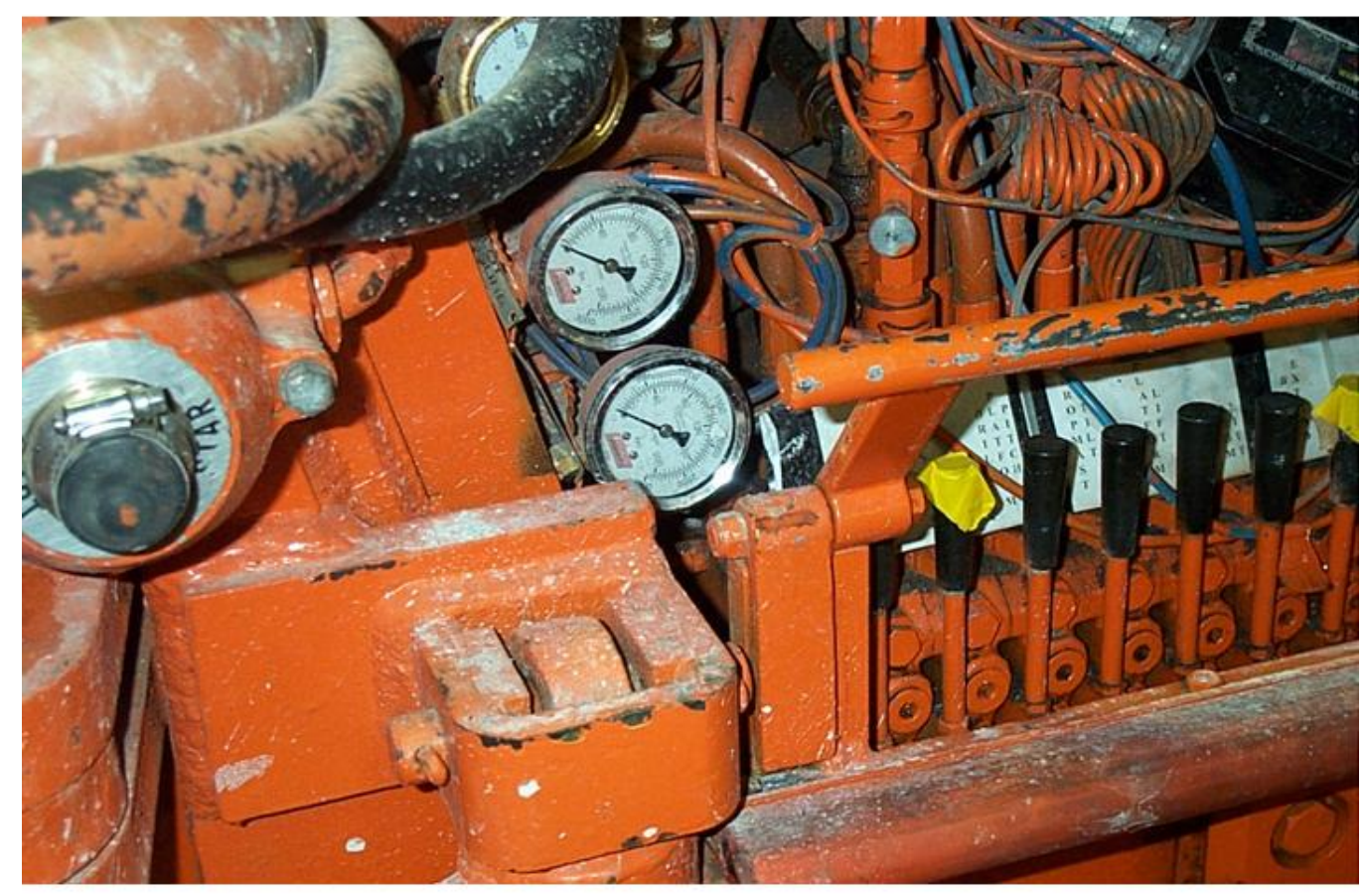

Figure 4.10 Location of Thrust Pressure Gauge

c. Determine direction to turn manual relief valve to reach desired thrust pressure (figure 4.11).

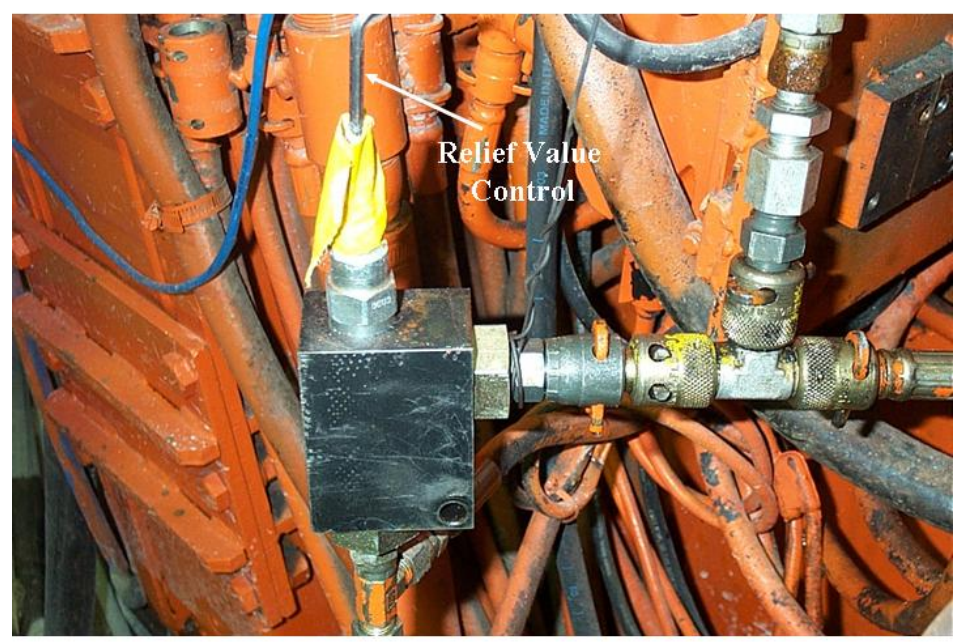

Figure 4.11 Location of Relief Valve Control

d. If desired thrust pressure is lower than existing pressure, reduce the pressure by turning the allen-wrench in a counter-clockwise direction. 
e. If desired thrust pressure is higher than existing pressure, increase pressure by turning allen-wrench in a clockwise direction.

f. Follow steps $a$ and $b$ mentioned above to verify new pressure setting.

g. If thrust setting does not match desired test pressure repeat steps above until desired setting is obtained.

\subsubsection{Setting Rotational Speed Configurations}

The rotational speed was measured utilizing a pulser disk, electro-sensors and a signal conditioner (figure 4.12.). The pulser disk mounts on the roof bolting machine chuck, therefore the drill steel passes through a hole in the disk. Embedded in the disk are magnets that are sensed when the drill chuck rotates. The sensor signal is then transmitted to the signal conditioner unit, which displays the rotation speed in $\mathrm{Hz}$, or magnetic pulses per second. The signal conditioner has a $0-10 \mathrm{Vdc}$ output, scaled to $\mathrm{Hz}$. This dc output is fed into the Bruel and Kjaer Pulse system and scaled into engineering units, represented by rpm.

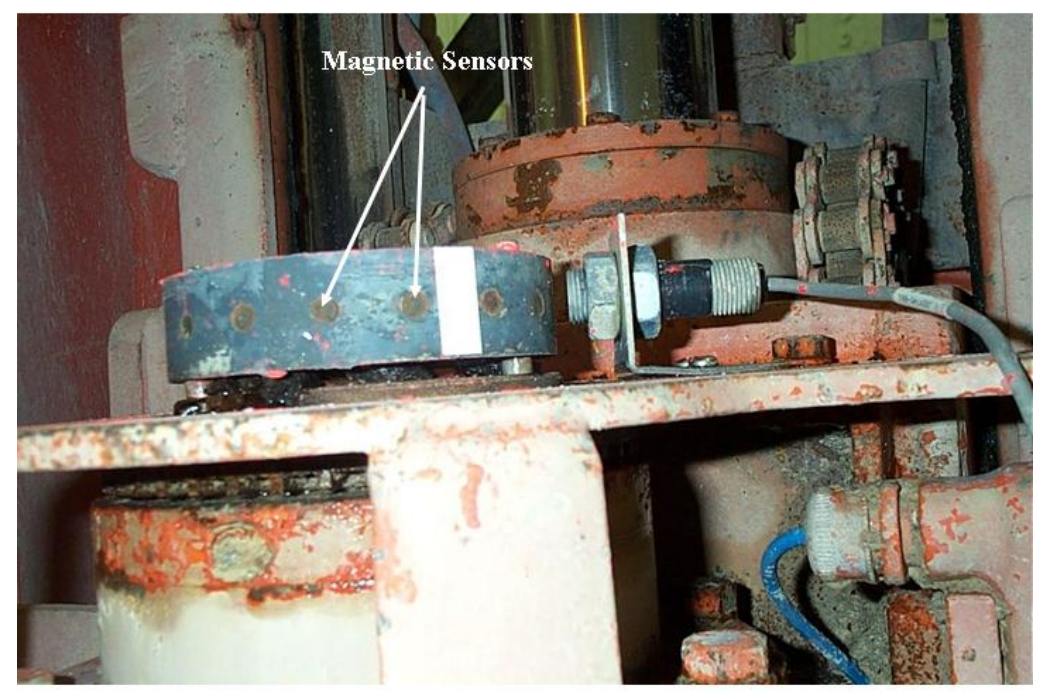

Figure 4.12 Pulser Disk and Electro-sensors Mounted on Drill Chuck 
The scaling associated with the rotational speed system is shown below:

$$
\begin{aligned}
& 0-240 \mathrm{~Hz}=0-1,800 \mathrm{rpm}=0-10 \mathrm{Vdc} \text { out or; } \\
& 1 \mathrm{~Hz}=7.5 \mathrm{rpm} \text { or; } \\
& 1 \mathrm{rpm}=5.556 \mathrm{mVdc} \text { out }
\end{aligned}
$$

Thus, the Bruel and Kjaer Pulse system then scales $5.556 \mathrm{mVdc}$ to $1 \mathrm{rpm}$.

\subsubsection{Determining Penetration Rate or Displacement During Testing}

To determine penetration rate during testing a string potentiometer was installed on the roof bolting machine (figure 4.13).

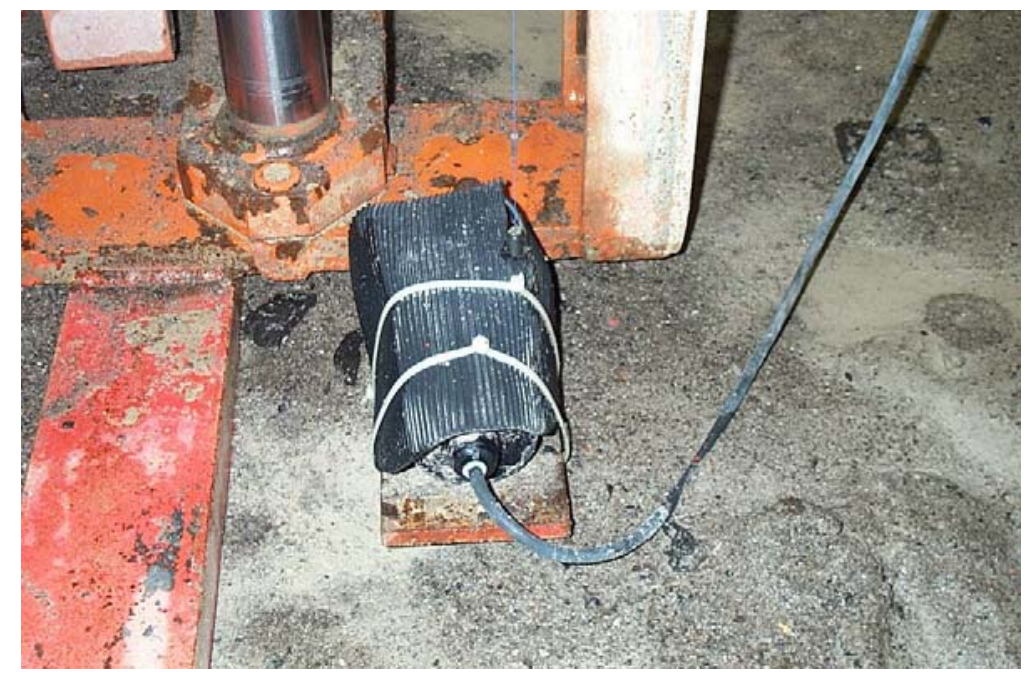

Figure 4.13 Location of String Potentiometer for Determination of Penetration Rate

The unit output voltage varied linearly with the distance the cable was displaced and was usable from two to eighty inches. The unit was installed on the bottom of the roof bolting machine with the cable attached to the chuck. The output voltage was then fed into the Bruel and Kjaer Pulse system per the calibration reports provided for the instrument. 


\subsubsection{Pulse System and Excel Data Collection Common to Speed and Displacement}

Data acquisition in the pulse system was started via a Visual Basic code launched in Excel. Speed and displacement data was fed into the pulse system and were displayed in windows in engineering units. Information in the pulse system was dynamically linked to the Excel spreadsheet and updated once per second. Once data collection was initiated in Excel, Visual Basic code reviewed the Excel cells containing the most recently collected speed, displacement, and time data and then copied the results to a table in the Excel worksheet, and then moved down into the next row. One second later, the dynamically linked data was updated, and the process repeated itself, adding rows of time, speed, and displacement data. This was plotted in essentially real time in Excel. Once the test was completed, an average of the speed data was calculated and used for the test report. The change in displacement and time were calculated and used to calculate the penetration rate, again for the test report. An example of a test report for one specific test is displayed below (figure 4.14). 


\section{Test Report}

\begin{tabular}{|c|c|}
\hline $\begin{array}{l}\text { Test Type } \\
\text { Test Mode } \\
\text { Material } \\
\text { Compressive Strength (lbs) }\end{array}$ & $\begin{array}{l}: \text { wet } \\
: \text { manual } \\
: \text { granite } \\
: 21,000\end{array}$ \\
\hline $\begin{array}{l}\text { Bit Manufacturer } \\
\text { Bit Type } \\
\text { Bit Size (in) }\end{array}$ & $\begin{array}{l}: \text { A } \\
: \text { carbid } \\
: 1\end{array}$ \\
\hline Drill Steel & : round \\
\hline $\begin{array}{l}\text { Water Flow Rate (gal/min) } \\
\text { Mist Flow Rate (qt/min) }\end{array}$ & $\begin{array}{l}: 3 \mathrm{~g} / \mathrm{m} \\
: \mathrm{N} / \mathrm{A}\end{array}$ \\
\hline $\begin{array}{l}\text { Set Thrust (lbs) } \\
\text { Average Thrust (lbs) }\end{array}$ & $\begin{array}{l}: 2,828 \\
: 3,113\end{array}$ \\
\hline $\begin{array}{l}\text { Set Rotation Speed (rpm) } \\
\text { Average Rotation Speed (rp) }\end{array}$ & $\begin{array}{l}: 500 \\
\text { m): } 508\end{array}$ \\
\hline Penetration Rate (in/sec) & : 0.434 \\
\hline $\begin{array}{l}\text { Sound Power (dB) } \\
\text { Sound Power (dBA) } \\
\text { Time (sec) }\end{array}$ & $\begin{array}{l}: 105.9 \\
: 105.4 \\
: 30.0\end{array}$ \\
\hline
\end{tabular}

Figure 4.14 Example of a Test Report - Sound Power

\subsection{Rock Media and Strength Property Testing of Drilling Media \\ 4.4.1 Type of Rock Media}

As mentioned earlier, for phase 1 of the research, differing drilling parameters were tested to determine sound power levels of the roof bolting machine during drilling into high compressive strength media (>20,000 psi). The type of material tested and utilized during phase 1 of the research study was Barre Gray Granite as shown in figure 4.15 below. 


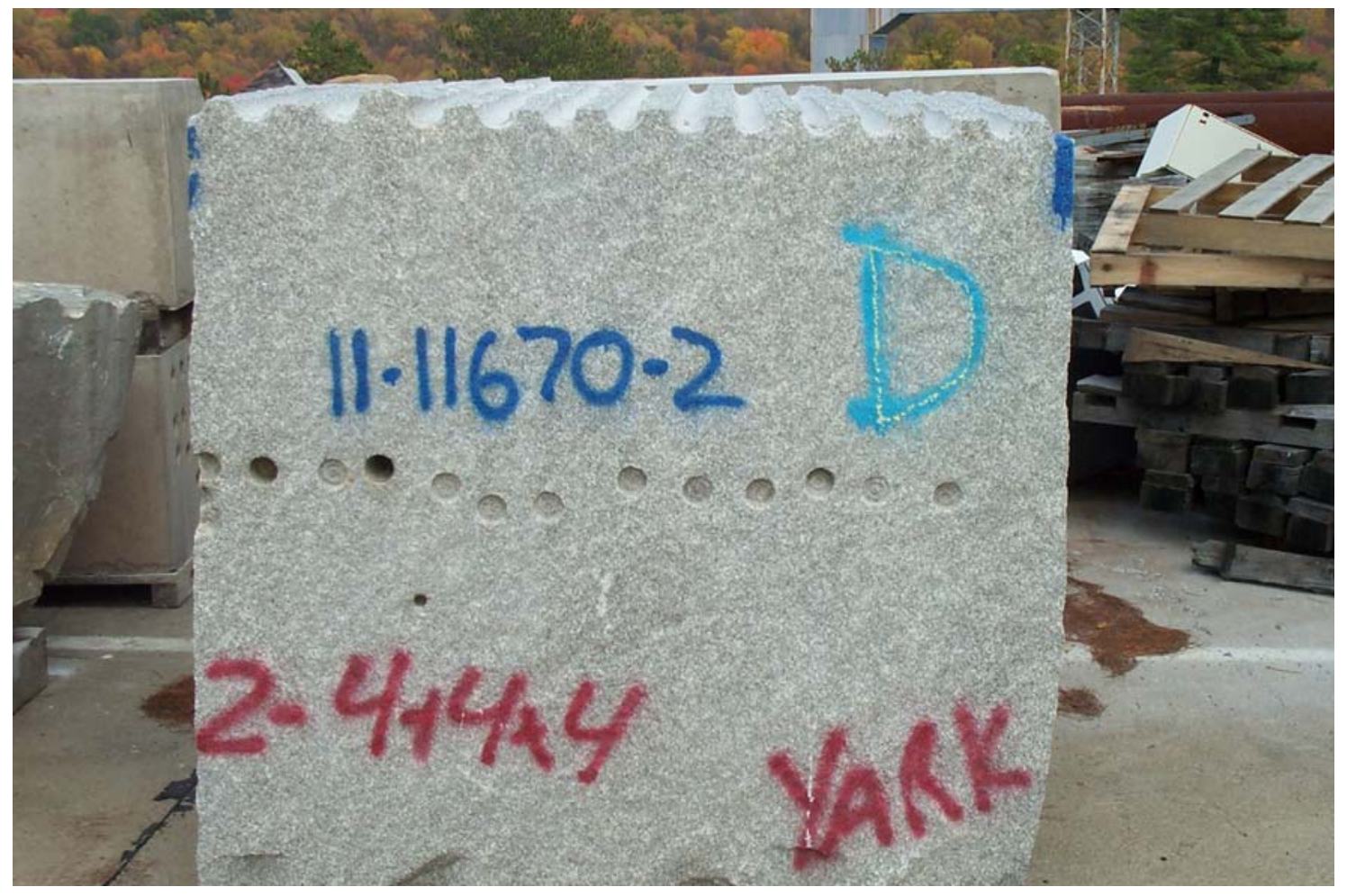

Figure 4.15 Barre Gray Granite - Rock Media Used for Testing in Phase 1

\subsubsection{Obtaining Rock Cores of Drilling Media}

The rock media, Barre Gray Granite, was core drilled at the laboratory to obtain rock samples for rock strength testing. The individual rock samples were then tested in the rock mechanics lab to determine significant rock properties, such as unconfined compressive strength, used during noise testing in the reverberation room. Figure 16 below displays several core samples obtained from the drilling of the Barre Gray Granite, rock media type used for phase 1 of the research study. 


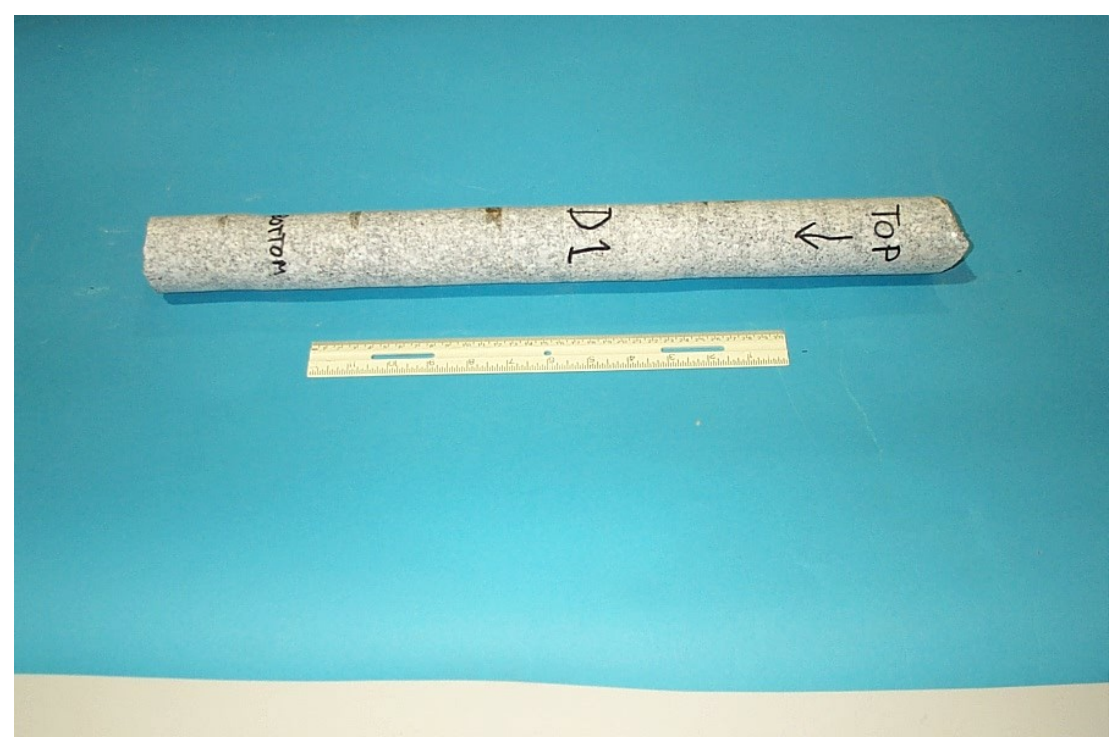

Figure 4.16 Sample of Core Collected from Barre Granite Rock Media

\subsubsection{Unconfined Compressive Strength Testing of Rock Media}

The rock cores obtained from the drilling procedure were then prepared and tested for rock strength properties (unconfined compressive strength). Dependent upon the size of samples available, the number of strength properties varied. The test procedures utilized adhered to the ASTM standards and were conducted on cores of 2-in in diameter. Results of the testing are shown in table 4.12 below.

Table 4.12 Unconfined Compressive Strength Results of Barre Gray Granite

\begin{tabular}{|c|c|c|c|c|c|c|c|}
\hline $\begin{array}{c}\text { Specimen } \\
\text { Number }\end{array}$ & $\begin{array}{c}\text { Length (L), } \\
\text { inches }\end{array}$ & $\begin{array}{l}\text { Diameter } \\
\text { (D), inches }\end{array}$ & L/D Ratio & $\begin{array}{c}\text { Area }(A) \\
\text { in }^{2}\end{array}$ & $\begin{array}{c}\text { Load at } \\
\text { Failure }(\mathbf{P}), \\
\text { pounds }\end{array}$ & $\begin{array}{c}\text { Compressive } \\
\text { Strength } \\
\text { (C), psi }\end{array}$ & $\begin{array}{c}\text { Corrected } \\
\text { Compressive } \\
\text { Strength } \\
\left(C^{\circ}\right), \text { psi }\end{array}$ \\
\hline D1 & 4.006 & 1.990 & 2.013 & 3.109 & 71,900 & 23,126 & 23,144 \\
\hline D2 & 3.997 & 1.990 & 2.009 & 3.109 & 72,880 & 23,442 & 23,454 \\
\hline D3 & 4.001 & 1.992 & 2.009 & 3.117 & 75,920 & 24,360 & 24,373 \\
\hline AVERAGE & & & & & 73,567 & 23,643 & 23,657 \\
\hline
\end{tabular}


The average unconfined compressive strength of all cores tested was 23,657 psi, approximately 24,000 psi for the Barre Gray Granite rock media.

\subsection{Testing of Differing Bits and Drill Steel}

\subsubsection{Drill Bits}

A variety of types and sizes of drill bits are being utilized in the mining industry today during roof bolting operations (figure 4.17).

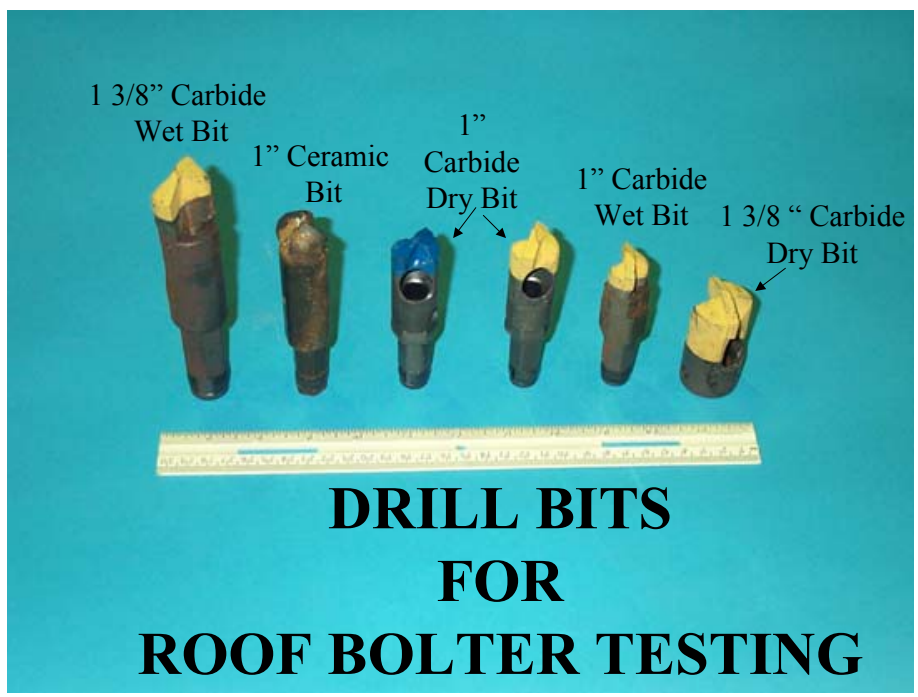

Figure 4.17 Types of Drill Bits Used During Roof Bolting Operations

Critical information related to the type and/or size of bits in relation to noise output is very limited in the mining industry today. Noise testing was performed in the reverberation room on a variety of differing types and sizes of drill bits. The different types of drill bits tested included:

- 1 -inch and 1 3/8-inch carbide bit used during dry drilling operations (new bit used for each test).

- 1 -inch and $13 / 8$-inch carbide bit used during wet drilling operations (including mist-system technology) (new bit used for each test) 


\subsubsection{Drill Steel}

The mining industry utilizes different types of drill rod during roof bolting operations. Significant information related to the type and/or size of drill steel in relation to noise output is unidentified in the mining industry today. Noise testing was performed in the reverberation room on a variety of differing types and sizes of drill steel. The different types of drill steel tested (figure 4.18) for noise generation included:

- $\quad 1$ inch and $13 / 8$ inch round drill steel

- 1 inch and $13 / 8$ inch hex drill steel

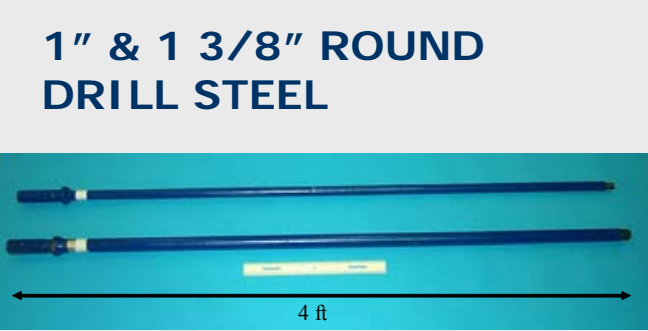

1" \& 1 3/ 8" HEX DRI LL STEEL

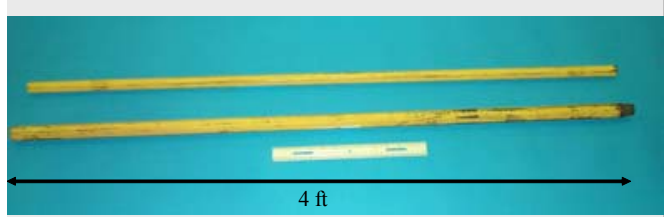

Figure 4.18 Types of Drill Steel Used During Roof Bolting Operations 


\subsection{Testing of Different Drilling Methods}

\subsubsection{Dry (Vacuum), Wet and "Mist" Systems}

During roof bolting operations, drilling of the immediate roof occurs by drilling the bolt hole dry (vacuum) or using water as a drilling fluid. Tests were conducted in the reverberation room to determine if the use of water during the drilling technique of a roof bolting operation minimizes noise output associated with the procedure. Noise testing was performed during dry and wet drilling operations. During wet drilling operations, differing flow rates of water was tested for noise characteristics. Additionally, the use of a "mist" system was also incorporated in the wet drilling tests to minimize the flow of water to the bit. The "mist" system is designed to provide minimal flow (e.g. quart/minute of water) to the bit, reducing the potential hazard of extreme amounts of water affecting the roof bolter operator. The "mist" system utilized a system of compressed air and water input for providing minimal flow rate to the bit. Figure 4.19 displays a photograph of the "mist" system used during noise testing.

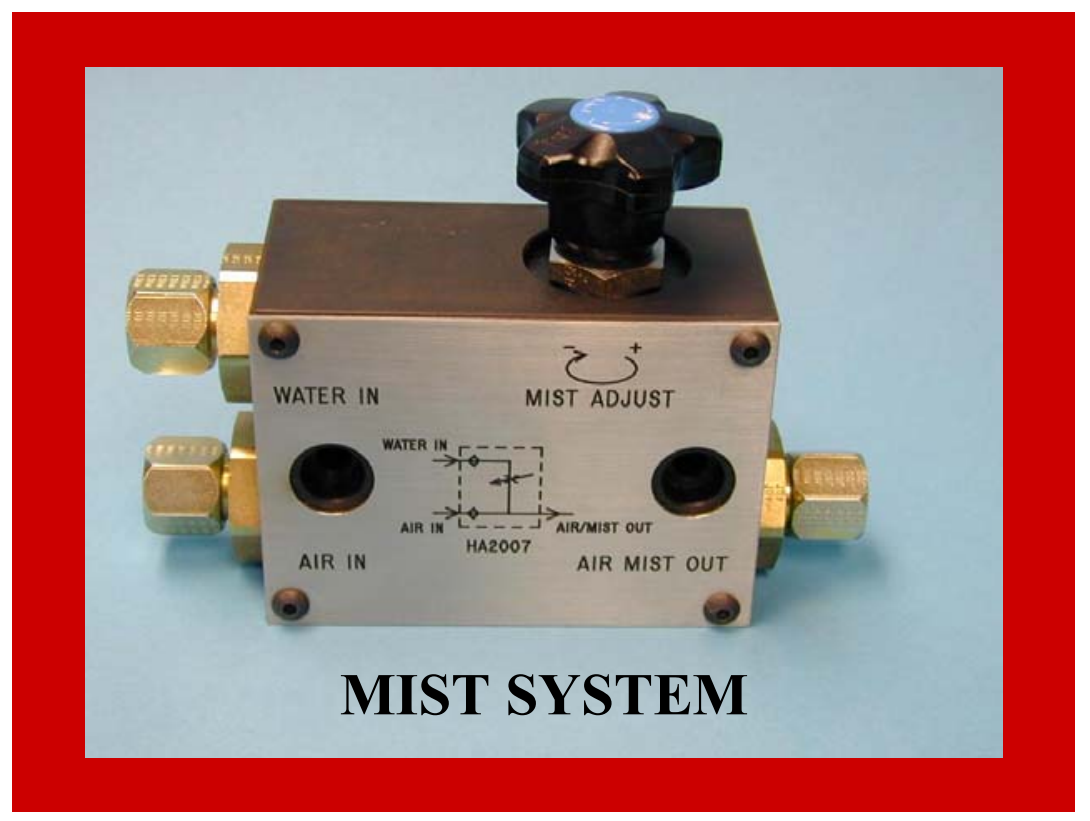

Figure 4.19 Photograph of "Mist" System Used During Noise Testing 


\subsection{Summary of Tests Conducted in the Reverberation Room}

In summary, a total of approximately 500 noise tests (determination of sound power) were performed to characterize the differing noise controls associated with roof bolting operations in high compressive strength rock media ( $>20,000 \mathrm{psi})$. All tests were performed in the Pittsburgh Research Laboratory's Reverberation Room to determine sound power levels, during drilling operations, associated with the following characteristics:

- Vacuum (dry) Drilling

- Wet Drilling (3 gallons of water per minute to drilling bit)

- Mist System (3 quarts of water per minute to drilling bit)

- Round Drill Steel

- Hex Drill Steel

- Drill Bit Size (1-inch and $13 / 8$-inch)

- Manual Drilling (differing thrust, rotational speed and penetration rate drilling parameters)

Please note, sound levels experienced by a roof bolter operator are determined both by the sound power radiated by the drilling operation and by the acoustic characteristics of the mine environment. The sound power is the quantity of most interest, because this information provides the sound radiated by the drilling procedure related to any utilization of engineering noise controls. Because of all the variations both geometrically and acoustically in underground mines it would be difficult to achieve uniform test conditions in an underground mine setting. Additionally, it would be impossible to control the acoustic environment underground, which would make it difficult to evaluate the roof bolting machine and its components for noise levels. Therefore, testing was conducted in the Pittsburgh Research Lab (PRL) Reverberation Chamber for sound power levels generated from the roof bolting machine. Utilizing the reverberation chamber provided the determination of sound power radiating from the machine in a 
controlled acoustic environment and would be independent of the many differing variables associated with the underground mining environment. The determination of sound power in the reverberation room provided a direct comparison of noise for any engineering noise controls tested during each individual test. The preceding chapter, Chapter 5, displays the data collected for all sound power tests conducted in the reverberation room, along with the methods and the applications used in determining constructive results related to the assessment of noise control technologies related to drilling operations associated with the roof bolting machine.

As mentioned earlier, testing noise control technologies related to the roof bolting machine were conducted in the reverberation room due to the varying geometries and the acoustical characteristics associated with underground coal mines. Chapter 6 provides a methodology for characterizing the acoustical uniqueness of an underground coal mine and with the use of an acoustical model, provides the ability of the user to predict the sound pressure level the roof bolting machine operator would experience, given the measured sound power levels collected from the laboratory (reverberation room). The model provides the mining community with a state-of-the-art opportunity to examine and measure sound power in the laboratory (related to engineering noise controls) and then directly associate or correlate the measured value to a sound pressure level experienced by the operator of a specific mining machine, specifically, the roof bolting machine, in determining overexposure to noise. 


\section{CHAPTER 5}

\section{APPLICATIONS OF SOUND POWER LEVEL MEASUREMENTS CONDUCTED IN THE REVERBERATION ROOM}

As mentioned in Chapter 4, a total of approximately 500 noise tests (determination of sound power) were performed to characterize the differing noise controls associated with roof bolting operations in high compressive strength rock media ( $>20,000 \mathrm{psi})$. All tests were performed in the Pittsburgh Research Laboratory's Reverberation Room to determine sound power levels of roof bolting operations associated with the following characteristics:

- Vacuum (dry) Drilling

- Wet Drilling (3 gallons of water per minute to drilling bit)

- Mist System (3 quarts of water per minute to drilling bit)

- Round Drill Steel

- Hex Drill Steel

- Drill Bit Size (1-inch and $13 / 8$-inch)

- Manual Drilling (differing thrust, rotational speed and penetration rate drilling parameters)

\subsection{Drilling Components and Parameters Utilized for Testing}

In formulating a conservative test plan, it was decided to use drilling components and parameters that were representative of industry usage. These are listed below in Table 5.1.

Table 5.1 Variables for Sound Power Level Testing

\begin{tabular}{ccc}
\hline Item & Units & Values \\
\hline Drilling type & ---- & vacuum, mist @ 3 qt/min, wet @ 3 gal/min \\
\hline Drill steel & ---- & round, hexagonal \\
\hline Drill bit size & in & one, one and three-eighths \\
\hline Rotation speed & rpm & $200,300,300,400,500,600$ \\
\hline Thrust & lbs & $2,121,2,828,3,535,4,242,4,949,5,656^{*}, 6,363^{*}$ \\
\hline$\bullet$ & $*$ One and three-eighths inch $\left(13 / 8^{\prime \prime}\right)$ bit size only, due to safety limitations. \\
\hline
\end{tabular}


Various combinations of these parameters are shown in table 5.1, in which, comprise the test configurations related to the testing of the high compressive strength rock media $(>20,000 \mathrm{psi})$. Data was not obtained or collected for tests utilizing a 1-inch bit and 1-inch drill steel at thrust settings 5,656 and 6,363 lbs respectively due to safety concerns when drilling into the high compressive strength media and using a 1-inch drill steel. Additionally, several data points were not collected where thrust settings were low $(2,121,2,828$ and $3535 \mathrm{lbs})$ and rotational speeds were high (500 and $600 \mathrm{rpm})$ due to ineffective performance of the drilling process. Additionally, the penetration depth (inches) was measured for each test and consequently the penetration rate (inches/second) for each test was determined or measured and displayed in the following tables listed below.

\subsection{Data Collected for Sound Power Level Tests}

Data collected for all sound power level tests conducted are shown in the following tables:

- Table 5.2 - Vacuum drilling method, 1-inch bit, round drill steel

- Table 5.3 - Vacuum drilling method, 1-inch bit, hex drill steel

- Table 5.4 - Vacuum drilling method, 1-3/8-inch bit, round drill steel

- Table 5.5 - Vacuum drilling method, 1-3/8-inch bit, hex drill steel

- Table 5.6 - Wet drilling method (3 gal $/ \mathrm{min}), 1$-inch bit, round drill steel

- Table 5.7 - Wet drilling method (3 gal $/ \mathrm{min}), 1$-inch bit, hex drill steel

- Table 5.8 - Wet drilling method (3 gal $/ \mathrm{min}), 1-3 / 8$-inch bit, round drill steel

- Table 5.9 - Wet drilling method (3 gal $/ \mathrm{min}), 1-3 / 8$-inch bit, hex drill steel

- Table 5.10 - Mist drilling method (3 qt/min), 1-inch bit, round drill steel

- Table 5.11 - Mist drilling method (3 qt/min), 1-inch bit, hex drill steel

- Table 5.12 - Mist drilling method (3 qt $/ \mathrm{min}), 1-3 / 8$-inch bit, round drill steel

- Table 5.13 - Mist drilling method (3 qt $/ \mathrm{min}), 1-3 / 8$-inch bit, hex drill steel

Tables 5.2 thru 5.13 are shown respectively on the following pages. 
Table 5.2 Sound Power Level Testing - Vacuum Method, 1-inch bit, Round Drill Steel

\begin{tabular}{|c|c|c|c|c|c|c|c|}
\hline \multicolumn{2}{|c|}{ SET POINTS } & \multicolumn{2}{|c|}{ AVERAGE } & \multicolumn{2}{|c|}{ SOUND POWER } & \multicolumn{2}{|c|}{ PENETRATION } \\
\hline $\begin{array}{c}\text { THRUST } \\
\text { (lbs) }\end{array}$ & $\begin{array}{c}\text { SPEED } \\
\text { (rpm) }\end{array}$ & $\begin{array}{c}\text { THRUST } \\
\text { (lbs) }\end{array}$ & $\begin{array}{c}\text { SPEED } \\
\text { (rpm) }\end{array}$ & $\begin{array}{c}\text { LINEAR } \\
\text { (dB) }\end{array}$ & $\begin{array}{c}\text { A-WGT } \\
\text { (dBA) }\end{array}$ & $\begin{array}{l}\text { DEPTH } \\
\text { (in) }\end{array}$ & $\begin{array}{l}\text { RATE } \\
\text { (in/sec) }\end{array}$ \\
\hline setthrst & setspd & avthrust & avspeed & spdb & spdba & pendepth & penrate \\
\hline \multirow{8}{*}{2,121} & \multirow{2}{*}{200} & 2,239 & 209 & 106.8 & 106.6 & 3.42 & 0.125 \\
\hline & & 2,228 & 210 & 107.1 & 107.1 & 3.14 & 0.114 \\
\hline & \multirow{2}{*}{300} & 2,282 & 306 & 108.2 & 108.3 & 3.49 & 0.128 \\
\hline & & 2,272 & 305 & 107.4 & 107.4 & 4.09 & 0.149 \\
\hline & \multirow{2}{*}{400} & 2,324 & 400 & 108.3 & 108.4 & 3.85 & 0.141 \\
\hline & & 2,280 & 402 & 108.5 & 108.6 & 3.79 & 0.139 \\
\hline & 500 & 2,220 & 514 & 109.3 & 109.5 & 4.38 & 0.168 \\
\hline & 600 & 2,241 & 609 & 108.7 & 108.8 & 3.53 & 0.134 \\
\hline \multirow{6}{*}{2,828} & 200 & 2,711 & 208 & 108.0 & 107.8 & 5.11 & 0.187 \\
\hline & \multirow{2}{*}{300} & 2,696 & 305 & 109.8 & 109.9 & 5.21 & 0.190 \\
\hline & & 2,705 & 306 & 109.4 & 109.4 & 5.64 & 0.205 \\
\hline & 400 & 2,701 & 402 & 109.8 & 109.9 & 4.82 & 0.177 \\
\hline & 500 & 2,865 & 509 & 109.9 & 110.1 & 5.82 & 0.226 \\
\hline & 600 & 2,892 & 602 & 110.0 & 110.1 & 5.20 & 0.201 \\
\hline \multirow{7}{*}{3,535} & 200 & 3,435 & 215 & 110.1 & 110.2 & 7.12 & 0.260 \\
\hline & \multirow{2}{*}{300} & 3,451 & 304 & 110.7 & 110.9 & 7.18 & 0.262 \\
\hline & & 3,620 & 311 & 109.5 & 109.6 & 9.97 & 0.390 \\
\hline & \multirow{2}{*}{400} & 3,487 & 405 & 111.1 & 111.5 & 6.28 & 0.229 \\
\hline & & 3,483 & 404 & 111.4 & 111.6 & 6.28 & 0.229 \\
\hline & 500 & 3,628 & 510 & 110.3 & 110.5 & 6.26 & 0.239 \\
\hline & 600 & 3,653 & 607 & 110.9 & 111.1 & 6.17 & 0.237 \\
\hline \multirow{6}{*}{4,242} & 200 & 4,085 & 208 & 111.0 & 111.2 & 9.67 & 0.353 \\
\hline & 300 & 4,097 & 305 & 111.3 & 111.6 & 9.76 & 0.358 \\
\hline & \multirow{2}{*}{400} & 4,111 & 404 & 111.5 & 111.5 & 8.39 & 0.305 \\
\hline & & 4,283 & 406 & 111.2 & 111.4 & 10.03 & 0.385 \\
\hline & 500 & 4,291 & 509 & 110.7 & 110.9 & 8.09 & 0.311 \\
\hline & 600 & 4,314 & 604 & 110.7 & 110.9 & 7.24 & 0.279 \\
\hline \multirow{7}{*}{4,949} & \multirow{2}{*}{200} & 4,744 & 221 & 110.4 & 110.4 & 8.63 & 0.313 \\
\hline & & 4,778 & 223 & 110.4 & 110.6 & 10.41 & 0.394 \\
\hline & 300 & 4,769 & 308 & 111.9 & 112.3 & 10.94 & 0.387 \\
\hline & \multirow{2}{*}{400} & 4,800 & 404 & 112.3 & 112.6 & 11.90 & 0.432 \\
\hline & & 4,821 & 406 & 110.3 & 110.4 & 10.93 & 0.422 \\
\hline & 500 & 4,870 & 507 & 111.1 & 111.4 & 8.22 & 0.311 \\
\hline & 600 & 4,822 & 607 & 110.4 & 110.7 & 5.78 & 0.222 \\
\hline
\end{tabular}


Table 5.3 Sound Power Level Testing - Vacuum Method, 1-inch bit, Hex Drill Steel

\begin{tabular}{|c|c|c|c|c|c|c|c|}
\hline \multicolumn{2}{|c|}{ SET POINTS } & \multicolumn{2}{|c|}{ AVERAGE } & \multicolumn{2}{|c|}{ SOUND POWER } & \multicolumn{2}{|c|}{ PENETRATION } \\
\hline $\begin{array}{c}\text { THRUST } \\
\text { (lbs) }\end{array}$ & $\begin{array}{c}\text { SPEED } \\
(\mathrm{rpm})\end{array}$ & $\begin{array}{c}\text { THRUST } \\
\text { (lbs) }\end{array}$ & $\begin{array}{c}\text { SPEED } \\
\text { (rpm) }\end{array}$ & $\begin{array}{c}\text { LINEAR } \\
\text { (dB) }\end{array}$ & $\begin{array}{c}\text { A-WGT } \\
\text { (dBA) }\end{array}$ & $\begin{array}{l}\text { DEPTH } \\
\text { (in) } \\
\end{array}$ & $\begin{array}{l}\text { RATE } \\
\text { (in/sec) }\end{array}$ \\
\hline setthrst & setspd & avthrust & avspeed & spdb & spdba & pendepth & penrate \\
\hline \multirow{5}{*}{2,121} & 200 & 2,334 & 206 & 108.9 & 109.0 & 4.6 & 0.165 \\
\hline & 300 & 2,333 & 303 & 110.0 & 110.2 & 3.9 & 0.141 \\
\hline & 400 & 2,344 & 404 & 110.8 & 111.0 & 2.9 & 0.107 \\
\hline & 500 & 2,226 & 508 & 109.9 & 110.2 & 3.9 & 0.150 \\
\hline & 600 & 2,241 & 602 & 112.4 & 112.8 & 4.2 & 0.163 \\
\hline \multirow{6}{*}{2,828} & 200 & 2,919 & 208 & 111.2 & 111.3 & 5.4 & 0.194 \\
\hline & 300 & 2,933 & 305 & 112.5 & 112.7 & 7.6 & 0.219 \\
\hline & \multirow{2}{*}{400} & 2,955 & 401 & 112.0 & 112.3 & 6.1 & 0.210 \\
\hline & & 2,849 & 406 & 110.2 & 110.5 & 4.8 & 0.187 \\
\hline & 500 & 2,877 & 508 & 110.8 & 111.1 & 5.5 & 0.212 \\
\hline & 600 & 2,890 & 606 & 112.2 & 112.5 & 2.3 & 0.089 \\
\hline \multirow{8}{*}{3,535} & \multirow{2}{*}{200} & 3,587 & 207 & 112.5 & 112.7 & 8.0 & 0.287 \\
\hline & & 3,588 & 209 & 111.3 & 111.6 & 8.5 & 0.330 \\
\hline & \multirow{2}{*}{300} & 3,622 & 307 & 112.5 & 112.8 & 8.7 & 0.334 \\
\hline & & 3,607 & 307 & 113.0 & 113.4 & 8.9 & 0.340 \\
\hline & \multirow{2}{*}{400} & 3,642 & 400 & 112.9 & 113.2 & 8.1 & 0.288 \\
\hline & & 3,660 & 398 & 113.0 & 113.4 & 8.8 & 0.314 \\
\hline & 500 & 3,622 & 508 & 113.1 & 113.6 & 4.4 & 0.212 \\
\hline & 600 & 3,651 & 606 & 112.5 & 112.9 & 4.5 & 0.173 \\
\hline \multirow{6}{*}{4,242} & \multirow{2}{*}{200} & 4,294 & 218 & 112.2 & 112.5 & 11.6 & 0.452 \\
\hline & & 4,238 & 208 & 110.9 & 110.8 & 7.0 & 0.249 \\
\hline & 300 & 4,254 & 305 & 113.0 & 113.3 & 10.7 & 0.382 \\
\hline & 400 & 4,258 & 402 & 112.4 & 112.7 & 10.1 & 0.361 \\
\hline & 500 & 4,344 & 508 & 113.5 & 114.0 & 7.2 & 0.290 \\
\hline & 600 & 4,362 & 607 & 112.4 & 112.9 & 4.4 & 0.165 \\
\hline \multirow{6}{*}{4,949} & \multirow{2}{*}{200} & 4,818 & 209 & 111.9 & 112.3 & 11.2 & 0.395 \\
\hline & & 4,916 & 211 & 112.6 & 113.0 & 11.3 & 0.495 \\
\hline & 300 & 4,869 & 306 & 112.8 & 113.2 & 13.8 & 0.475 \\
\hline & 400 & 4,898 & 407 & 113.0 & 113.3 & 12.5 & 0.445 \\
\hline & 500 & 4,979 & 510 & 113.9 & 114.3 & 13.0 & 0.509 \\
\hline & 600 & 4,995 & 607 & 112.6 & 113.0 & 4.6 & 0.172 \\
\hline
\end{tabular}


Table 5.4 Sound Power Level Testing - Vacuum Method, 1-3/8-inch bit, Round Drill Steel

\begin{tabular}{|c|c|c|c|c|c|c|c|}
\hline \multicolumn{2}{|c|}{ SET POINTS } & \multicolumn{2}{|c|}{ AVERAGE } & \multicolumn{2}{|c|}{ SOUND POWER } & \multicolumn{2}{|c|}{ PENETRATION } \\
\hline $\begin{array}{c}\text { THRUST } \\
\text { (lbs) } \\
\text { setthrst }\end{array}$ & $\begin{array}{c}\text { SPEED } \\
\text { (rpm) } \\
\text { setspd }\end{array}$ & $\begin{array}{c}\text { THRUST } \\
\text { (lbs) } \\
\text { avthrust }\end{array}$ & $\begin{array}{c}\text { SPEED } \\
\text { (rpm) } \\
\text { avspeed }\end{array}$ & $\begin{array}{c}\text { LINEAR } \\
\text { (dB) } \\
\text { spdb }\end{array}$ & $\begin{array}{c}\text { A-WGT } \\
\text { (dBA) } \\
\text { spdba }\end{array}$ & $\begin{array}{l}\text { DEPTH } \\
\text { (in) } \\
\text { pendepth }\end{array}$ & $\begin{array}{l}\text { RATE } \\
\text { (in/sec) } \\
\text { penrate }\end{array}$ \\
\hline \multirow{3}{*}{2,121} & 200 & 2,268 & 203 & 105.7 & 105.5 & 2.12 & 0.087 \\
\hline & 300 & 2,285 & 306 & 106.5 & 106.1 & 1.91 & 0.078 \\
\hline & 400 & 2,293 & 402 & 108.8 & 108.6 & 1.84 & 0.076 \\
\hline \multirow{5}{*}{2,828} & \multirow{2}{*}{200} & 2,915 & 211 & 108.5 & 108.8 & 3.12 & 0.128 \\
\hline & & 2,908 & 215 & 108.2 & 108.5 & 2.96 & 0.121 \\
\hline & \multirow{2}{*}{300} & 2,925 & 308 & 108.3 & 108.5 & 3.56 & 0.146 \\
\hline & & 2,923 & 311 & 108.1 & 108.3 & 2.94 & 0.120 \\
\hline & 400 & 2,952 & 404 & 109.2 & 109.6 & 3.42 & 0.139 \\
\hline \multirow{6}{*}{3,535} & \multirow{2}{*}{200} & 3,527 & 211 & 108.3 & 108.5 & 3.92 & 0.161 \\
\hline & & 3,522 & 213 & 108.1 & 108.3 & 4.30 & 0.176 \\
\hline & \multirow{2}{*}{300} & 3,545 & 306 & 109.2 & 109.6 & 4.96 & 0.204 \\
\hline & & 3,545 & 305 & 108.6 & 108.9 & 4.40 & 0.181 \\
\hline & \multirow{2}{*}{400} & 3,580 & 402 & 109.7 & 110.1 & 5.41 & 0.220 \\
\hline & & 3,567 & 402 & 109.8 & 110.2 & 4.43 & 0.182 \\
\hline \multirow{7}{*}{4,242} & 200 & 4,183 & 208 & 111.3 & 111.8 & 5.95 & 0.205 \\
\hline & \multirow{2}{*}{300} & 4,181 & 306 & 112.4 & 113.0 & 5.72 & 0.197 \\
\hline & & 4,228 & 309 & 111.3 & 111.7 & 5.53 & 0.212 \\
\hline & \multirow{2}{*}{400} & 4,239 & 403 & 112.5 & 113.0 & 4.51 & 0.173 \\
\hline & & 4,360 & 405 & 112.1 & 112.5 & 2.61 & 0.093 \\
\hline & 500 & 4,303 & 511 & 111.1 & 111.3 & 1.66 & 0.059 \\
\hline & 600 & 4,405 & 606 & 109.9 & 110.0 & 1.32 & 0.047 \\
\hline \multirow{6}{*}{4,949} & 200 & 4,842 & 210 & 111.6 & 112.1 & 7.27 & 0.251 \\
\hline & \multirow{2}{*}{300} & 4,865 & 307 & 111.7 & 112.3 & 6.32 & 0.218 \\
\hline & & 4,923 & 314 & 112.2 & 112.7 & 7.17 & 0.279 \\
\hline & 400 & 4,886 & 405 & 113.6 & 114.2 & 6.85 & 0.237 \\
\hline & 500 & 5,082 & 509 & 110.8 & 111.0 & 1.83 & 0.065 \\
\hline & 600 & 5,090 & 604 & 109.8 & 109.8 & 1.53 & 0.005 \\
\hline \multirow{5}{*}{5,656} & 200 & 5,415 & 215 & 113.1 & 113.6 & 8.33 & 0.287 \\
\hline & 300 & 5,438 & 307 & 111.9 & 112.5 & 7.87 & 0.271 \\
\hline & 400 & 5,446 & 403 & 112.5 & 113.1 & 7.25 & 0.250 \\
\hline & 500 & 5,677 & 510 & 106.9 & 106.8 & 1.61 & 0.056 \\
\hline & 600 & 5,684 & 604 & 108.7 & 108.7 & 1.47 & 0.052 \\
\hline \multirow{8}{*}{6,363} & \multirow{2}{*}{200} & 6,195 & 207 & 112.9 & 113.4 & 9.48 & 0.339 \\
\hline & & 6,242 & 212 & 112.3 & 112.7 & 10.74 & 0.381 \\
\hline & \multirow{2}{*}{300} & 6,234 & 312 & 113.7 & 114.3 & 9.92 & 0.354 \\
\hline & & 6,218 & 310 & 112.7 & 113.1 & 9.90 & 0.353 \\
\hline & \multirow{2}{*}{400} & 6,167 & 402 & 114.1 & 114.8 & 8.35 & 0.288 \\
\hline & & 6,237 & 402 & 113.6 & 114.1 & 5.84 & 0.208 \\
\hline & 500 & 6,261 & 505 & 109.5 & 109.8 & 2.29 & 0.081 \\
\hline & 600 & 6,283 & 602 & 106.5 & 106.1 & 1.40 & 0.049 \\
\hline
\end{tabular}


Table 5.5 Sound Power Level Testing - Vacuum Method, 1-3/8-inch bit, Hex Drill Steel

\begin{tabular}{|c|c|c|c|c|c|c|c|}
\hline \multicolumn{2}{|c|}{ SET POINTS } & \multicolumn{2}{|c|}{ AVERAGE } & \multicolumn{2}{|c|}{ SOUND POWER } & \multicolumn{2}{|c|}{ PENETRATION } \\
\hline \multirow{2}{*}{$\begin{array}{c}\text { THRUST } \\
\text { (lbs) } \\
\text { setthrst }\end{array}$} & \multirow{2}{*}{$\begin{array}{c}\text { SPEED } \\
\text { (rpm) } \\
\text { setspd }\end{array}$} & $\begin{array}{c}\text { THRUST } \\
\text { (lbs) }\end{array}$ & $\begin{array}{c}\text { SPEED } \\
\text { (rpm) }\end{array}$ & $\begin{array}{c}\text { LINEAR } \\
\text { (dB) }\end{array}$ & $\begin{array}{c}\text { A-WGT } \\
\text { (dBA) }\end{array}$ & $\begin{array}{c}\text { DEPTH } \\
\text { (in) }\end{array}$ & $\begin{array}{l}\text { RATE } \\
\text { (in/sec) }\end{array}$ \\
\hline & & avthrust & avspeed & spdb & spdba & pendepth & penrate \\
\hline \multirow{3}{*}{2,121} & 200 & 2,283 & 212 & 106.1 & 106.3 & 1.6 & 0.067 \\
\hline & 300 & 2,302 & 309 & 109.0 & 109.5 & 1.9 & 0.078 \\
\hline & 400 & 2,326 & 402 & 110.0 & 110.4 & 2.1 & 0.084 \\
\hline \multirow{3}{*}{2,828} & 200 & 2,892 & 209 & 109.3 & 109.7 & 2.8 & 0.115 \\
\hline & 300 & 2,914 & 308 & 109.9 & 110.4 & 3.6 & 0.134 \\
\hline & 400 & 2,943 & 405 & 112.2 & 113.0 & 3.5 & 0.145 \\
\hline \multirow{5}{*}{3,535} & 200 & 3,559 & 208 & 109.2 & 109.6 & 4.4 & 0.180 \\
\hline & \multirow{2}{*}{300} & 3,575 & 304 & 111.3 & 111.9 & 5.0 & 0.205 \\
\hline & & 3,715 & 313 & 111.9 & 112.5 & 3.9 & 0.150 \\
\hline & \multirow{2}{*}{400} & 3,591 & 402 & 112.2 & 112.8 & 4.9 & 0.200 \\
\hline & & 3741 & 405 & 112.7 & 113.3 & 4.3 & 0.167 \\
\hline \multirow{7}{*}{4,242} & 200 & 4,321 & 214 & 112.3 & 112.8 & 6.5 & 0.225 \\
\hline & \multirow{2}{*}{300} & 4,316 & 309 & 113.4 & 114.1 & 5.7 & 0.195 \\
\hline & & 4,342 & 313 & 112.6 & 113.3 & 4.9 & 0.187 \\
\hline & \multirow{2}{*}{400} & 4,330 & 402 & 113.9 & 114.6 & 5.9 & 0.202 \\
\hline & & 4,357 & 403 & 113.8 & 114.6 & 3.8 & 0.150 \\
\hline & 500 & 4,407 & 505 & 113.9 & 114.7 & 3.1 & 0.115 \\
\hline & 600 & 4,420 & 604 & 113.4 & 114.1 & 1.6 & 0.059 \\
\hline \multirow{7}{*}{4,949} & 200 & 4,979 & 212 & 113.2 & 113.8 & 7.3 & 0.253 \\
\hline & \multirow{2}{*}{300} & 5,001 & 310 & 113.1 & 113.8 & 8.3 & 0.285 \\
\hline & & 4,958 & 309 & 113.1 & 113.7 & 6.7 & 0.247 \\
\hline & \multirow{2}{*}{400} & 5,047 & 405 & 114.8 & 115.5 & 5.8 & 0.200 \\
\hline & & 4,973 & 409 & 113.6 & 114.3 & 4.4 & 0.161 \\
\hline & 500 & 4,982 & 511 & 114.0 & 114.7 & 2.8 & 0.104 \\
\hline & 600 & 4,992 & 604 & 113.2 & 113.9 & 1.2 & 0.044 \\
\hline \multirow{8}{*}{5,656} & \multirow{2}{*}{200} & 5,558 & 211 & 113.5 & 114.1 & 8.7 & 0.301 \\
\hline & & 5,485 & 218 & 112.7 & 113.3 & 8.7 & 0.324 \\
\hline & \multirow{2}{*}{300} & 5,497 & 313 & 113.7 & 114.4 & 7.3 & 0.271 \\
\hline & & 5,502 & 310 & 113.7 & 114.3 & 8.4 & 0.312 \\
\hline & \multirow{2}{*}{400} & 5,576 & 405 & 115.3 & 116.1 & 6.1 & 0.211 \\
\hline & & 5,510 & 408 & 114.5 & 115.2 & 4.6 & 0.167 \\
\hline & 500 & 5,523 & 511 & 113.9 & 114.7 & 2.9 & 0.103 \\
\hline & 600 & 5,544 & 600 & 112.8 & 113.4 & 2.5 & 0.089 \\
\hline \multirow{8}{*}{6,363} & \multirow{2}{*}{200} & 6,342 & 212 & 113.5 & 114.1 & 9.8 & 0.337 \\
\hline & & 6,224 & 211 & 114.0 & 114.6 & 10.2 & 0.361 \\
\hline & 300 & 6,360 & 311 & 114.5 & 115.2 & 10.5 & 0.361 \\
\hline & & 6,234 & 309 & 115.1 & 115.7 & 9.8 & 0.347 \\
\hline & 400 & 6,382 & 404 & 115.5 & 116.2 & 6.6 & 0.227 \\
\hline & & 6,244 & 402 & 114.5 & 115.3 & 5.8 & 0.206 \\
\hline & 500 & 6,256 & 506 & 113.7 & 114.3 & 2.8 & 0.099 \\
\hline & 600 & 6,205 & 603 & 112.6 & 113.2 & 1.8 & 0.065 \\
\hline
\end{tabular}


Table 5.6 Sound Power Level Testing - Wet Drilling Method (3 gal/min), 1-inch bit, Round Drill Steel

\begin{tabular}{|c|c|c|c|c|c|c|c|}
\hline \multicolumn{2}{|c|}{ SET POINTS } & \multicolumn{2}{|c|}{ AVERAGE } & \multicolumn{2}{|c|}{ SOUND POWER } & \multicolumn{2}{|c|}{ PENETRATION } \\
\hline $\begin{array}{c}\text { THRUST } \\
\text { (lbs) }\end{array}$ & $\begin{array}{c}\text { SPEED } \\
\text { (rpm) }\end{array}$ & \multirow{2}{*}{$\begin{array}{c}\text { THRUST } \\
\text { (lbs) } \\
\text { avthrust }\end{array}$} & \multirow{2}{*}{$\begin{array}{c}\text { SPEED } \\
\text { (rpm) } \\
\text { avspeed }\end{array}$} & \multirow{2}{*}{$\begin{array}{c}\text { LINEAR } \\
\text { (dB) } \\
\text { spdb } \\
\end{array}$} & \multirow{2}{*}{$\begin{array}{c}\text { A-WGT } \\
\text { (dBA) } \\
\text { spdba } \\
\end{array}$} & \multirow{2}{*}{$\begin{array}{l}\text { DEPTH } \\
\text { (in) } \\
\text { pendepth }\end{array}$} & \multirow{2}{*}{$\begin{array}{r}\text { RATE } \\
\text { (in/sec) } \\
\text { penrate } \\
\end{array}$} \\
\hline setthrst & setspd & & & & & & \\
\hline \multirow{8}{*}{2,121} & \multirow{2}{*}{200} & 2,313 & 207 & 103.3 & 102.1 & 5.4 & 0.224 \\
\hline & & 2,306 & 211 & 102.9 & 102.0 & 5.2 & 0.213 \\
\hline & \multirow{2}{*}{300} & 2,321 & 309 & 103.4 & 102.2 & 4.1 & 0.168 \\
\hline & & 2,318 & 308 & 104.8 & 104.0 & 5.8 & 0.237 \\
\hline & \multirow{2}{*}{400} & 2,335 & 402 & 103.8 & 102.9 & 4.2 & 0.169 \\
\hline & & 2,329 & 405 & 106.2 & 105.5 & 6.4 & 0.262 \\
\hline & 500 & 2,448 & 503 & 103.6 & 102.4 & 5.7 & 0.222 \\
\hline & 600 & 2,461 & 605 & 104.6 & 103.6 & 5.6 & 0.218 \\
\hline \multirow{8}{*}{2,828} & 200 & 2,909 & 205 & 104.0 & 103.5 & 4.2 & 0.340 \\
\hline & \multirow{2}{*}{300} & 3,084 & 311 & 105.3 & 104.3 & 8.9 & 0.347 \\
\hline & & 3,005 & 312 & 105.0 & 104.4 & 4.5 & 0.367 \\
\hline & \multirow{2}{*}{400} & 2,978 & 402 & 104.9 & 103.9 & 7.3 & 0.298 \\
\hline & & 3,098 & 403 & 104.4 & 103.2 & 7.8 & 0.301 \\
\hline & \multirow{2}{*}{500} & 3,113 & 508 & 105.9 & 105.4 & 11.4 & 0.434 \\
\hline & & 3,012 & 507 & 103.7 & 102.5 & 9.3 & 0.357 \\
\hline & 600 & 3,129 & 605 & 106.4 & 105.7 & 9.8 & 0.377 \\
\hline \multirow{6}{*}{3,535} & 200 & 3,591 & 201 & 104.9 & 104.4 & 5.7 & 0.463 \\
\hline & \multirow{2}{*}{300} & 3,605 & 308 & 106.5 & 106.3 & 6.6 & 0.540 \\
\hline & & 3,601 & 314 & 106.0 & 105.8 & 6.3 & 0.519 \\
\hline & 400 & 3,617 & 401 & 107.1 & 106.8 & 7.5 & 0.681 \\
\hline & 500 & 3,815 & 511 & 106.2 & 105.9 & 11.2 & 0.540 \\
\hline & 600 & 3,820 & 604 & 107.7 & 107.7 & 15.1 & 0.586 \\
\hline \multirow{8}{*}{4,242} & \multirow{2}{*}{200} & 4,275 & 210 & 106.4 & 105.8 & 6.2 & 0.616 \\
\hline & & 4,272 & 213 & 106.3 & 105.7 & 5.2 & 0.511 \\
\hline & \multirow{2}{*}{300} & 4,285 & 309 & 107.4 & 107.0 & 6.7 & 0.654 \\
\hline & & 4,285 & 315 & 106.9 & 106.5 & 6.5 & 0.642 \\
\hline & \multirow{2}{*}{400} & 4,288 & 411 & 107.6 & 107.3 & 7.0 & 0.680 \\
\hline & & 4,296 & 411 & 108.8 & 108.6 & 8.0 & 0.799 \\
\hline & 500 & 4,411 & 508 & 106.3 & 105.8 & 15.6 & 0.594 \\
\hline & 600 & 4,434 & 595 & 106.9 & 106.7 & 15.4 & 0.598 \\
\hline \multirow{8}{*}{4,949} & 200 & 4,888 & 206 & 106.7 & 106.2 & 5.6 & 0.681 \\
\hline & 200 & 4,899 & 205 & 106.8 & 106.3 & 5.1 & 0.626 \\
\hline & 300 & 4,898 & 302 & 107.8 & 107.6 & 6.8 & 0.843 \\
\hline & 500 & 4,916 & 307 & 108.3 & 108.2 & 6.3 & 0.770 \\
\hline & 400 & 4,927 & 412 & 108.2 & 108.1 & 7.7 & 0.955 \\
\hline & 400 & 4,912 & 412 & 109.0 & 108.9 & 7.5 & 0.928 \\
\hline & 500 & 4,876 & 510 & 107.5 & 107.1 & 18.7 & 0.723 \\
\hline & 600 & 4,902 & 607 & 106.6 & 106.2 & 17.2 & 0.672 \\
\hline
\end{tabular}


Table 5.7 Sound Power Level Testing - Wet Drilling Method (3 gal/min), 1-inch bit, Hex Drill Steel

\begin{tabular}{|c|c|c|c|c|c|c|c|}
\hline \multicolumn{2}{|c|}{ SET POINTS } & \multicolumn{2}{|c|}{ AVERAGE } & \multicolumn{2}{|c|}{ SOUND POWER } & \multicolumn{2}{|c|}{ PENETRATION } \\
\hline $\begin{array}{c}\text { THRUST } \\
\text { (lbs) }\end{array}$ & $\begin{array}{c}\text { SPEED } \\
\text { (rpm) }\end{array}$ & $\begin{array}{c}\text { THRUST } \\
\text { (lbs) }\end{array}$ & $\begin{array}{c}\text { SPEED } \\
\text { (rpm) }\end{array}$ & $\begin{array}{c}\text { LINEAR } \\
\text { (dB) }\end{array}$ & $\begin{array}{c}\text { A-WGT } \\
\text { (dBA) }\end{array}$ & $\begin{array}{l}\text { DEPTH } \\
\text { (in) }\end{array}$ & $\begin{array}{l}\text { RATE } \\
\text { (in/sec) }\end{array}$ \\
\hline setthrst & setspd & avthrust & avspeed & spdb & spdba & pendepth & penrate \\
\hline \multirow{5}{*}{2,121} & 200 & 2,314 & 207 & 102.1 & 100.6 & 1.8 & 0.196 \\
\hline & 300 & 2,332 & 315 & 101.6 & 100.5 & 2.4 & 0.255 \\
\hline & 400 & 2,347 & 404 & 104.0 & 103.8 & 2.3 & 0.249 \\
\hline & 500 & 2,295 & 508 & 105.7 & 105.6 & 4.3 & 0.175 \\
\hline & 600 & 2,306 & 607 & 106.0 & 105.9 & 4.3 & 0.176 \\
\hline \multirow{7}{*}{2,828} & \multirow{2}{*}{200} & 2,924 & 214 & 103.1 & 101.5 & 2.9 & 0.320 \\
\hline & & 2,932 & 198 & 105.1 & 104.2 & 3.2 & 0.317 \\
\hline & 300 & 2,939 & 306 & 103.9 & 102.8 & 3.6 & 0.386 \\
\hline & \multirow{2}{*}{400} & 2,957 & 406 & 105.2 & 104.8 & 3.5 & 0.458 \\
\hline & & 3,121 & 403 & 105.8 & 105.7 & 7.8 & 0.309 \\
\hline & 500 & 3,135 & 507 & 107.4 & 107.7 & 8.3 & 0.342 \\
\hline & 600 & 3,147 & 602 & 107.2 & 107.2 & 9.5 & 0.389 \\
\hline \multirow{10}{*}{3,535} & \multirow{2}{*}{200} & 3,670 & 215 & 104.4 & 103.8 & 3.8 & 0.416 \\
\hline & & 3,665 & 204 & 104.7 & 103.9 & 3.8 & 0.428 \\
\hline & \multirow{2}{*}{300} & 3,715 & 316 & 106.0 & 105.3 & 8.5 & 0.344 \\
\hline & & 3,720 & 304 & 106.1 & 105.9 & 6.5 & 0.537 \\
\hline & \multirow{2}{*}{400} & 3,578 & 409 & 108.0 & 108.2 & 4.6 & 0.457 \\
\hline & & 3,581 & 402 & 108.0 & 107.9 & 4.9 & 0.576 \\
\hline & \multirow{2}{*}{500} & 3,741 & 517 & 107.6 & 107.5 & 11.2 & 0.451 \\
\hline & & 3,644 & 504 & 108.0 & 108.3 & 10.5 & 0.435 \\
\hline & \multirow{2}{*}{600} & 3,755 & 606 & 108.2 & 108.3 & 11.1 & 0.443 \\
\hline & & 3,657 & 605 & 106.8 & 106.9 & 8.8 & 0.353 \\
\hline \multirow{7}{*}{4,242} & \multirow{2}{*}{200} & 4,273 & 202 & 103.0 & 101.7 & 6.3 & 0.680 \\
\hline & & 4,349 & 216 & 105.7 & 105.2 & 11.4 & 0.463 \\
\hline & 300 & 4,272 & 310 & 104.6 & 103.8 & 6.6 & 0.719 \\
\hline & \multirow{2}{*}{400} & 4,297 & 412 & 106.6 & 106.1 & 7.4 & 0.810 \\
\hline & & 4,296 & 398 & 105.2 & 104.8 & 7.5 & 0.805 \\
\hline & 500 & 4,382 & 511 & 108.0 & 108.1 & 14.6 & 0.597 \\
\hline & 600 & 4,392 & 614 & 108.5 & 108.4 & 14.8 & 0.600 \\
\hline \multirow{7}{*}{4,949} & \multirow{2}{*}{200} & 4,793 & 215 & 105.8 & 105.1 & 12.9 & 0.529 \\
\hline & & 4,930 & 209 & 104.8 & 104.7 & 6.1 & 0.762 \\
\hline & \multirow{2}{*}{300} & 4,940 & 306 & 105.8 & 105.6 & 9.4 & 1.025 \\
\hline & & 4,806 & 314 & 106.0 & 105.5 & 12.7 & 0.518 \\
\hline & 400 & 4,944 & 414 & 106.4 & 105.7 & 8.9 & 0.965 \\
\hline & 500 & 4,831 & 509 & 108.0 & 108.1 & 14.6 & 0.598 \\
\hline & 600 & 4,850 & 578 & 108.0 & 108.3 & 14.4 & 0.556 \\
\hline
\end{tabular}


Table 5.8 Sound Power Level Testing - Wet Drilling Method (3 gal/min), 1-3/8-inch bit, Round Drill Steel

\begin{tabular}{|c|c|c|c|c|c|c|c|}
\hline \multicolumn{2}{|c|}{ SET POINTS } & \multicolumn{2}{|c|}{ AVERAGE } & \multicolumn{2}{|c|}{ SOUND POWER } & \multicolumn{2}{|c|}{ PENETRATION } \\
\hline $\begin{array}{c}\text { THRUST } \\
\text { (lbs) }\end{array}$ & $\begin{array}{c}\text { SPEED } \\
\text { (rpm) }\end{array}$ & $\begin{array}{c}\text { THRUST } \\
\text { (lbs) }\end{array}$ & $\begin{array}{c}\text { SPEED } \\
\text { (rpm) }\end{array}$ & $\begin{array}{c}\text { LINEAR } \\
\text { (dB) }\end{array}$ & $\begin{array}{c}\text { A-WGT } \\
\text { (dBA) }\end{array}$ & $\begin{array}{c}\text { DEPTH } \\
\text { (in) }\end{array}$ & $\begin{array}{l}\text { RATE } \\
\text { (in/sec) }\end{array}$ \\
\hline setthrst & setspd & avthrust & avspeed & spdb & spdba & pendepth & penrate \\
\hline \multirow{6}{*}{2,121} & \multirow{2}{*}{200} & 2,335 & 210 & 105.8 & 104.9 & 1.0 & 0.094 \\
\hline & & 2,337 & 208 & 105.1 & 103.9 & 1.0 & 0.094 \\
\hline & \multirow{2}{*}{300} & 2,340 & 310 & 105.1 & 104.3 & 2.6 & 0.107 \\
\hline & & 2,337 & 311 & 105.6 & 105.0 & 3.0 & 0.123 \\
\hline & \multirow{2}{*}{400} & 2,351 & 406 & 106.9 & 106.6 & 2.7 & 0.113 \\
\hline & & 2,347 & 407 & 105.8 & 105.5 & 2.9 & 0.120 \\
\hline \multirow{6}{*}{2,828} & \multirow{2}{*}{200} & 2,916 & 211 & 104.3 & 103.5 & 3.0 & 0.122 \\
\hline & & 2,915 & 209 & 104.3 & 103.6 & 3.4 & 0.141 \\
\hline & \multirow{2}{*}{300} & 2,937 & 305 & 105.2 & 104.9 & 4.5 & 0.188 \\
\hline & & 2,935 & 305 & 105.0 & 104.5 & 4.4 & 0.181 \\
\hline & \multirow{2}{*}{400} & 2,959 & 411 & 106.3 & 106.1 & 4.6 & 0.189 \\
\hline & & 2,955 & 411 & 106.8 & 106.7 & 4.5 & 0.185 \\
\hline \multirow{6}{*}{3,535} & \multirow{2}{*}{200} & 3,611 & 218 & 106.2 & 105.9 & 5.0 & 0.203 \\
\hline & & 3,609 & 214 & 105.6 & 105.3 & 6.0 & 0.246 \\
\hline & \multirow{2}{*}{300} & 3,623 & 313 & 105.5 & 105.1 & 6.5 & 0.266 \\
\hline & & 3,621 & 311 & 106.3 & 106.0 & 6.3 & 0.261 \\
\hline & \multirow{2}{*}{400} & 3,709 & 408 & 108.4 & 108.0 & 5.9 & 0.366 \\
\hline & & 3,701 & 411 & 108.7 & 108.5 & 6.4 & 0.394 \\
\hline \multirow{8}{*}{4,242} & \multirow{2}{*}{200} & 4,187 & 217 & 107.2 & 106.8 & 5.1 & 0.320 \\
\hline & & 4,188 & 215 & 106.6 & 106.0 & 4.6 & 0.285 \\
\hline & \multirow{2}{*}{300} & 4,210 & 313 & 108.3 & 108.1 & 6.0 & 0.368 \\
\hline & & 4,202 & 307 & 107.9 & 107.6 & 5.4 & 0.335 \\
\hline & \multirow{2}{*}{400} & 4,233 & 408 & 109.0 & 108.8 & 8.1 & 0.429 \\
\hline & & 4,230 & 407 & 109.1 & 108.9 & 6.9 & 0.424 \\
\hline & 500 & 4,456 & 510 & 108.7 & 108.9 & 8.4 & 0.321 \\
\hline & 600 & 4,485 & 603 & 109.0 & 109.2 & 9.5 & 0.365 \\
\hline & 200 & 4,833 & 211 & 107.0 & 106.5 & 6.4 & 0.393 \\
\hline & & 4,808 & 217 & 106.9 & 106.3 & 7.0 & 0.428 \\
\hline & & 4,816 & 309 & 108.7 & 108.5 & 7.5 & 0.464 \\
\hline 4,949 & 300 & 4,826 & 310 & 107.8 & 107.4 & 7.7 & 0.466 \\
\hline & & 4,840 & 403 & 108.5 & 108.3 & 8.0 & 0.489 \\
\hline & 500 & 5,110 & 506 & 109.6 & 109.8 & 11.0 & 0.409 \\
\hline & 600 & 5,136 & 604 & 110.6 & 110.8 & 10.2 & 0.386 \\
\hline & 200 & 5,649 & 210 & 108.2 & 108.0 & 5.5 & 0.447 \\
\hline & & 5,644 & 212 & 107.5 & 107.3 & 5.1 & 0.411 \\
\hline & 300 & 5,662 & 311 & 109.3 & 109.2 & 6.8 & 0.558 \\
\hline 5,656 & 80 & 5,512 & 310 & 108.5 & 108.6 & 7.3 & 0.604 \\
\hline & 400 & 5,669 & 411 & 110.3 & 110.2 & 7.9 & 0.650 \\
\hline & & 5,666 & 401 & 109.0 & 108.7 & 7.0 & 0.573 \\
\hline & 500 & 5,740 & 507 & 110.1 & 110.3 & 12.1 & 0.436 \\
\hline & 600 & 5,755 & 604 & 110.1 & 110.4 & 11.6 & 0.429 \\
\hline & 200 & 6,298 & 206 & 108.3 & 108.0 & 6.2 & 0.511 \\
\hline & 300 & 6,307 & 308 & 109.8 & 109.7 & 6.8 & 0.560 \\
\hline 6363 & 400 & 6,320 & 407 & 109.7 & 109.6 & 7.6 & 0.628 \\
\hline & & 6,148 & 402 & 109.2 & 109.3 & 15.4 & 0.594 \\
\hline & 500 & 6,161 & 504 & 108.4 & 108.4 & 11.9 & 0.452 \\
\hline & 600 & 6,369 & 601 & 109.6 & 109.4 & 18.2 & 0.688 \\
\hline
\end{tabular}


Table 5.9 Sound Power Level Testing - Wet Drilling Method (3 gal/min), 1-3/8-inch bit, Hex Drill Steel

\begin{tabular}{|c|c|c|c|c|c|c|c|}
\hline \multicolumn{2}{|c|}{ SET POINTS } & \multicolumn{2}{|c|}{ AVERAGE } & \multicolumn{2}{|c|}{ SOUND POWER } & \multicolumn{2}{|c|}{ PENETRATION } \\
\hline $\begin{array}{c}\text { THRUST } \\
\text { (lbs) }\end{array}$ & $\begin{array}{c}\text { SPEED } \\
\text { (rpm) }\end{array}$ & $\begin{array}{c}\text { THRUST } \\
\text { (lbs) }\end{array}$ & $\begin{array}{c}\text { SPEED } \\
(\mathrm{rpm})\end{array}$ & $\begin{array}{c}\text { LINEAR } \\
\text { (dB) }\end{array}$ & $\begin{array}{c}\text { A-WGT } \\
\text { (dBA) }\end{array}$ & $\begin{array}{l}\text { DEPTH } \\
\text { (in) }\end{array}$ & $\begin{array}{l}\text { RATE } \\
\text { (in/sec) }\end{array}$ \\
\hline setthrst & setspd & avthrust & avspeed & spdb & spdba & pendepth & penrate \\
\hline \multirow{3}{*}{2,121} & 200 & 2,338 & 209 & 104.5 & 104.2 & 1.3 & 0.055 \\
\hline & 300 & 2,360 & 311 & 105.0 & 105.0 & 2.1 & 0.086 \\
\hline & 400 & 2,378 & 403 & 106.3 & 106.1 & 2.4 & 0.099 \\
\hline \multirow{3}{*}{2,828} & 200 & 2,915 & 213 & 104.5 & 104.2 & 2.3 & 0.094 \\
\hline & 300 & 2,937 & 309 & 106.2 & 106.3 & 3.3 & 0.134 \\
\hline & 400 & 2,961 & 402 & 107.0 & 107.0 & 3.9 & 0.160 \\
\hline \multirow{3}{*}{3,535} & 200 & 3,593 & 209 & 105.0 & 104.9 & 4.7 & 0.190 \\
\hline & 300 & 3,606 & 312 & 105.1 & 105.0 & 5.7 & 0.234 \\
\hline & 400 & 3,622 & 400 & 106.1 & 106.1 & 5.9 & 0.246 \\
\hline \multirow{8}{*}{4,242} & \multirow{2}{*}{200} & 4,402 & 212 & 105.7 & 104.9 & 5.9 & 0.223 \\
\hline & & 4,207 & 208 & 105.8 & 105.7 & 2.6 & 0.285 \\
\hline & \multirow{2}{*}{300} & 4,227 & 302 & 106.7 & 106.8 & 3.3 & 0.358 \\
\hline & & 4,277 & 309 & 106.4 & 106.4 & 6.8 & 0.278 \\
\hline & \multirow{2}{*}{400} & 4,258 & 411 & 107.4 & 107.5 & 4.5 & 0.484 \\
\hline & & 4,286 & 398 & 107.5 & 107.6 & 8.5 & 0.348 \\
\hline & 500 & 4,454 & 505 & 107.9 & 108.0 & 9.2 & 0.338 \\
\hline & 600 & 4,478 & 604 & 108.9 & 109.2 & 9.4 & 0.357 \\
\hline \multirow{8}{*}{4,949} & \multirow{2}{*}{200} & 4,848 & 207 & 106.6 & 106.4 & 4.5 & 0.372 \\
\hline & & 4,846 & 206 & 106.7 & 106.4 & 3.9 & 0.320 \\
\hline & \multirow{2}{*}{300} & 4,859 & 315 & 107.9 & 107.9 & 4.9 & 0.406 \\
\hline & & 4,852 & 313 & 107.5 & 107.5 & 4.8 & 0.390 \\
\hline & \multirow{2}{*}{400} & 4,867 & 407 & 110.3 & 110.5 & 5.5 & 0.601 \\
\hline & & 5,000 & 401 & 107.4 & 107.2 & 9.6 & 0.365 \\
\hline & 500 & 5,014 & 506 & 108.1 & 108.0 & 9.7 & 0.353 \\
\hline & 600 & 5,027 & 602 & 109.1 & 109.1 & 9.4 & 0.356 \\
\hline \multirow{8}{*}{5,656} & \multirow{2}{*}{200} & 5,435 & 201 & 107.4 & 107.5 & 3.8 & 0.408 \\
\hline & & 5,595 & 216 & 107.1 & 106.9 & 9.5 & 0.361 \\
\hline & \multirow{2}{*}{300} & 5,539 & 315 & 109.1 & 109.3 & 6.0 & 0.488 \\
\hline & & 5,539 & 308 & 108.5 & 108.6 & 6.0 & 0.497 \\
\hline & \multirow{2}{*}{400} & 5,561 & 413 & 108.8 & 108.8 & 7.5 & 0.610 \\
\hline & & 5,586 & 424 & 109.2 & 109.2 & 5.6 & 0.550 \\
\hline & 500 & 5,642 & 510 & 109.0 & 109.0 & 10.8 & 0.411 \\
\hline & 600 & 5,664 & 604 & 108.8 & 108.9 & 11.9 & 0.422 \\
\hline \multirow{9}{*}{6,363} & \multirow{2}{*}{200} & 6,200 & 204 & 108.5 & 108.6 & 4.8 & 0.523 \\
\hline & & 6,155 & 196 & 107.7 & 107.7 & 5.8 & 0.567 \\
\hline & \multirow{2}{*}{300} & 6,197 & 316 & 108.7 & 108.8 & 5.7 & 0.616 \\
\hline & & 6,137 & 304 & 109.1 & 109.1 & 6.0 & 0.598 \\
\hline & \multirow{2}{*}{400} & 6,219 & 405 & 110.7 & 110.8 & 6.5 & 0.710 \\
\hline & & 6,213 & 408 & 109.8 & 110.0 & 5.7 & 0.618 \\
\hline & 500 & 6,334 & 508 & 109.4 & 109.4 & 17.9 & 0.675 \\
\hline & 600 & 6,323 & 598 & 110.2 & 110.2 & 17.1 & 0.657 \\
\hline & & 6,346 & 604 & 110.7 & 110.7 & 14.0 & 0.529 \\
\hline
\end{tabular}


Table 5.10 Sound Power Level Testing - Mist Drilling Method (3 qt/min), 1-inch bit, Round Drill Steel

\begin{tabular}{|c|c|c|c|c|c|c|c|}
\hline \multicolumn{2}{|c|}{ SET POINTS } & \multicolumn{2}{|c|}{ AVERAGE } & \multicolumn{2}{|c|}{ SOUND POWER } & \multicolumn{2}{|c|}{ PENETRATION } \\
\hline $\begin{array}{c}\text { THRUST } \\
\text { (lbs) }\end{array}$ & $\begin{array}{c}\text { SPEED } \\
(\text { rpm) }\end{array}$ & \multirow{2}{*}{$\begin{array}{c}\text { THRUST } \\
\text { (lbs) } \\
\text { avthrust }\end{array}$} & \multirow{2}{*}{$\begin{array}{c}\text { SPEED } \\
\text { (rpm) } \\
\text { avspeed }\end{array}$} & \multirow{2}{*}{$\begin{array}{c}\text { LINEAR } \\
\text { (dB) } \\
\text { spdb }\end{array}$} & \multirow{2}{*}{$\begin{array}{c}\text { A-WGT } \\
\text { (dBA) } \\
\text { spdba }\end{array}$} & \multirow{2}{*}{$\begin{array}{l}\text { DEPTH } \\
\text { (in) } \\
\text { pendepth }\end{array}$} & \multirow{2}{*}{$\begin{array}{l}\text { RATE } \\
\text { (in/sec) } \\
\text { penrate }\end{array}$} \\
\hline setthrst & setspd & & & & & & \\
\hline \multirow{5}{*}{2,121} & 200 & 2,418 & 214 & 105.3 & 104.6 & 4.05 & 0.1580 \\
\hline & 300 & 2,432 & 307 & 106.5 & 105.8 & 4.84 & 0.1910 \\
\hline & 400 & 2,445 & 402 & 107.4 & 106.7 & 5.53 & 0.2180 \\
\hline & 500 & 2,458 & 507 & 107.5 & 107.4 & 6.60 & 0.2600 \\
\hline & 600 & 2,472 & 593 & 107.7 & 107.7 & 5.58 & 0.2220 \\
\hline \multirow{5}{*}{2,828} & 200 & 2,978 & 216 & 105.0 & 104.5 & 6.93 & 0.2730 \\
\hline & 300 & 2,993 & 301 & 107.4 & 107.1 & 8.85 & 0.3510 \\
\hline & 400 & 3,004 & 408 & 108.4 & 107.9 & 8.99 & 0.3590 \\
\hline & 500 & 3,004 & 510 & 108.7 & 108.5 & 8.05 & 0.3190 \\
\hline & 600 & 3,012 & 605 & 109.4 & 109.2 & 8.45 & 0.3280 \\
\hline \multirow{5}{*}{3,535} & 200 & 3,685 & 213 & 106.5 & 106.3 & 9.16 & 0.3610 \\
\hline & 300 & 3,700 & 306 & 108.6 & 108.5 & 9.93 & 0.3920 \\
\hline & 400 & 3,716 & 404 & 109.1 & 109.1 & 12.06 & 0.4690 \\
\hline & 500 & 3,734 & 509 & 109.9 & 109.7 & 11.36 & 0.4520 \\
\hline & 600 & 3,758 & 607 & 110.1 & 110.1 & 11.70 & 0.4600 \\
\hline \multirow{5}{*}{4,242} & 200 & 4,335 & 216 & 100.2 & 107.9 & 10.85 & 0.4270 \\
\hline & 300 & 4,350 & 305 & 109.3 & 109.2 & 13.96 & 0.5410 \\
\hline & 400 & 4,364 & 407 & 110.5 & 110.5 & 14.83 & 0.5910 \\
\hline & 500 & 4,381 & 508 & 110.9 & 111.1 & 14.22 & 0.5610 \\
\hline & 600 & 4,397 & 606 & 111.1 & 111.2 & 14.94 & 0.5770 \\
\hline \multirow{5}{*}{4,949} & 200 & 4,928 & 210 & 109.1 & 108.9 & 14.11 & 0.5640 \\
\hline & 300 & 4,947 & 307 & 110.2 & 110.2 & 16.39 & 0.6440 \\
\hline & 400 & 4,966 & 405 & 110.8 & 110.9 & 17.50 & 0.6900 \\
\hline & 500 & 4,994 & 502 & 112.0 & 112.2 & 16.66 & 0.7300 \\
\hline & 600 & 4,825 & 584 & 112.4 & 112.5 & 23.19 & 0.9200 \\
\hline
\end{tabular}


Table 5.11 Sound Power Level Testing - Mist Drilling Method (3 qt/min), 1-inch bit, Hex Drill Steel

\begin{tabular}{|c|c|c|c|c|c|c|c|}
\hline \multicolumn{2}{|c|}{ SET POINTS } & \multicolumn{2}{|c|}{ AVERAGE } & \multicolumn{2}{|c|}{ SOUND POWER } & \multicolumn{2}{|c|}{ PENETRATION } \\
\hline $\begin{array}{c}\text { THRUST } \\
\text { (lbs) }\end{array}$ & $\begin{array}{c}\text { SPEED } \\
\text { (rpm) }\end{array}$ & \multirow{2}{*}{$\begin{array}{c}\text { THRUST } \\
\text { (lbs) } \\
\text { avthrust }\end{array}$} & \multirow{2}{*}{$\begin{array}{c}\text { SPEED } \\
\text { (rpm) } \\
\text { avspeed }\end{array}$} & \multirow{2}{*}{$\begin{array}{c}\text { LINEAR } \\
\text { (dB) } \\
\text { spdb } \\
\end{array}$} & \multirow{2}{*}{$\begin{array}{c}\text { A-WGT } \\
\text { (dBA) } \\
\text { spdba }\end{array}$} & \multirow{2}{*}{$\begin{array}{l}\text { DEPTH } \\
\text { (in) } \\
\text { pendepth }\end{array}$} & \multirow{2}{*}{$\begin{array}{l}\text { RATE } \\
\text { (in/sec) } \\
\text { penrate } \\
\end{array}$} \\
\hline setthrst & setspd & & & & & & \\
\hline \multirow{5}{*}{2,121} & 200 & 2,347 & 216 & 105.4 & 104.6 & 3.77 & 0.1520 \\
\hline & 300 & 2,357 & 307 & 106.8 & 106.5 & 4.93 & 0.1950 \\
\hline & 400 & 2,370 & 405 & 107.8 & 107.9 & 4.72 & 0.1910 \\
\hline & 500 & 2,387 & 508 & 108.0 & 108.1 & 4.73 & 0.1950 \\
\hline & 600 & 2,404 & 607 & 108.2 & 108.5 & 4.56 & 0.1850 \\
\hline \multirow{5}{*}{2,828} & 200 & 2,989 & 216 & 106.4 & 105.9 & 6.14 & 0.2460 \\
\hline & 300 & 2,999 & 308 & 108.0 & 107.8 & 7.02 & 0.2840 \\
\hline & 400 & 3,008 & 406 & 109.7 & 109.8 & 6.40 & 0.2800 \\
\hline & 500 & 3,022 & 505 & 109.3 & 109.6 & 6.80 & 0.2730 \\
\hline & 600 & 3,036 & 606 & 110.0 & 110.3 & 5.50 & 0.2230 \\
\hline \multirow{5}{*}{3,535} & 200 & 3,686 & 218 & 107.1 & 106.7 & 8.53 & 0.3430 \\
\hline & 300 & 3,699 & 302 & 108.6 & 108.5 & 10.11 & 0.4070 \\
\hline & 400 & 3,709 & 404 & 110.9 & 110.9 & 9.66 & 0.3880 \\
\hline & 500 & 3,723 & 501 & 111.0 & 111.3 & 9.28 & 0.3740 \\
\hline & 600 & 3,738 & 604 & 112.0 & 112.4 & 9.37 & 0.3790 \\
\hline \multirow{5}{*}{4,242} & 200 & 4,239 & 204 & 108.1 & 107.8 & 10.04 & 0.4170 \\
\hline & 300 & 4,247 & 309 & 110.2 & 110.1 & 13.07 & 0.5380 \\
\hline & 400 & 4,257 & 404 & 111.4 & 111.7 & 12.05 & 0.4880 \\
\hline & 500 & 4,269 & 508 & 111.9 & 112.3 & 11.25 & 0.4650 \\
\hline & 600 & 4,278 & 606 & 111.8 & 112.2 & 12.60 & 0.5190 \\
\hline \multirow{5}{*}{4,949} & 200 & 4,899 & 212 & 109.3 & 109.3 & 11.52 & 0.4750 \\
\hline & 300 & 4,916 & 310 & 111.2 & 111.4 & 12.21 & 0.4920 \\
\hline & 400 & 4,909 & 403 & 111.3 & 111.6 & 13.21 & 0.5400 \\
\hline & 500 & 4,929 & 506 & 113.4 & 113.9 & 12.39 & 0.5180 \\
\hline & 600 & 4,955 & 608 & 113.1 & 113.6 & 13.31 & 0.5440 \\
\hline
\end{tabular}


Table 5.12 Sound Power Level Testing - Mist Drilling Method (3 qt/min), 1-3/8-inch bit, Round Drill Steel

\begin{tabular}{|c|c|c|c|c|c|c|c|}
\hline \multicolumn{2}{|c|}{ SET POINTS } & \multicolumn{2}{|c|}{ AVERAGE } & \multicolumn{2}{|c|}{ SOUND POWER } & \multicolumn{2}{|c|}{ PENETRATION } \\
\hline $\begin{array}{c}\text { THRUST } \\
\text { (lbs) } \\
\text { setthrst }\end{array}$ & $\begin{array}{c}\text { SPEED } \\
\text { (rpm) } \\
\text { setspd }\end{array}$ & $\begin{array}{c}\text { THRUST } \\
\text { (lbs) } \\
\text { avthrust }\end{array}$ & $\begin{array}{c}\text { SPEED } \\
\text { (rpm) } \\
\text { avspeed }\end{array}$ & $\begin{array}{c}\text { LINEAR } \\
\text { (dB) } \\
\text { spdb }\end{array}$ & $\begin{array}{c}\text { A-WGT } \\
\text { (dBA) } \\
\text { spdba }\end{array}$ & $\begin{array}{l}\text { DEPTH } \\
\text { (in) } \\
\text { pendepth }\end{array}$ & $\begin{array}{l}\text { RATE } \\
\text { (in/sec) } \\
\text { penrate }\end{array}$ \\
\hline \multirow{5}{*}{3,535} & 200 & 3,748 & 219 & 108.6 & 108.4 & 4.51 & 0.2050 \\
\hline & 300 & 3,752 & 310 & 109.6 & 109.7 & 5.73 & 0.2190 \\
\hline & 400 & 3,756 & 402 & 110.8 & 111.1 & 6.12 & 0.2360 \\
\hline & 500 & 3,779 & 510 & 111.4 & 111.8 & 5.94 & 0.2310 \\
\hline & 600 & 3,789 & 606 & 112.1 & 112.6 & 5.78 & 0.2240 \\
\hline \multirow{5}{*}{4,242} & 200 & 4,352 & 214 & 110.8 & 110.9 & 6.66 & 0.2580 \\
\hline & 300 & 4,361 & 311 & 111.7 & 112.0 & 7.03 & 0.2730 \\
\hline & 400 & 4,371 & 406 & 112.2 & 112.5 & 7.88 & 0.3060 \\
\hline & 500 & 4,383 & 510 & 112.3 & 112.7 & 8.09 & 0.3140 \\
\hline & 600 & 4,396 & 609 & 112.6 & 113.1 & 6.94 & 0.2700 \\
\hline \multirow{5}{*}{4,949} & 200 & 4,953 & 218 & 111.3 & 111.5 & 7.62 & 0.2910 \\
\hline & 300 & 4,965 & 309 & 111.2 & 111.3 & 9.33 & 0.3580 \\
\hline & 400 & 4,967 & 401 & 111.7 & 112.1 & 7.93 & 0.3050 \\
\hline & 500 & 4,986 & 512 & 112.2 & 112.6 & 8.83 & 0.3350 \\
\hline & 600 & 5,007 & 607 & 112.9 & 113.4 & 8.26 & 0.3140 \\
\hline \multirow{5}{*}{5,656} & 200 & 5,523 & 216 & 111.6 & 111.8 & 9.14 & 0.3580 \\
\hline & 300 & 5,528 & 312 & 110.3 & 110.4 & 9.91 & 0.3820 \\
\hline & 400 & 5,942 & 403 & 113.3 & 113.6 & 10.88 & 0.4160 \\
\hline & 500 & 5,558 & 510 & 113.1 & 113.6 & 10.60 & 0.4120 \\
\hline & 600 & 5,569 & 608 & 114.5 & 114.8 & 9.93 & 0.3760 \\
\hline \multirow{5}{*}{6,363} & 200 & 6,244 & 218 & 109.9 & 109.8 & 10.17 & 0.3970 \\
\hline & 300 & 6,256 & 309 & 111.1 & 111.2 & 12.39 & 0.4850 \\
\hline & 400 & 6,275 & 401 & 112.6 & 112.9 & 13.91 & 0.5370 \\
\hline & 500 & 6,294 & 509 & 113.8 & 114.3 & 13.58 & 0.5240 \\
\hline & 600 & 6,317 & 608 & 113.0 & 113.4 & 12.44 & 0.4830 \\
\hline
\end{tabular}


Table 5.13 Sound Power Level Testing - Mist Drilling Method (3 qt/min), 1-3/8-inch bit, Hex Drill Steel

\begin{tabular}{|c|c|c|c|c|c|c|c|}
\hline \multicolumn{2}{|c|}{ SET POINTS } & \multicolumn{2}{|c|}{ AVERAGE } & \multicolumn{2}{|c|}{ SOUND POWER } & \multicolumn{2}{|c|}{ PENETRATION } \\
\hline $\begin{array}{c}\text { THRUST } \\
\text { (lbs) } \\
\text { setthrst }\end{array}$ & $\begin{array}{c}\text { SPEED } \\
\text { (rpm) } \\
\text { setspd }\end{array}$ & $\begin{array}{c}\text { THRUST } \\
\text { (lbs) } \\
\text { avthrust }\end{array}$ & $\begin{array}{l}\text { SPEED } \\
\text { (rpm) } \\
\text { avspeed }\end{array}$ & $\begin{array}{c}\text { LINEAR } \\
\text { (dB) } \\
\text { spdb }\end{array}$ & $\begin{array}{c}\text { A-WGT } \\
\text { (dBA) } \\
\text { spdba }\end{array}$ & $\begin{array}{l}\text { DEPTH } \\
\text { (in) } \\
\text { pendepth }\end{array}$ & $\begin{array}{l}\text { RATE } \\
\text { (in/sec) } \\
\text { penrate }\end{array}$ \\
\hline \multirow{5}{*}{3,535} & 200 & 3,680 & 213 & 107.9 & 107.9 & 4.64 & 0.2110 \\
\hline & 300 & 3,692 & 305 & 110.1 & 109.9 & 5.43 & 0.2500 \\
\hline & 400 & 3,717 & 403 & 111.2 & 111.7 & 4.05 & 0.1850 \\
\hline & 500 & 3,736 & 509 & 112.5 & 112.9 & 3.84 & 0.1730 \\
\hline & 600 & 3,752 & 606 & 113.2 & 113.3 & 4.14 & 0.1880 \\
\hline \multirow{5}{*}{4,242} & 200 & 4,298 & 213 & 108.5 & 108.7 & 4.98 & 0.2290 \\
\hline & 300 & 4,310 & 314 & 111.2 & 111.6 & 5.78 & 0.2640 \\
\hline & 400 & 4,326 & 402 & 112.0 & 112.5 & 5.95 & 0.2740 \\
\hline & 500 & 4,338 & 508 & 113.4 & 114.0 & 4.76 & 0.2160 \\
\hline & 600 & 4,357 & 607 & 114.2 & 114.8 & 4.88 & 0.2720 \\
\hline \multirow{5}{*}{4,949} & 200 & 4,977 & 212 & 107.3 & 107.3 & 6.34 & 0.2910 \\
\hline & 300 & 4,998 & 303 & 108.0 & 108.0 & 7.12 & 0.3270 \\
\hline & 400 & 5,013 & 398 & 111.8 & 112.3 & 6.56 & 0.3000 \\
\hline & 500 & 5,037 & 511 & 113.7 & 114.2 & 5.13 & 0.2370 \\
\hline & 600 & 5,060 & 606 & 115.6 & 116.2 & 5.78 & 0.2670 \\
\hline \multirow{5}{*}{5,656} & 200 & 5,617 & 211 & 110.3 & 110.5 & 7.87 & 0.3990 \\
\hline & 300 & 5,632 & 306 & 112.7 & 113.1 & 9.10 & 0.4110 \\
\hline & 400 & 5,646 & 404 & 113.2 & 113.6 & 8.92 & 0.4020 \\
\hline & 500 & 5,671 & 512 & 116.3 & 117.0 & 8.09 & 0.3660 \\
\hline & 600 & 5,686 & 595 & 115.5 & 116.1 & 8.20 & 0.3740 \\
\hline \multirow{5}{*}{6,363} & 200 & 6,260 & 212 & 111.7 & 111.9 & 9.36 & 0.4320 \\
\hline & 300 & 6,287 & 312 & 113.2 & 113.6 & 10.41 & 0.4810 \\
\hline & 400 & 6,317 & 404 & 114.5 & 114.9 & 10.00 & 0.4620 \\
\hline & 500 & 6,347 & 507 & 115.4 & 115.9 & 11.78 & 0.5380 \\
\hline & 600 & 6,306 & 598 & 116.3 & 116.9 & 9.05 & 0.4030 \\
\hline
\end{tabular}

Nomenclature within tables 5.2 thru 5.13 include:

SET POINTS - these represent the settings for thrust and rotational speed prior to the drilling procedure

o Thrust (lbs) - setthrst - thrust setting prior to drilling

o Speed (rpm) - setspd - rotational speed setting prior to drilling

AVERAGE - represents the average thrust and speed measured during the drilling portion of the test

o Thrust (lbs) - avthrust - average thrust during the test 
o Speed (rpm) - avspeed - average rotational speed during the test

SOUND POWER - represents the total noise energy emitted from machine during the test

o Linear $(\mathrm{dB})-\mathrm{spdb}-$ linear sound power determined for test

o A-WGT (dBA) - spdba - a-weighted sound power determined for test

PENETRATION - the length of run the drill bit encountered during a test

o Depth (in) - pendepth - The depth, in inches, the bit penetrated the rock media during a test

o Rate (in/sec) - penrate - The rate, in inches per second, the bit traveled thru the rock media during the test.

\subsection{Experimental Test Results - Sound Power Levels}

The data, represented graphically, listed in the following discussion are the average sound power levels $\left(\mathrm{L}_{\mathrm{wA}}\right)$ expressed in A-weighted decibels $(\mathrm{dBA})$ and the penetration rates (in/sec) monitored at a given test configuration. Furthermore, all similar tests (e.g., same steel shape and bit size) were averaged for a given thrust or rotation speed. This approach facilitated the illustrating of trends showing the affects of thrusts or rotation speeds on the data. As a result, relationships were determined for sound power, penetration rate, thrust and rotational speed related to the different types of drilling methods (vacuum, wet and mist). The laboratory data was characterized and plotted for each test configuration as shown below. 


\subsubsection{Round Drill Steel Compared to Hexagonal Drill Steel (Penetration Rate and Sound Power)}

Figure 5.1 below represents plots of thrust vs. penetration rate for one-inch round and oneinch hex drill steel given differing rotational speeds.
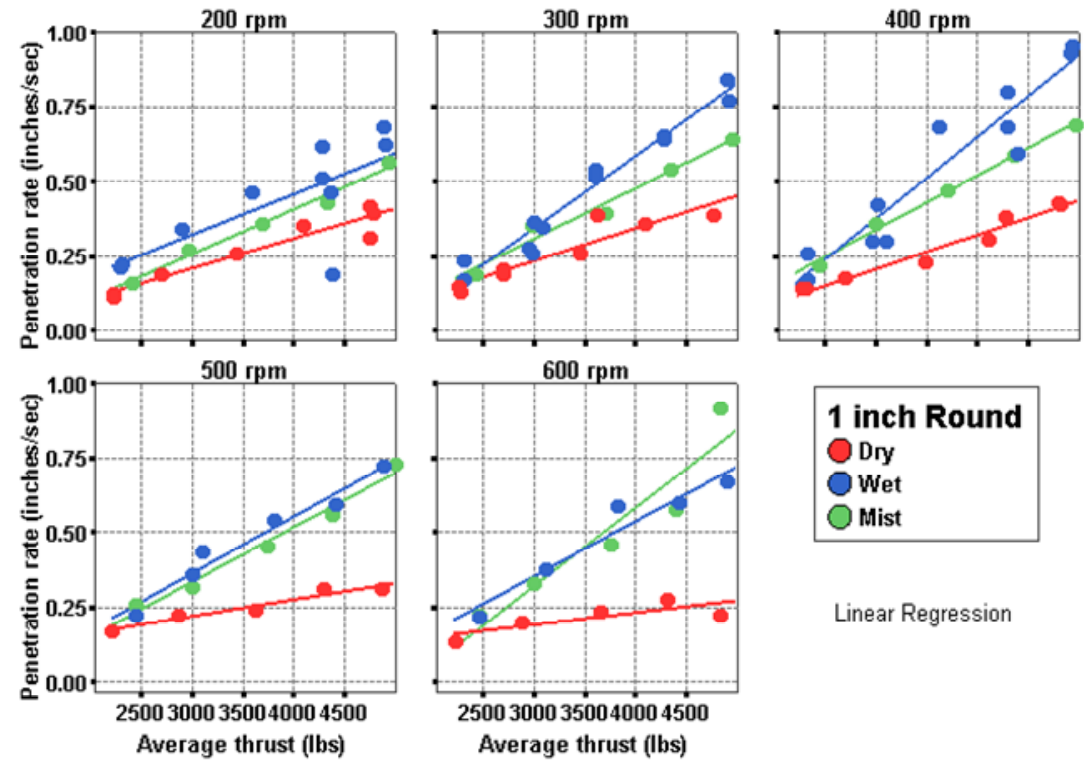

Linear Regression
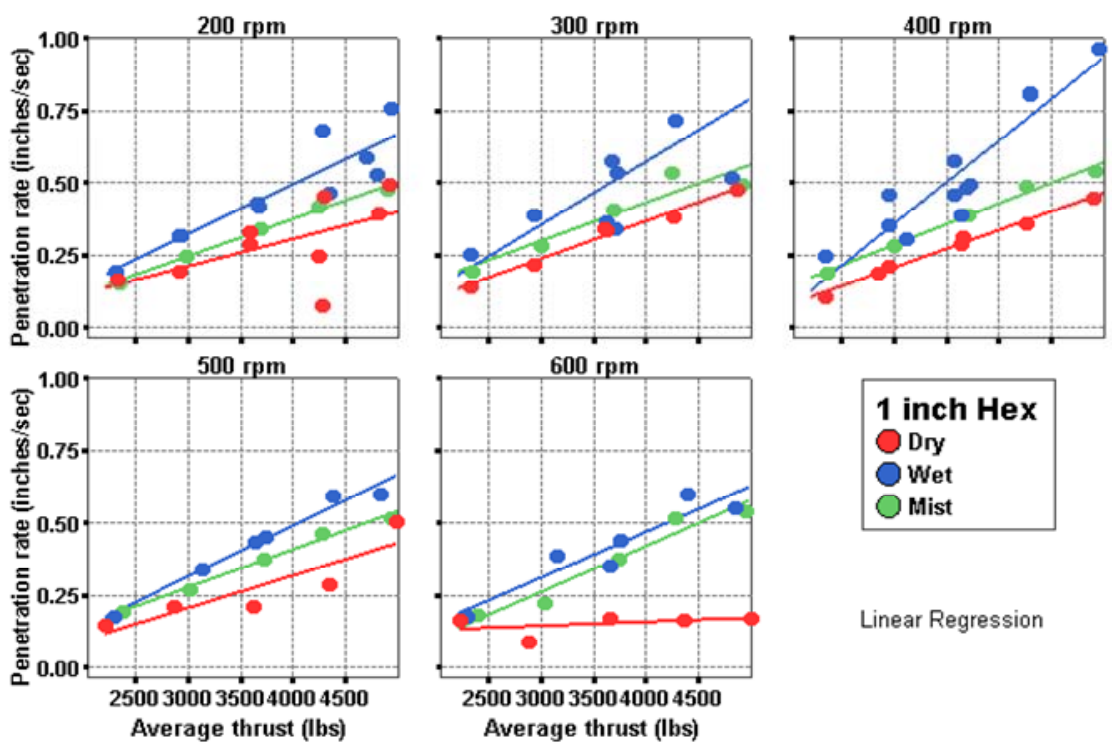

Linear Regression

Figure 5.1 Drill Steels - Round and Hex (1-inch) - Thrust vs. Penetration Rate 
In most cases, for both the one-inch round and hex drill steel, the data represents higher penetration rates when utilizing a wet, mist and dry drilling system respectively. However, for the one-inch round drill steel, penetration rates were higher using a mist system of drilling as compared to a wet system when the rotational speed was higher, specifically at $600 \mathrm{rpm}$. The data also shows that penetration rates did increase as the thrust was increased for both the one-inch round and hex drill steel with the exception of the one-inch hex drill steel at the higher rotational speed of $600 \mathrm{rpm}$. The penetration rate for this remained fairly constant as the thrust was increased.

Figure 5.2 represents plots of penetration rates vs. sound power for one-inch round and oneinch hex drill steel given differing rotational speeds. 

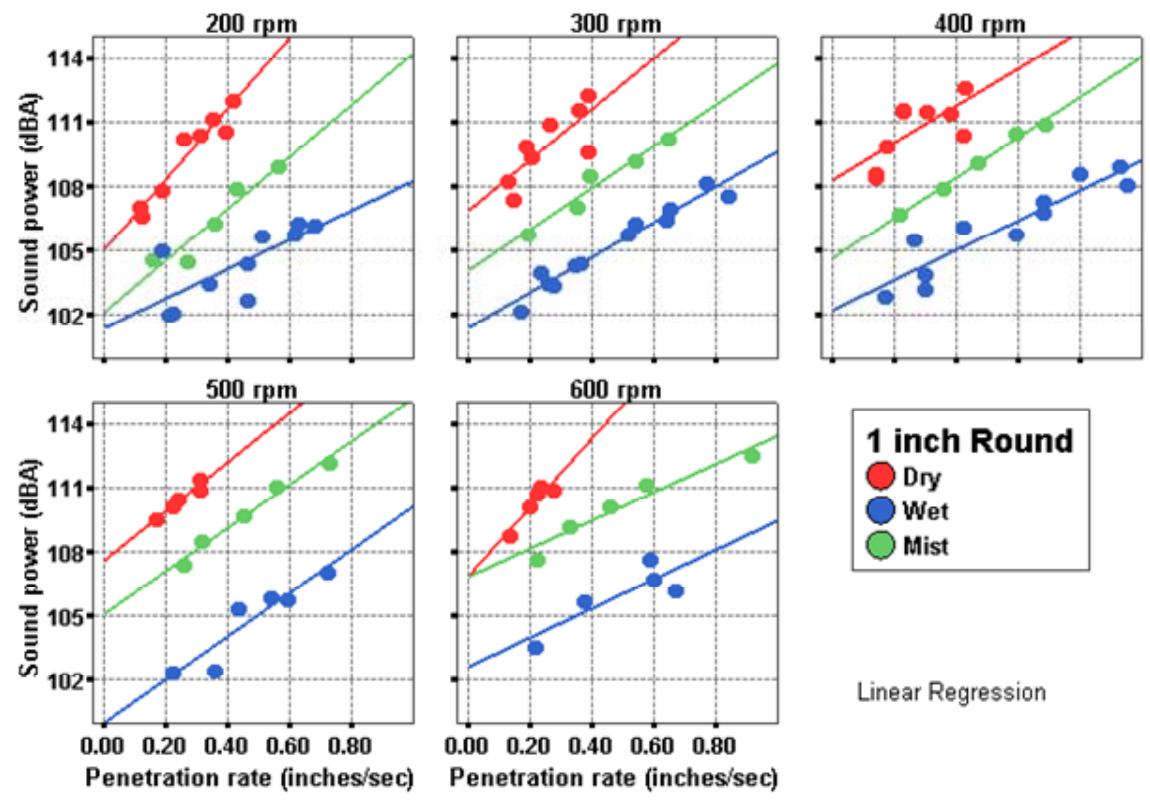

Linear Regression
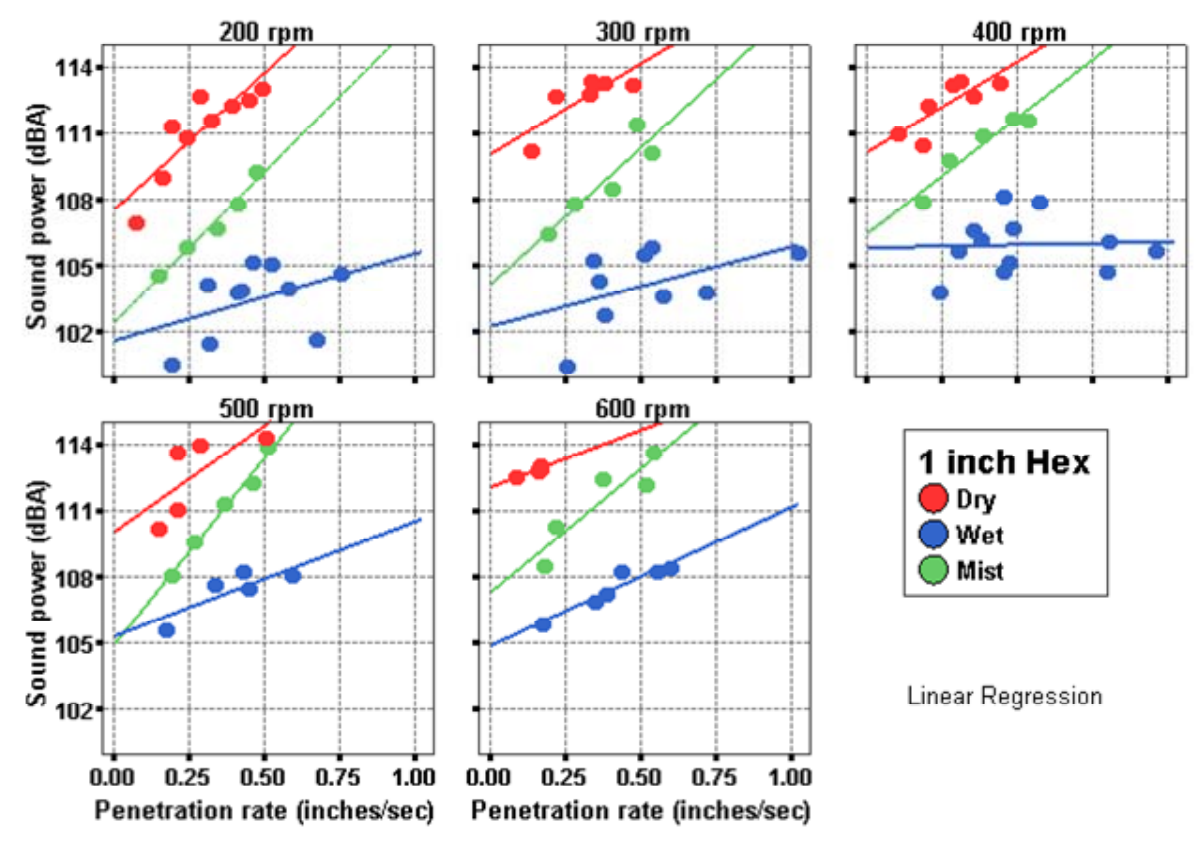

Linear Regression

Figure 5.2 Drill Steels - Round and Hex (1-inch) - Penetration Rate vs. Sound Power 
For all cases, sound power levels were highest during vacuum or dry drilling tests and the levels decreased during mist and wet system type of drilling respectively as shown in figure 5.2. In general, for all configurations, as the penetration rate increased, the sound power level increased as well. Additionally, sound power levels for the round drill steel were lower than compared to the hex type drill steel. Figure 5.3 below represents plots of thrust vs. penetration rate for 1.375 -inch round and hex drill steel given differing rotational speeds. 

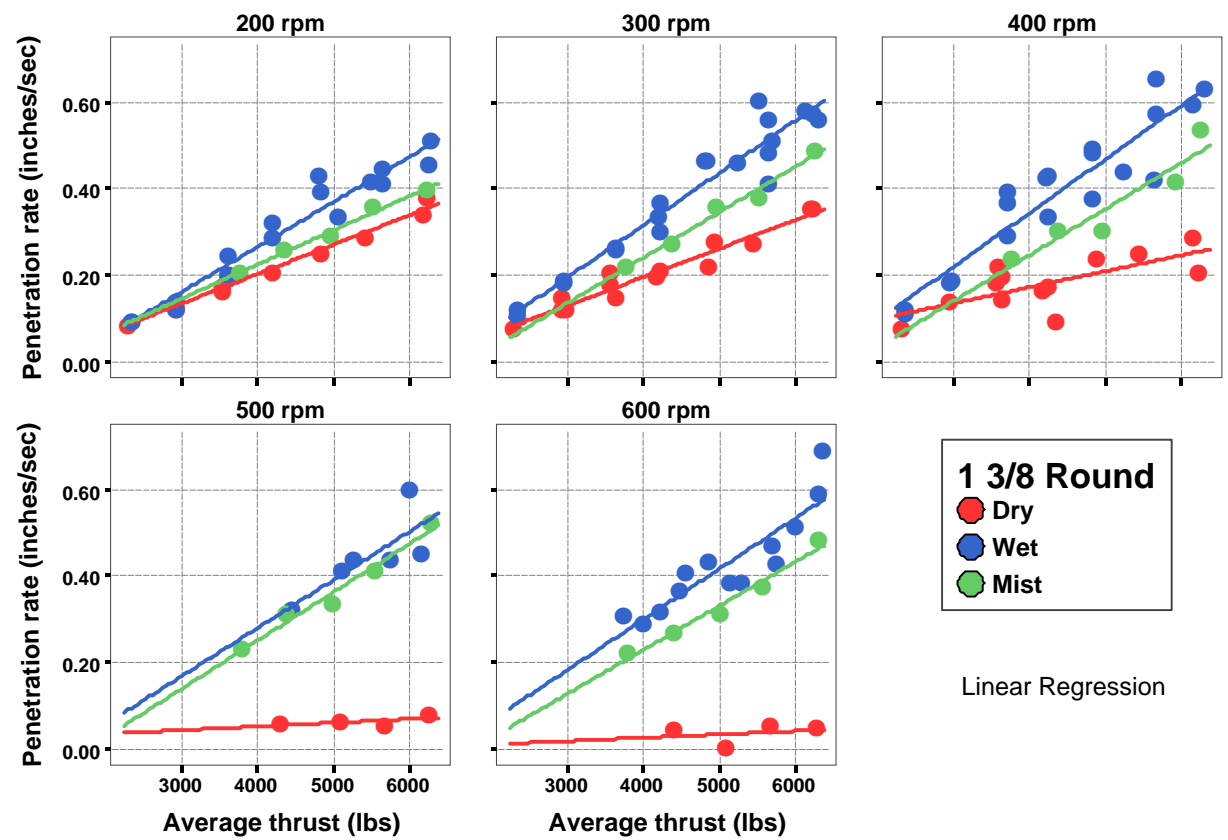

Linear Regression Average thrust (Ibs)
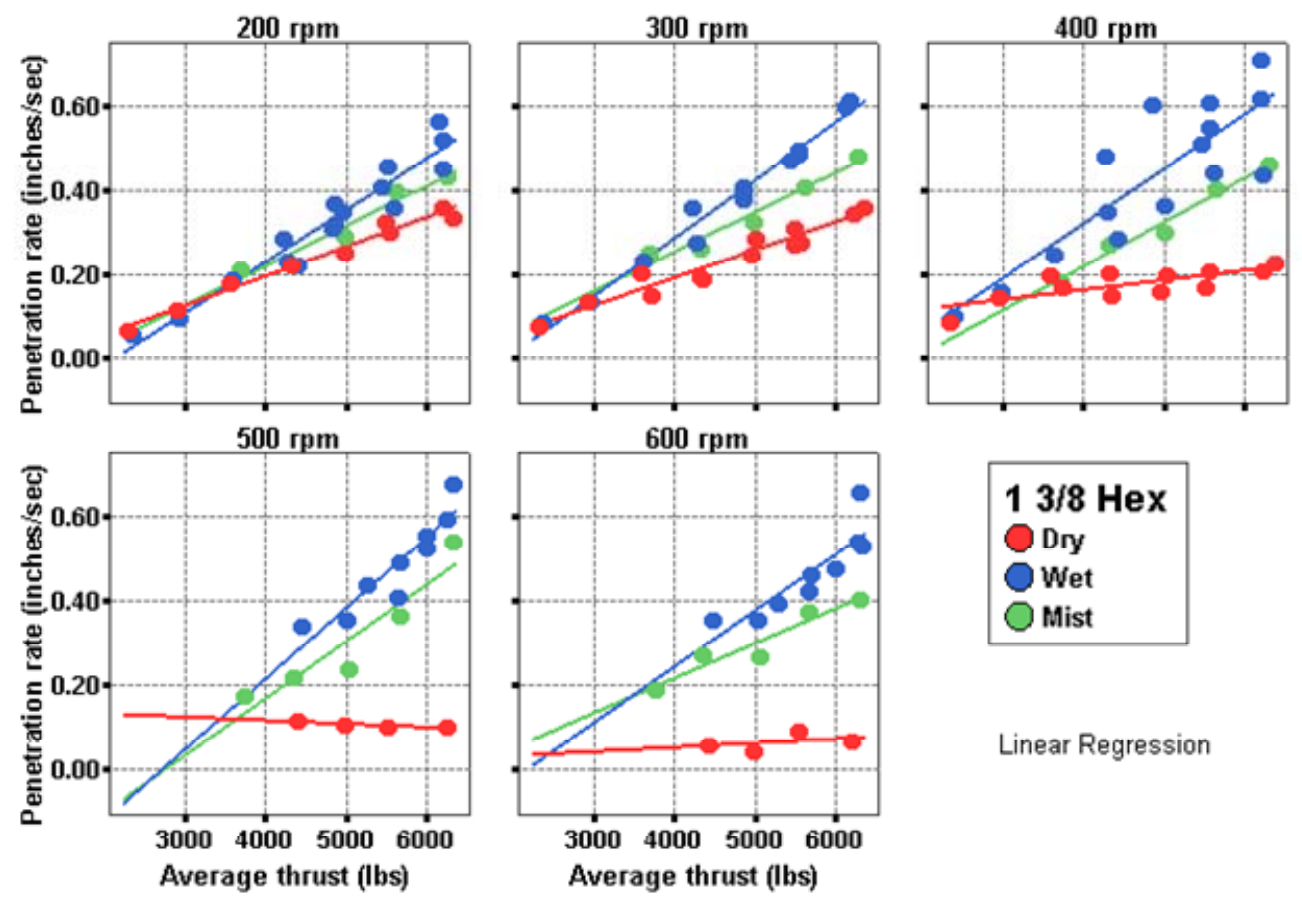

\section{$13 / 8 \mathrm{Hex}$ \\ ODry \\ Wet \\ Mist}

Linear Regression

Figure 5.3 Drill Steels - Round and Hex (1.375-inch) - Thrust vs. Penetration Rate 
As seen earlier with the one-inch round and hex drill steel in figure 5.1, the data represented for the 1.375-inch round and hex drill steel also presents higher penetration rates when using a wet, mist and dry drilling system respectively. However, penetration rates are significantly decreased when utilizing a dry or vacuum drilling system and operating at higher rotational speeds, specifically, 400 thru $600 \mathrm{rpm}$. Additionally, penetration rates did increase as the thrust was increased for both the 1.375-inch round and hex drill steel until a vacuum type of drilling system was used and rotational speeds were higher. Figure 5.4 displays plots of penetration rates vs. sound power for 1.375-inch round and hex drill steel given differing rotational speeds. 


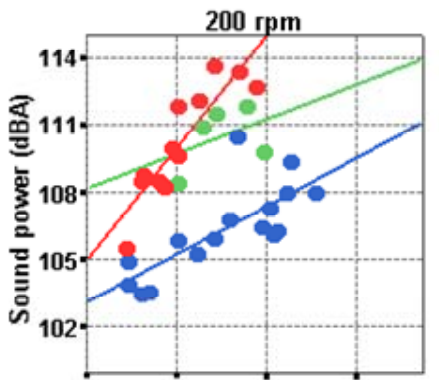

$500 \mathrm{rpm}$

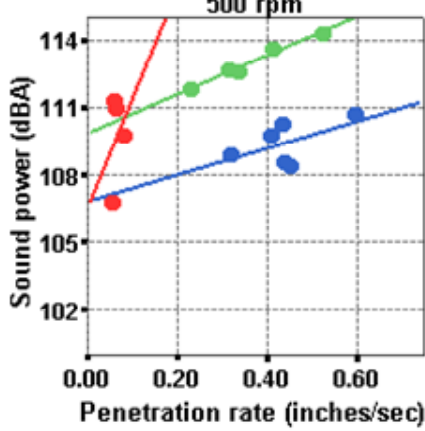

Penetration rate (inches/sec)

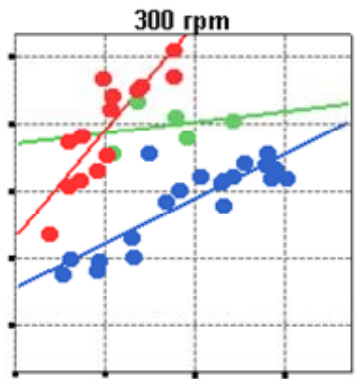

$600 \mathrm{rpm}$

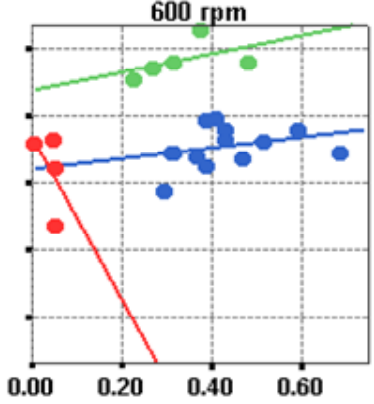

Penetration rate (inches/sec)

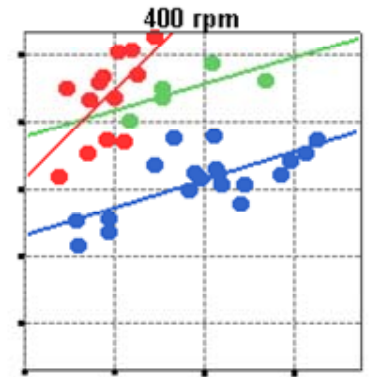

$13 / 8$ inch Round Dry Wet Mist

Linear Regression
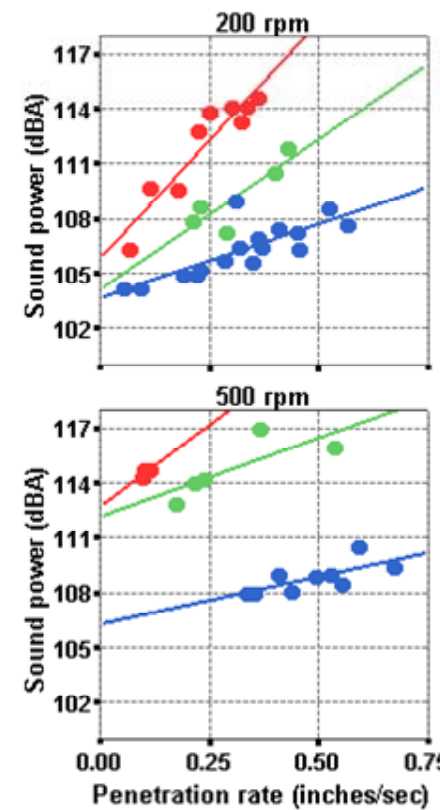

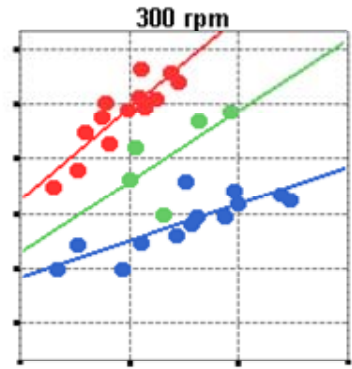

$600 \mathrm{rpm}$

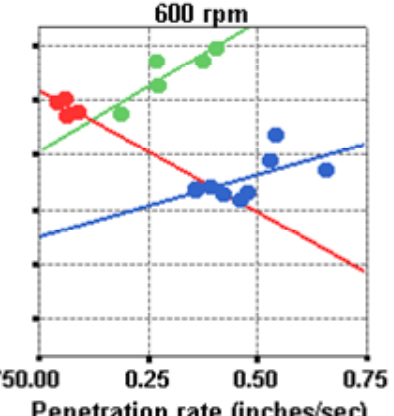

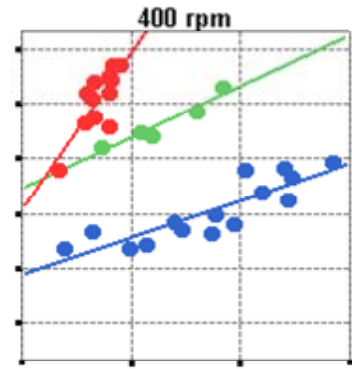

$13 / 8$ Hex

Dry

Wet

Mist

Linear Regression

Figure 5.4 Drill Steels - Round and Hex (1.375-inch) - Penetration Rate vs. Sound Power 
In general, sound power levels were lowest during wet drilling tests and highest when utilizing a vacuum or dry method of drilling. Additionally, the penetration rates for the vacuum drilling method were much lower as compared to the mist or wet systems of drilling. Minimal penetration rates were observed at higher rotational speeds utilizing the dry or vacuum method of drilling and sound power levels were higher utilizing the 1.375-inch hex drill steel as compared to the round steel and the one-inch hex results showed sound power levels less than one-inch round at lower rotational speeds but the advantage disappears at 500 and $600 \mathrm{rpm}$.

\subsubsection{One-Inch Diameter Compared to One and Three-Eighths Inch Diameter Drill Bits}

Figure 5.5 represents plots of penetration rates vs. thrust for comparing one-inch to 1.375 inch round and hex drill steel given differing rotational speeds. 

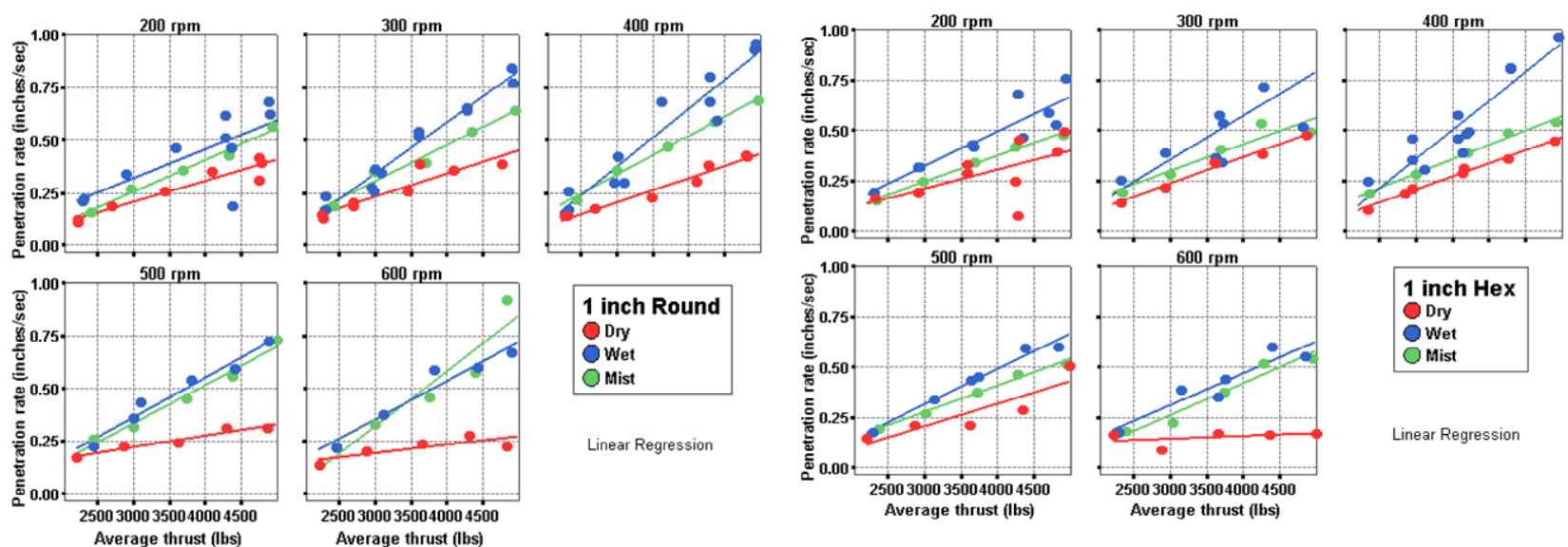

Linear Regression
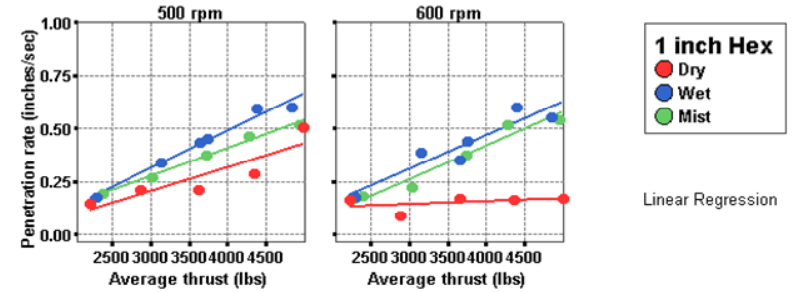

Linear Regression
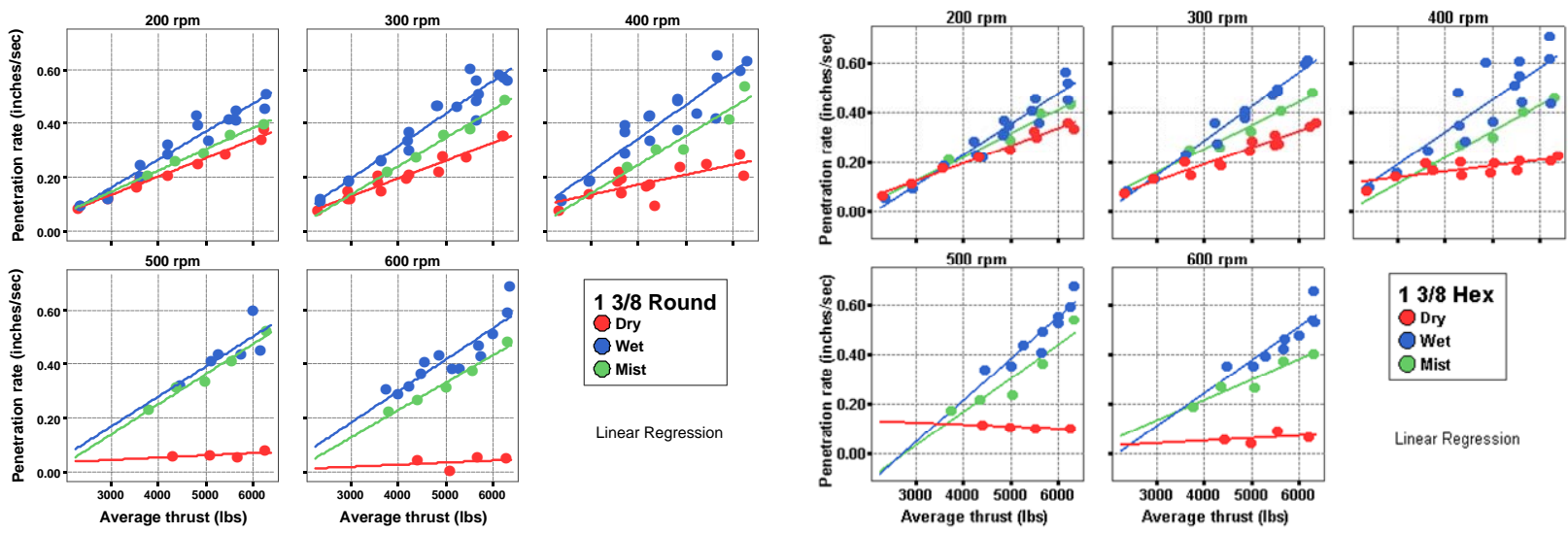

Figure 5.5 One-inch vs. 1.375-inch Drill Bit (Penetration Rate vs. Thrust)

As shown in figure 5.5 above, the thrust has a significant affect on the penetration rate for most cases. The one-inch drill bit performance was on the order of two to three times that of the 1.375inch drill bit. However, the thrust had minimal influence relative to using a dry method of drilling at the higher rotational speeds, specifically, 500 and $600 \mathrm{rpm}$. The one-inch drill bit performed significantly better than the 1.375 -inch drill bit relative to rotational speed. Figure 5.6 displays plots of penetration rates vs. sound power levels for comparing one-inch to 1.375 -inch round and hex drill bits given differing rotational speeds. 

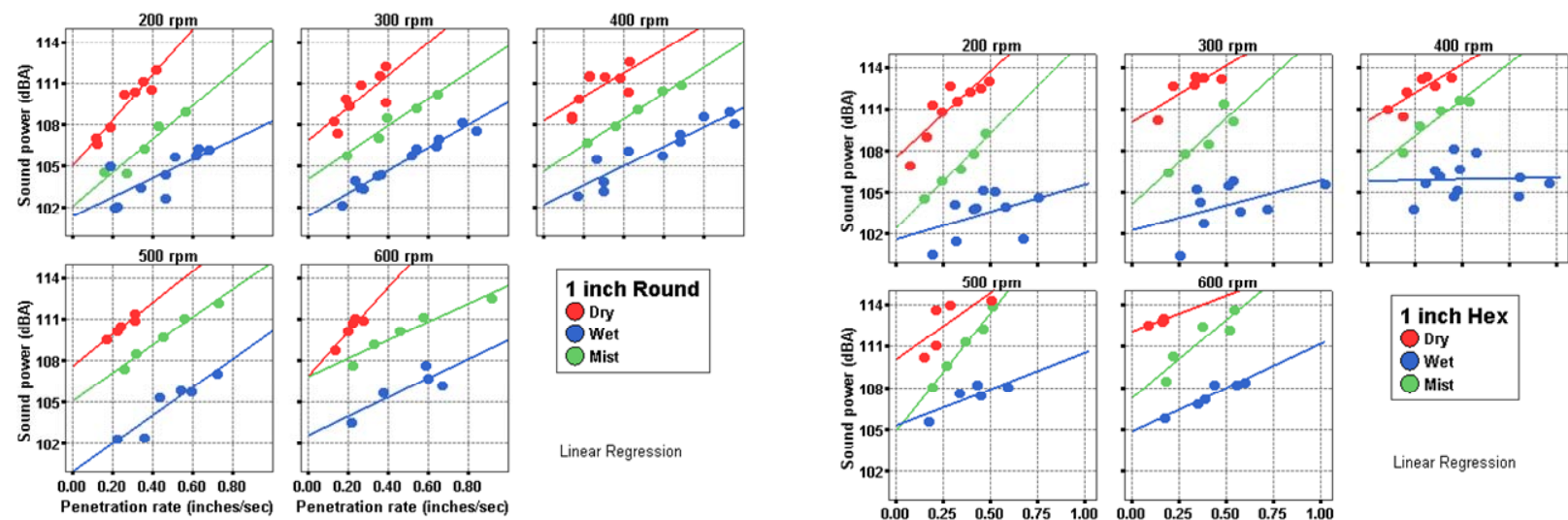

Linear Regression
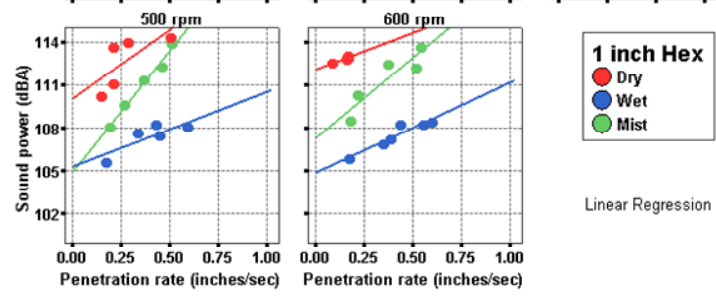

Dry

Wist

Linear Regression
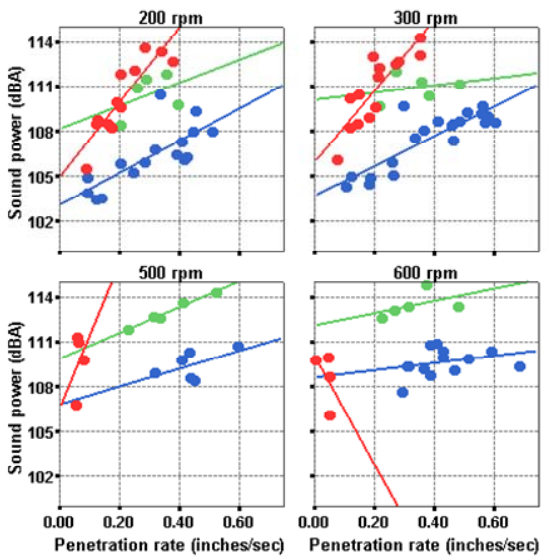
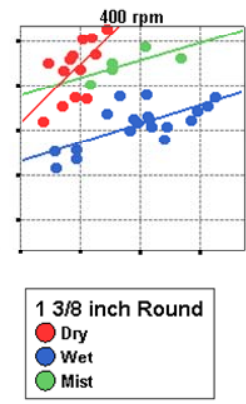

Linear Regression
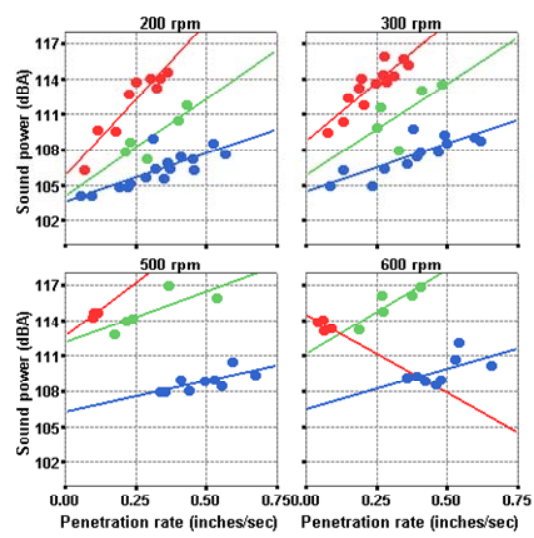

Figure 5.6 One-inch vs. 1.375-inch Drill Bit (Penetration Rate vs. Sound Power Level)

Sound power levels experienced with the 1.375-inch diameter bit were observed to be higher than experienced with the one-inch diameter bit, varying approximately by $2.5 \mathrm{dBA}$. Additionally, sound power levels for either a one-inch or 1.375-inch diameter bit were lowest during the wet drilling method. Penetration rates using a one-inch diameter bit were typically higher than when using a 1.375-inch diameter bit independent upon the type of drilling method used. As was the case with thrust, when using rotation speed as a comparative basis, the vacuum round drill steel results indicate 
a lower sound power than similar hex drill steel tests. For wet testing, there is no difference between the one-inch and 1.375-inch round and hex results.

\subsubsection{General Conclusions Regarding Data Collection}

When comparing round and hex drill steel, round drill steel should be used when utilizing the vacuum type of drilling method and hex drill steels when performing the wet or mist type of drilling method. While increasing the thrust does yield an increased sound power level for both of the round and hex drill steel, the differences are negligible. When comparing rotational speed affect relative to round or hex drill steel, the round drill steel, during vacuum type drilling, provides a lower sound power level than similar hex drill steel tests. For wet or mist system type of drilling, their appears to be no difference between the one-inch and 1.375-inch round and hex drill steel. Upon comparing penetration rates relative to round or hex drill steel in relation to thrust or rotational speed, their appears to be minimal affect attributed to thrust or rotational speeds.

When comparing the one-inch diameter bits to the 1.375-inch diameter bits, the one-inch diameter drill bits are slightly quieter than the 1.375-inch diameter drill bits. The penetration rates relative to the one-inch drill bits are noticeably higher than the 1.375 -inch bits, on an order of two to three times higher. When comparing the 1-inch bit to the 1.375-inch bit relative to rotational speed, the one-inch bit performed significantly better than the 1.375-inch bit. For optimal performance and lower sound power levels, rotational speeds in the range of 200-400 rpm performed better and were quieter.

When comparing the different types of drilling methods, specifically vacuum, mist or wet, wet and mist drilling, penetration rates utilizing a wet or mist system drilling technique were much higher than using a dry or vacuum type drilling method. Additionally, utilizing a wet or mist system proved to emit less noise than similar tests conducted under vacuum or dry 
conditions. Much of the difference is attributable to the lubricating affect of the water or mist, which attenuates higher frequency noise. An example of this effect is given in figure $5.7(17,22)$. Here, one-inch round data tested at a thrust of 4,949 pounds and a rotation speed of $200 \mathrm{rpm}$ is given for testing under both vacuum and wet drilling system conditions. For all one-third octave band frequencies of $1,000 \mathrm{~Hz}$ and greater, it is clearly shown that the sound power levels are greater for vacuum drilling. Four examples of this are listed in table 5.14. For each case, the sound power level contributions for the one-third octave bands from 50 through $800 \mathrm{~Hz}$ are essentially the same for vacuum and wet drilling, e.g., for the one-inch round case they are 95 $\mathrm{dBA}$ and $96 \mathrm{dBA}$ respectively. There is a significantly larger difference in the frequency range 1 $\mathrm{kHz}$ through $10 \mathrm{kHz}$. For the one-inch round example, there is a $5 \mathrm{dBA}$ difference. Similar results are listed for the other three cases.

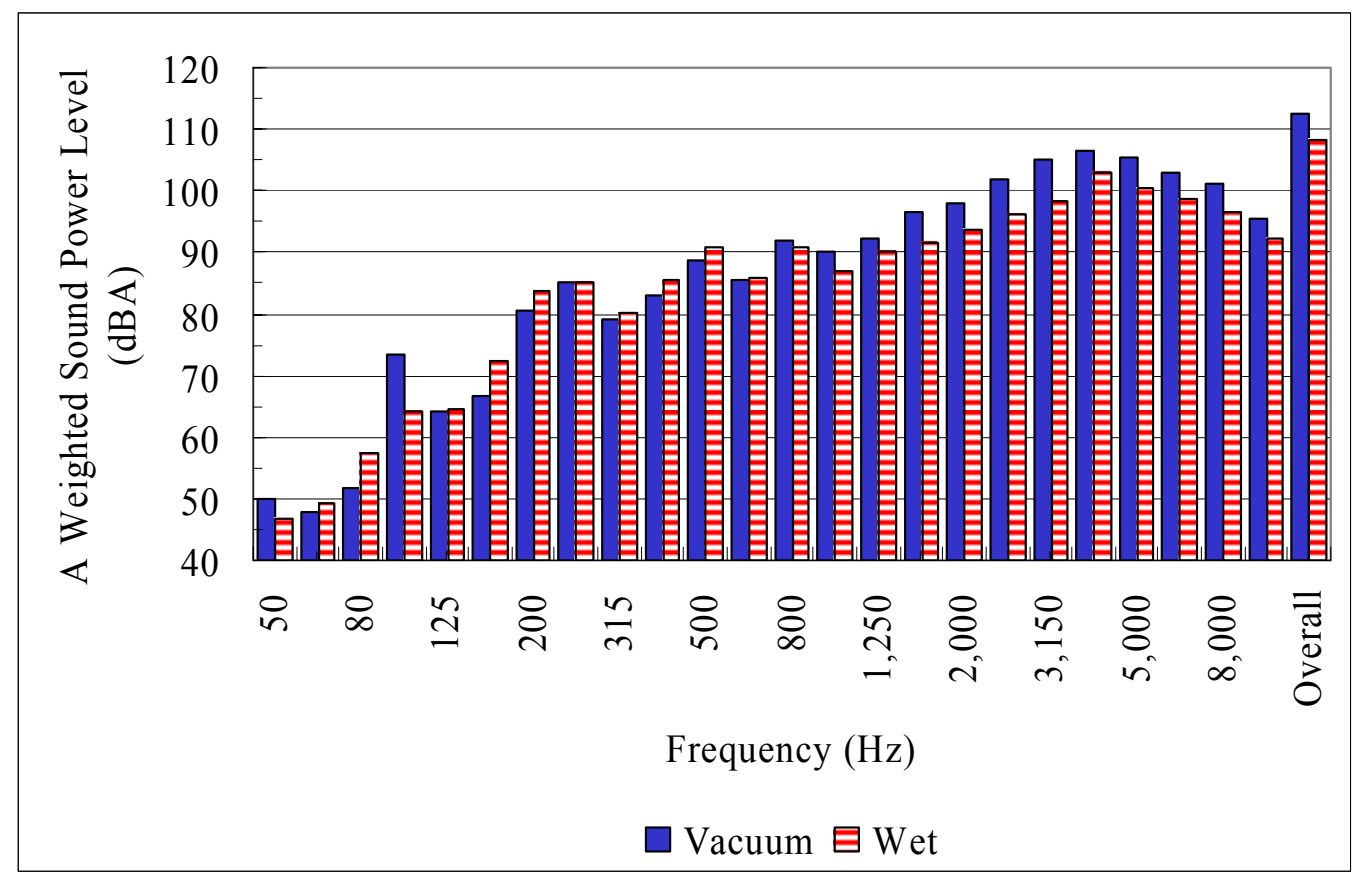

Figure 5.7 One-inch Round Drill Steel - Vacuum and Wet - Sound Power Levels - 4,949 lbs Thrust, 200 rpm Rotational Speed 
Table 5.14 - Sound Power Level Contributions of Two Frequency Bands

\begin{tabular}{|c|c|c|c|c|}
\hline $\begin{array}{l}\text { Size \& } \\
\text { Shape }\end{array}$ & $\begin{array}{l}\text { Thrust (lbs) } \\
\text { Speed (rpm) }\end{array}$ & $\begin{array}{l}\text { Frequency } \\
\text { Band } \\
(\mathbf{H z}) \\
\end{array}$ & $\begin{array}{l}\text { Vacuum } \\
\mathbf{L}_{\mathrm{wA}} \\
\end{array}$ & $\begin{array}{l}\text { Wet } \\
\mathbf{L}_{\text {wA }} \\
\end{array}$ \\
\hline \multirow{2}{*}{$\begin{array}{l}\text { 1-inch } \\
\text { round }\end{array}$} & \multirow{2}{*}{$\begin{array}{l}4,949 \\
400 \\
\end{array}$} & 50 through 800 & 95 & 96 \\
\hline & & $1 \mathrm{k}$ through $10 \mathrm{k}$ & 113 & 108 \\
\hline \multirow{2}{*}{$\begin{array}{l}1-3 / 8 \text { inch } \\
\text { round }\end{array}$} & \multirow{2}{*}{$\begin{array}{l}6,363 \\
400 \\
\end{array}$} & 50 through 800 & 96 & 96 \\
\hline & & $1 \mathrm{k}$ through $10 \mathrm{k}$ & 115 & 109 \\
\hline \multirow{2}{*}{$\begin{array}{l}\text { 1-inch } \\
\text { hex }\end{array}$} & \multirow{2}{*}{$\begin{array}{l}4,949 \\
400 \\
\end{array}$} & 50 through 800 & 93 & 96 \\
\hline & & $1 \mathrm{k}$ through $10 \mathrm{k}$ & 112 & 105 \\
\hline \multirow{2}{*}{$\begin{array}{l}1-3 / 8 \text { inch } \\
\text { hex }\end{array}$} & \multirow{2}{*}{$\begin{array}{l}5,656 \\
200\end{array}$} & 50 through 800 & 97 & 95 \\
\hline & & $1 \mathrm{k}$ through $10 \mathrm{k}$ & 114 & 107 \\
\hline
\end{tabular}

Further analysis indicated another key point. The overall A-weighted sound power levels are essentially unaffected by the sound power generated in the one-third octave bands below $1 \mathrm{kHz}$. For each example given, the overall A-weighted sound power level is the same as the $1 \mathrm{kHz}$ through $10 \mathrm{kHz}$ contributions, given rounding the sound power levels to the nearest $\mathrm{dBA}$.

\subsection{Development of a Statistical Model for Determining Sound Power Levels}

\section{$\underline{5.4 .1 \quad \text { Introduction }}$}

The next step of the research was to compile, summarize and statistically correlate all of the data collected (approximately 500 tests) for drilling into a high-compressive strength media ( $>20,000$ psi) by developing one equation, which, would be used to determine sound power levels given any drilling method (vacuum, wet or mist) and utilizing differing drilling parameters or configurations related to thrust, rotational speed, bit size and type of drill steel used. A commercially available, statistical software package, SPSS was used to correlate all of the data.

In order to statistically correlate the data into one useful equation, the data from each test had to be organized into a useful form. The laboratory data is shown in table 5.15. Each individual test supplied the following independent data: 1) bit size; 2) drill steel type; 3) thrust utilized; 4) rotational speed and 5) type of drilling method (vacuum, mist or wet). The dependent information derived 
from the statistical approach was the sound power level generated from each test configuration. As shown in table 5.15, the independent variables utilized for the model were:

Water $=0 \mathrm{gpm}$ for the vacuum drilling method

$0.75 \mathrm{gpm}$ for the mist drilling method

3 gpm for the wet drilling method

Thrust $=\quad$ average thrust level used for the individual test, in lbs.

Speed $=\quad$ average rotational speed used for the individual test, in rpm

Bit Size $\quad=\quad 1$ for 1 -inch and 1.375 for 1.375 -inch

Drill Steel $=0$ for hex drill steel and 1 for round drill steel

It was determined the penetration rate measured for each test was not to be included as a specific independent variable when developing the one equation for predicting sound power. The penetration rates measured for each test were directly affected by all of the independent variables listed above. Therefore, a direct correlation between the dependent variable, sound power and the penetration rate cannot exist due to the contribution required by all of the independent variables (drilling method, thrust, speed, bit size and type of drill steel) in determining the penetration rate. 
Table 5.15 Laboratory Data Utilized for Input into the Statistical Model

\begin{tabular}{|r|r|r|r|r|r|}
\hline $\begin{array}{c}\text { Sound Power } \\
\text { dBA }\end{array}$ & $\begin{array}{c}\text { Speed } \\
\text { rpm }\end{array}$ & $\begin{array}{c}\text { Thrust } \\
\text { lbs }\end{array}$ & $\begin{array}{c}\text { Water } \\
\text { gpm }\end{array}$ & $\begin{array}{c}\text { Bit Size } \\
\text { in. }\end{array}$ & $\begin{array}{c}\text { Drill Steel } \\
\text { (hex/round) }\end{array}$ \\
\hline 106.60 & 209.00 & 2239.00 & .00 & 1.000 & 1.000 \\
\hline 107.10 & 210.00 & 2228.00 & .00 & 1.000 & 1.000 \\
\hline 108.30 & 306.00 & 2282.00 & .00 & 1.000 & 1.000 \\
\hline 107.40 & 305.00 & 2272.00 & .00 & 1.000 & 1.000 \\
\hline 108.40 & 400.00 & 2324.00 & .00 & 1.000 & 1.000 \\
\hline 108.60 & 402.00 & 2280.00 & .00 & 1.000 & 1.000 \\
\hline 109.50 & 514.00 & 2220.00 & .00 & 1.000 & 1.000 \\
\hline 108.80 & 609.00 & 2241.00 & .00 & 1.000 & 1.000 \\
\hline 107.80 & 208.00 & 2711.00 & .00 & 1.000 & 1.000 \\
\hline 109.90 & 305.00 & 2696.00 & .00 & 1.000 & 1.000 \\
\hline 109.40 & 306.00 & 2705.00 & .00 & 1.000 & 1.000 \\
\hline 109.90 & 402.00 & 2701.00 & .00 & 1.000 & 1.000 \\
\hline 110.10 & 509.00 & 2865.00 & .00 & 1.000 & 1.000 \\
\hline 110.10 & 602.00 & 2882.00 & .00 & 1.000 & 1.000 \\
\hline 110.20 & 215.00 & 3435.00 & .00 & 1.000 & 1.000 \\
\hline 110.90 & 304.00 & 3451.00 & .00 & 1.000 & 1.000 \\
\hline 109.60 & 311.00 & 3620.00 & .00 & 1.000 & 1.000 \\
\hline 111.50 & 405.00 & 3487.00 & .00 & 1.000 & 1.000 \\
\hline 111.60 & 404.00 & 3483.00 & .00 & 1.000 & 1.000 \\
\hline 110.50 & 510.00 & 3628.00 & .00 & 1.000 & 1.000 \\
\hline 111.10 & 607.00 & 3653.00 & .00 & 1.000 & 1.000 \\
\hline 111.20 & 208.00 & 4085.00 & .00 & 1.000 & 1.000 \\
\hline 111.60 & 305.00 & 4097.00 & .00 & 1.000 & 1.000 \\
\hline 111.50 & 404.00 & 4111.00 & .00 & 1.000 & 1.000 \\
\hline 111.40 & 406.00 & 4283.00 & .00 & 1.000 & 1.000 \\
\hline 110.90 & 509.00 & 4291.00 & .00 & 1.000 & 1.000 \\
\hline 110.90 & 604.00 & 4314.00 & .00 & 1.000 & 1.000 \\
\hline 110.40 & 221.00 & 4744.00 & .00 & 1.000 & 1.000 \\
\hline 110.60 & 223.00 & 4778.00 & .00 & 1.000 & 1.000 \\
\hline 112.30 & 308.00 & 4769.00 & .00 & 1.000 & 1.000 \\
\hline 112.60 & 404.00 & 4800.00 & .00 & 1.000 & 1.000 \\
\hline 110.40 & 406.00 & 4821.00 & .00 & 1.000 & 1.000 \\
\hline 111.40 & 507.00 & 4870.00 & .00 & 1.000 & 1.000 \\
\hline 110.70 & 607.00 & 4822.00 & .00 & 1.000 & 1.000 \\
\hline 112.00 & 211.00 & 4745.00 & .00 & 1.000 & 1.000 \\
\hline 105.50 & 203.00 & 2268.00 & .00 & 1.375 & 1.000 \\
\hline 106.10 & 306.00 & 2285.00 & .00 & 1.375 & 1.000 \\
\hline 108.60 & 402.00 & 2293.00 & .00 & 1.375 & 1.000 \\
\hline 108.80 & 211.00 & 2915.00 & .00 & 1.375 & 1.000 \\
\hline 108.50 & 215.00 & 2908.00 & .00 & 1.375 & 1.000 \\
\hline 108.50 & 308.00 & 2925.00 & .00 & 1.375 & 1.000 \\
\hline & & & & & \\
\hline & & & & & \\
\hline & & & & &
\end{tabular}




\begin{tabular}{|r|r|r|r|r|r|}
\hline $\begin{array}{c}\text { Sound Power } \\
\text { dBA }\end{array}$ & $\begin{array}{c}\text { Speed } \\
\text { rpm }\end{array}$ & $\begin{array}{c}\text { Thrust } \\
\text { lbs }\end{array}$ & $\begin{array}{c}\text { Water } \\
\text { gpm }\end{array}$ & $\begin{array}{c}\text { Bit Size } \\
\text { in. }\end{array}$ & $\begin{array}{c}\text { Drill Steel } \\
\text { (hex/round })\end{array}$ \\
\hline 108.30 & 311.00 & 2923.00 & .00 & 1.375 & 1.000 \\
\hline 109.60 & 404.00 & 2952.00 & .00 & 1.375 & 1.000 \\
\hline 108.50 & 211.00 & 3527.00 & .00 & 1.375 & 1.000 \\
\hline 108.30 & 213.00 & 3522.00 & .00 & 1.375 & 1.000 \\
\hline 109.60 & 306.00 & 3545.00 & .00 & 1.375 & 1.000 \\
\hline 108.90 & 305.00 & 3545.00 & .00 & 1.375 & 1.000 \\
\hline 110.10 & 402.00 & 3580.00 & .00 & 1.375 & 1.000 \\
\hline 110.20 & 402.00 & 3567.00 & .00 & 1.375 & 1.000 \\
\hline 111.80 & 208.00 & 4183.00 & .00 & 1.375 & 1.000 \\
\hline 113.00 & 306.00 & 4181.00 & .00 & 1.375 & 1.000 \\
\hline 111.70 & 309.00 & 4228.00 & .00 & 1.375 & 1.000 \\
\hline 113.00 & 403.00 & 4239.00 & .00 & 1.375 & 1.000 \\
\hline 112.50 & 405.00 & 4360.00 & .00 & 1.375 & 1.000 \\
\hline 111.30 & 511.00 & 4303.00 & .00 & 1.375 & 1.000 \\
\hline 110.00 & 606.00 & 4405.00 & .00 & 1.375 & 1.000 \\
\hline 112.10 & 210.00 & 4842.00 & .00 & 1.375 & 1.000 \\
\hline 112.30 & 307.00 & 4865.00 & .00 & 1.375 & 1.000 \\
\hline 112.70 & 314.00 & 4923.00 & .00 & 1.375 & 1.000 \\
\hline 114.20 & 405.00 & 4886.00 & .00 & 1.375 & 1.000 \\
\hline 111.00 & 509.00 & 5082.00 & .00 & 1.375 & 1.000 \\
\hline 113.60 & 215.00 & 5415.00 & .00 & 1.375 & 1.000 \\
\hline 112.50 & 307.00 & 5438.00 & .00 & 1.375 & 1.000 \\
\hline 113.10 & 403.00 & 5446.00 & .00 & 1.375 & 1.000 \\
\hline 113.40 & 207.00 & 6195.00 & .00 & 1.375 & 1.000 \\
\hline 112.70 & 212.00 & 6242.00 & .00 & 1.375 & 1.000 \\
\hline 114.30 & 312.00 & 6234.00 & .00 & 1.375 & 1.000 \\
\hline 113.10 & 310.00 & 6218.00 & .00 & 1.375 & 1.000 \\
\hline 114.80 & 402.00 & 6167.00 & .00 & 1.375 & 1.000 \\
\hline 114.10 & 402.00 & 6237.00 & .00 & 1.375 & 1.000 \\
\hline 111.40 & 155.00 & 6225.00 & .00 & 1.375 & 1.000 \\
\hline 112.80 & 402.00 & 4180.00 & .00 & 1.375 & 1.000 \\
\hline 110.20 & 318.00 & 2979.00 & .00 & 1.375 & 1.000 \\
\hline 110.00 & 223.00 & 3609.00 & .00 & 1.375 & 1.000 \\
\hline 112.10 & 411.00 & 3625.00 & .00 & 1.375 & 1.000 \\
\hline 112.00 & 405.00 & 3628.00 & .00 & 1.375 & 1.000 \\
\hline 110.50 & 312.00 & 3623.00 & .00 & 1.375 & 1.000 \\
\hline 109.60 & 221.00 & 3615.00 & .00 & 1.375 & 1.000 \\
\hline 109.00 & 206.00 & 2334.00 & .00 & 1.000 & .000 \\
\hline 110.20 & 303.00 & 2333.00 & .00 & 1.000 & .000 \\
\hline 111.00 & 404.00 & 2344.00 & .00 & 1.000 & .000 \\
\hline 110.20 & 506.00 & 2226.00 & .00 & 1.000 & .000 \\
\hline 112.80 & 602.00 & 2241.00 & .00 & 1.000 & .000 \\
\hline 111.30 & 208.00 & 2919.00 & .00 & 1.000 & .000 \\
\hline & & & & & \\
\hline
\end{tabular}




\begin{tabular}{|r|r|r|r|r|r|}
\hline $\begin{array}{c}\text { Sound Power } \\
\text { dBA }\end{array}$ & $\begin{array}{c}\text { Speed } \\
\text { rpm }\end{array}$ & $\begin{array}{c}\text { Thrust } \\
\text { lbs }\end{array}$ & $\begin{array}{c}\text { Water } \\
\text { gpm }\end{array}$ & $\begin{array}{c}\text { Bit Size } \\
\text { in. }\end{array}$ & $\begin{array}{c}\text { Drill Steel } \\
\text { (hex/round }\end{array}$ \\
\hline 112.70 & 305.00 & 2933.00 & .00 & 1.000 & .000 \\
\hline 112.30 & 401.00 & 2955.00 & .00 & 1.000 & .000 \\
\hline 110.50 & 406.00 & 2840.00 & .00 & 1.000 & .000 \\
\hline 111.10 & 508.00 & 2877.00 & .00 & 1.000 & .000 \\
\hline 112.50 & 606.00 & 2890.00 & .00 & 1.000 & .000 \\
\hline 112.70 & 207.00 & 3587.00 & .00 & 1.000 & .000 \\
\hline 111.60 & 209.00 & 3588.00 & .00 & 1.000 & .000 \\
\hline 112.80 & 307.00 & 3622.00 & .00 & 1.000 & .000 \\
\hline 113.40 & 307.00 & 3607.00 & .00 & 1.000 & .000 \\
\hline 113.20 & 400.00 & 3642.00 & .00 & 1.000 & .000 \\
\hline 113.40 & 398.00 & 3660.00 & .00 & 1.000 & .000 \\
\hline 113.60 & 508.00 & 3622.00 & .00 & 1.000 & .000 \\
\hline 112.90 & 606.00 & 3651.00 & .00 & 1.000 & .000 \\
\hline 112.50 & 218.00 & 4294.00 & .00 & 1.000 & .000 \\
\hline 110.80 & 208.00 & 4238.00 & .00 & 1.000 & .000 \\
\hline 113.30 & 305.00 & 4254.00 & .00 & 1.000 & .000 \\
\hline 112.70 & 402.00 & 4258.00 & .00 & 1.000 & .000 \\
\hline 114.00 & 508.00 & 4344.00 & .00 & 1.000 & .000 \\
\hline 112.90 & 607.00 & 4362.00 & .00 & 1.000 & .000 \\
\hline 112.30 & 209.00 & 4818.00 & .00 & 1.000 & .000 \\
\hline 113.00 & 211.00 & 4916.00 & .00 & 1.000 & .000 \\
\hline 113.20 & 306.00 & 4869.00 & .00 & 1.000 & .000 \\
\hline 113.30 & 407.00 & 4898.00 & .00 & 1.000 & .000 \\
\hline 114.30 & 510.00 & 4979.00 & .00 & 1.000 & .000 \\
\hline 113.00 & 607.00 & 4995.00 & .00 & 1.000 & .000 \\
\hline 106.30 & 212.00 & 2283.00 & .00 & 1.375 & .000 \\
\hline 109.50 & 309.00 & 2302.00 & .00 & 1.375 & .000 \\
\hline 110.40 & 402.00 & 2326.00 & .00 & 1.375 & .000 \\
\hline 109.70 & 209.00 & 2892.00 & .00 & 1.375 & .000 \\
\hline 110.40 & 308.00 & 2914.00 & .00 & 1.375 & .000 \\
\hline 113.00 & 405.00 & 2943.00 & .00 & 1.375 & .000 \\
\hline 109.60 & 208.00 & 3559.00 & .00 & 1.375 & .000 \\
\hline 111.90 & 304.00 & 3575.00 & .00 & 1.375 & .000 \\
\hline 112.50 & 313.00 & 3715.00 & .00 & 1.375 & .000 \\
\hline 112.80 & 402.00 & 3591.00 & .00 & 1.375 & .000 \\
\hline 113.30 & 405.00 & 3741.00 & .00 & 1.375 & .000 \\
\hline 112.80 & 214.00 & 4321.00 & .00 & 1.375 & .000 \\
\hline 114.10 & 309.00 & 4316.00 & .00 & 1.375 & .000 \\
\hline 113.30 & 313.00 & 4342.00 & .00 & 1.375 & .000 \\
\hline 114.60 & 402.00 & 4330.00 & .00 & 1.375 & .000 \\
\hline 114.60 & 403.00 & 4357.00 & .00 & 1.375 & .000 \\
\hline 114.70 & 505.00 & 4407.00 & .00 & 1.375 & .000 \\
\hline 114.10 & 604.00 & 4420.00 & .00 & 1.375 & .000 \\
\hline & & & & & \\
\hline
\end{tabular}




\begin{tabular}{|r|r|r|r|r|r|}
\hline $\begin{array}{c}\text { Sound Power } \\
\text { dBA }\end{array}$ & $\begin{array}{c}\text { Speed } \\
\text { rpm }\end{array}$ & $\begin{array}{c}\text { Thrust } \\
\text { lbs }\end{array}$ & $\begin{array}{c}\text { Water } \\
\text { gpm }\end{array}$ & $\begin{array}{c}\text { Bit Size } \\
\text { in. }\end{array}$ & $\begin{array}{c}\text { Drill Steel } \\
\text { (hex/round })\end{array}$ \\
\hline 113.80 & 212.00 & 4979.00 & .00 & 1.375 & .000 \\
\hline 113.80 & 310.00 & 5001.00 & .00 & 1.375 & .000 \\
\hline 113.70 & 309.00 & 4958.00 & .00 & 1.375 & .000 \\
\hline 115.50 & 405.00 & 5047.00 & .00 & 1.375 & .000 \\
\hline 114.30 & 409.00 & 4973.00 & .00 & 1.375 & .000 \\
\hline 114.70 & 511.00 & 4982.00 & .00 & 1.375 & .000 \\
\hline 113.90 & 604.00 & 4992.00 & .00 & 1.375 & .000 \\
\hline 114.10 & 211.00 & 5558.00 & .00 & 1.375 & .000 \\
\hline 113.30 & 218.00 & 5485.00 & .00 & 1.375 & .000 \\
\hline 114.40 & 313.00 & 5497.00 & .00 & 1.375 & .000 \\
\hline 114.30 & 310.00 & 5502.00 & .00 & 1.375 & .000 \\
\hline 116.10 & 405.00 & 5576.00 & .00 & 1.375 & .000 \\
\hline 115.20 & 408.00 & 5510.00 & .00 & 1.375 & .000 \\
\hline 114.70 & 511.00 & 5523.00 & .00 & 1.375 & .000 \\
\hline 113.40 & 600.00 & 5544.00 & .00 & 1.375 & .000 \\
\hline 114.10 & 212.00 & 6342.00 & .00 & 1.375 & .000 \\
\hline 114.60 & 211.00 & 6224.00 & .00 & 1.375 & .000 \\
\hline 115.20 & 311.00 & 6360.00 & .00 & 1.375 & .000 \\
\hline 115.70 & 309.00 & 6234.00 & .00 & 1.375 & .000 \\
\hline 116.20 & 404.00 & 6382.00 & .00 & 1.375 & .000 \\
\hline 115.30 & 402.00 & 6244.00 & .00 & 1.375 & .000 \\
\hline 114.30 & 506.00 & 6256.00 & .00 & 1.375 & .000 \\
\hline 113.20 & 603.00 & 6205.00 & .00 & 1.375 & .000 \\
\hline 102.10 & 207.00 & 2313.00 & 3.00 & 1.000 & 1.000 \\
\hline 102.00 & 211.00 & 2306.00 & 3.00 & 1.000 & 1.000 \\
\hline 102.20 & 309.00 & 2321.00 & 3.00 & 1.000 & 1.000 \\
\hline 104.00 & 308.00 & 2318.00 & 3.00 & 1.000 & 1.000 \\
\hline 102.90 & 402.00 & 2335.00 & 3.00 & 1.000 & 1.000 \\
\hline 105.50 & 405.00 & 2329.00 & 3.00 & 1.000 & 1.000 \\
\hline 102.40 & 503.00 & 2448.00 & 3.00 & 1.000 & 1.000 \\
\hline 103.60 & 605.00 & 2461.00 & 3.00 & 1.000 & 1.000 \\
\hline 103.50 & 205.00 & 2909.00 & 3.00 & 1.000 & 1.000 \\
\hline 104.30 & 311.00 & 3084.00 & 3.00 & 1.000 & 1.000 \\
\hline 104.40 & 312.00 & 3005.00 & 3.00 & 1.000 & 1.000 \\
\hline 103.90 & 402.00 & 2978.00 & 3.00 & 1.000 & 1.000 \\
\hline 103.20 & 403.00 & 3098.00 & 3.00 & 1.000 & 1.000 \\
\hline 105.40 & 508.00 & 3113.00 & 3.00 & 1.000 & 1.000 \\
\hline 102.50 & 507.00 & 3012.00 & 3.00 & 1.000 & 1.000 \\
\hline 105.70 & 605.00 & 3129.00 & 3.00 & 1.000 & 1.000 \\
\hline 104.40 & 201.00 & 3591.00 & 3.00 & 1.000 & 1.000 \\
\hline 106.30 & 308.00 & 3605.00 & 3.00 & 1.000 & 1.000 \\
\hline 105.80 & 314.00 & 3601.00 & 3.00 & 1.000 & 1.000 \\
\hline 106.80 & 401.00 & 3617.00 & 3.00 & 1.000 & 1.000 \\
\hline & & & & & \\
\hline
\end{tabular}




\begin{tabular}{|r|r|r|r|r|r|}
\hline $\begin{array}{c}\text { Sound Power } \\
\text { dBA }\end{array}$ & $\begin{array}{c}\text { Speed } \\
\text { rpm }\end{array}$ & $\begin{array}{c}\text { Thrust } \\
\text { lbs }\end{array}$ & $\begin{array}{c}\text { Water } \\
\text { gpm }\end{array}$ & $\begin{array}{c}\text { Bit Size } \\
\text { in. }\end{array}$ & $\begin{array}{c}\text { Drill Steel } \\
\text { (hex/round) }\end{array}$ \\
\hline 105.90 & 511.00 & 3815.00 & 3.00 & 1.000 & 1.000 \\
\hline 107.70 & 604.00 & 3820.00 & 3.00 & 1.000 & 1.000 \\
\hline 105.80 & 210.00 & 4275.00 & 3.00 & 1.000 & 1.000 \\
\hline 105.70 & 213.00 & 4272.00 & 3.00 & 1.000 & 1.000 \\
\hline 107.00 & 309.00 & 4285.00 & 3.00 & 1.000 & 1.000 \\
\hline 106.50 & 315.00 & 4285.00 & 3.00 & 1.000 & 1.000 \\
\hline 107.30 & 411.00 & 4288.00 & 3.00 & 1.000 & 1.000 \\
\hline 108.60 & 411.00 & 4296.00 & 3.00 & 1.000 & 1.000 \\
\hline 105.80 & 508.00 & 4411.00 & 3.00 & 1.000 & 1.000 \\
\hline 106.70 & 595.00 & 4434.00 & 3.00 & 1.000 & 1.000 \\
\hline 106.20 & 206.00 & 4888.00 & 3.00 & 1.000 & 1.000 \\
\hline 106.30 & 205.00 & 4899.00 & 3.00 & 1.000 & 1.000 \\
\hline 107.60 & 302.00 & 4898.00 & 3.00 & 1.000 & 1.000 \\
\hline 108.20 & 307.00 & 4916.00 & 3.00 & 1.000 & 1.000 \\
\hline 108.10 & 412.00 & 4927.00 & 3.00 & 1.000 & 1.000 \\
\hline 108.90 & 412.00 & 4912.00 & 3.00 & 1.000 & 1.000 \\
\hline 107.10 & 510.00 & 4876.00 & 3.00 & 1.000 & 1.000 \\
\hline 106.20 & 607.00 & 4902.00 & 3.00 & 1.000 & 1.000 \\
\hline 105.80 & 407.00 & 4398.00 & 3.00 & 1.000 & 1.000 \\
\hline 105.00 & 212.00 & 4371.00 & 3.00 & 1.000 & 1.000 \\
\hline 106.10 & 400.00 & 3028.00 & 3.00 & 1.000 & 1.000 \\
\hline 103.40 & 304.00 & 2953.00 & 3.00 & 1.000 & 1.000 \\
\hline 102.70 & 215.00 & 4368.00 & 3.00 & 1.000 & 1.000 \\
\hline 103.50 & 305.00 & 2985.00 & 3.00 & 1.000 & 1.000 \\
\hline 104.90 & 210.00 & 2335.00 & 3.00 & 1.375 & 1.000 \\
\hline 103.90 & 208.00 & 2337.00 & 3.00 & 1.375 & 1.000 \\
\hline 104.30 & 310.00 & 2340.00 & 3.00 & 1.375 & 1.000 \\
\hline 105.00 & 311.00 & 2337.00 & 3.00 & 1.375 & 1.000 \\
\hline 106.60 & 406.00 & 2351.00 & 3.00 & 1.375 & 1.000 \\
\hline 105.50 & 407.00 & 2347.00 & 3.00 & 1.375 & 1.000 \\
\hline 103.50 & 211.00 & 2916.00 & 3.00 & 1.375 & 1.000 \\
\hline 103.60 & 209.00 & 2915.00 & 3.00 & 1.375 & 1.000 \\
\hline 104.90 & 305.00 & 2937.00 & 3.00 & 1.375 & 1.000 \\
\hline 104.50 & 305.00 & 2935.00 & 3.00 & 1.375 & 1.000 \\
\hline 106.10 & 411.00 & 2959.00 & 3.00 & 1.375 & 1.000 \\
\hline 106.70 & 411.00 & 2955.00 & 3.00 & 1.375 & 1.000 \\
\hline 105.90 & 218.00 & 3611.00 & 3.00 & 1.375 & 1.000 \\
\hline 105.30 & 214.00 & 3609.00 & 3.00 & 1.375 & 1.000 \\
\hline 105.10 & 313.00 & 3623.00 & 3.00 & 1.375 & 1.000 \\
\hline 106.00 & 311.00 & 3621.00 & 3.00 & 1.375 & 1.000 \\
\hline 108.00 & 408.00 & 3709.00 & 3.00 & 1.375 & 1.000 \\
\hline 108.50 & 411.00 & 3701.00 & 3.00 & 1.375 & 1.000 \\
\hline 106.80 & 217.00 & 4187.00 & 3.00 & 1.375 & 1.000 \\
\hline & & & & & \\
\hline
\end{tabular}




\begin{tabular}{|r|r|r|r|r|r|}
\hline $\begin{array}{c}\text { Sound Power } \\
\text { dBA }\end{array}$ & $\begin{array}{c}\text { Speed } \\
\text { rpm }\end{array}$ & $\begin{array}{c}\text { Thrust } \\
\text { lbs }\end{array}$ & $\begin{array}{c}\text { Water } \\
\text { gpm }\end{array}$ & $\begin{array}{c}\text { Bit Size } \\
\text { in. }\end{array}$ & $\begin{array}{c}\text { Drill Steel } \\
\text { (hex/round) }\end{array}$ \\
\hline 106.00 & 215.00 & 4188.00 & 3.00 & 1.375 & 1.000 \\
\hline 108.10 & 313.00 & 4210.00 & 3.00 & 1.375 & 1.000 \\
\hline 107.60 & 307.00 & 4202.00 & 3.00 & 1.375 & 1.000 \\
\hline 108.80 & 408.00 & 4233.00 & 3.00 & 1.375 & 1.000 \\
\hline 108.90 & 407.00 & 4230.00 & 3.00 & 1.375 & 1.000 \\
\hline 108.90 & 510.00 & 4456.00 & 3.00 & 1.375 & 1.000 \\
\hline 109.20 & 603.00 & 4485.00 & 3.00 & 1.375 & 1.000 \\
\hline 106.50 & 211.00 & 4833.00 & 3.00 & 1.375 & 1.000 \\
\hline 106.30 & 217.00 & 4808.00 & 3.00 & 1.375 & 1.000 \\
\hline 108.50 & 309.00 & 4816.00 & 3.00 & 1.375 & 1.000 \\
\hline 107.40 & 310.00 & 4826.00 & 3.00 & 1.375 & 1.000 \\
\hline 107.40 & 403.00 & 4839.00 & 3.00 & 1.375 & 1.000 \\
\hline 108.30 & 403.00 & 4840.00 & 3.00 & 1.375 & 1.000 \\
\hline 109.80 & 506.00 & 5110.00 & 3.00 & 1.375 & 1.000 \\
\hline 110.80 & 604.00 & 5136.00 & 3.00 & 1.375 & 1.000 \\
\hline 108.00 & 210.00 & 5649.00 & 3.00 & 1.375 & 1.000 \\
\hline 107.30 & 212.00 & 5644.00 & 3.00 & 1.375 & 1.000 \\
\hline 109.20 & 311.00 & 5662.00 & 3.00 & 1.375 & 1.000 \\
\hline 108.60 & 310.00 & 5512.00 & 3.00 & 1.375 & 1.000 \\
\hline 110.20 & 411.00 & 5669.00 & 3.00 & 1.375 & 1.000 \\
\hline 108.70 & 401.00 & 5666.00 & 3.00 & 1.375 & 1.000 \\
\hline 110.30 & 507.00 & 5740.00 & 3.00 & 1.375 & 1.000 \\
\hline 110.40 & 604.00 & 5755.00 & 3.00 & 1.375 & 1.000 \\
\hline 108.00 & 206.00 & 6298.00 & 3.00 & 1.375 & 1.000 \\
\hline 109.40 & 178.00 & 6270.00 & 3.00 & 1.375 & 1.000 \\
\hline 109.70 & 308.00 & 6307.00 & 3.00 & 1.375 & 1.000 \\
\hline 109.00 & 307.00 & 6143.00 & 3.00 & 1.375 & 1.000 \\
\hline 109.60 & 407.00 & 6320.00 & 3.00 & 1.375 & 1.000 \\
\hline 109.30 & 402.00 & 6148.00 & 3.00 & 1.375 & 1.000 \\
\hline 108.40 & 504.00 & 6161.00 & 3.00 & 1.375 & 1.000 \\
\hline 109.40 & 601.00 & 6369.00 & 3.00 & 1.375 & 1.000 \\
\hline 110.40 & 578.00 & 6311.00 & 3.00 & 1.375 & 1.000 \\
\hline 108.60 & 310.00 & 6230.00 & 3.00 & 1.375 & 1.000 \\
\hline 110.70 & 506.00 & 6009.00 & 3.00 & 1.375 & 1.000 \\
\hline 109.90 & 562.00 & 6018.00 & 3.00 & 1.375 & 1.000 \\
\hline 109.10 & 565.00 & 5692.00 & 3.00 & 1.375 & 1.000 \\
\hline 108.80 & 571.00 & 5286.00 & 3.00 & 1.375 & 1.000 \\
\hline 108.60 & 472.00 & 5270.00 & 3.00 & 1.375 & 1.000 \\
\hline 108.30 & 415.00 & 5249.00 & 3.00 & 1.375 & 1.000 \\
\hline 108.40 & 332.00 & 5229.00 & 3.00 & 1.375 & 1.000 \\
\hline 110.00 & 544.00 & 4868.00 & 3.00 & 1.375 & 1.000 \\
\hline 110.90 & 577.00 & 4554.00 & 3.00 & 1.375 & 1.000 \\
\hline 109.40 & 579.00 & 4223.00 & 3.00 & 1.375 & 1.000 \\
\hline & & & & & \\
\hline
\end{tabular}




\begin{tabular}{|r|r|r|r|r|r|}
\hline $\begin{array}{c}\text { Sound Power } \\
\text { dBA }\end{array}$ & $\begin{array}{c}\text { Speed } \\
\text { rpm }\end{array}$ & $\begin{array}{c}\text { Thrust } \\
\text { lbs }\end{array}$ & $\begin{array}{c}\text { Water } \\
\text { gpm }\end{array}$ & $\begin{array}{c}\text { Bit Size } \\
\text { in. }\end{array}$ & $\begin{array}{c}\text { Drill Steel } \\
\text { (hex/round) }\end{array}$ \\
\hline 107.70 & 572.00 & 3987.00 & 3.00 & 1.375 & 1.000 \\
\hline 109.40 & 582.00 & 3734.00 & 3.00 & 1.375 & 1.000 \\
\hline 108.60 & 577.00 & 4892.00 & 3.00 & 1.375 & 1.000 \\
\hline 109.10 & 408.00 & 3703.00 & 3.00 & 1.375 & 1.000 \\
\hline 109.70 & 313.00 & 4210.00 & 3.00 & 1.375 & 1.000 \\
\hline 110.30 & 413.00 & 4233.00 & 3.00 & 1.375 & 1.000 \\
\hline 108.80 & 405.00 & 4841.00 & 3.00 & 1.375 & 1.000 \\
\hline 106.10 & 214.00 & 5496.00 & 3.00 & 1.375 & 1.000 \\
\hline 108.70 & 301.00 & 5653.00 & 3.00 & 1.375 & 1.000 \\
\hline 108.70 & 310.00 & 5653.00 & 3.00 & 1.375 & 1.000 \\
\hline 110.40 & 409.00 & 5661.00 & 3.00 & 1.375 & 1.000 \\
\hline 109.30 & 300.00 & 5711.00 & 3.00 & 1.375 & 1.000 \\
\hline 110.50 & 202.00 & 5057.00 & 3.00 & 1.375 & 1.000 \\
\hline 100.60 & 207.00 & 2314.00 & 3.00 & 1.000 & .000 \\
\hline 100.50 & 315.00 & 2332.00 & 3.00 & 1.000 & .000 \\
\hline 103.80 & 404.00 & 2347.00 & 3.00 & 1.000 & .000 \\
\hline 105.60 & 508.00 & 2295.00 & 3.00 & 1.000 & .000 \\
\hline 105.90 & 607.00 & 2306.00 & 3.00 & 1.000 & .000 \\
\hline 101.50 & 214.00 & 2924.00 & 3.00 & 1.000 & .000 \\
\hline 104.20 & 198.00 & 2932.00 & 3.00 & 1.000 & .000 \\
\hline 102.80 & 306.00 & 2939.00 & 3.00 & 1.000 & .000 \\
\hline 104.80 & 406.00 & 2957.00 & 3.00 & 1.000 & .000 \\
\hline 105.70 & 403.00 & 3121.00 & 3.00 & 1.000 & .000 \\
\hline 107.70 & 507.00 & 3135.00 & 3.00 & 1.000 & .000 \\
\hline 107.20 & 602.00 & 3147.00 & 3.00 & 1.000 & .000 \\
\hline 103.80 & 215.00 & 3670.00 & 3.00 & 1.000 & .000 \\
\hline 103.90 & 204.00 & 3665.00 & 3.00 & 1.000 & .000 \\
\hline 105.30 & 316.00 & 3715.00 & 3.00 & 1.000 & .000 \\
\hline 105.90 & 304.00 & 3720.00 & 3.00 & 1.000 & .000 \\
\hline 108.20 & 409.00 & 3578.00 & 3.00 & 1.000 & .000 \\
\hline 107.90 & 402.00 & 3581.00 & 3.00 & 1.000 & .000 \\
\hline 107.50 & 517.00 & 3741.00 & 3.00 & 1.000 & .000 \\
\hline 108.30 & 504.00 & 3644.00 & 3.00 & 1.000 & .000 \\
\hline 108.30 & 606.00 & 3755.00 & 3.00 & 1.000 & .000 \\
\hline 106.90 & 605.00 & 3657.00 & 3.00 & 1.000 & .000 \\
\hline 101.70 & 202.00 & 4273.00 & 3.00 & 1.000 & .000 \\
\hline 105.20 & 216.00 & 4349.00 & 3.00 & 1.000 & .000 \\
\hline 103.80 & 310.00 & 4272.00 & 3.00 & 1.000 & .000 \\
\hline 106.10 & 412.00 & 4297.00 & 3.00 & 1.000 & .000 \\
\hline 104.80 & 398.00 & 4296.00 & 3.00 & 1.000 & .000 \\
\hline 108.10 & 511.00 & 4382.00 & 3.00 & 1.000 & .000 \\
\hline 108.40 & 614.00 & 4392.00 & 3.00 & 1.000 & .000 \\
\hline 105.10 & 215.00 & 4793.00 & 3.00 & 1.000 & .000 \\
\hline & & & & & \\
\hline
\end{tabular}




\begin{tabular}{|r|r|r|r|r|r|}
\hline $\begin{array}{c}\text { Sound Power } \\
\text { dBA }\end{array}$ & $\begin{array}{c}\text { Speed } \\
\text { rpm }\end{array}$ & $\begin{array}{c}\text { Thrust } \\
\text { lbs }\end{array}$ & $\begin{array}{c}\text { Water } \\
\text { gpm }\end{array}$ & $\begin{array}{c}\text { Bit Size } \\
\text { in. }\end{array}$ & $\begin{array}{c}\text { Drill Steel } \\
\text { (hex/round }\end{array}$ \\
\hline 104.70 & 209.00 & 4930.00 & 3.00 & 1.000 & .000 \\
\hline 105.60 & 306.00 & 4940.00 & 3.00 & 1.000 & .000 \\
\hline 105.50 & 314.00 & 4806.00 & 3.00 & 1.000 & .000 \\
\hline 105.70 & 414.00 & 4944.00 & 3.00 & 1.000 & .000 \\
\hline 108.10 & 509.00 & 4831.00 & 3.00 & 1.000 & .000 \\
\hline 108.30 & 578.00 & 4850.00 & 3.00 & 1.000 & .000 \\
\hline 105.20 & 409.00 & 3696.00 & 3.00 & 1.000 & .000 \\
\hline 104.00 & 201.00 & 4694.00 & 3.00 & 1.000 & .000 \\
\hline 106.70 & 401.00 & 3726.00 & 3.00 & 1.000 & .000 \\
\hline 103.70 & 319.00 & 3682.00 & 3.00 & 1.000 & .000 \\
\hline 106.60 & 403.00 & 2957.00 & 3.00 & 1.000 & .000 \\
\hline 104.30 & 307.00 & 3618.00 & 3.00 & 1.000 & .000 \\
\hline 106.20 & 400.00 & 3635.00 & 3.00 & 1.000 & .000 \\
\hline 104.20 & 209.00 & 2338.00 & 3.00 & 1.375 & .000 \\
\hline 105.00 & 311.00 & 2360.00 & 3.00 & 1.375 & .000 \\
\hline 106.10 & 403.00 & 2378.00 & 3.00 & 1.375 & .000 \\
\hline 104.20 & 213.00 & 2915.00 & 3.00 & 1.375 & .000 \\
\hline 106.30 & 309.00 & 2937.00 & 3.00 & 1.375 & .000 \\
\hline 107.00 & 402.00 & 2961.00 & 3.00 & 1.375 & .000 \\
\hline 104.90 & 209.00 & 3593.00 & 3.00 & 1.375 & .000 \\
\hline 105.00 & 312.00 & 3606.00 & 3.00 & 1.375 & .000 \\
\hline 106.10 & 400.00 & 3622.00 & 3.00 & 1.375 & .000 \\
\hline 104.90 & 212.00 & 4402.00 & 3.00 & 1.375 & .000 \\
\hline 105.70 & 208.00 & 4207.00 & 3.00 & 1.375 & .000 \\
\hline 106.80 & 302.00 & 4227.00 & 3.00 & 1.375 & .000 \\
\hline 106.40 & 309.00 & 4277.00 & 3.00 & 1.375 & .000 \\
\hline 107.50 & 411.00 & 4258.00 & 3.00 & 1.375 & .000 \\
\hline 107.60 & 398.00 & 4286.00 & 3.00 & 1.375 & .000 \\
\hline 108.00 & 505.00 & 4454.00 & 3.00 & 1.375 & .000 \\
\hline 109.20 & 604.00 & 4478.00 & 3.00 & 1.375 & .000 \\
\hline 106.40 & 207.00 & 4848.00 & 3.00 & 1.375 & .000 \\
\hline 106.40 & 206.00 & 4846.00 & 3.00 & 1.375 & .000 \\
\hline 107.90 & 315.00 & 4859.00 & 3.00 & 1.375 & .000 \\
\hline 107.50 & 313.00 & 4852.00 & 3.00 & 1.375 & .000 \\
\hline 110.50 & 407.00 & 4867.00 & 3.00 & 1.375 & .000 \\
\hline 107.20 & 401.00 & 5000.00 & 3.00 & 1.375 & .000 \\
\hline 108.00 & 506.00 & 5014.00 & 3.00 & 1.375 & .000 \\
\hline 109.10 & 602.00 & 5027.00 & 3.00 & 1.375 & .000 \\
\hline 107.50 & 201.00 & 5435.00 & 3.00 & 1.375 & .000 \\
\hline 106.90 & 216.00 & 5595.00 & 3.00 & 1.375 & .000 \\
\hline 109.30 & 315.00 & 5539.00 & 3.00 & 1.375 & .000 \\
\hline 108.60 & 308.00 & 5539.00 & 3.00 & 1.375 & .000 \\
\hline 108.80 & 413.00 & 5561.00 & 3.00 & 1.375 & .000 \\
\hline & & & & & \\
\hline
\end{tabular}




\begin{tabular}{|r|r|r|r|r|r|}
\hline $\begin{array}{c}\text { Sound Power } \\
\text { dBA }\end{array}$ & $\begin{array}{c}\text { Speed } \\
\text { rpm }\end{array}$ & $\begin{array}{c}\text { Thrust } \\
\text { lbs }\end{array}$ & $\begin{array}{c}\text { Water } \\
\text { gpm }\end{array}$ & $\begin{array}{c}\text { Bit Size } \\
\text { in. }\end{array}$ & $\begin{array}{c}\text { Drill Steel } \\
\text { (hex/round }\end{array}$ \\
\hline 109.20 & 424.00 & 5586.00 & 3.00 & 1.375 & .000 \\
\hline 109.00 & 510.00 & 5642.00 & 3.00 & 1.375 & .000 \\
\hline 108.90 & 604.00 & 5664.00 & 3.00 & 1.375 & .000 \\
\hline 108.60 & 204.00 & 6200.00 & 3.00 & 1.375 & .000 \\
\hline 107.70 & 196.00 & 6155.00 & 3.00 & 1.375 & .000 \\
\hline 108.80 & 316.00 & 6197.00 & 3.00 & 1.375 & .000 \\
\hline 109.10 & 304.00 & 6137.00 & 3.00 & 1.375 & .000 \\
\hline 110.80 & 405.00 & 6219.00 & 3.00 & 1.375 & .000 \\
\hline 110.00 & 408.00 & 6213.00 & 3.00 & 1.375 & .000 \\
\hline 109.40 & 508.00 & 6334.00 & 3.00 & 1.375 & .000 \\
\hline 110.20 & 598.00 & 6323.00 & 3.00 & 1.375 & .000 \\
\hline 110.70 & 604.00 & 6346.00 & 3.00 & 1.375 & .000 \\
\hline 112.20 & 556.00 & 6299.00 & 3.00 & 1.375 & .000 \\
\hline 110.50 & 453.00 & 6274.00 & 3.00 & 1.375 & .000 \\
\hline 108.50 & 436.00 & 6007.00 & 3.00 & 1.375 & .000 \\
\hline 109.00 & 561.00 & 6020.00 & 3.00 & 1.375 & .000 \\
\hline 108.60 & 543.00 & 5694.00 & 3.00 & 1.375 & .000 \\
\hline 108.90 & 428.00 & 5668.00 & 3.00 & 1.375 & .000 \\
\hline 108.10 & 428.00 & 5266.00 & 3.00 & 1.375 & .000 \\
\hline 109.30 & 579.00 & 5280.00 & 3.00 & 1.375 & .000 \\
\hline 109.00 & 453.00 & 6004.00 & 3.00 & 1.375 & .000 \\
\hline 108.40 & 596.00 & 4993.00 & 3.00 & 1.375 & .000 \\
\hline 108.10 & 481.00 & 4969.00 & 3.00 & 1.375 & .000 \\
\hline 107.50 & 401.00 & 4933.00 & 3.00 & 1.375 & .000 \\
\hline 107.30 & 403.00 & 4610.00 & 3.00 & 1.375 & .000 \\
\hline 107.70 & 484.00 & 4622.00 & 3.00 & 1.375 & .000 \\
\hline 109.00 & 590.00 & 4636.00 & 3.00 & 1.375 & .000 \\
\hline 108.50 & 586.00 & 4348.00 & 3.00 & 1.375 & .000 \\
\hline 110.20 & 473.00 & 4216.00 & 3.00 & 1.375 & .000 \\
\hline 106.10 & 376.00 & 4179.00 & 3.00 & 1.375 & .000 \\
\hline 107.90 & 475.00 & 3714.00 & 3.00 & 1.375 & .000 \\
\hline 110.10 & 555.00 & 3728.00 & 3.00 & 1.375 & .000 \\
\hline 109.60 & 510.00 & 3709.00 & 3.00 & 1.375 & .000 \\
\hline 109.00 & 213.00 & 4836.00 & 3.00 & 1.375 & .000 \\
\hline 109.80 & 304.00 & 4853.00 & 3.00 & 1.375 & .000 \\
\hline 107.90 & 304.00 & 5453.00 & 3.00 & 1.375 & .000 \\
\hline 110.40 & 405.00 & 5468.00 & 3.00 & 1.375 & .000 \\
\hline 106.30 & 403.00 & 4432.00 & 3.00 & 1.375 & .000 \\
\hline 105.20 & 205.00 & 4265.00 & 3.00 & 1.375 & .000 \\
\hline 105.60 & 213.00 & 4971.00 & 3.00 & 1.375 & .000 \\
\hline 106.30 & 210.00 & 5523.00 & 3.00 & 1.375 & .000 \\
\hline 108.00 & 401.00 & 5624.00 & 3.00 & 1.375 & .000 \\
\hline 106.90 & 405.00 & 6231.00 & 3.00 & 1.375 & .000 \\
\hline & & & & & \\
\hline
\end{tabular}




\begin{tabular}{|r|r|r|r|r|r|}
\hline $\begin{array}{c}\text { Sound Power } \\
\text { dBA }\end{array}$ & $\begin{array}{c}\text { Speed } \\
\text { rpm }\end{array}$ & $\begin{array}{c}\text { Thrust } \\
\text { lbs }\end{array}$ & $\begin{array}{c}\text { Water } \\
\text { gpm }\end{array}$ & $\begin{array}{c}\text { Bit Size } \\
\text { in. }\end{array}$ & $\begin{array}{c}\text { Drill Steel } \\
\text { (hex/round) }\end{array}$ \\
\hline 107.30 & 218.00 & 6210.00 & 3.00 & 1.375 & .000 \\
\hline 104.60 & 214.00 & 2418.00 & .75 & 1.000 & 1.000 \\
\hline 105.80 & 307.00 & 2432.00 & .75 & 1.000 & 1.000 \\
\hline 106.70 & 402.00 & 2445.00 & .75 & 1.000 & 1.000 \\
\hline 107.40 & 507.00 & 2458.00 & .75 & 1.000 & 1.000 \\
\hline 107.70 & 593.00 & 2472.00 & .75 & 1.000 & 1.000 \\
\hline 104.50 & 216.00 & 2978.00 & .75 & 1.000 & 1.000 \\
\hline 107.10 & 301.00 & 2993.00 & .75 & 1.000 & 1.000 \\
\hline 107.90 & 408.00 & 3004.00 & .75 & 1.000 & 1.000 \\
\hline 108.50 & 510.00 & 3004.00 & .75 & 1.000 & 1.000 \\
\hline 109.20 & 605.00 & 3012.00 & .75 & 1.000 & 1.000 \\
\hline 106.30 & 213.00 & 3685.00 & .75 & 1.000 & 1.000 \\
\hline 108.50 & 306.00 & 3700.00 & .75 & 1.000 & 1.000 \\
\hline 109.10 & 404.00 & 3716.00 & .75 & 1.000 & 1.000 \\
\hline 109.70 & 509.00 & 3734.00 & .75 & 1.000 & 1.000 \\
\hline 110.10 & 607.00 & 3758.00 & .75 & 1.000 & 1.000 \\
\hline 107.90 & 216.00 & 4335.00 & .75 & 1.000 & 1.000 \\
\hline 109.20 & 305.00 & 4350.00 & .75 & 1.000 & 1.000 \\
\hline 110.50 & 407.00 & 4364.00 & .75 & 1.000 & 1.000 \\
\hline 111.10 & 508.00 & 4381.00 & .75 & 1.000 & 1.000 \\
\hline 111.20 & 606.00 & 4397.00 & .75 & 1.000 & 1.000 \\
\hline 108.90 & 210.00 & 4928.00 & .75 & 1.000 & 1.000 \\
\hline 110.20 & 307.00 & 4947.00 & .75 & 1.000 & 1.000 \\
\hline 110.90 & 405.00 & 4966.00 & .75 & 1.000 & 1.000 \\
\hline 112.20 & 502.00 & 4994.00 & .75 & 1.000 & 1.000 \\
\hline 112.50 & 584.00 & 4825.00 & .75 & 1.000 & 1.000 \\
\hline 108.40 & 219.00 & 3748.00 & .75 & 1.375 & 1.000 \\
\hline 109.70 & 310.00 & 3752.00 & .75 & 1.375 & 1.000 \\
\hline 111.10 & 402.00 & 3756.00 & .75 & 1.375 & 1.000 \\
\hline 111.80 & 510.00 & 3779.00 & .75 & 1.375 & 1.000 \\
\hline 112.60 & 606.00 & 3789.00 & .75 & 1.375 & 1.000 \\
\hline 110.90 & 214.00 & 4352.00 & .75 & 1.375 & 1.000 \\
\hline 112.00 & 311.00 & 4361.00 & .75 & 1.375 & 1.000 \\
\hline 112.50 & 406.00 & 4371.00 & .75 & 1.375 & 1.000 \\
\hline 112.70 & 510.00 & 4383.00 & .75 & 1.375 & 1.000 \\
\hline 113.10 & 609.00 & 4396.00 & .75 & 1.375 & 1.000 \\
\hline 111.50 & 218.00 & 4953.00 & .75 & 1.375 & 1.000 \\
\hline 111.30 & 309.00 & 4965.00 & .75 & 1.375 & 1.000 \\
\hline 112.10 & 401.00 & 4967.00 & .75 & 1.375 & 1.000 \\
\hline 112.60 & 512.00 & 4986.00 & .75 & 1.375 & 1.000 \\
\hline 113.40 & 607.00 & 5007.00 & .75 & 1.375 & 1.000 \\
\hline 111.80 & 216.00 & 5523.00 & .75 & 1.375 & 1.000 \\
\hline 110.40 & 312.00 & 5528.00 & .75 & 1.375 & 1.000 \\
\hline & & & & & \\
\hline
\end{tabular}




\begin{tabular}{|r|r|r|r|r|r|}
\hline $\begin{array}{c}\text { Sound Power } \\
\text { dBA }\end{array}$ & $\begin{array}{c}\text { Speed } \\
\text { rpm }\end{array}$ & $\begin{array}{c}\text { Thrust } \\
\text { lbs }\end{array}$ & $\begin{array}{c}\text { Water } \\
\text { gpm }\end{array}$ & $\begin{array}{c}\text { Bit Size } \\
\text { in. }\end{array}$ & $\begin{array}{c}\text { Drill Steel } \\
\text { (hex/round }\end{array}$ \\
\hline 113.60 & 403.00 & 5942.00 & .75 & 1.375 & 1.000 \\
\hline 113.60 & 510.00 & 5558.00 & .75 & 1.375 & 1.000 \\
\hline 114.80 & 608.00 & 5569.00 & .75 & 1.375 & 1.000 \\
\hline 109.80 & 218.00 & 6244.00 & .75 & 1.375 & 1.000 \\
\hline 111.20 & 309.00 & 6256.00 & .75 & 1.375 & 1.000 \\
\hline 112.90 & 401.00 & 6275.00 & .75 & 1.375 & 1.000 \\
\hline 114.30 & 509.00 & 6294.00 & .75 & 1.375 & 1.000 \\
\hline 113.40 & 608.00 & 6317.00 & .75 & 1.375 & 1.000 \\
\hline 107.20 & 216.00 & 2347.00 & .75 & 1.000 & .000 \\
\hline 108.09 & 307.00 & 2357.00 & .75 & 1.000 & .000 \\
\hline 109.04 & 405.00 & 2370.00 & .75 & 1.000 & .000 \\
\hline 110.04 & 508.00 & 2387.00 & .75 & 1.000 & .000 \\
\hline 111.00 & 607.00 & 2404.00 & .75 & 1.000 & .000 \\
\hline 108.07 & 216.00 & 2989.00 & .75 & 1.000 & .000 \\
\hline 108.86 & 308.00 & 2999.00 & .75 & 1.000 & .000 \\
\hline 109.69 & 406.00 & 3008.00 & .75 & 1.000 & .000 \\
\hline 110.54 & 505.00 & 3022.00 & .75 & 1.000 & .000 \\
\hline 111.39 & 606.00 & 3036.00 & .75 & 1.000 & .000 \\
\hline 109.02 & 218.00 & 3686.00 & .75 & 1.000 & .000 \\
\hline 109.64 & 302.00 & 3699.00 & .75 & 1.000 & .000 \\
\hline 110.38 & 404.00 & 3709.00 & .75 & 1.000 & .000 \\
\hline 111.09 & 501.00 & 3723.00 & .75 & 1.000 & .000 \\
\hline 111.83 & 604.00 & 3738.00 & .75 & 1.000 & .000 \\
\hline 109.68 & 204.00 & 4239.00 & .75 & 1.000 & .000 \\
\hline 110.34 & 309.00 & 4247.00 & .75 & 1.000 & .000 \\
\hline 110.93 & 404.00 & 4257.00 & .75 & 1.000 & .000 \\
\hline 111.58 & 508.00 & 4269.00 & .75 & 1.000 & .000 \\
\hline 112.19 & 606.00 & 4278.00 & .75 & 1.000 & .000 \\
\hline 110.63 & 212.00 & 4899.00 & .75 & 1.000 & .000 \\
\hline 111.14 & 310.00 & 4916.00 & .75 & 1.000 & .000 \\
\hline 111.59 & 403.00 & 4909.00 & .75 & 1.000 & .000 \\
\hline 112.11 & 506.00 & 4929.00 & .75 & 1.000 & .000 \\
\hline 112.63 & 608.00 & 4955.00 & .75 & 1.000 & .000 \\
\hline 107.90 & 213.00 & 3680.00 & .75 & 1.375 & .000 \\
\hline 109.90 & 305.00 & 3692.00 & .75 & 1.375 & .000 \\
\hline 111.70 & 403.00 & 3717.00 & .75 & 1.375 & .000 \\
\hline 112.90 & 509.00 & 3736.00 & .75 & 1.375 & .000 \\
\hline 113.30 & 606.00 & 3752.00 & .75 & 1.375 & .000 \\
\hline 108.70 & 213.00 & 4298.00 & .75 & 1.375 & .000 \\
\hline 111.60 & 314.00 & 4310.00 & .75 & 1.375 & .000 \\
\hline 112.50 & 402.00 & 4326.00 & .75 & 1.375 & .000 \\
\hline 114.00 & 508.00 & 4338.00 & .75 & 1.375 & .000 \\
\hline 114.80 & 607.00 & 4357.00 & .75 & 1.375 & .000 \\
\hline & & & & & \\
\hline
\end{tabular}




\begin{tabular}{|r|r|r|r|r|r|}
\hline $\begin{array}{c}\text { Sound Power } \\
\text { dBA }\end{array}$ & $\begin{array}{c}\text { Speed } \\
\text { rpm }\end{array}$ & $\begin{array}{c}\text { Thrust } \\
\text { lbs }\end{array}$ & $\begin{array}{c}\text { Water } \\
\text { gpm }\end{array}$ & $\begin{array}{c}\text { Bit Size } \\
\text { in. }\end{array}$ & $\begin{array}{c}\text { Drill Steel } \\
\text { (hex/round) }\end{array}$ \\
\hline 107.30 & 212.00 & 4977.00 & .75 & 1.375 & .000 \\
\hline 108.00 & 303.00 & 4998.00 & .75 & 1.375 & .000 \\
\hline 112.30 & 398.00 & 5013.00 & .75 & 1.375 & .000 \\
\hline 114.20 & 511.00 & 5037.00 & .75 & 1.375 & .000 \\
\hline 116.20 & 606.00 & 5060.00 & .75 & 1.375 & .000 \\
\hline 110.50 & 211.00 & 5617.00 & .75 & 1.375 & .000 \\
\hline 113.10 & 306.00 & 5632.00 & .75 & 1.375 & .000 \\
\hline 113.60 & 404.00 & 5646.00 & .75 & 1.375 & .000 \\
\hline 117.00 & 512.00 & 5671.00 & .75 & 1.375 & .000 \\
\hline 116.10 & 595.00 & 5686.00 & .75 & 1.375 & .000 \\
\hline 111.90 & 212.00 & 6260.00 & .75 & 1.375 & .000 \\
\hline 113.60 & 312.00 & 6287.00 & .75 & 1.375 & .000 \\
\hline 114.90 & 404.00 & 6317.00 & .75 & 1.375 & .000 \\
\hline 115.90 & 507.00 & 6347.00 & .75 & 1.375 & .000 \\
\hline 116.90 & 598.00 & 6306.00 & .75 & 1.375 & .000 \\
\hline & & & & & \\
\hline
\end{tabular}

Utilizing the sound power level as the dependent variable and the rotational speed, thrust, drilling method, bit size and drill steel type as the independent variables, a statistical approach utilizing a multiple linear regression analysis, was performed to fit the data and to provide an accurate representation for obtaining one equation to determine the sound power level given any drilling method or drilling configuration used. Table 5.16 represents the regression coefficients determined from the statistical model run.

Table 5.16 Regression Coefficients Determined from the Statistical Model

\begin{tabular}{|l|r|}
\hline (Constant) & 101.708 \\
Water & -1.766 \\
Thrust & .001 \\
Speed & .007 \\
Bit Size & 2.568 \\
Drill Steel & -.640 \\
\hline
\end{tabular}

\subsubsection{Statistical Accuracy of the Model}

The statistical accuracy of the data fit is shown in the histogram below (figure 5.8) and tabulated in table 5.17. Additionally, $\mathrm{R}^{2}$, the coefficient of determination, or the measure of the 
goodness of fit of a linear model, was equal to .849 , indicating the model to be a good fit or representation of the data set.

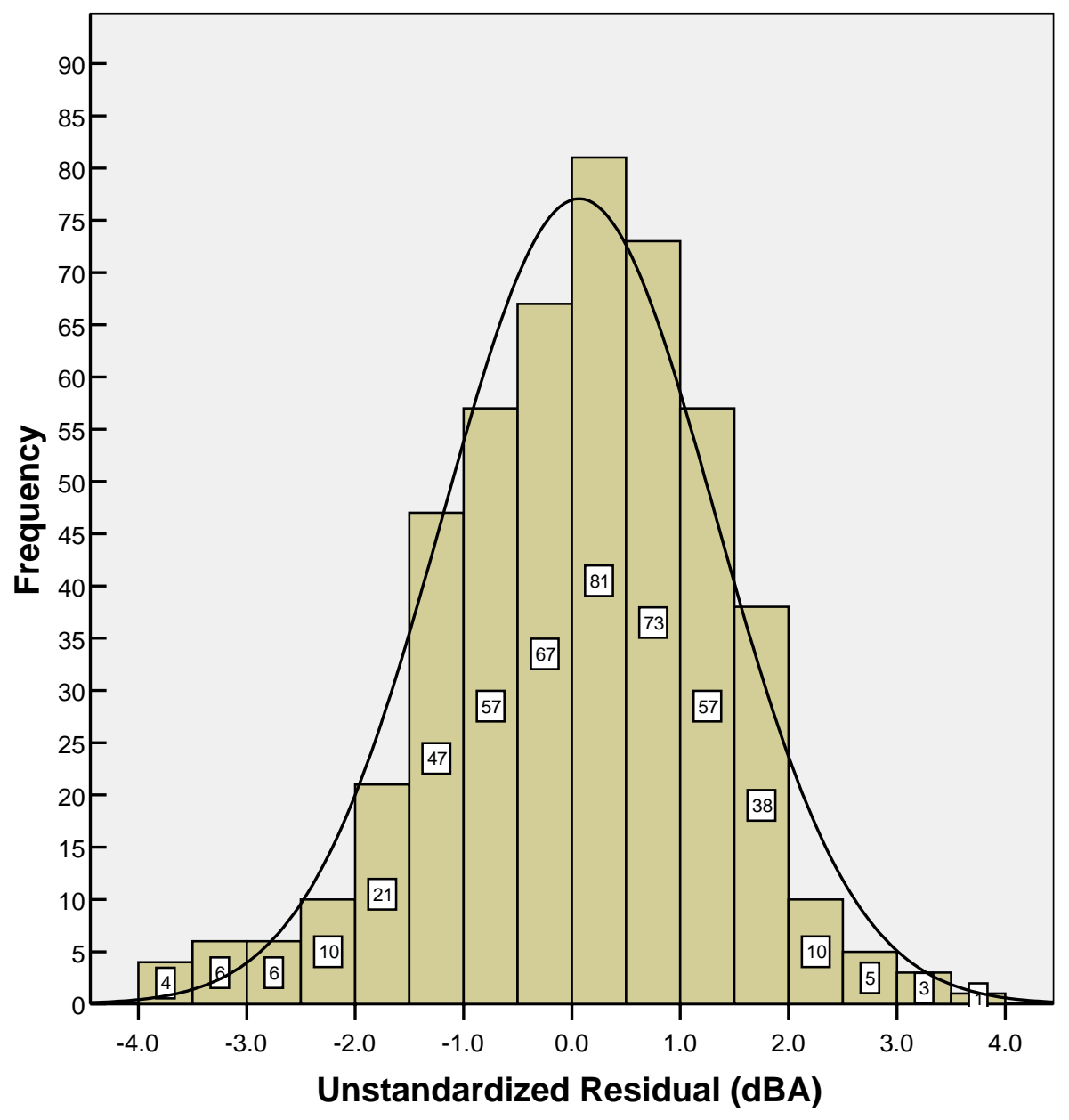

Figure 5.8 Histogram Representing the Fit Accuracy of Statistical Run of Model

As shown in figure 5.8, the data follows a nice "bell-shaped" curve, indicating the data set is normally distributed. Also, figure 5.8 displays, graphically, the residuals (laboratory minus model values of sound power) from the data set. As shown, five residuals were determined to be plus or minus 3.5 to $4.0 \mathrm{dBA}$ and nine residuals at plus or minus 3.0 to $3.5 \mathrm{dBA}$. The remaining 472 residuals all fell within plus or minus 0 to $3.0 \mathrm{dBA}$. Therefore, $97 \%$ of the data fell within a residual 
of 0 to $3.0 \mathrm{dBA}$ and would be well received within the acoustical community, particularly during prediction exercises.

Table 5.17 Comparing Laboratory Results to Model Results (Sound Power Level)

\begin{tabular}{|c|c|c|c|c|c|c|c|}
\hline $\begin{array}{c}\text { Sound Power } \\
\text { dBA } \\
\text { Laboratory }\end{array}$ & $\begin{array}{l}\text { Speed } \\
\text { rpm }\end{array}$ & $\begin{array}{c}\text { Thrust } \\
\text { lbs }\end{array}$ & $\begin{array}{l}\text { Water } \\
\text { gpm }\end{array}$ & $\begin{array}{l}\text { Bit Size } \\
\quad \text { in. }\end{array}$ & $\begin{array}{c}\text { Drill Steel } \\
\text { (hex/round) }\end{array}$ & $\begin{array}{c}\text { Sound Power } \\
\text { dBA } \\
\text { Model }\end{array}$ & $\begin{array}{c}\text { Sound Power } \\
\text { dBA } \\
\text { Difference }\end{array}$ \\
\hline 106.60 & 209.00 & 2239.00 & .00 & 1.000 & 1.000 & 107.75978 & -1.15978 \\
\hline 107.10 & 210.00 & 2228.00 & .00 & 1.000 & 1.000 & 107.75385 & -.65385 \\
\hline 108.30 & 306.00 & 2282.00 & .00 & 1.000 & 1.000 & 108.40316 & -.10316 \\
\hline 107.40 & 305.00 & 2272.00 & .00 & 1.000 & 1.000 & 108.38604 & -.98604 \\
\hline 108.40 & 400.00 & 2324.00 & .00 & 1.000 & 1.000 & 109.02700 & -.62700 \\
\hline 108.60 & 402.00 & 2280.00 & .00 & 1.000 & 1.000 & 108.99101 & -.39101 \\
\hline 109.50 & 514.00 & 2220.00 & .00 & 1.000 & 1.000 & 109.61354 & -.11354 \\
\hline 108.80 & 609.00 & 2241.00 & .00 & 1.000 & 1.000 & 110.22048 & -1.42048 \\
\hline 107.80 & 208.00 & 2711.00 & .00 & 1.000 & 1.000 & 108.27164 & -.47164 \\
\hline 109.90 & 305.00 & 2696.00 & .00 & 1.000 & 1.000 & 108.85136 & 1.04864 \\
\hline 109.40 & 306.00 & 2705.00 & .00 & 1.000 & 1.000 & 108.86739 & .53261 \\
\hline 109.90 & 402.00 & 2701.00 & .00 & 1.000 & 1.000 & 109.45304 & .44696 \\
\hline 110.10 & 509.00 & 2865.00 & .00 & 1.000 & 1.000 & 110.29067 & -.19067 \\
\hline 110.10 & 602.00 & 2882.00 & .00 & 1.000 & 1.000 & 110.88093 & -.78093 \\
\hline 110.20 & 215.00 & 3435.00 & .00 & 1.000 & 1.000 & 109.10923 & 1.09077 \\
\hline 110.90 & 304.00 & 3451.00 & .00 & 1.000 & 1.000 & 109.67380 & 1.22620 \\
\hline 109.60 & 311.00 & 3620.00 & .00 & 1.000 & 1.000 & 109.90230 & -.30230 \\
\hline 111.50 & 405.00 & 3487.00 & .00 & 1.000 & 1.000 & 110.33409 & 1.16591 \\
\hline 111.60 & 404.00 & 3483.00 & .00 & 1.000 & 1.000 & 110.32355 & 1.27645 \\
\hline 110.50 & 510.00 & 3628.00 & .00 & 1.000 & 1.000 & 111.13419 & -.63419 \\
\hline 111.10 & 607.00 & 3653.00 & .00 & 1.000 & 1.000 & 111.75781 & -.65781 \\
\hline 111.20 & 208.00 & 4085.00 & .00 & 1.000 & 1.000 & 109.77955 & 1.42045 \\
\hline 111.60 & 305.00 & 4097.00 & .00 & 1.000 & 1.000 & 110.38891 & 1.21109 \\
\hline 111.50 & 404.00 & 4111.00 & .00 & 1.000 & 1.000 & 111.01276 & .48724 \\
\hline 111.40 & 406.00 & 4283.00 & .00 & 1.000 & 1.000 & 111.21381 & .18619 \\
\hline 110.90 & 509.00 & 4291.00 & .00 & 1.000 & 1.000 & 111.85566 & -.95566 \\
\hline 110.90 & 604.00 & 4314.00 & .00 & 1.000 & 1.000 & 112.46480 & -1.56480 \\
\hline 110.40 & 221.00 & 4744.00 & .00 & 1.000 & 1.000 & 110.58269 & -.18269 \\
\hline 110.60 & 223.00 & 4778.00 & .00 & 1.000 & 1.000 & 110.63229 & -.03229 \\
\hline 112.30 & 308.00 & 4769.00 & .00 & 1.000 & 1.000 & 111.14485 & 1.15515 \\
\hline 112.60 & 404.00 & 4800.00 & .00 & 1.000 & 1.000 & 111.76891 & .83109 \\
\hline 110.40 & 406.00 & 4821.00 & .00 & 1.000 & 1.000 & 111.80425 & -1.40425 \\
\hline 111.40 & 507.00 & 4870.00 & .00 & 1.000 & 1.000 & 112.47880 & -1.07880 \\
\hline 110.70 & 607.00 & 4822.00 & .00 & 1.000 & 1.000 & 113.04075 & -2.34075 \\
\hline 112.00 & 211.00 & 4745.00 & .00 & 1.000 & 1.000 & 110.52232 & 1.47768 \\
\hline 105.50 & 203.00 & 2268.00 & .00 & 1.375 & 1.000 & 108.65847 & -3.15847 \\
\hline
\end{tabular}




\begin{tabular}{|c|c|c|c|c|c|c|c|}
\hline $\begin{array}{c}\text { Sound Power } \\
\text { dBA } \\
\text { Laboratory }\end{array}$ & $\begin{array}{c}\text { Speed } \\
\text { rpm }\end{array}$ & $\begin{array}{l}\text { Thrust } \\
\text { lbs }\end{array}$ & $\begin{array}{l}\text { Water } \\
\text { gpm }\end{array}$ & $\begin{array}{l}\text { Bit Size } \\
\text { in. }\end{array}$ & $\begin{array}{l}\text { Drill Steel } \\
\text { (hex/round) }\end{array}$ & $\begin{array}{c}\text { Sound Power } \\
\text { dBA } \\
\text { Model }\end{array}$ & $\begin{array}{c}\text { Sound Power } \\
\text { dBA } \\
\text { Difference }\end{array}$ \\
\hline 106.10 & 306.00 & 2285.00 & .00 & 1.375 & 1.000 & 109.31019 & -3.21019 \\
\hline 108.60 & 402.00 & 2293.00 & .00 & 1.375 & 1.000 & 109.90901 & -1.30901 \\
\hline 108.80 & 211.00 & 2915.00 & .00 & 1.375 & 1.000 & 109.41770 & -.61770 \\
\hline 108.50 & 215.00 & 2908.00 & .00 & 1.375 & 1.000 & 109.43460 & -.93460 \\
\hline 108.50 & 308.00 & 2925.00 & .00 & 1.375 & 1.000 & 110.02486 & -1.52486 \\
\hline 108.30 & 311.00 & 2923.00 & .00 & 1.375 & 1.000 & 110.04110 & -1.74110 \\
\hline 109.60 & 404.00 & 2952.00 & .00 & 1.375 & 1.000 & 110.64453 & -1.04453 \\
\hline 108.50 & 211.00 & 3527.00 & .00 & 1.375 & 1.000 & 110.08935 & -1.58935 \\
\hline 108.30 & 213.00 & 3522.00 & .00 & 1.375 & 1.000 & 110.09615 & -1.79615 \\
\hline 109.60 & 306.00 & 3545.00 & .00 & 1.375 & 1.000 & 110.69300 & -1.09300 \\
\hline 108.90 & 305.00 & 3545.00 & .00 & 1.375 & 1.000 & 110.68685 & -1.78685 \\
\hline 110.10 & 402.00 & 3580.00 & .00 & 1.375 & 1.000 & 111.32145 & -1.22145 \\
\hline 110.20 & 402.00 & 3567.00 & .00 & 1.375 & 1.000 & 111.30718 & -1.10718 \\
\hline 111.80 & 208.00 & 4183.00 & .00 & 1.375 & 1.000 & 110.79084 & 1.00916 \\
\hline 113.00 & 306.00 & 4181.00 & .00 & 1.375 & 1.000 & 111.39098 & 1.60902 \\
\hline 111.70 & 309.00 & 4228.00 & .00 & 1.375 & 1.000 & 111.46100 & .23900 \\
\hline 113.00 & 403.00 & 4239.00 & .00 & 1.375 & 1.000 & 112.05082 & .94918 \\
\hline 112.50 & 405.00 & 4360.00 & .00 & 1.375 & 1.000 & 112.19591 & .30409 \\
\hline 111.30 & 511.00 & 4303.00 & .00 & 1.375 & 1.000 & 112.78486 & -1.48486 \\
\hline 110.00 & 606.00 & 4405.00 & .00 & 1.375 & 1.000 & 113.48070 & -3.48070 \\
\hline 112.10 & 210.00 & 4842.00 & .00 & 1.375 & 1.000 & 111.52637 & .57363 \\
\hline 112.30 & 307.00 & 4865.00 & .00 & 1.375 & 1.000 & 112.14780 & .15220 \\
\hline 112.70 & 314.00 & 4923.00 & .00 & 1.375 & 1.000 & 112.25447 & .44553 \\
\hline 114.20 & 405.00 & 4886.00 & .00 & 1.375 & 1.000 & 112.77318 & 1.42682 \\
\hline 111.00 & 509.00 & 5082.00 & .00 & 1.375 & 1.000 & 113.62749 & -2.62749 \\
\hline 113.60 & 215.00 & 5415.00 & .00 & 1.375 & 1.000 & 112.18594 & 1.41406 \\
\hline 112.50 & 307.00 & 5438.00 & .00 & 1.375 & 1.000 & 112.77664 & -.27664 \\
\hline 113.10 & 403.00 & 5446.00 & .00 & 1.375 & 1.000 & 113.37546 & -.27546 \\
\hline 113.40 & 207.00 & 6195.00 & .00 & 1.375 & 1.000 & 112.99280 & .40720 \\
\hline 112.70 & 212.00 & 6242.00 & .00 & 1.375 & 1.000 & 113.07511 & -.37511 \\
\hline 114.30 & 312.00 & 6234.00 & .00 & 1.375 & 1.000 & 113.68096 & .61904 \\
\hline 113.10 & 310.00 & 6218.00 & .00 & 1.375 & 1.000 & 113.65110 & -.55110 \\
\hline 114.80 & 402.00 & 6167.00 & .00 & 1.375 & 1.000 & 114.16059 & .63941 \\
\hline 114.10 & 402.00 & 6237.00 & .00 & 1.375 & 1.000 & 114.23741 & -.13741 \\
\hline 111.40 & 155.00 & 6225.00 & .00 & 1.375 & 1.000 & 112.70612 & -1.30612 \\
\hline 112.80 & 402.00 & 4180.00 & .00 & 1.375 & 1.000 & 111.97993 & .82007 \\
\hline 110.20 & 318.00 & 2979.00 & .00 & 1.375 & 1.000 & 110.14559 & .05441 \\
\hline 110.00 & 223.00 & 3609.00 & .00 & 1.375 & 1.000 & 110.25309 & -.25309 \\
\hline 112.10 & 411.00 & 3625.00 & .00 & 1.375 & 1.000 & 111.42615 & .67385 \\
\hline 112.00 & 405.00 & 3628.00 & .00 & 1.375 & 1.000 & 111.39257 & .60743 \\
\hline 110.50 & 312.00 & 3623.00 & .00 & 1.375 & 1.000 & 110.81548 & -.31548 \\
\hline
\end{tabular}




\begin{tabular}{|c|c|c|c|c|c|c|c|}
\hline $\begin{array}{c}\text { Sound Power } \\
\text { dBA } \\
\text { Laboratory }\end{array}$ & $\begin{array}{c}\text { Speed } \\
\text { rpm }\end{array}$ & $\begin{array}{l}\text { Thrust } \\
\text { lbs }\end{array}$ & $\begin{array}{c}\text { Water } \\
\text { gpm }\end{array}$ & $\begin{array}{l}\text { Bit Size } \\
\text { in. }\end{array}$ & $\begin{array}{c}\text { Drill Steel } \\
\text { (hex/round) }\end{array}$ & $\begin{array}{c}\text { Sound Power } \\
\text { dBA } \\
\text { Model }\end{array}$ & $\begin{array}{c}\text { Sound Power } \\
\text { dBA } \\
\text { Difference }\end{array}$ \\
\hline 109.60 & 221.00 & 3615.00 & .00 & 1.375 & 1.000 & 110.24738 & -.64738 \\
\hline 109.00 & 206.00 & 2334.00 & .00 & 1.000 & .000 & 108.64027 & .35973 \\
\hline 110.20 & 303.00 & 2333.00 & .00 & 1.000 & .000 & 109.23536 & 96464 \\
\hline 111.00 & 404.00 & 2344.00 & .00 & 1.000 & .000 & 109.86820 & 1.13180 \\
\hline 110.20 & 506.00 & 2226.00 & .00 & 1.000 & .000 & 110.36562 & -.16562 \\
\hline 112.80 & 602.00 & 2241.00 & .00 & 1.000 & .000 & 110.97212 & 1.82788 \\
\hline 111.30 & 208.00 & 2919.00 & .00 & 1.000 & .000 & 109.29458 & 2.00542 \\
\hline 112.70 & 305.00 & 2933.00 & .00 & 1.000 & .000 & 109.90613 & 2.79387 \\
\hline 112.30 & 401.00 & 2955.00 & .00 & 1.000 & .000 & 110.52031 & 1.77969 \\
\hline 110.50 & 406.00 & 2840.00 & .00 & 1.000 & .000 & 110.42484 & .07516 \\
\hline 111.10 & 508.00 & 2877.00 & .00 & 1.000 & .000 & 111.09236 & .00764 \\
\hline 112.50 & 606.00 & 2890.00 & .00 & 1.000 & .000 & 111.70896 & .79104 \\
\hline 112.70 & 207.00 & 3587.00 & .00 & 1.000 & .000 & 110.02154 & 2.67846 \\
\hline 111.60 & 209.00 & 3588.00 & .00 & 1.000 & .000 & 110.03493 & 1.56507 \\
\hline 112.80 & 307.00 & 3622.00 & .00 & 1.000 & .000 & 110.67457 & 2.12543 \\
\hline 113.40 & 307.00 & 3607.00 & .00 & 1.000 & .000 & 110.65811 & 2.74189 \\
\hline 113.20 & 400.00 & 3642.00 & .00 & 1.000 & .000 & 111.26813 & 1.93187 \\
\hline 113.40 & 398.00 & 3660.00 & .00 & 1.000 & .000 & 111.27559 & 2.12441 \\
\hline 113.60 & 508.00 & 3622.00 & .00 & 1.000 & .000 & 111.90997 & 1.69003 \\
\hline 112.90 & 606.00 & 3651.00 & .00 & 1.000 & .000 & 112.54414 & .35586 \\
\hline 112.50 & 218.00 & 4294.00 & .00 & 1.000 & .000 & 110.86505 & 1.63495 \\
\hline 110.80 & 208.00 & 4238.00 & .00 & 1.000 & .000 & 110.74213 & .05787 \\
\hline 113.30 & 305.00 & 4254.00 & .00 & 1.000 & .000 & 111.35588 & 1.94412 \\
\hline 112.70 & 402.00 & 4258.00 & .00 & 1.000 & .000 & 111.95646 & .74354 \\
\hline 114.00 & 508.00 & 4344.00 & .00 & 1.000 & .000 & 112.70234 & 1.29766 \\
\hline 112.90 & 607.00 & 4362.00 & .00 & 1.000 & .000 & 113.33058 & -.43058 \\
\hline 112.30 & 209.00 & 4818.00 & .00 & 1.000 & .000 & 111.38481 & .91519 \\
\hline 113.00 & 211.00 & 4916.00 & .00 & 1.000 & .000 & 111.50465 & 1.49535 \\
\hline 113.20 & 306.00 & 4869.00 & .00 & 1.000 & .000 & 112.03697 & 1.16303 \\
\hline 113.30 & 407.00 & 4898.00 & .00 & 1.000 & .000 & 112.68957 & .61043 \\
\hline 114.30 & 510.00 & 4979.00 & .00 & 1.000 & .000 & 113.41153 & .88847 \\
\hline 113.00 & 607.00 & 4995.00 & .00 & 1.000 & .000 & 114.02528 & -1.02528 \\
\hline 106.30 & 212.00 & 2283.00 & .00 & 1.375 & .000 & 109.52491 & -3.22491 \\
\hline 109.50 & 309.00 & 2302.00 & .00 & 1.375 & .000 & 110.14195 & -.64195 \\
\hline 110.40 & 402.00 & 2326.00 & .00 & 1.375 & .000 & 110.73989 & -.33989 \\
\hline 109.70 & 209.00 & 2892.00 & .00 & 1.375 & .000 & 110.17483 & -.47483 \\
\hline 110.40 & 308.00 & 2914.00 & .00 & 1.375 & .000 & 110.80745 & -.40745 \\
\hline 113.00 & 405.00 & 2943.00 & .00 & 1.375 & .000 & 111.43547 & 1.56453 \\
\hline 109.60 & 208.00 & 3559.00 & .00 & 1.375 & .000 & 110.90069 & -1.30069 \\
\hline 111.90 & 304.00 & 3575.00 & .00 & 1.375 & .000 & 111.50829 & .39171 \\
\hline 112.50 & 313.00 & 3715.00 & .00 & 1.375 & .000 & 111.71725 & .78275 \\
\hline 112.80 & 402.00 & 3591.00 & .00 & 1.375 & .000 & 112.12819 & .67181 \\
\hline
\end{tabular}




\begin{tabular}{|c|c|c|c|c|c|c|c|}
\hline $\begin{array}{c}\text { Sound Power } \\
\text { dBA } \\
\text { Laboratory } \\
\end{array}$ & $\begin{array}{c}\text { Speed } \\
\text { rpm }\end{array}$ & $\begin{array}{c}\text { Thrust } \\
\text { lbs }\end{array}$ & $\begin{array}{l}\text { Water } \\
\text { gpm }\end{array}$ & $\begin{array}{c}\text { Bit Size } \\
\text { in. }\end{array}$ & $\begin{array}{c}\text { Drill Steel } \\
\text { (hex/round) }\end{array}$ & $\begin{array}{c}\text { Sound Power } \\
\text { dBA } \\
\text { Model } \\
\end{array}$ & $\begin{array}{c}\text { Sound Power } \\
\text { dBA } \\
\text { Difference } \\
\end{array}$ \\
\hline 113.30 & 405.00 & 3741.00 & .00 & 1.375 & .000 & 112.31124 & .98876 \\
\hline 112.80 & 214.00 & 4321.00 & .00 & 1.375 & .000 & 111.77384 & 1.02616 \\
\hline 114.10 & 309.00 & 4316.00 & .00 & 1.375 & .000 & 112.35225 & 1.74775 \\
\hline 113.30 & 313.00 & 4342.00 & .00 & 1.375 & .000 & 112.40536 & .89464 \\
\hline 114.60 & 402.00 & 4330.00 & .00 & 1.375 & .000 & 112.93921 & 1.66079 \\
\hline 114.60 & 403.00 & 4357.00 & .00 & 1.375 & .000 & 112.97499 & 1.62501 \\
\hline 114.70 & 505.00 & 4407.00 & .00 & 1.375 & .000 & 113.65678 & 1.04322 \\
\hline 114.10 & 604.00 & 4420.00 & .00 & 1.375 & .000 & 114.27953 & -.17953 \\
\hline 113.80 & 212.00 & 4979.00 & .00 & 1.375 & .000 & 112.48368 & 1.31632 \\
\hline 113.80 & 310.00 & 5001.00 & .00 & 1.375 & .000 & 113.11016 & .68984 \\
\hline 113.70 & 309.00 & 4958.00 & .00 & 1.375 & .000 & 113.05682 & .64318 \\
\hline 115.50 & 405.00 & 5047.00 & .00 & 1.375 & .000 & 113.74453 & 1.75547 \\
\hline 114.30 & 409.00 & 4973.00 & .00 & 1.375 & .000 & 113.68791 & .61209 \\
\hline 114.70 & 511.00 & 4982.00 & .00 & 1.375 & .000 & 114.32470 & .37530 \\
\hline 113.90 & 604.00 & 4992.00 & .00 & 1.375 & .000 & 114.90728 & -1.00728 \\
\hline 114.10 & 211.00 & 5558.00 & .00 & 1.375 & .000 & 113.11296 & .98704 \\
\hline 113.30 & 218.00 & 5485.00 & .00 & 1.375 & .000 & 113.07587 & 22413 \\
\hline 114.40 & 313.00 & 5497.00 & .00 & 1.375 & .000 & 113.67294 & .72706 \\
\hline 114.30 & 310.00 & 5502.00 & .00 & 1.375 & .000 & 113.65999 & .64001 \\
\hline 116.10 & 405.00 & 5576.00 & .00 & 1.375 & .000 & 114.32509 & 1.77491 \\
\hline 115.20 & 408.00 & 5510.00 & .00 & 1.375 & .000 & 114.27110 & .92890 \\
\hline 114.70 & 511.00 & 5523.00 & .00 & 1.375 & .000 & 114.91843 & -.21843 \\
\hline 113.40 & 600.00 & 5544.00 & .00 & 1.375 & .000 & 115.48850 & -2.08850 \\
\hline 114.10 & 212.00 & 6342.00 & .00 & 1.375 & .000 & 113.97952 & .12048 \\
\hline 114.60 & 211.00 & 6224.00 & .00 & 1.375 & .000 & 113.84387 & .75613 \\
\hline 115.20 & 311.00 & 6360.00 & .00 & 1.375 & .000 & 114.60776 & .59224 \\
\hline 115.70 & 309.00 & 6234.00 & .00 & 1.375 & .000 & 114.45718 & 1.24282 \\
\hline 116.20 & 404.00 & 6382.00 & .00 & 1.375 & .000 & 115.20350 & .99650 \\
\hline 115.30 & 402.00 & 6244.00 & .00 & 1.375 & .000 & 115.03976 & .26024 \\
\hline 114.30 & 506.00 & 6256.00 & .00 & 1.375 & .000 & 115.69214 & -1.39214 \\
\hline 113.20 & 603.00 & 6205.00 & .00 & 1.375 & .000 & 116.23236 & -3.03236 \\
\hline 102.10 & 207.00 & 2313.00 & 3.00 & 1.000 & 1.000 & 102.73010 & -.63010 \\
\hline 102.00 & 211.00 & 2306.00 & 3.00 & 1.000 & 1.000 & 102.74700 & -.74700 \\
\hline 102.20 & 309.00 & 2321.00 & 3.00 & 1.000 & 1.000 & 103.36580 & -1.16580 \\
\hline 104.00 & 308.00 & 2318.00 & 3.00 & 1.000 & 1.000 & 103.35636 & .64364 \\
\hline 102.90 & 402.00 & 2335.00 & 3.00 & 1.000 & 1.000 & 103.95277 & -1.05277 \\
\hline 105.50 & 405.00 & 2329.00 & 3.00 & 1.000 & 1.000 & 103.96462 & 1.53538 \\
\hline 102.40 & 503.00 & 2448.00 & 3.00 & 1.000 & 1.000 & 104.69755 & -2.29755 \\
\hline 103.60 & 605.00 & 2461.00 & 3.00 & 1.000 & 1.000 & 105.33874 & -1.73874 \\
\hline 103.50 & 205.00 & 2909.00 & 3.00 & 1.000 & 1.000 & 103.37190 & .12810 \\
\hline 104.30 & 311.00 & 3084.00 & 3.00 & 1.000 & 1.000 & 104.21546 & .08454 \\
\hline 104.40 & 312.00 & 3005.00 & 3.00 & 1.000 & 1.000 & 104.13490 & .26510 \\
\hline
\end{tabular}




\begin{tabular}{|c|c|c|c|c|c|c|c|}
\hline $\begin{array}{c}\text { Sound Power } \\
\text { dBA } \\
\text { Laboratory }\end{array}$ & $\begin{array}{c}\text { Speed } \\
\text { rpm }\end{array}$ & $\begin{array}{c}\text { Thrust } \\
\text { lbs }\end{array}$ & $\begin{array}{l}\text { Water } \\
\text { gpm }\end{array}$ & $\begin{array}{c}\text { Bit Size } \\
\text { in. }\end{array}$ & $\begin{array}{c}\text { Drill Steel } \\
\text { (hex/round) }\end{array}$ & $\begin{array}{c}\text { Sound Power } \\
\text { dBA } \\
\text { Model }\end{array}$ & $\begin{array}{c}\text { Sound Power } \\
\text { dBA } \\
\text { Difference }\end{array}$ \\
\hline 103.90 & 402.00 & 2978.00 & 3.00 & 1.000 & 1.000 & 104.65844 & -.75844 \\
\hline 103.20 & 403.00 & 3098.00 & 3.00 & 1.000 & 1.000 & 104.79628 & -1.59628 \\
\hline 105.40 & 508.00 & 3113.00 & 3.00 & 1.000 & 1.000 & 105.45810 & -.05810 \\
\hline 102.50 & 507.00 & 3012.00 & 3.00 & 1.000 & 1.000 & 105.34111 & -2.84111 \\
\hline 105.70 & 605.00 & 3129.00 & 3.00 & 1.000 & 1.000 & 106.07185 & -.37185 \\
\hline 104.40 & 201.00 & 3591.00 & 3.00 & 1.000 & 1.000 & 104.09578 & .30422 \\
\hline 106.30 & 308.00 & 3605.00 & 3.00 & 1.000 & 1.000 & 104.76880 & 1.53120 \\
\hline 105.80 & 314.00 & 3601.00 & 3.00 & 1.000 & 1.000 & 104.80128 & .99872 \\
\hline 106.80 & 401.00 & 3617.00 & 3.00 & 1.000 & 1.000 & 105.35357 & 1.44643 \\
\hline 107.70 & 604.00 & 3820.00 & 3.00 & 1.000 & 1.000 & 106.82405 & .87595 \\
\hline 105.80 & 210.00 & 4275.00 & 3.00 & 1.000 & 1.000 & 104.90176 & .89824 \\
\hline 105.70 & 213.00 & 4272.00 & 3.00 & 1.000 & 1.000 & 104.91691 & .78309 \\
\hline 107.00 & 309.00 & 4285.00 & 3.00 & 1.000 & 1.000 & 105.52122 & 1.47878 \\
\hline 106.50 & 315.00 & 4285.00 & 3.00 & 1.000 & 1.000 & 105.55810 & .94190 \\
\hline 107.30 & 411.00 & 4288.00 & 3.00 & 1.000 & 1.000 & 106.15143 & 1.14857 \\
\hline 108.60 & 411.00 & 4296.00 & 3.00 & 1.000 & 1.000 & 106.16021 & 2.43979 \\
\hline 105.80 & 508.00 & 4411.00 & 3.00 & 1.000 & 1.000 & 106.88261 & -1.08261 \\
\hline 106.70 & 595.00 & 4434.00 & 3.00 & 1.000 & 1.000 & 107.44257 & -.74257 \\
\hline 106.20 & 206.00 & 4888.00 & 3.00 & 1.000 & 1.000 & 105.54993 & .65007 \\
\hline 106.30 & 205.00 & 4899.00 & 3.00 & 1.000 & 1.000 & 105.55585 & .74415 \\
\hline 107.60 & 302.00 & 4898.00 & 3.00 & 1.000 & 1.000 & 106.15094 & 1.44906 \\
\hline 108.20 & 307.00 & 4916.00 & 3.00 & 1.000 & 1.000 & 106.20143 & 1.99857 \\
\hline 108.10 & 412.00 & 4927.00 & 3.00 & 1.000 & 1.000 & 106.85886 & 1.24114 \\
\hline 108.90 & 412.00 & 4912.00 & 3.00 & 1.000 & 1.000 & 106.84240 & 2.05760 \\
\hline 107.10 & 510.00 & 4876.00 & 3.00 & 1.000 & 1.000 & 107.40522 & -.30522 \\
\hline 106.20 & 607.00 & 4902.00 & 3.00 & 1.000 & 1.000 & 108.02994 & -1.82994 \\
\hline 105.80 & 407.00 & 4398.00 & 3.00 & 1.000 & 1.000 & 106.24757 & -.44757 \\
\hline 105.00 & 212.00 & 4371.00 & 3.00 & 1.000 & 1.000 & 105.01941 & -.01941 \\
\hline 106.10 & 400.00 & 3028.00 & 3.00 & 1.000 & 1.000 & 104.70102 & 1.39898 \\
\hline 103.40 & 304.00 & 2953.00 & 3.00 & 1.000 & 1.000 & 104.02866 & -.62866 \\
\hline 102.70 & 215.00 & 4368.00 & 3.00 & 1.000 & 1.000 & 105.03456 & -2.33456 \\
\hline 103.50 & 305.00 & 2985.00 & 3.00 & 1.000 & 1.000 & 104.06993 & -.56993 \\
\hline 104.90 & 210.00 & 2335.00 & 3.00 & 1.375 & 1.000 & 103.67642 & 1.22358 \\
\hline 103.90 & 208.00 & 2337.00 & 3.00 & 1.375 & 1.000 & 103.66632 & .23368 \\
\hline 104.30 & 310.00 & 2340.00 & 3.00 & 1.375 & 1.000 & 104.29653 & .00347 \\
\hline 105.00 & 311.00 & 2337.00 & 3.00 & 1.375 & 1.000 & 104.29939 & .70061 \\
\hline 106.60 & 406.00 & 2351.00 & 3.00 & 1.375 & 1.000 & 104.89865 & 1.70135 \\
\hline 105.50 & 407.00 & 2347.00 & 3.00 & 1.375 & 1.000 & 104.90040 & .59960 \\
\hline 103.50 & 211.00 & 2916.00 & 3.00 & 1.375 & 1.000 & 104.32019 & -.82019 \\
\hline 103.60 & 209.00 & 2915.00 & 3.00 & 1.375 & 1.000 & 104.30680 & -.70680 \\
\hline 104.90 & 305.00 & 2937.00 & 3.00 & 1.375 & 1.000 & 104.92099 & -.02099 \\
\hline 104.50 & 305.00 & 2935.00 & 3.00 & 1.375 & 1.000 & 104.91879 & -.41879 \\
\hline
\end{tabular}




\begin{tabular}{|c|c|c|c|c|c|c|c|}
\hline $\begin{array}{c}\text { Sound Power } \\
\text { dBA } \\
\text { Laboratory }\end{array}$ & $\begin{array}{c}\text { Speed } \\
\text { rpm }\end{array}$ & $\begin{array}{c}\text { Thrust } \\
\text { lbs }\end{array}$ & $\begin{array}{c}\text { Water } \\
\text { gpm }\end{array}$ & $\begin{array}{l}\text { Bit Size } \\
\text { in. }\end{array}$ & $\begin{array}{c}\text { Drill Steel } \\
\text { (hex/round) }\end{array}$ & $\begin{array}{c}\text { Sound Power } \\
\text { dBA } \\
\text { Model }\end{array}$ & $\begin{array}{c}\text { Sound Power } \\
\text { dBA } \\
\text { Difference }\end{array}$ \\
\hline 106.10 & 411.00 & 2959.00 & 3.00 & 1.375 & 1.000 & 105.59664 & .50336 \\
\hline 106.70 & 411.00 & 2955.00 & 3.00 & 1.375 & 1.000 & 105.59225 & 1.10775 \\
\hline 105.90 & 218.00 & 3611.00 & 3.00 & 1.375 & 1.000 & 105.12595 & .77405 \\
\hline 105.30 & 214.00 & 3609.00 & 3.00 & 1.375 & 1.000 & 105.09917 & .20083 \\
\hline 105.10 & 313.00 & 3623.00 & 3.00 & 1.375 & 1.000 & 105.72302 & -.62302 \\
\hline 106.00 & 311.00 & 3621.00 & 3.00 & 1.375 & 1.000 & 105.70853 & .29147 \\
\hline 108.00 & 408.00 & 3709.00 & 3.00 & 1.375 & 1.000 & 106.40130 & 1.59870 \\
\hline 108.50 & 411.00 & 3701.00 & 3.00 & 1.375 & 1.000 & 106.41096 & 2.08904 \\
\hline 106.80 & 217.00 & 4187.00 & 3.00 & 1.375 & 1.000 & 105.75195 & 1.04805 \\
\hline 106.00 & 215.00 & 4188.00 & 3.00 & 1.375 & 1.000 & 105.74075 & .25925 \\
\hline 108.10 & 313.00 & 4210.00 & 3.00 & 1.375 & 1.000 & 106.36723 & 1.73277 \\
\hline 107.60 & 307.00 & 4202.00 & 3.00 & 1.375 & 1.000 & 106.32157 & 1.27843 \\
\hline 108.80 & 408.00 & 4233.00 & 3.00 & 1.375 & 1.000 & 106.97637 & 1.82363 \\
\hline 108.90 & 407.00 & 4230.00 & 3.00 & 1.375 & 1.000 & 106.96693 & 1.93307 \\
\hline 108.90 & 510.00 & 4456.00 & 3.00 & 1.375 & 1.000 & 107.84802 & 1.05198 \\
\hline 109.20 & 603.00 & 4485.00 & 3.00 & 1.375 & 1.000 & 108.45145 & .74855 \\
\hline 106.50 & 211.00 & 4833.00 & 3.00 & 1.375 & 1.000 & 106.42403 & .07597 \\
\hline 106.30 & 217.00 & 4808.00 & 3.00 & 1.375 & 1.000 & 106.43347 & -.13347 \\
\hline 108.50 & 309.00 & 4816.00 & 3.00 & 1.375 & 1.000 & 107.00771 & 1.49229 \\
\hline 107.40 & 310.00 & 4826.00 & 3.00 & 1.375 & 1.000 & 107.02483 & .37517 \\
\hline 107.40 & 403.00 & 4839.00 & 3.00 & 1.375 & 1.000 & 107.61070 & -.21070 \\
\hline 108.30 & 403.00 & 4840.00 & 3.00 & 1.375 & 1.000 & 107.61180 & .68820 \\
\hline 109.80 & 506.00 & 5110.00 & 3.00 & 1.375 & 1.000 & 108.54118 & 1.25882 \\
\hline 110.80 & 604.00 & 5136.00 & 3.00 & 1.375 & 1.000 & 109.17205 & 1.62795 \\
\hline 108.00 & 210.00 & 5649.00 & 3.00 & 1.375 & 1.000 & 107.31342 & .68658 \\
\hline 107.30 & 212.00 & 5644.00 & 3.00 & 1.375 & 1.000 & 107.32022 & -.02022 \\
\hline 109.20 & 311.00 & 5662.00 & 3.00 & 1.375 & 1.000 & 107.94846 & 1.25154 \\
\hline 108.60 & 310.00 & 5512.00 & 3.00 & 1.375 & 1.000 & 107.77769 & .82231 \\
\hline 110.20 & 411.00 & 5669.00 & 3.00 & 1.375 & 1.000 & 108.57077 & 1.62923 \\
\hline 108.70 & 401.00 & 5666.00 & 3.00 & 1.375 & 1.000 & 108.50601 & .19399 \\
\hline 110.30 & 507.00 & 5740.00 & 3.00 & 1.375 & 1.000 & 109.23873 & 1.06127 \\
\hline 110.40 & 604.00 & 5755.00 & 3.00 & 1.375 & 1.000 & 109.85138 & .54862 \\
\hline 108.00 & 206.00 & 6298.00 & 3.00 & 1.375 & 1.000 & 108.00109 & -.00109 \\
\hline 109.40 & 178.00 & 6270.00 & 3.00 & 1.375 & 1.000 & 107.79826 & 1.60174 \\
\hline 109.70 & 308.00 & 6307.00 & 3.00 & 1.375 & 1.000 & 108.63789 & 1.06211 \\
\hline 109.00 & 307.00 & 6143.00 & 3.00 & 1.375 & 1.000 & 108.45175 & .54825 \\
\hline 109.60 & 407.00 & 6320.00 & 3.00 & 1.375 & 1.000 & 109.26063 & .33937 \\
\hline 109.30 & 402.00 & 6148.00 & 3.00 & 1.375 & 1.000 & 109.04114 & .25886 \\
\hline 108.40 & 504.00 & 6161.00 & 3.00 & 1.375 & 1.000 & 109.68232 & -1.28232 \\
\hline 109.40 & 601.00 & 6369.00 & 3.00 & 1.375 & 1.000 & 110.50679 & -1.10679 \\
\hline 110.40 & 578.00 & 6311.00 & 3.00 & 1.375 & 1.000 & 110.30177 & .09823 \\
\hline 108.60 & 310.00 & 6230.00 & 3.00 & 1.375 & 1.000 & 108.56567 & .03433 \\
\hline
\end{tabular}




\begin{tabular}{|c|c|c|c|c|c|c|c|}
\hline $\begin{array}{c}\text { Sound Power } \\
\text { dBA } \\
\text { Laboratory } \\
\end{array}$ & $\begin{array}{c}\text { Speed } \\
\text { rpm }\end{array}$ & $\begin{array}{l}\text { Thrust } \\
\text { lbs }\end{array}$ & $\begin{array}{c}\text { Water } \\
\text { gpm }\end{array}$ & $\begin{array}{l}\text { Bit Size } \\
\text { in. }\end{array}$ & $\begin{array}{c}\text { Drill Steel } \\
\text { (hex/round) }\end{array}$ & $\begin{array}{c}\text { Sound Power } \\
\text { dBA } \\
\text { Model } \\
\end{array}$ & $\begin{array}{c}\text { Sound Power } \\
\text { dBA } \\
\text { Difference } \\
\end{array}$ \\
\hline 110.70 & 506.00 & 6009.00 & 3.00 & 1.375 & 1.000 & 109.52780 & 1.17220 \\
\hline 109.90 & 562.00 & 6018.00 & 3.00 & 1.375 & 1.000 & 109.88187 & .01813 \\
\hline 109.10 & 565.00 & 5692.00 & 3.00 & 1.375 & 1.000 & 109.54254 & -.44254 \\
\hline 108.80 & 571.00 & 5286.00 & 3.00 & 1.375 & 1.000 & 109.13384 & -.33384 \\
\hline 108.60 & 472.00 & 5270.00 & 3.00 & 1.375 & 1.000 & 108.50780 & .09220 \\
\hline 108.30 & 415.00 & 5249.00 & 3.00 & 1.375 & 1.000 & 108.13442 & .16558 \\
\hline 108.40 & 332.00 & 5229.00 & 3.00 & 1.375 & 1.000 & 107.60233 & .79767 \\
\hline 110.00 & 544.00 & 4868.00 & 3.00 & 1.375 & 1.000 & 108.50915 & 1.49085 \\
\hline 110.90 & 577.00 & 4554.00 & 3.00 & 1.375 & 1.000 & 108.36738 & 2.53262 \\
\hline 109.40 & 579.00 & 4223.00 & 3.00 & 1.375 & 1.000 & 108.01641 & 1.38359 \\
\hline 107.70 & 572.00 & 3987.00 & 3.00 & 1.375 & 1.000 & 107.71438 & -.01438 \\
\hline 109.40 & 582.00 & 3734.00 & 3.00 & 1.375 & 1.000 & 107.49819 & 1.90181 \\
\hline 108.60 & 577.00 & 4892.00 & 3.00 & 1.375 & 1.000 & 108.73832 & -.13832 \\
\hline 109.10 & 408.00 & 3703.00 & 3.00 & 1.375 & 1.000 & 106.39471 & 2.70529 \\
\hline 109.70 & 313.00 & 4210.00 & 3.00 & 1.375 & 1.000 & 106.36723 & 3.33277 \\
\hline 110.30 & 413.00 & 4233.00 & 3.00 & 1.375 & 1.000 & 107.00710 & 3.29290 \\
\hline 108.80 & 405.00 & 4841.00 & 3.00 & 1.375 & 1.000 & 107.62519 & 1.17481 \\
\hline 106.10 & 214.00 & 5496.00 & 3.00 & 1.375 & 1.000 & 107.17009 & -1.07009 \\
\hline 108.70 & 301.00 & 5653.00 & 3.00 & 1.375 & 1.000 & 107.87712 & .82288 \\
\hline 108.70 & 310.00 & 5653.00 & 3.00 & 1.375 & 1.000 & 107.93244 & .76756 \\
\hline 110.40 & 409.00 & 5661.00 & 3.00 & 1.375 & 1.000 & 108.54970 & 1.85030 \\
\hline 109.30 & 300.00 & 5711.00 & 3.00 & 1.375 & 1.000 & 107.93463 & 1.36537 \\
\hline 110.50 & 202.00 & 5057.00 & 3.00 & 1.375 & 1.000 & 106.61455 & 3.88545 \\
\hline 100.60 & 207.00 & 2314.00 & 3.00 & 1.000 & .000 & 103.52586 & -2.92586 \\
\hline 100.50 & 315.00 & 2332.00 & 3.00 & 1.000 & .000 & 104.20941 & -3.70941 \\
\hline 103.80 & 404.00 & 2347.00 & 3.00 & 1.000 & .000 & 104.77289 & -.97289 \\
\hline 105.60 & 508.00 & 2295.00 & 3.00 & 1.000 & .000 & 105.35504 & .24496 \\
\hline 105.90 & 607.00 & 2306.00 & 3.00 & 1.000 & .000 & 105.97559 & -.07559 \\
\hline 101.50 & 214.00 & 2924.00 & 3.00 & 1.000 & .000 & 104.23834 & -2.73834 \\
\hline 104.20 & 198.00 & 2932.00 & 3.00 & 1.000 & .000 & 104.14878 & .05122 \\
\hline 102.80 & 306.00 & 2939.00 & 3.00 & 1.000 & .000 & 104.82026 & -2.02026 \\
\hline 104.80 & 406.00 & 2957.00 & 3.00 & 1.000 & .000 & 105.45464 & -.65464 \\
\hline 105.70 & 403.00 & 3121.00 & 3.00 & 1.000 & .000 & 105.61619 & .08381 \\
\hline 107.70 & 507.00 & 3135.00 & 3.00 & 1.000 & .000 & 106.27076 & 1.42924 \\
\hline 107.20 & 602.00 & 3147.00 & 3.00 & 1.000 & .000 & 106.86783 & .33217 \\
\hline 103.80 & 215.00 & 3670.00 & 3.00 & 1.000 & .000 & 105.06319 & -1.26319 \\
\hline 103.90 & 204.00 & 3665.00 & 3.00 & 1.000 & .000 & 104.99010 & -1.09010 \\
\hline 105.30 & 316.00 & 3715.00 & 3.00 & 1.000 & .000 & 105.73335 & -.43335 \\
\hline 105.90 & 304.00 & 3720.00 & 3.00 & 1.000 & .000 & 105.66509 & .23491 \\
\hline 108.20 & 409.00 & 3578.00 & 3.00 & 1.000 & .000 & 106.15460 & 2.04540 \\
\hline 107.90 & 402.00 & 3581.00 & 3.00 & 1.000 & .000 & 106.11487 & 1.78513 \\
\hline 107.50 & 517.00 & 3741.00 & 3.00 & 1.000 & .000 & 106.99729 & .50271 \\
\hline
\end{tabular}




\begin{tabular}{|c|c|c|c|c|c|c|c|}
\hline $\begin{array}{c}\text { Sound Power } \\
\text { dBA } \\
\text { Laboratory }\end{array}$ & $\begin{array}{l}\text { Speed } \\
\text { rpm }\end{array}$ & $\begin{array}{c}\text { Thrust } \\
\text { lbs }\end{array}$ & $\begin{array}{l}\text { Water } \\
\text { gpm }\end{array}$ & $\begin{array}{l}\text { Bit Size } \\
\text { in. }\end{array}$ & $\begin{array}{c}\text { Drill Steel } \\
\text { (hex/round) }\end{array}$ & $\begin{array}{c}\text { Sound Power } \\
\text { dBA } \\
\text { Model }\end{array}$ & $\begin{array}{c}\text { Sound Power } \\
\text { dBA } \\
\text { Difference }\end{array}$ \\
\hline 108.30 & 504.00 & 3644.00 & 3.00 & 1.000 & .000 & 106.81093 & 1.48907 \\
\hline 108.30 & 606.00 & 3755.00 & 3.00 & 1.000 & .000 & 107.55967 & .74033 \\
\hline 106.90 & 605.00 & 3657.00 & 3.00 & 1.000 & .000 & 107.44597 & -.54597 \\
\hline 101.70 & 202.00 & 4273.00 & 3.00 & 1.000 & .000 & 105.64506 & -3.94506 \\
\hline 105.20 & 216.00 & 4349.00 & 3.00 & 1.000 & .000 & 105.81452 & -.61452 \\
\hline 103.80 & 310.00 & 4272.00 & 3.00 & 1.000 & .000 & 106.30776 & -2.50776 \\
\hline 106.10 & 412.00 & 4297.00 & 3.00 & 1.000 & .000 & 106.96212 & -.86212 \\
\hline 104.80 & 398.00 & 4296.00 & 3.00 & 1.000 & .000 & 106.87498 & -2.07498 \\
\hline 108.10 & 511.00 & 4382.00 & 3.00 & 1.000 & .000 & 107.66389 & .43611 \\
\hline 108.40 & 614.00 & 4392.00 & 3.00 & 1.000 & .000 & 108.30793 & .09207 \\
\hline 105.10 & 215.00 & 4793.00 & 3.00 & 1.000 & .000 & 106.29565 & -1.19565 \\
\hline 104.70 & 209.00 & 4930.00 & 3.00 & 1.000 & .000 & 106.40912 & -1.70912 \\
\hline 105.60 & 306.00 & 4940.00 & 3.00 & 1.000 & .000 & 107.01629 & -1.41629 \\
\hline 105.50 & 314.00 & 4806.00 & 3.00 & 1.000 & .000 & 106.91840 & -1.41840 \\
\hline 105.70 & 414.00 & 4944.00 & 3.00 & 1.000 & .000 & 107.68447 & -1.98447 \\
\hline 108.10 & 509.00 & 4831.00 & 3.00 & 1.000 & .000 & 108.14436 & -.04436 \\
\hline 108.30 & 578.00 & 4850.00 & 3.00 & 1.000 & .000 & 108.58930 & -.28930 \\
\hline 105.20 & 409.00 & 3696.00 & 3.00 & 1.000 & .000 & 106.28411 & -1.08411 \\
\hline 104.00 & 201.00 & 4694.00 & 3.00 & 1.000 & .000 & 106.10095 & -2.10095 \\
\hline 106.70 & 401.00 & 3726.00 & 3.00 & 1.000 & .000 & 106.26786 & .43214 \\
\hline 103.70 & 319.00 & 3682.00 & 3.00 & 1.000 & .000 & 105.71558 & -2.01558 \\
\hline 106.60 & 403.00 & 2957.00 & 3.00 & 1.000 & .000 & 105.43620 & 1.16380 \\
\hline 104.30 & 307.00 & 3618.00 & 3.00 & 1.000 & .000 & 105.57158 & -1.27158 \\
\hline 106.20 & 400.00 & 3635.00 & 3.00 & 1.000 & .000 & 106.16184 & .03816 \\
\hline 104.20 & 209.00 & 2338.00 & 3.00 & 1.375 & .000 & 104.46823 & -.26823 \\
\hline 105.00 & 311.00 & 2360.00 & 3.00 & 1.375 & .000 & 105.11929 & -.11929 \\
\hline 106.10 & 403.00 & 2378.00 & 3.00 & 1.375 & .000 & 105.70451 & .39549 \\
\hline 104.20 & 213.00 & 2915.00 & 3.00 & 1.375 & .000 & 105.12605 & -.92605 \\
\hline 106.30 & 309.00 & 2937.00 & 3.00 & 1.375 & .000 & 105.74024 & .55976 \\
\hline 107.00 & 402.00 & 2961.00 & 3.00 & 1.375 & .000 & 106.33818 & .66182 \\
\hline 104.90 & 209.00 & 3593.00 & 3.00 & 1.375 & .000 & 105.84555 & -.94555 \\
\hline 105.00 & 312.00 & 3606.00 & 3.00 & 1.375 & .000 & 106.49288 & -1.49288 \\
\hline 106.10 & 400.00 & 3622.00 & 3.00 & 1.375 & .000 & 107.05131 & -.95131 \\
\hline 104.90 & 212.00 & 4402.00 & 3.00 & 1.375 & .000 & 106.75184 & -1.85184 \\
\hline 105.70 & 208.00 & 4207.00 & 3.00 & 1.375 & .000 & 106.51325 & -.81325 \\
\hline 106.80 & 302.00 & 4227.00 & 3.00 & 1.375 & .000 & 107.11295 & -.31295 \\
\hline 106.40 & 309.00 & 4277.00 & 3.00 & 1.375 & .000 & 107.21084 & -.81084 \\
\hline 107.50 & 411.00 & 4258.00 & 3.00 & 1.375 & .000 & 107.81691 & -.31691 \\
\hline 107.60 & 398.00 & 4286.00 & 3.00 & 1.375 & .000 & 107.76774 & -.16774 \\
\hline 108.00 & 505.00 & 4454.00 & 3.00 & 1.375 & .000 & 108.60976 & -.60976 \\
\hline 109.20 & 604.00 & 4478.00 & 3.00 & 1.375 & .000 & 109.24458 & -.04458 \\
\hline 106.40 & 207.00 & 4848.00 & 3.00 & 1.375 & .000 & 107.21058 & -.81058 \\
\hline
\end{tabular}




\begin{tabular}{|c|c|c|c|c|c|c|c|}
\hline $\begin{array}{c}\text { Sound Power } \\
\text { dBA } \\
\text { Laboratory } \\
\end{array}$ & $\begin{array}{c}\text { Speed } \\
\text { rpm }\end{array}$ & $\begin{array}{l}\text { Thrust } \\
\text { lbs }\end{array}$ & $\begin{array}{l}\text { Water } \\
\text { gpm }\end{array}$ & $\begin{array}{c}\text { Bit Size } \\
\text { in. }\end{array}$ & $\begin{array}{c}\text { Drill Steel } \\
\text { (hex/round) }\end{array}$ & $\begin{array}{c}\text { Sound Power } \\
\text { dBA } \\
\text { Model } \\
\end{array}$ & $\begin{array}{c}\text { Sound Power } \\
\text { dBA } \\
\text { Difference } \\
\end{array}$ \\
\hline 106.40 & 206.00 & 4846.00 & 3.00 & 1.375 & .000 & 107.20224 & -.80224 \\
\hline 107.90 & 315.00 & 4859.00 & 3.00 & 1.375 & .000 & 107.88645 & .01355 \\
\hline 107.50 & 313.00 & 4852.00 & 3.00 & 1.375 & .000 & 107.86647 & -.36647 \\
\hline 110.50 & 407.00 & 4867.00 & 3.00 & 1.375 & .000 & 108.46068 & 2.03932 \\
\hline 107.20 & 401.00 & 5000.00 & 3.00 & 1.375 & .000 & 108.56977 & -1.36977 \\
\hline 108.00 & 506.00 & 5014.00 & 3.00 & 1.375 & .000 & 109.23049 & -1.23049 \\
\hline 109.10 & 602.00 & 5027.00 & 3.00 & 1.375 & .000 & 109.83480 & -.73480 \\
\hline 107.50 & 201.00 & 5435.00 & 3.00 & 1.375 & .000 & 107.81791 & -.31791 \\
\hline 106.90 & 216.00 & 5595.00 & 3.00 & 1.375 & .000 & 108.08570 & -1.18570 \\
\hline 109.30 & 315.00 & 5539.00 & 3.00 & 1.375 & .000 & 108.63272 & .66728 \\
\hline 108.60 & 308.00 & 5539.00 & 3.00 & 1.375 & .000 & 108.58970 & .01030 \\
\hline 108.80 & 413.00 & 5561.00 & 3.00 & 1.375 & .000 & 109.25920 & -.45920 \\
\hline 109.20 & 424.00 & 5586.00 & 3.00 & 1.375 & .000 & 109.35425 & -.15425 \\
\hline 109.00 & 510.00 & 5642.00 & 3.00 & 1.375 & .000 & 109.94428 & -.94428 \\
\hline 108.90 & 604.00 & 5664.00 & 3.00 & 1.375 & .000 & 110.54618 & -1.64618 \\
\hline 108.60 & 204.00 & 6200.00 & 3.00 & 1.375 & .000 & 108.67591 & -.07591 \\
\hline 107.70 & 196.00 & 6155.00 & 3.00 & 1.375 & .000 & 108.57735 & -.87735 \\
\hline 108.80 & 316.00 & 6197.00 & 3.00 & 1.375 & .000 & 109.36100 & -.56100 \\
\hline 109.10 & 304.00 & 6137.00 & 3.00 & 1.375 & .000 & 109.22140 & -.12140 \\
\hline 110.80 & 405.00 & 6219.00 & 3.00 & 1.375 & .000 & 109.93216 & .86784 \\
\hline 110.00 & 408.00 & 6213.00 & 3.00 & 1.375 & .000 & 109.94402 & .05598 \\
\hline 109.40 & 508.00 & 6334.00 & 3.00 & 1.375 & .000 & 110.69144 & -1.29144 \\
\hline 110.20 & 598.00 & 6323.00 & 3.00 & 1.375 & .000 & 111.23253 & -1.03253 \\
\hline 110.70 & 604.00 & 6346.00 & 3.00 & 1.375 & .000 & 111.29465 & -.59465 \\
\hline 112.20 & 556.00 & 6299.00 & 3.00 & 1.375 & .000 & 110.94805 & 1.25195 \\
\hline 110.50 & 453.00 & 6274.00 & 3.00 & 1.375 & .000 & 110.28754 & .21246 \\
\hline 108.50 & 436.00 & 6007.00 & 3.00 & 1.375 & .000 & 109.89003 & -1.39003 \\
\hline 109.00 & 561.00 & 6020.00 & 3.00 & 1.375 & .000 & 110.67258 & -1.67258 \\
\hline 108.60 & 543.00 & 5694.00 & 3.00 & 1.375 & .000 & 110.20418 & -1.60418 \\
\hline 108.90 & 428.00 & 5668.00 & 3.00 & 1.375 & .000 & 109.46882 & -.56882 \\
\hline 108.10 & 428.00 & 5266.00 & 3.00 & 1.375 & .000 & 109.02764 & -.92764 \\
\hline 109.30 & 579.00 & 5280.00 & 3.00 & 1.375 & .000 & 109.97109 & -.67109 \\
\hline 109.00 & 453.00 & 6004.00 & 3.00 & 1.375 & .000 & 109.99123 & -.99123 \\
\hline 108.40 & 596.00 & 4993.00 & 3.00 & 1.375 & .000 & 109.76061 & -1.36061 \\
\hline 108.10 & 481.00 & 4969.00 & 3.00 & 1.375 & .000 & 109.02745 & -.92745 \\
\hline 107.50 & 401.00 & 4933.00 & 3.00 & 1.375 & .000 & 108.49624 & -.99624 \\
\hline 107.30 & 403.00 & 4610.00 & 3.00 & 1.375 & .000 & 108.15405 & -.85405 \\
\hline 107.70 & 484.00 & 4622.00 & 3.00 & 1.375 & .000 & 108.66507 & -.96507 \\
\hline 109.00 & 590.00 & 4636.00 & 3.00 & 1.375 & .000 & 109.33193 & -.33193 \\
\hline 108.50 & 586.00 & 4348.00 & 3.00 & 1.375 & .000 & 108.99128 & -.49128 \\
\hline 110.20 & 473.00 & 4216.00 & 3.00 & 1.375 & .000 & 108.15189 & 2.04811 \\
\hline 106.10 & 376.00 & 4179.00 & 3.00 & 1.375 & .000 & 107.51509 & -1.41509 \\
\hline
\end{tabular}




\begin{tabular}{|c|c|c|c|c|c|c|c|}
\hline $\begin{array}{c}\text { Sound Power } \\
\text { dBA } \\
\text { Laboratory }\end{array}$ & $\begin{array}{l}\text { Speed } \\
\text { rpm }\end{array}$ & $\begin{array}{c}\text { Thrust } \\
\text { lbs }\end{array}$ & $\begin{array}{l}\text { Water } \\
\text { gpm }\end{array}$ & $\begin{array}{c}\text { Bit Size } \\
\text { in. }\end{array}$ & $\begin{array}{c}\text { Drill Steel } \\
\text { (hex/round) }\end{array}$ & $\begin{array}{c}\text { Sound Power } \\
\text { dBA } \\
\text { Model }\end{array}$ & $\begin{array}{c}\text { Sound Power } \\
\text { dBA } \\
\text { Difference }\end{array}$ \\
\hline 107.90 & 475.00 & 3714.00 & 3.00 & 1.375 & .000 & 107.61325 & .28675 \\
\hline 110.10 & 555.00 & 3728.00 & 3.00 & 1.375 & .000 & 108.12032 & 1.97968 \\
\hline 109.60 & 510.00 & 3709.00 & 3.00 & 1.375 & .000 & 107.82288 & 1.77712 \\
\hline 109.00 & 213.00 & 4836.00 & 3.00 & 1.375 & .000 & 107.23428 & 1.76572 \\
\hline 109.80 & 304.00 & 4853.00 & 3.00 & 1.375 & .000 & 107.81225 & 1.98775 \\
\hline 107.90 & 304.00 & 5453.00 & 3.00 & 1.375 & .000 & 108.47073 & -.57073 \\
\hline 110.40 & 405.00 & 5468.00 & 3.00 & 1.375 & .000 & 109.10797 & 1.29203 \\
\hline 106.30 & 403.00 & 4432.00 & 3.00 & 1.375 & .000 & 107.95870 & -1.65870 \\
\hline 105.20 & 205.00 & 4265.00 & 3.00 & 1.375 & .000 & 106.55846 & -1.35846 \\
\hline 105.60 & 213.00 & 4971.00 & 3.00 & 1.375 & .000 & 107.38244 & -1.78244 \\
\hline 106.30 & 210.00 & 5523.00 & 3.00 & 1.375 & .000 & 107.96980 & -1.66980 \\
\hline 108.00 & 401.00 & 5624.00 & 3.00 & 1.375 & .000 & 109.25459 & -1.25459 \\
\hline 106.90 & 405.00 & 6231.00 & 3.00 & 1.375 & .000 & 109.94533 & -3.04533 \\
\hline 107.30 & 218.00 & 6210.00 & 3.00 & 1.375 & .000 & 108.77293 & -1.47293 \\
\hline 104.60 & 214.00 & 2418.00 & .75 & 1.000 & 1.000 & 106.71231 & -2.11231 \\
\hline 105.80 & 307.00 & 2432.00 & .75 & 1.000 & 1.000 & 107.29927 & -1.49927 \\
\hline 106.70 & 402.00 & 2445.00 & .75 & 1.000 & 1.000 & 107.89744 & -1.19744 \\
\hline 107.40 & 507.00 & 2458.00 & .75 & 1.000 & 1.000 & 108.55706 & -1.15706 \\
\hline 107.70 & 593.00 & 2472.00 & .75 & 1.000 & 1.000 & 109.10101 & -1.40101 \\
\hline 104.50 & 216.00 & 2978.00 & .75 & 1.000 & 1.000 & 107.33918 & -2.83918 \\
\hline 107.10 & 301.00 & 2993.00 & .75 & 1.000 & 1.000 & 107.87808 & -.77808 \\
\hline 107.90 & 408.00 & 3004.00 & .75 & 1.000 & 1.000 & 108.54780 & -.64780 \\
\hline 108.50 & 510.00 & 3004.00 & .75 & 1.000 & 1.000 & 109.17472 & -.67472 \\
\hline 109.20 & 605.00 & 3012.00 & .75 & 1.000 & 1.000 & 109.76739 & -.56739 \\
\hline 106.30 & 213.00 & 3685.00 & .75 & 1.000 & 1.000 & 108.09665 & -1.79665 \\
\hline 108.50 & 306.00 & 3700.00 & .75 & 1.000 & 1.000 & 108.68471 & -.18471 \\
\hline 109.10 & 404.00 & 3716.00 & .75 & 1.000 & 1.000 & 109.30461 & -.20461 \\
\hline 109.70 & 509.00 & 3734.00 & .75 & 1.000 & 1.000 & 109.96972 & -.26972 \\
\hline 110.10 & 607.00 & 3758.00 & .75 & 1.000 & 1.000 & 110.59839 & -.49839 \\
\hline 107.90 & 216.00 & 4335.00 & .75 & 1.000 & 1.000 & 108.82844 & -.92844 \\
\hline 109.20 & 305.00 & 4350.00 & .75 & 1.000 & 1.000 & 109.39192 & -.19192 \\
\hline 110.50 & 407.00 & 4364.00 & .75 & 1.000 & 1.000 & 110.03420 & .46580 \\
\hline 111.10 & 508.00 & 4381.00 & .75 & 1.000 & 1.000 & 110.67363 & .42637 \\
\hline 111.20 & 606.00 & 4397.00 & .75 & 1.000 & 1.000 & 111.29353 & -.09353 \\
\hline 108.90 & 210.00 & 4928.00 & .75 & 1.000 & 1.000 & 109.44236 & -.54236 \\
\hline 110.20 & 307.00 & 4947.00 & .75 & 1.000 & 1.000 & 110.05940 & .14060 \\
\hline 110.90 & 405.00 & 4966.00 & .75 & 1.000 & 1.000 & 110.68259 & 21741 \\
\hline 112.20 & 502.00 & 4994.00 & .75 & 1.000 & 1.000 & 111.30950 & .89050 \\
\hline 112.50 & 584.00 & 4825.00 & .75 & 1.000 & 1.000 & 111.62803 & .87197 \\
\hline 108.40 & 219.00 & 3748.00 & .75 & 1.375 & 1.000 & 109.10640 & -.70640 \\
\hline 109.70 & 310.00 & 3752.00 & .75 & 1.375 & 1.000 & 109.67011 & .02989 \\
\hline 111.10 & 402.00 & 3756.00 & .75 & 1.375 & 1.000 & 110.23995 & .86005 \\
\hline
\end{tabular}




\begin{tabular}{|c|c|c|c|c|c|c|c|}
\hline $\begin{array}{c}\text { Sound Power } \\
\text { dBA } \\
\text { Laboratory } \\
\end{array}$ & $\begin{array}{c}\text { Speed } \\
\text { rpm }\end{array}$ & $\begin{array}{l}\text { Thrust } \\
\text { lbs }\end{array}$ & $\begin{array}{c}\text { Water } \\
\text { gpm }\end{array}$ & $\begin{array}{l}\text { Bit Size } \\
\text { in. }\end{array}$ & $\begin{array}{c}\text { Drill Steel } \\
\text { (hex/round) }\end{array}$ & $\begin{array}{c}\text { Sound Power } \\
\text { dBA } \\
\text { Model } \\
\end{array}$ & $\begin{array}{c}\text { Sound Power } \\
\text { dBA } \\
\text { Difference } \\
\end{array}$ \\
\hline 111.80 & 510.00 & 3779.00 & .75 & 1.375 & 1.000 & 110.92899 & .87101 \\
\hline 112.60 & 606.00 & 3789.00 & .75 & 1.375 & 1.000 & 111.53001 & 1.06999 \\
\hline 110.90 & 214.00 & 4352.00 & .75 & 1.375 & 1.000 & 109.73854 & 1.16146 \\
\hline 112.00 & 311.00 & 4361.00 & .75 & 1.375 & 1.000 & 110.34461 & 1.65539 \\
\hline 112.50 & 406.00 & 4371.00 & .75 & 1.375 & 1.000 & 110.93948 & 1.56052 \\
\hline 112.70 & 510.00 & 4383.00 & .75 & 1.375 & 1.000 & 111.59186 & 1.10814 \\
\hline 113.10 & 609.00 & 4396.00 & .75 & 1.375 & 1.000 & 112.21461 & .88539 \\
\hline 111.50 & 218.00 & 4953.00 & .75 & 1.375 & 1.000 & 110.42270 & 1.07730 \\
\hline 111.30 & 309.00 & 4965.00 & .75 & 1.375 & 1.000 & 110.99518 & .30482 \\
\hline 112.10 & 401.00 & 4967.00 & .75 & 1.375 & 1.000 & 111.56284 & .53716 \\
\hline 112.60 & 512.00 & 4986.00 & .75 & 1.375 & 1.000 & 112.26592 & .33408 \\
\hline 113.40 & 607.00 & 5007.00 & .75 & 1.375 & 1.000 & 112.87287 & .52713 \\
\hline 111.80 & 216.00 & 5523.00 & .75 & 1.375 & 1.000 & 111.03597 & .76403 \\
\hline 110.40 & 312.00 & 5528.00 & .75 & 1.375 & 1.000 & 111.63150 & -1.23150 \\
\hline 113.60 & 403.00 & 5942.00 & .75 & 1.375 & 1.000 & 112.64516 & .95484 \\
\hline 113.60 & 510.00 & 5558.00 & .75 & 1.375 & 1.000 & 112.88138 & .71862 \\
\hline 114.80 & 608.00 & 5569.00 & .75 & 1.375 & 1.000 & 113.49579 & 1.30421 \\
\hline 109.80 & 218.00 & 6244.00 & .75 & 1.375 & 1.000 & 111.83953 & -2.03953 \\
\hline 111.20 & 309.00 & 6256.00 & .75 & 1.375 & 1.000 & 112.41201 & -1.21201 \\
\hline 112.90 & 401.00 & 6275.00 & .75 & 1.375 & 1.000 & 112.99832 & -.09832 \\
\hline 114.30 & 509.00 & 6294.00 & .75 & 1.375 & 1.000 & 113.68297 & .61703 \\
\hline 113.40 & 608.00 & 6317.00 & .75 & 1.375 & 1.000 & 114.31669 & -.91669 \\
\hline 107.20 & 216.00 & 2347.00 & .75 & 1.000 & .000 & 107.44135 & -.24214 \\
\hline 108.09 & 307.00 & 2357.00 & .75 & 1.000 & .000 & 108.01163 & .07535 \\
\hline 109.04 & 405.00 & 2370.00 & .75 & 1.000 & .000 & 108.62823 & .41334 \\
\hline 110.04 & 508.00 & 2387.00 & .75 & 1.000 & .000 & 109.27995 & .76261 \\
\hline 111.00 & 607.00 & 2404.00 & .75 & 1.000 & .000 & 109.90709 & 1.09197 \\
\hline 108.07 & 216.00 & 2989.00 & .75 & 1.000 & .000 & 108.14592 & -.07862 \\
\hline 108.86 & 308.00 & 2999.00 & .75 & 1.000 & .000 & 108.72235 & .13419 \\
\hline 109.69 & 406.00 & 3008.00 & .75 & 1.000 & .000 & 109.33456 & .35732 \\
\hline 110.54 & 505.00 & 3022.00 & .75 & 1.000 & .000 & 109.95841 & .57811 \\
\hline 111.39 & 606.00 & 3036.00 & .75 & 1.000 & .000 & 110.59454 & .79825 \\
\hline 109.02 & 218.00 & 3686.00 & .75 & 1.000 & .000 & 108.92314 & .10098 \\
\hline 109.64 & 302.00 & 3699.00 & .75 & 1.000 & .000 & 109.45370 & .18855 \\
\hline 110.38 & 404.00 & 3709.00 & .75 & 1.000 & .000 & 110.09159 & 29003 \\
\hline 111.09 & 501.00 & 3723.00 & .75 & 1.000 & .000 & 110.70314 & .38187 \\
\hline 111.83 & 604.00 & 3738.00 & .75 & 1.000 & .000 & 111.35267 & .47389 \\
\hline 109.68 & 204.00 & 4239.00 & .75 & 1.000 & .000 & 109.44399 & .23960 \\
\hline 110.34 & 309.00 & 4247.00 & .75 & 1.000 & .000 & 110.09813 & .24184 \\
\hline 110.93 & 404.00 & 4257.00 & .75 & 1.000 & .000 & 110.69300 & 24097 \\
\hline 111.58 & 508.00 & 4269.00 & .75 & 1.000 & .000 & 111.34538 & .23574 \\
\hline 112.19 & 606.00 & 4278.00 & .75 & 1.000 & .000 & 111.95760 & .22768 \\
\hline
\end{tabular}




\begin{tabular}{|c|c|c|c|c|c|c|c|}
\hline $\begin{array}{c}\text { Sound Power } \\
\text { dBA } \\
\text { Laboratory }\end{array}$ & $\begin{array}{l}\text { Speed } \\
\text { rpm }\end{array}$ & $\begin{array}{c}\text { Thrust } \\
\text { lbs }\end{array}$ & $\begin{array}{c}\text { Water } \\
\text { gpm }\end{array}$ & $\begin{array}{l}\text { Bit Size } \\
\text { in. }\end{array}$ & $\begin{array}{c}\text { Drill Steel } \\
\text { (hex/round) }\end{array}$ & $\begin{array}{c}\text { Sound Power } \\
\text { dBA } \\
\text { Model } \\
\end{array}$ & $\begin{array}{c}\text { Sound Power } \\
\text { dBA } \\
\text { Difference } \\
\end{array}$ \\
\hline 110.63 & 212.00 & 4899.00 & .75 & 1.000 & .000 & 110.21749 & .41267 \\
\hline 111.14 & 310.00 & 4916.00 & .75 & 1.000 & .000 & 110.83848 & 29710 \\
\hline 111.59 & 403.00 & 4909.00 & .75 & 1.000 & .000 & 111.40240 & .18382 \\
\hline 112.11 & 506.00 & 4929.00 & .75 & 1.000 & .000 & 112.05742 & .05347 \\
\hline 112.63 & 608.00 & 4955.00 & .75 & 1.000 & .000 & 112.71287 & -.08592 \\
\hline 107.90 & 213.00 & 3680.00 & .75 & 1.375 & .000 & 109.78957 & -1.88957 \\
\hline 109.90 & 305.00 & 3692.00 & .75 & 1.375 & .000 & 110.36819 & -.46819 \\
\hline 111.70 & 403.00 & 3717.00 & .75 & 1.375 & .000 & 110.99796 & .70204 \\
\hline 112.90 & 509.00 & 3736.00 & .75 & 1.375 & .000 & 111.67032 & 1.22968 \\
\hline 113.30 & 606.00 & 3752.00 & .75 & 1.375 & .000 & 112.28407 & 1.01593 \\
\hline 108.70 & 213.00 & 4298.00 & 75 & 1.375 & .000 & 110.46780 & -1.76780 \\
\hline 111.60 & 314.00 & 4310.00 & .75 & 1.375 & .000 & 111.10174 & .49826 \\
\hline 112.50 & 402.00 & 4326.00 & .75 & 1.375 & .000 & 111.66017 & .83983 \\
\hline 114.00 & 508.00 & 4338.00 & .75 & 1.375 & .000 & 112.32485 & 1.67515 \\
\hline 114.80 & 607.00 & 4357.00 & .75 & 1.375 & .000 & 112.95418 & 1.84582 \\
\hline 107.30 & 212.00 & 4977.00 & .75 & 1.375 & .000 & 111.20683 & -3.90683 \\
\hline 108.00 & 303.00 & 4998.00 & .75 & 1.375 & .000 & 111.78919 & -3.78919 \\
\hline 112.30 & 398.00 & 5013.00 & .75 & 1.375 & .000 & 112.38955 & -.08955 \\
\hline 114.20 & 511.00 & 5037.00 & .75 & 1.375 & .000 & 113.11041 & 1.08959 \\
\hline 116.20 & 606.00 & 5060.00 & .75 & 1.375 & .000 & 113.71955 & 2.48045 \\
\hline 110.50 & 211.00 & 5617.00 & .75 & 1.375 & .000 & 111.90306 & -1.40306 \\
\hline 113.10 & 306.00 & 5632.00 & .75 & 1.375 & .000 & 112.50342 & .59658 \\
\hline 113.60 & 404.00 & 5646.00 & .75 & 1.375 & .000 & 113.12112 & .47888 \\
\hline 117.00 & 512.00 & 5671.00 & .75 & 1.375 & .000 & 113.81235 & 3.18765 \\
\hline 116.10 & 595.00 & 5686.00 & .75 & 1.375 & .000 & 114.33896 & 1.76104 \\
\hline 111.90 & 212.00 & 6260.00 & .75 & 1.375 & .000 & 112.61488 & -.71488 \\
\hline 113.60 & 312.00 & 6287.00 & .75 & 1.375 & .000 & 113.25914 & .34086 \\
\hline 114.90 & 404.00 & 6317.00 & .75 & 1.375 & .000 & 113.85752 & 1.04248 \\
\hline 115.90 & 507.00 & 6347.00 & .75 & 1.375 & .000 & 114.52351 & 1.37649 \\
\hline 116.90 & 598.00 & 6306.00 & .75 & 1.375 & .000 & 115.03782 & 1.86218 \\
\hline
\end{tabular}

\subsubsection{Development of An Equation for Determining a Sound Power Level}

The dependent variable, sound power level was then modeled by the following equation using the regression coefficients determined from table 5.16:

Sound Power Level $(\mathrm{dBA})=101.708-1.766($ water $)+.001($ thrust $)$

$+.007($ rotational speed $)+2.588($ bit size $)-.640($ drill steel type $)$ 
Utilizing equation (8) above, the mining community can now determine a sound power level, during the drilling cycle in high compressive rock media $(>20,000 \mathrm{psi})$ for a roof bolting machine using a simple equation developed from laboratory testing and statistical modeling.

Using equation (8) from above, an example is shown below illustrating the use of the equation and determining a sound power level given a specific drilling method (wet, mist or vacuum), thrust setting, rotational speed, bit size and type of drill steel. Assume a roof bolter operator is drilling into a high-compressive strength media ( $>20,000 \mathrm{psi})$, using the wet method of drilling, using a 1.375inch bit with round drill steel, a rotational speed set at $600 \mathrm{rpm}$ and a thrust setting at 4,000 lbs. Using equation (8) above and inputting the specific drilling parameters, the mining community could then determine a sound power level with significant confidence as shown below:

Sound Power Level $(\mathrm{dBA})=101.708-1.766($ water $)+.001($ thrust $)$

$+.007($ rotational speed $)+2.588($ bit size $)-.640($ drill steel type $)$

Sound Power Level $(\mathrm{dBA})=101.708-1.766(3)+.001(4,000)+0.007(600)+2.588(1.375)-$ $.640(1)$

$$
=101.708-5.30+4+4.20+3.56-0.640=107.53 \mathrm{dBA}
$$

By comparing the predicted sound power level of $107.53 \mathrm{dBA}$ above to the measured sound power level from the laboratory measurement shown below is:

$\begin{array}{rcrrrr}\begin{array}{c}\text { Sound Power } \\ \text { dBA }\end{array} & \begin{array}{c}\text { Speed } \\ \text { rpm }\end{array} & \begin{array}{c}\text { Thrust } \\ \text { lbs }\end{array} & \begin{array}{c}\text { Water } \\ \text { gpm }\end{array} & \begin{array}{c}\text { Bit Size } \\ \text { in. }\end{array} & \begin{array}{c}\text { Drill Steel } \\ \text { (hex/round) }\end{array} \\ \begin{array}{r}\text { Laboratory } \\ 107.70\end{array} & 572.00 & 3987.00 & 3.00 & 1.375 & 1.000\end{array}$


Sound Power Level $(\mathrm{dBA})=107.70-107.53=0.17 \mathrm{dBA}$, which,

demonstrates a significant correlation between the measured and predicted (determined) sound power level from the statistical model. The statistical model equation (equation 8), provides the mining community with a simple and reliable approach in determining a sound power level for a roof bolting machine during the drilling operation in high compressive strength rock media, given any type of drilling method (vacuum, wet or mist) and drilling parameter configuration (thrust, rotational speed, bit size and type of drill steel). Chapter 6 will then offer and provide the mining community with two different approaches in predicting sound pressure levels at the operator position of a roof bolting machine. One method of prediction, will utilize overall sound power levels either measured from laboratory tests or determined (predicted) from equation (8). The other approach, a more sophisticated and reliable approach, would predict sound pressure levels at the operator position of the roof bolting machine, using full-octave band frequency measurements obtained from laboratory testing for input into a computer model for simulating and predicting sound pressure levels from sound power level measurements. 


\section{Chapter 6}

\section{DEVELOPMENT AND UTILIZATION OF MODELS FOR PREDICTING SOUND PRESSURE LEVELS FROM LABORATORY TESTS}

\subsection{Introduction}

Underground mining machines are subject to many variables that can affect the noise levels measured. Some of these variables cannot be controlled while others can be influenced or even controlled by the machine operator. The acoustic environment in which the mining machines operate is a critical factor affecting the sound pressure levels measured. Underground mines are enclosed areas, which usually represent diffused fields. A diffuse sound field is a sound field in which the time average of the mean-square sound pressure is everywhere the same and the flow of acoustic energy in all directions is equally probable. The geometry and the composition of the surfaces influence the overall sound level by the number of rays (sound waves) being reflected or absorbed. Mine entries also have various shapes, rectangular, square, or arched, and various dimensions as well. These variations in shape and size affect the overall sound energy that is reflected or absorbed. These are the variables that cannot be controlled in the acoustic environment, and include geometry and composition of the surfaces, shape of the mine opening, and the compressive strength of the affected medium. Two methods of predicting the acoustic environment properties associated with underground coal mining machines and the sound pressure level experienced at the operator utilizing laboratory results are provided in this chapter. One model, demonstrates the prediction of sound pressure levels, given overall sound power levels and the second model, a more sophisticated and reliable modeling approach, utilizes full-octave band frequency measurements obtained from laboratory and mine testing for input, thereby, used for predicting sound pressure levels at the operator position. The objective for the development of the respective models is to provide a methodology for determining a miners' effective noise dosage related to measured and determined engineering noise control 
tests determined from laboratory trials dependent upon overall and full-octave band sound power levels. Upon completion of the models, the measured sound power determined in the laboratory, with a calculated or predicted sound absorption coefficient, could then be entered into the model to determine an operator's noise dosage relative to the drilling cycle of the roof bolting machine. The first model discussed will provide the mining community with a method to determine sound pressure levels experienced by the roof bolting operator, through inputting an overall sound power level. The second model presented will provide a more reliable approach in determining sound pressure levels experienced by the roof bolting machine operator utilizing full-octave band frequency sound power levels. This will be achieved using a ray-tracing program to predict the steady-state sound pressure level and the associated sound decay in a mine environment. This information will provide a snapshot of the environment and calculate the noise levels throughout the environment, additionally, it will account for the positions of an operator with respect to a machine and ultimately, provide the mining industry with a method to model a simple event within a mine section and determine the noise dosage to the roof bolting machine operator.

\subsection{Model for Predicting Sound Pressure Levels Using Overall Sound Power Levels}

\section{$\underline{6.2 .1 \quad \text { Introduction }}$}

It would be a time consuming and complex task to try to develop a model of all shapes and sizes of different mines. However, the acoustic differences are small and can be broken down into two shapes, a tunnel or a flat room. The acoustic properties of these two shapes are flexible enough to be applied to most other shapes. Underground noise travels both as a direct path and as multiple reflected paths. The number of reflections depends on the shape, dimensions, and the absorption property of the walls and roof. This absorption property is called the sabine absorption coefficient, $\alpha$, and is used to describe the degree of reflectivity of the walls and roof. The sabine absorption coefficient ranges from zero to one, where zero is total 
reflection and one is total absorption. A low sabine absorption coefficient means the environment is highly reverberant and a sabine absorption coefficient that is near one such as 0.9 means that most of the sound is absorbed upon reflection. In the case of a high sabine absorption coefficient a lower level of sound occurs as compared to a lower sabine absorption coefficient for that particular environment.

\subsubsection{Predicting Underground Sound Pressure Levels from Measurements Above Ground}

To predict underground sound levels from above ground measurements there are two basic techniques used. One method is the room acoustics method and the other is the imaging method. The room acoustic method describes the sound level in a large room where the sound undergoes a large number of reflections from the room's walls, roof, and floor. The imaging method is used to describe the tunnel surfaces, where the sound rays are traced from the source to the receiver and the sound energy is summed. The imaging method is more complex then the room acoustic method. The imaging method models a tunnel which is " $U$ " shaped rather than a square channel, however the modeling of the square channel is acoustically accurate. The reason being is that the individual sound rays differ only in a small and random manner.

\subsubsection{Differences Between the Room Acoustic Method and Imaging Method}

To illustrate the difference between the room acoustic method and the imaging method for predicting underground sound pressure levels, figure 6.1 provides an example for a tunnel $200 \mathrm{ft}$ long with a $10 \mathrm{ft}$-square cross-section. A sabine absorption coefficient of 0.2 is used for the walls with a source having a sound power of $100 \mathrm{dBA}$. 


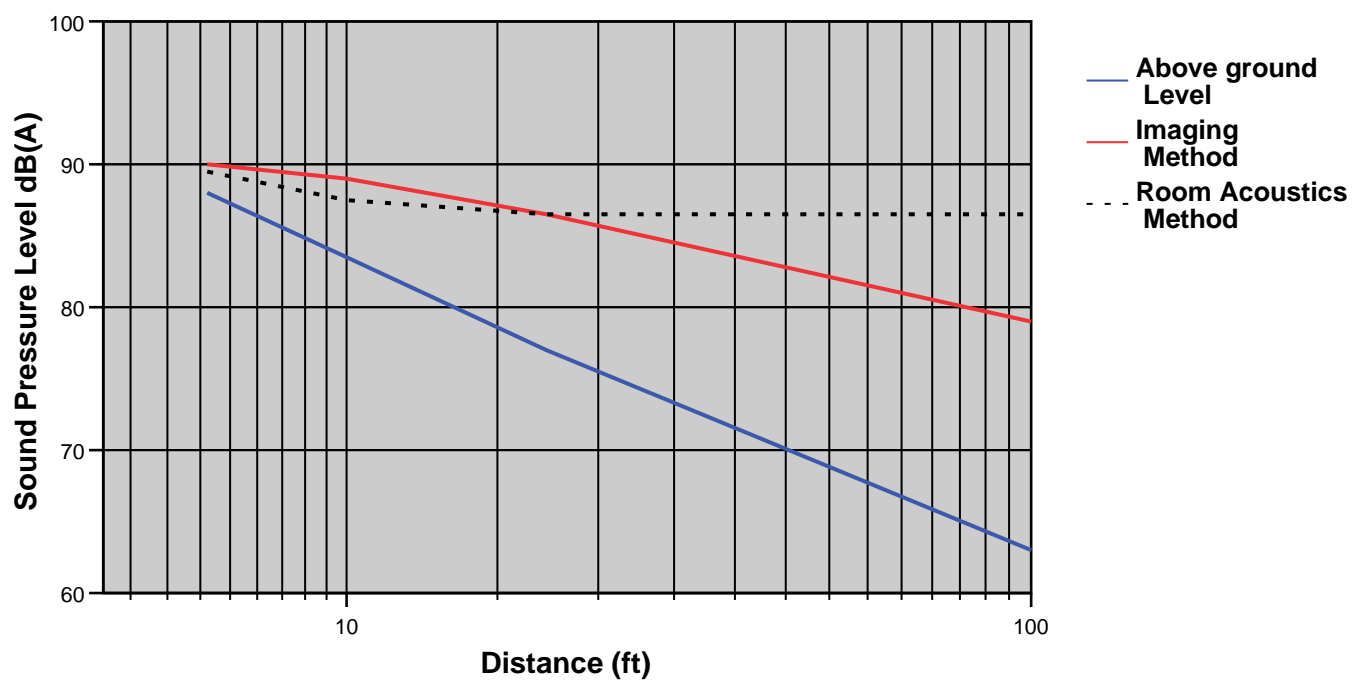

Figure 6.1 Comparison of Imaging and Room Acoustics Method of Predicting Sound Pressure Levels

The imaging and room acoustics predictive techniques are very close up to about 30 feet from the source of noise. Subsequent to $30 \mathrm{ft}$, the imaging method decreases at the same rate as the above ground sound level and the room acoustic method reaches some sound power value and does not decrease any further. The room acoustic method assumes a diffuse field throughout the tunnel where as the imaging method only assumes a diffuse field near the source, but not farther down the tunnel. The imaging method differs in sound levels as to where the location of the person is from the noise source. The room acoustics method differs in sound levels only until 30 $\mathrm{ft}$. from the noise source and does not decrease after $30 \mathrm{ft}$. While observing machine operators they are located typically close to the noise source or in the near field. The near field is the sound field close to the sound source (between the source and the far field) where the instantaneous sound pressure and particle velocity are not in phase with each other. Conversely, the far field is a portion of a sound field of a sound source in which the sound pressure level decreases by $6 \mathrm{~dB}$ for each doubling of the distance from the source. In the case of operators located in the near field, both the room acoustics and imaging method would work for predicting 
sound pressure levels. However, when examining other mine personnel away from the noise source or within the far field, the sound pressure levels in the far field would have greater accuracy with the imaging method. The reason for this is the imaging method assumes a diffuse field only near the source, and not further down the tunnel thus giving a better representation of the sound in a tunnel.

\subsubsection{Predicting Sound Levels at a Single Point}

Patterson, et.al (23), developed curves, plotting the correction factors for using above ground measurements to predict underground sound pressure levels for tunnels (figure 6.2) and flat rooms (figure 6.3). The curves plotted represent different sabine absorption coefficients and are plotted as a function of normalized distance from the acoustic center of the noise source. The correction factor is larger for tunnels as compared to flat rooms; this is due to the tunnels being more confined than the rooms, therefore, creating more reflections of sound.

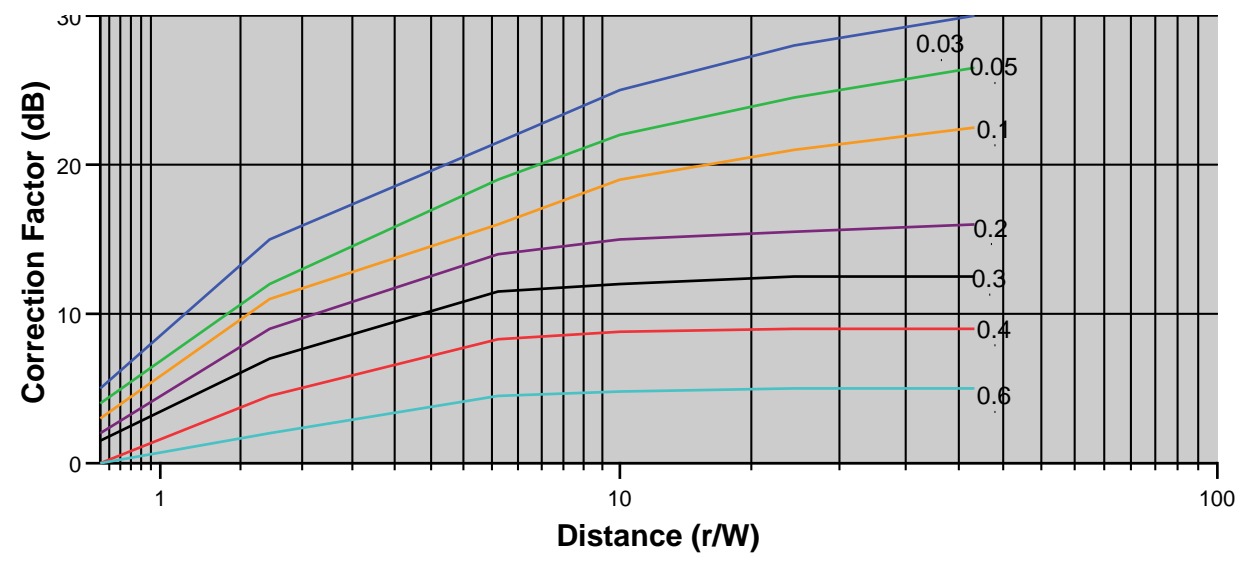

Figure 6.2 Correction Factors for Converting Above Ground Measurements to Underground Sound Pressure Levels (Tunnels) 


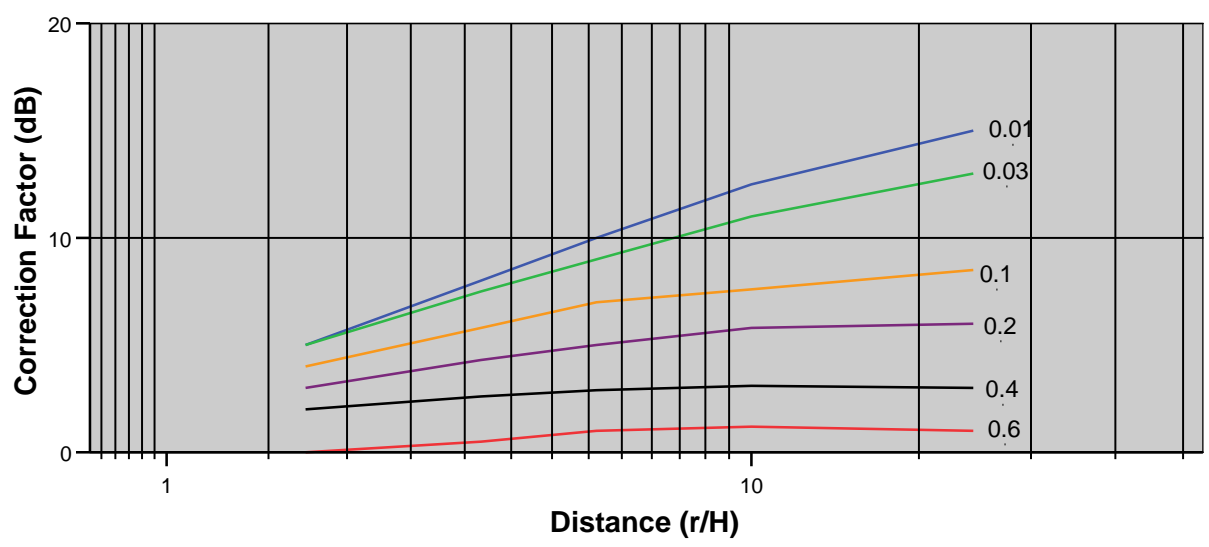

Figure 6.3 Correction Factors for Converting Above Ground Measurements to Underground Sound Pressure Levels (Flat Rooms)

The limitation of figures 6.2 and 6.3 is they only provide correction factors at a single point, relative to a measured distance from the source as measured above ground for determining sound pressure levels underground. To determine sound pressure levels below ground at any point, one would have to know the exact distances mine personnel are from the noise source and then measure sound pressure levels above ground from the specific distances to provide correction factors for determining sound pressure levels underground at the relative distances, a very cumbersome and unfriendly approach.

\subsubsection{Predicting Sound Levels at Multiple Points}

A more direct method in determining the underground sound pressure level at any point underground without having to conduct or measure all the above ground sound pressure level measurements would be to know or determine the sound power of the noise source above ground. Patterson, et.al (24), developed curves to determine the A-weighted sound pressure level at any point underground, using the measured or known sound power level of the machine. Figures 6.4 and 6.5 represent plots for determining two correction factors, namely $\mathrm{G}$ and $\mathrm{F}$, for determining the underground A-weighted, sound pressure level at a specific location for tunnels and flat rooms, respectively if you can identify the sabine absorption coefficient and the sound power of the noise source. 
The following equation is used to determine the underground A-weighted, sound pressure level.

$$
\mathrm{L}_{\mathrm{p}}(\text { underground })=\mathrm{L}_{\mathrm{w}}(\text { above ground })-(\mathrm{G}+\mathrm{F})
$$

where:

$\mathrm{L}_{\mathrm{p}}$ (underground $)=\mathrm{A}$-weighted sound pressure level, $\mathrm{dBA}-$ predicted underground $\mathrm{L}_{\mathrm{w}}($ above ground $)=\mathrm{A}-$ weighted sound power level, $\mathrm{dBA}-$ measured above ground $\mathrm{G}$ and $\mathrm{F}=$ Correction factors

Using the statistical model equation developed in the previous section, Development of An Equation for Determining a Sound Power Level, one could then predict the sound pressure level, experienced by a roof bolting machine operator utilizing this modeling approach. For example, assume a roof bolter operator is drilling into a high-compressive strength media $(>20,000 \mathrm{psi})$, using the wet method of drilling, using a 1.375-inch bit with round drill steel, a rotational speed set at $600 \mathrm{rpm}$ and a thrust setting at 4,000 lbs. Using the statistical model equation and inputting the specific drilling parameters, the sound power level is shown below:

Sound Power Level $(\mathrm{dBA})=101.708-1.766($ water $)+.001($ thrust $)+.007($ rotational speed $)+$ 2.588(bit size) - .640(drill steel type)

Sound Power Level $(\mathrm{dBA})=101.708-1.766(3)+.001(4,000)+0.007(600)+2.588(1.375)-$ $.640(1)$

$$
=101.708-5.30+4+4.20+3.56-0.640=107.5 \mathrm{dBA}
$$

Determining a sound power level of $107.5 \mathrm{dBA}$, one could then use figure 6.4 to determine the sound pressure level at a specific distance from the noise source, for example $30 \mathrm{ft}$. Assuming the tunnel width is $16 \mathrm{ft}$ and the sabine absorption coefficient is 0.2 , therefore, $\mathrm{r}$ would equal 30 
$\mathrm{ft}$ and $\mathrm{W}$ would equal $16 \mathrm{ft}$ and the normalized source-to-distance, $\mathrm{r} / \mathrm{W}$, would equal 30ft/16ft, or 1.9. Using figure $6.4, \mathrm{G}$ would equal $-2.5 \mathrm{dBA}$ and $\mathrm{F}$ would equal $23 \mathrm{dBA}$ and then using equation (9):

$$
\begin{aligned}
& \left.\mathrm{L}_{\mathrm{p}}(\text { underground })=\mathrm{L}_{\mathrm{w}} \text { (above ground }\right)-(\mathrm{G}+\mathrm{F}) \\
& \mathrm{L}_{\mathrm{p}}(\text { underground })=107.5 \mathrm{dBA}-(-2.5+23)=107.53-(20.5)=87.0 \mathrm{dBA}, 30 \mathrm{ft} \text { from the }
\end{aligned}
$$
noise source. 

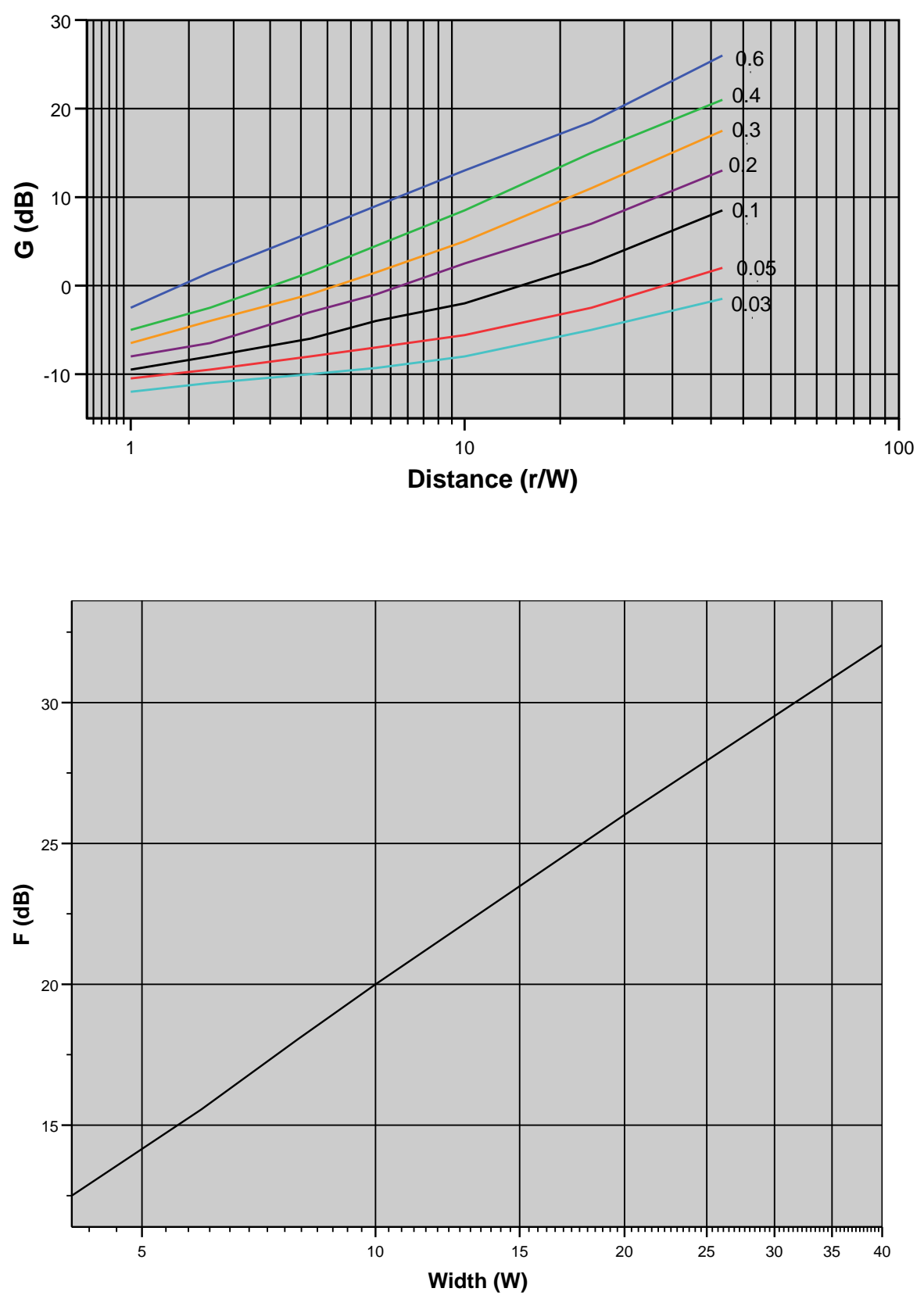

Figure 6.4 Correction Factors for Determining Underground Sound Pressure Levels from Sound Power Measurements Above Ground (Tunnels) 

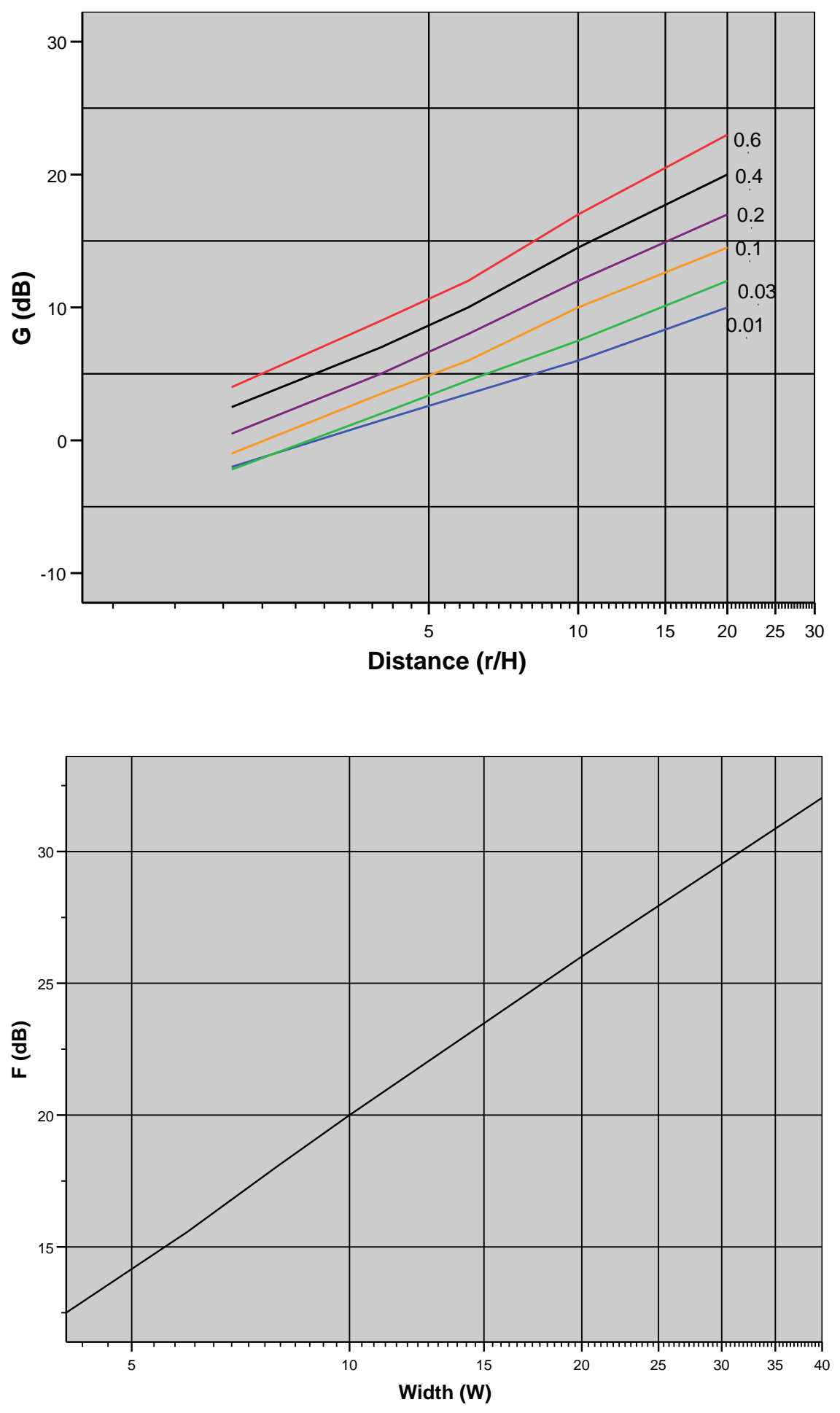

Figure 6.5 Correction Factors for Determining Underground Sound Pressure Levels from Sound Power Measurements Above Ground (Tunnels) 


\subsubsection{Predicting Sound Levels in the Near-Field}

Determining an underground sound pressure level near the machine or the noise source is a more difficult task, due to encountering the geometric near field. The shape and size of the machine and the location of the noise source on the machine plays an important role in the behavior of sound pressure levels. For example, two machines may have far field sound pressure levels equal to each other, but could have very different sound pressure levels near the machine. For example, when measuring sound pressure levels close to the noise source, an error of one or two-feet can be much more significant than measuring a sound pressure level 40-50 ft away from the noise source.

To address the near field issue relative to sound pressure level measurements, Patterson (20), developed correction factor curves, which are used for calculating sound pressure levels close to the noise source for tunnels and flat rooms (figure 6.6). Several assumptions were determined when using the correction curves and consisted of: 1) the machine shape and size can influence the results and the curves are only approximations; 2) the location of the acoustic center of the noise source must be accurate and 3) the curves are on the conservative side and the predicted sound pressure levels may be 1-2 dBA greater than would be measured underground. 

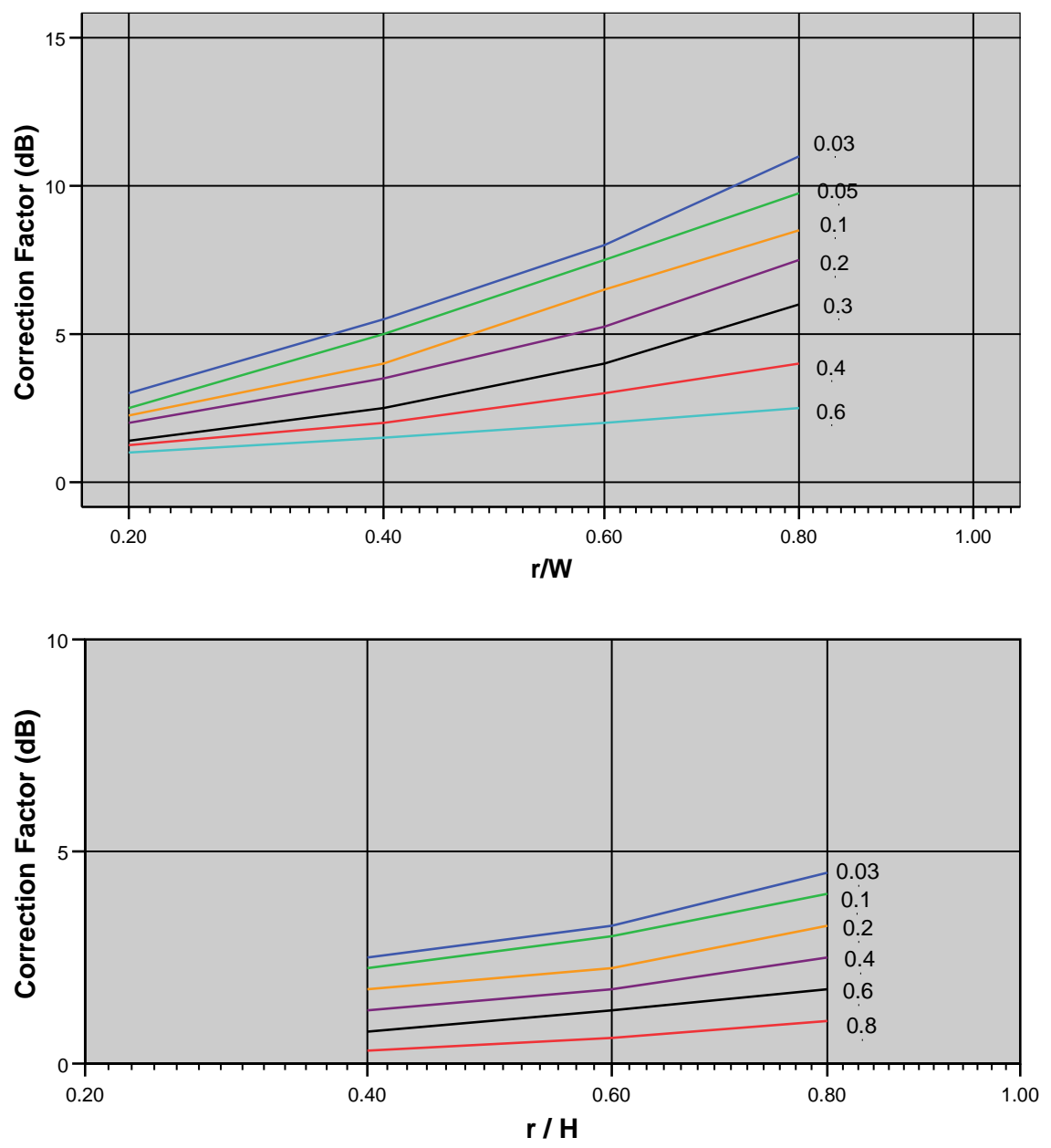

Figure 6.6 Correction Factors for Determining Sound Pressure Levels Underground in the Near Field (Top-Tunnel and Bottom-Flat Room)

As mentioned above, the acoustic center of a noise source has to be measured accurately. One can locate the acoustic center of a noise source by: 1) assuming all measurements for sound power are made at $25 \mathrm{ft}$ from the geometric center of the machine; 2) record the sound pressure level $25 \mathrm{ft}$ from the front of the machine; 3) move the microphone at the rear and move the microphone in and out until the same sound pressure level is experienced as in the front of the machine, the halfway distance between the two measurements is the acoustic center and 4) repeat the process on the left and right sides of the machine to find the acoustic center along that particular axis. For utilization of this model, knowledge of sound power level and the acoustic center are necessary information in predicting underground sound pressure levels. 
Using figure 6.6 above, one could then determine or predict the underground sound pressure level at the operator position of a roof bolting machine taking into account the assumptions used for the development of the curves in figure 6.6 mentioned above. However, this type of approach for predicting sound pressure levels underground utilizes numerous assumptions and adopts a very conservative approach. Additionally, locating the acoustic center of the piece of equipment can also be very difficult, dependent upon the type, location and the number of noise sources associated with the particular machine. The location of the acoustic center depends upon numerous parameters and can be strongly influenced by minimal details of a machine, such as, the machine having a reflective surface behind a noise source, in which, would provide additional sound energy towards the operator, therefore the acoustic center would be closer than typically measured from the operator to the noise source. For the reasons mentioned above, this type of modeling approach, determining sound pressure levels in the nearfield, is a very approximate approach. Section 6.3 provides a more reliable approach for determining sound pressure levels in the near-field.

\subsubsection{Limitations of Model Utilizing Overall Sound Power Levels}

Section 6.2 provided several methods for determining sound pressure levels underground using overall sound power levels measured. However, the approach contained several limitations. As mentioned in section 6.2.2.4, Predicting Sound Levels in the Near-Field, numerous assumptions were required and a conservative approach was used to predict sound pressure levels in the near-field. More importantly, the model predictions utilized absorption coefficients, which, were determined using the suitable methods available 30 years ago. The authors did mention that a more thorough investigation relative to the dependence of acoustic absorption on ore type and mine environment was needed to be conducted and many more measurements would be needed to obtain extreme confidence in the results of the model. 
Section 6.3 provides a more reliable modeling approach, utilizing measured absorption coefficients, for predicting sound pressure levels underground using laboratory results. Additionally, the model developed in section 6.3, provides a more accurate description of the sound pressure levels experienced by operators of roof bolting machine equipment in the nearfield.

\subsection{Model for Predicting Sound Pressure Levels Using Full-Octave Band Frequency Sound Power Levels}

\section{$\underline{6.3 .1 \quad \text { Ray-tracing Technique }}$}

Ray-tracing is a technique that can be used to predict sound fields in mines of various shapes and sizes. A computer program will simulate rays that are emitted from each noise source in a random or deterministic fashion. Each ray in the program is then reflected and scattered by surfaces, barriers and objects until it reaches a receiver. The great potential of raytracing techniques is the ability to display contour maps of noise levels of various mining machines and then using the information to determine a noise dosage of operators in a particular mine environment.

\subsubsection{Raynoise Computer Program}

The Raynoise program was the noise modeling software utilized for displaying and predicting sound pressure levels experienced by roof bolter operators (figure 6.7). 


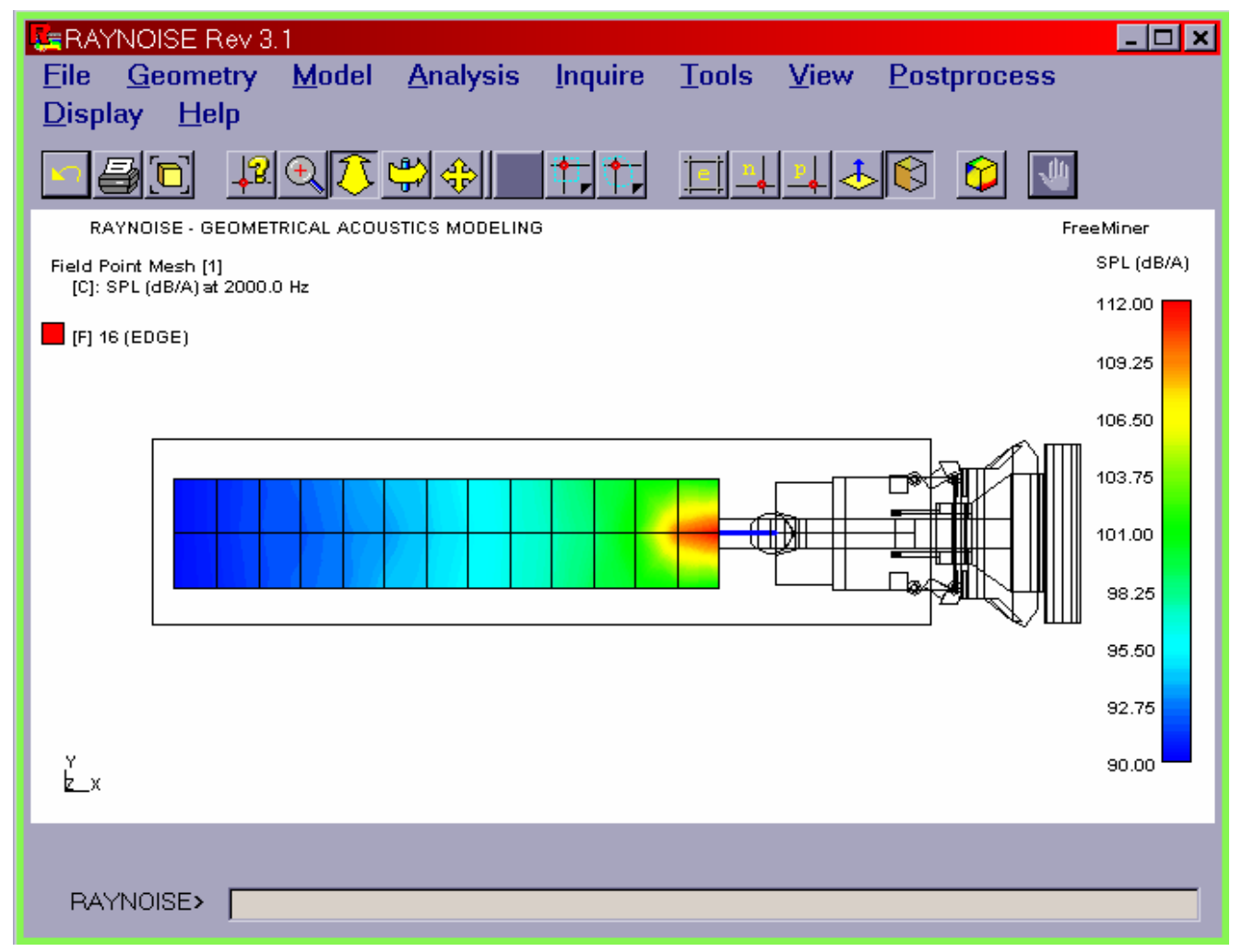

Figure 6.7 Sound Pressure Level Contour Plot Using the Raynoise Program

The Raynoise program uses a ray-tracing based technique to calculate the noise characteristics of a given source/room configuration. A key aspect of the package is that the noise sources and material properties are defined in terms of full octave-band, not one-third octave-band format. The program also has the capability of importing model information in AutoCAD DXF format. Additionally, the package has command file capabilities that allow complete model and test definitions to be written and processed. This capability is extremely helpful for processing a variety of tests in bulk and for varying parameters for a single test. The program also has command-line operation capabilities that allow it to be used as a 'black box' by other software. For example, "Rayserve" is an in-house package developed at the Pittsburgh Research Laboratory. Rayserve creates a shell around the Raynoise package that allows it to act as a noise profile engine, or "black box". The benefit is that many tests can be processed in bulk using the 
Rayserve program (25). This is extremely beneficial because when Raynoise is running it takes a lot of processor time, making a computer unusable until model run completion. Rayserve also automatically calculates the overall sound pressure level results for a given test setup by running the test at each octave band frequency and combining the results. However, Raynoise does have some limitations. One limitation is the package can only make calculations for a specific frequency and to generate overall results, a model needs to be run at each octave band frequencies and the resultant sound pressure level for each frequency band is then combined interdependent of the Raynoise package.

\section{$\underline{6.3 .3 \quad \text { Absorption Coefficients }}$}

Classic absorption/reverberation estimation using T60 measurements (measuring how sound decays over a period of time and distance) will not work well in the underground mining environment because the classic absorption theory assumes (1) a finite room, (2) a diffuse field and (3) relatively uniform absorption. None of these factors is true in an open ended mine entry. The assumption then is to treat the mine entry as an "infinite" duct, i.e. very little of the acoustic power traveling down the duct is ever reflected back into the source area. In order to determine the absorption coefficient, the measurements are matched to a ray model (or image source model) of the acoustic field radiated from the source in an "infinite" duct. The entry is modeled as a finite entry with an absorption coefficient of $\alpha=1$ at both ends to make it appear infinite. The ray model (Figure 6.8) is used to calculate the sound pressure level at the measurement positions based on varying absorption coefficients relative to the acoustic environment. 


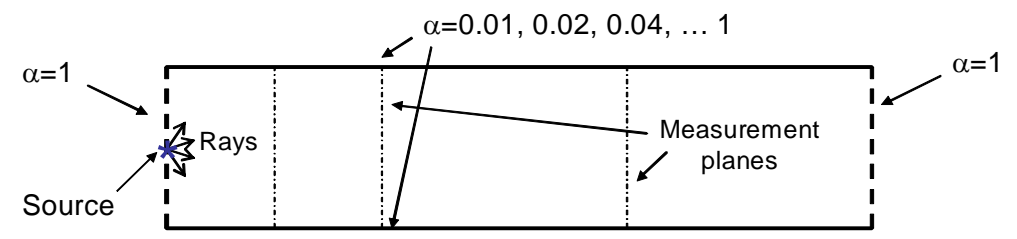

Figure 6.8 Illustration of Ray Tracing for Analyzing the Acoustic Environment

Since the entry, associated with underground coal mining, is fairly wide ( $>15 \mathrm{ft}$ across), this method will work well, even at low frequencies within the frequency spectrum. The procedure used for collecting acoustical data in the mine environment for estimating the absorption coefficients for utilization in the ray tracing model, is provided in section 6.3 below.

\subsubsection{Method for Determining Absorption Coefficients in an Underground Coal Mine}

The method utilized to determine the absorption coefficients in an underground coal mine is displayed below.

\subsubsection{Underground Measurements and Testing Parameters}

Figure 6.9 displays the measurement scheme used in determining the coefficients of absorption in an underground mine setting. 


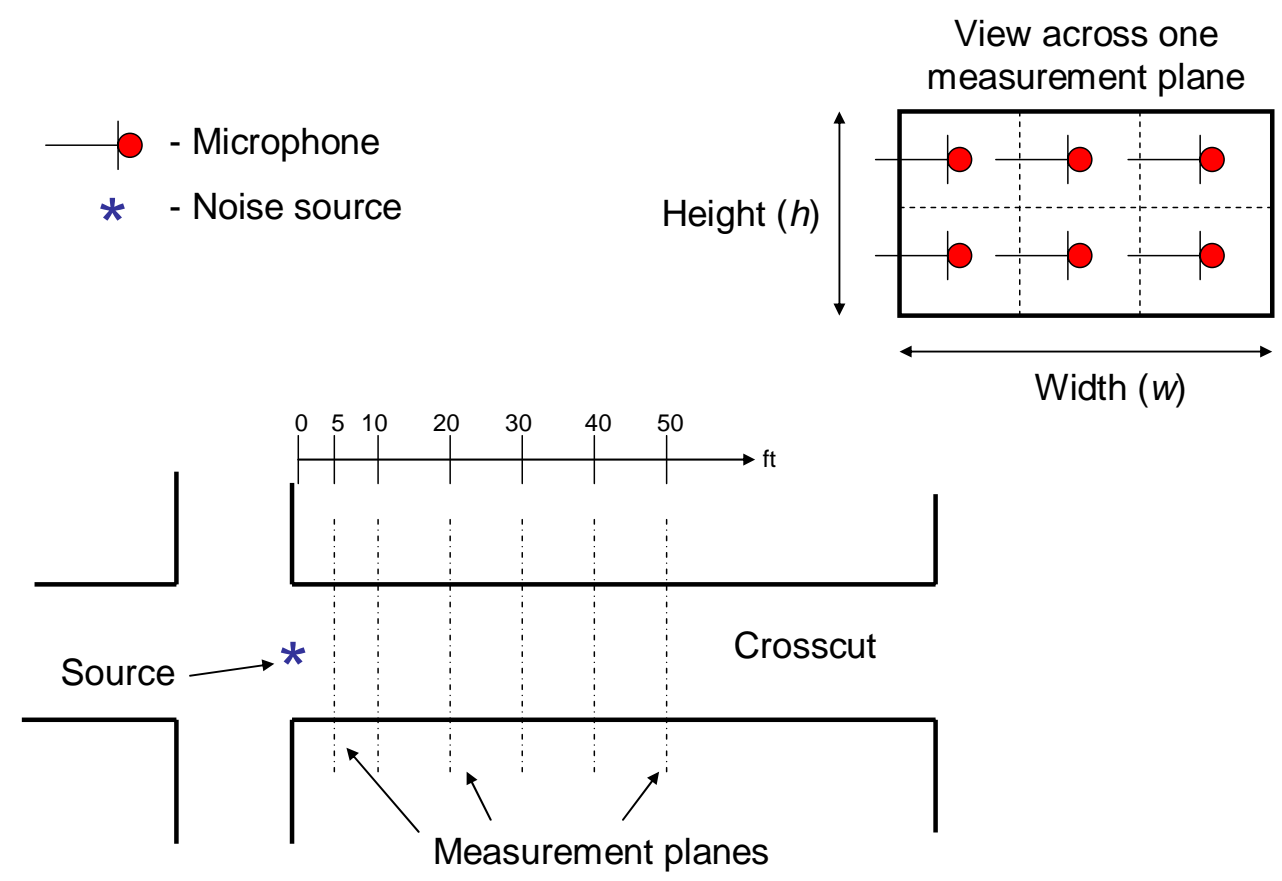

Figure 6.9 Measurement Layout Used for Determining Absorption Coefficients in an Underground Coal Mine

The calibrated noise source (fan) was positioned near the end of a crosscut, or the edge of the mine entry as shown in figure 6.9 above. Figure 6.10 shows a picture of the calibrated noise source to be utilized for conducting the underground mine tests. 


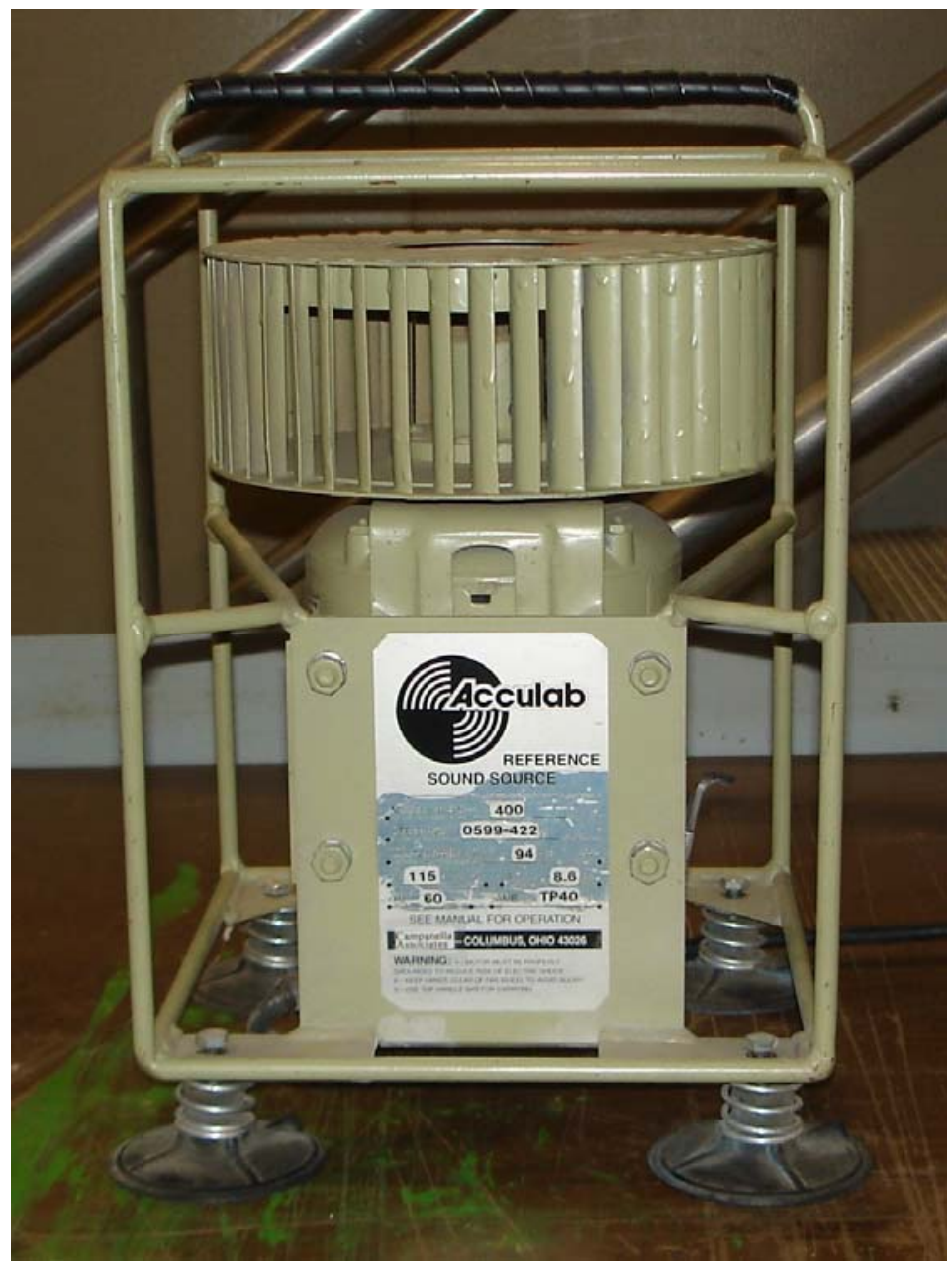

Figure 6.10 Photograph of Calibrated Sound Source for Underground Testing

The noise source (fan) was placed at the midway point of the crosscut and at a position halfway between the floor and roof of the crosscut. The actual position of the noise source was recorded and documented for analysis procedures to be performed in determining the absorption coefficients of the mine environment. The octave-band sound power levels for the calibrated noise source are shown in table 6.1 below. 
Table 6.1 One-Third Octave-Band Sound Power Levels for Calibrated Noise Source

\begin{tabular}{|c|c|}
\hline $\begin{array}{c}\text { Octave-band } \\
\text { (Hz) }\end{array}$ & $\begin{array}{c}\text { Sound Power } \\
\text { (dB) }\end{array}$ \\
\hline 63 & 72.8 \\
\hline 125 & 78.9 \\
\hline 250 & 80.1 \\
\hline 500 & 79.9 \\
\hline 1000 & 83.6 \\
\hline 2000 & 84.8 \\
\hline 4000 & 83.0 \\
\hline 8000 & 80.2 \\
\hline
\end{tabular}

Additionally, the actual dimensions of the crosscut were measured and recorded. The crosscut was divided into equal areas or sub-sections and the center of each sub-section represented a measurement location as shown in figure 6.9 above. Several measurement planes were developed and measured to collect the acoustical data across the measured planes within each subsection previously established. At each measurement location, the one-third octave band sound pressure level was measured due to the calibrated noise source and recorded at the 63hertz thru 8,000-hertz one-third octave bands. A Brüel and Kjaer 2260 Investigator was used to collect the one-third octave band data and shown in figure 6.11 below. The Brüel and Kjaer 2260 Investigator is a handheld real-time one-third octave band device with frequency analysis, statistics and logging capabilities. 


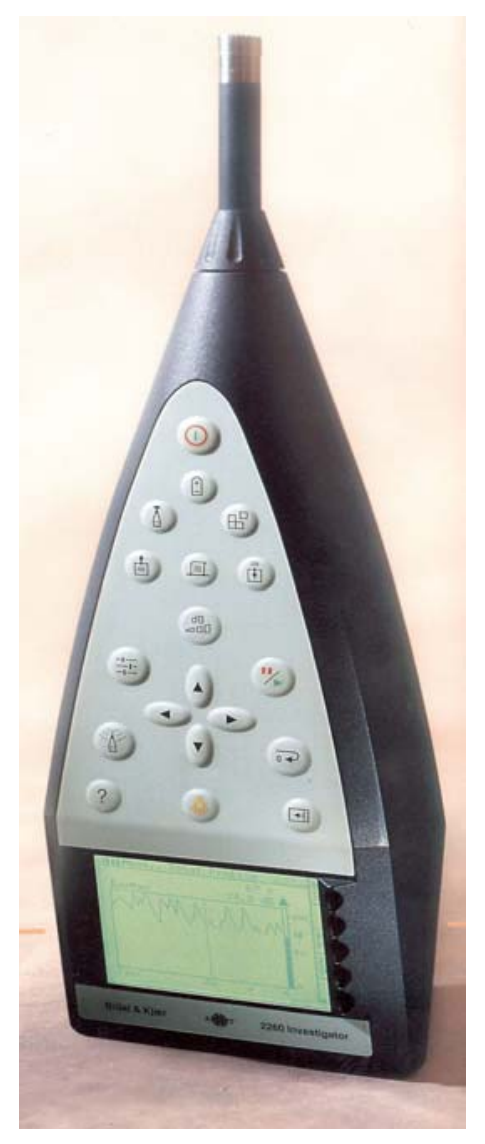

Figure 6.11 Photograph of a Brüel and Kjaer 2260 Investigator

Utilizing the measurement scheme from figure 6.9 for underground testing, the calibrated noise source (fan) was placed inside the right open end of a crosscut. A total of forty-eight, one-third octave band measurements were performed using the Brüel and Kjaer 2260 Investigator for characterization of the acoustical mining environment. Two measurements were conducted at each of the twenty-four monitoring points within the crosscut, therefore, accounting for fortyeight measurements. At each monitoring point, a measurement (bottom point) was conducted 0.7 meters from the floor and the other measurement was performed at 1.4 meters (top point) from the floor. The length of the crosscut measured 22 meters. Figure 6.12 provides the location of the measuring points (twenty-four) and the position of the measurement planes with respect to 
the width and height of the crosscut, utilized for characterizing the acoustical properties of the mining environment.

\begin{tabular}{lllllllll}
$\mathbf{2 2 m}$ & $\mathbf{1 9 m}$ & $\mathbf{1 6 m}$ & $\mathbf{1 3 m}$ & $\mathbf{1 0 m}$ & $\mathbf{7 m}$ & $\mathbf{4 m}$ & $\mathbf{1 m}$ & \\
\hline 22 & 19 & 16 & 13 & 10 & 7 & 4 & 1 \\
23 & 20 & 17 & 14 & 11 & 8 & 5 & 2 & source \\
24 & 21 & 18 & 15 & 12 & 9 & 6 & 3 &
\end{tabular}

$\begin{array}{llllllllll}\text { width } & 6.6 \mathrm{~m} & 6.0 \mathrm{~m} & 5.3 \mathrm{~m} & 5.6 \mathrm{~m} & 5.7 \mathrm{~m} & 5.6 \mathrm{~m} & 5.6 \mathrm{~m} & 5.1 \mathrm{~m}\end{array}$

$\begin{array}{lllllllll}\text { height } & 2.3 \mathrm{~m} & 2.3 \mathrm{~m} & 2.2 \mathrm{~m} & 2.1 \mathrm{~m} & 2.3 \mathrm{~m} & 2.3 \mathrm{~m} & 2.2 \mathrm{~m} & 2.1 \mathrm{~m}\end{array}$

Figure 6.12 Measurement Locations for Determining Acoustical Properties Underground

An example of the one-third octave data collected for all forty-eight measuring points is shown in table 6.2. 
Table 6.2 Example of the One-Third Octave Data Collected Underground

\begin{tabular}{|c|c|c|c|}
\hline Instrument: & & 2260 & \\
\hline Start Time: & & 08/06/2004 03:28:40 AM & \\
\hline End Time: & & 08/06/2004 03:28:55 AM & \\
\hline Elapsed Time: & & $0: 00: 15$ & \\
\hline Bandwidth: & & $1 / 3$ Octave & \\
\hline Calibration Time: & & 11/04/2003 04:19:15 PM & \\
\hline Calibration Level: & & $93.9 \mathrm{~dB}$ & \\
\hline 08/06/2004 03:28:40 AM - 03:28:55 AM & & & \\
\hline $\mathrm{Hz}$ & LLeq & LLSMax & LLSMin \\
\hline 63 & 65.54 & 66.76 & 63.02 \\
\hline 80 & 64.3 & 65.54 & 62.53 \\
\hline 100 & 67.56 & 68.79 & 65.12 \\
\hline 125 & 74.08 & 74.55 & 72.75 \\
\hline 160 & 66.04 & 67.56 & 64.64 \\
\hline 200 & 62.93 & 63.53 & 62.25 \\
\hline 250 & 64.64 & 65.79 & 60.93 \\
\hline 315 & 66.06 & 66.88 & 63.42 \\
\hline 400 & 69.09 & 70.01 & 67.7 \\
\hline 500 & 68.58 & 70.31 & 67.53 \\
\hline 630 & 67.25 & 68.15 & 66.38 \\
\hline 800 & 69.44 & 70.33 & 68.2 \\
\hline 1000 & 72.41 & 73.18 & 70.13 \\
\hline 1250 & 73.39 & 73.95 & 70.66 \\
\hline 1600 & 73.86 & 74.46 & 71.57 \\
\hline 2000 & 72 & 72.48 & 70.25 \\
\hline 2500 & 71.18 & 71.54 & 68.81 \\
\hline 3150 & 69.72 & 70.19 & 67.8 \\
\hline 4000 & 68.36 & 68.59 & 66.33 \\
\hline 5000 & 67.96 & 68.16 & 65.92 \\
\hline 6300 & 66.32 & 66.6 & 64.32 \\
\hline 8000 & 64.58 & 64.78 & 62.72 \\
\hline A & 82.19 & 82.49 & 80.13 \\
\hline $\mathrm{L}$ & 83.43 & 83.68 & 81.45 \\
\hline
\end{tabular}

It should be noted that Table 6.2 represents data collected for one measuring point, for this case it was measurement location number one, bottom measurement (see figure 6.12), therefore, forty-seven additional tests were conducted representing a similar format for obtaining the necessary data for characterization of the mining environment and for input into the Raynoise program. 


\subsubsection{Utilizing the Excelparse Program for Calculating Octave-Band Information}

As mentioned in section 6.3.4.1, data from underground testing was collected in one-third octave bands. The program, Raynoise, used for displaying and predicting sound pressure levels experienced by roof bolter operators requires full-octave band data. Therefore, a program was developed, referred to as Excelparse, to convert the one-third octave band data collected from underground testing to full-octave band data for input into the Raynoise program.

Upon completion of the underground testing, the data was downloaded to a portable computer. The data is in an Excel format with a separate file for each point measured as shown in section 6.3.4.1 (table 6.2). The Excelparse program extracts the sound pressure level information from each individual file and combines the results for all points measured into one file. Figure 6.13 displays a screenshot of the data from the Excelparse program. 


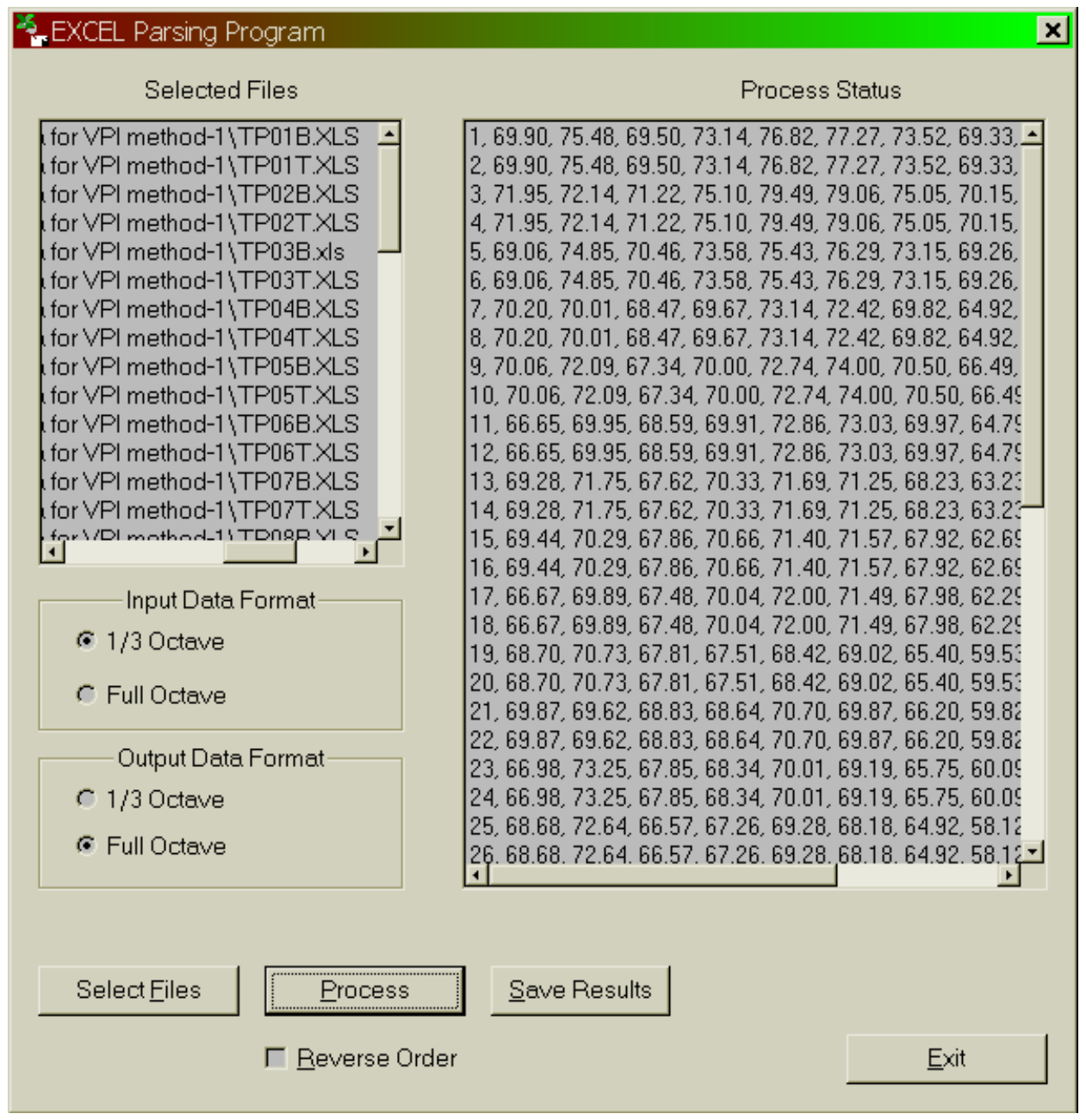

Figure 6.13 Screenshot of the Excelparse Program

The program determines full-octave band data from the one-third octave band data collected

from the underground measurements. The equation used in the program which converts one-

third to full-octave band sound pressure levels is shown below.

$$
\mathrm{SPL}=10 * \text { LOG10 (temp) }
$$

where

SPL $=$ Sound Pressure Level (in respective full-octave band)

$($ temp $)=10^{(\text {Previous one-third octave/10) }}+10^{(\text {Actual one-third octave/10) }}+10^{(\text {Next one-third octave/10) }}$ 
For example, by utilizing equation 8 and table 6.2 above, the full-octave band of $63 \mathrm{~Hz}$ could be obtained from one-third octave band data as shown below:

$$
\text { SPL }(63 \mathrm{~Hz} \text {-Octave Band })=10 * \text { LOG10 }\left\{10^{(65.44 / 10)}+10^{(65.54 / 10)}+10^{(64.3 / 10)}\right\}
$$

yields the following:

$$
\begin{aligned}
& \text { SPL (63 Hz-Octave Band) }-10 * \text { LOG10 }\left\{10^{(6.54)}+10^{(6.55)}+10^{(6.43)}\right\} \\
& \text { SPL (63 Hz-Octave Band) }-10 * \text { LOG10 }\{3,467,368.50+3,548,133.89+2,691,534.80\} \\
& \text { SPL (63 Hz-Octave Band) }-10 * \text { LOG10 }\{9,707,037.19\} \\
& \text { SPL (63 Hz-Octave Band) }-10 * 6.99 \\
& \text { SPL (63 Hz-Octave Band) }-69.9 \mathrm{~dB}
\end{aligned}
$$

Table 6.3, shown below, represents the full-octave band data (for $63 \mathrm{~Hz}, 125 \mathrm{~Hz}, 250 \mathrm{~Hz}, 500$ $\mathrm{Hz}, 1000 \mathrm{~Hz}, 2,000 \mathrm{~Hz}, 4,000 \mathrm{~Hz}$ and 8,000 Hz), generated from the Excelparse program for all forty-eight measuring points within the crosscut in the underground coal mine as shown in figure 6.12. 
Table 6.3 Measured Full-Octave Band Sound Pressure Levels from Underground Testing

\begin{tabular}{|c|c|c|c|c|c|c|c|c|}
\hline \multirow[t]{2}{*}{ Point Number } & \multicolumn{8}{|c|}{ Full-Octave Bands } \\
\hline & 63 & 125 & 250 & 500 & 1000 & 2000 & 4000 & 8000 \\
\hline & $\mathrm{dB}$ & $\mathrm{dB}$ & $\mathrm{dB}$ & $\mathrm{dB}$ & $\mathrm{dB}$ & $\mathrm{dB}$ & $\mathrm{dB}$ & $\mathrm{dB}$ \\
\hline 1 & 69.9 & 75.48 & 69.5 & 73.14 & 76.82 & 77.27 & 73.52 & 69.33 \\
\hline 2 & 69.9 & 75.48 & 69.5 & 73.14 & 76.82 & 77.27 & 73.52 & 69.33 \\
\hline 3 & 71.95 & 72.14 & 71.22 & 75.1 & 79.49 & 79.06 & 75.05 & 70.15 \\
\hline 4 & 71.95 & 72.14 & 71.22 & 75.1 & 79.49 & 79.06 & 75.05 & 70.15 \\
\hline 5 & 69.06 & 74.85 & 70.46 & 73.58 & 75.43 & 76.29 & 73.15 & 69.26 \\
\hline 6 & 69.06 & 74.85 & 70.46 & 73.58 & 75.43 & 76.29 & 73.15 & 69.26 \\
\hline 7 & 70.2 & 70.01 & 68.47 & 69.67 & 73.14 & 72.42 & 69.82 & 64.92 \\
\hline 8 & 70.2 & 70.01 & 68.47 & 69.67 & 73.14 & 72.42 & 69.82 & 64.92 \\
\hline 9 & 70.06 & 72.09 & 67.34 & 70 & 72.74 & 74 & 70.5 & 66.49 \\
\hline 10 & 70.06 & 72.09 & 67.34 & 70 & 72.74 & 74 & 70.5 & 66.49 \\
\hline 11 & 66.65 & 69.95 & 68.59 & 69.91 & 72.86 & 73.03 & 69.97 & 64.79 \\
\hline 12 & 66.65 & 69.95 & 68.59 & 69.91 & 72.86 & 73.03 & 69.97 & 64.79 \\
\hline 13 & 69.28 & 71.75 & 67.62 & 70.33 & 71.69 & 71.25 & 68.23 & 63.23 \\
\hline 14 & 69.28 & 71.75 & 67.62 & 70.33 & 71.69 & 71.25 & 68.23 & 63.23 \\
\hline 15 & 69.44 & 70.29 & 67.86 & 70.66 & 71.4 & 71.57 & 67.92 & 62.69 \\
\hline 16 & 69.44 & 70.29 & 67.86 & 70.66 & 71.4 & 71.57 & 67.92 & 62.69 \\
\hline 17 & 66.67 & 69.89 & 67.48 & 70.04 & 72 & 71.49 & 67.98 & 62.29 \\
\hline 18 & 66.67 & 69.89 & 67.48 & 70.04 & 72 & 71.49 & 67.98 & 62.29 \\
\hline 19 & 68.7 & 70.73 & 67.81 & 67.51 & 68.42 & 69.02 & 65.4 & 59.53 \\
\hline 20 & 68.7 & 70.73 & 67.81 & 67.51 & 68.42 & 69.02 & 65.4 & 59.53 \\
\hline 21 & 69.87 & 69.62 & 68.83 & 68.64 & 70.7 & 69.87 & 66.2 & 59.82 \\
\hline 22 & 69.87 & 69.62 & 68.83 & 68.64 & 70.7 & 69.87 & 66.2 & 59.82 \\
\hline 23 & 66.98 & 73.25 & 67.85 & 68.34 & 70.01 & 69.19 & 65.75 & 60.09 \\
\hline 24 & 66.98 & 73.25 & 67.85 & 68.34 & 70.01 & 69.19 & 65.75 & 60.09 \\
\hline 25 & 68.68 & 72.64 & 66.57 & 67.26 & 69.28 & 68.18 & 64.92 & 58.12 \\
\hline 26 & 68.68 & 72.64 & 66.57 & 67.26 & 69.28 & 68.18 & 64.92 & 58.12 \\
\hline 27 & 70.27 & 74.89 & 67.77 & 68.55 & 69 & 68.38 & 64.35 & 58.33 \\
\hline 28 & 70.27 & 74.89 & 67.77 & 68.55 & 69 & 68.38 & 64.35 & 58.33 \\
\hline 29 & 67.68 & 70.5 & 68.16 & 67.9 & 69.37 & 68.71 & 64.47 & 58.29 \\
\hline 30 & 67.68 & 70.5 & 68.16 & 67.9 & 69.37 & 68.71 & 64.47 & 58.29 \\
\hline 31 & 67.63 & 68.81 & 65.75 & 67.2 & 67.02 & 66.64 & 62.24 & 56.68 \\
\hline 32 & 67.63 & 68.81 & 65.75 & 67.2 & 67.02 & 66.64 & 62.24 & 56.68 \\
\hline 33 & 68.92 & 71.99 & 66.8 & 67.43 & 67.99 & 66.82 & 63.08 & 56.85 \\
\hline 34 & 68.92 & 71.99 & 66.8 & 67.43 & 67.99 & 66.82 & 63.08 & 56.85 \\
\hline 35 & 67.89 & 69.57 & 68.24 & 66.78 & 68.06 & 66.64 & 62.53 & 56.69 \\
\hline 36 & 67.89 & 69.57 & 68.24 & 66.78 & 68.06 & 66.64 & 62.53 & 56.69 \\
\hline 37 & 67.24 & 70.63 & 65.12 & 66.65 & 66.32 & 64.99 & 60.93 & 55.36 \\
\hline 38 & 67.24 & 70.63 & 65.12 & 66.65 & 66.32 & 64.99 & 60.93 & 55.36 \\
\hline 39 & 67.59 & 70.58 & 65.24 & 66.98 & 65.87 & 65.17 & 60.36 & 55.49 \\
\hline 40 & 67.59 & 70.58 & 65.24 & 66.98 & 65.87 & 65.17 & 60.36 & 55.49 \\
\hline 41 & 67.63 & 68.89 & 67.42 & 65.77 & 66.1 & 64.52 & 60.41 & 55.19 \\
\hline 42 & 67.63 & 68.89 & 67.42 & 65.77 & 66.1 & 64.52 & 60.41 & 55.19 \\
\hline 43 & 64.84 & 69.52 & 64.85 & 64.69 & 63.02 & 62.58 & 58.19 & 54.77 \\
\hline 44 & 64.84 & 69.52 & 64.85 & 64.69 & 63.02 & 62.58 & 58.19 & 54.77 \\
\hline 45 & 66.79 & 72.14 & 63.97 & 63.53 & 64.85 & 63.72 & 58.62 & 54.77 \\
\hline 46 & 66.79 & 72.14 & 63.97 & 63.53 & 64.85 & 63.72 & 58.62 & 54.77 \\
\hline 47 & 69.33 & 72.9 & 65.59 & 64.33 & 64.86 & 63.65 & 59.51 & 54.88 \\
\hline 48 & 69.33 & 72.9 & 65.59 & 64.33 & 64.86 & 63.65 & 59.51 & 54.88 \\
\hline
\end{tabular}




\subsubsection{Development of an Equivalent Model in Raynoise for Predicting Sound Pressure Levels}

The test conditions documented from the underground testing in figure 6.6 where then used to create an equivalent underground model utilizing the Raynoise package. The specific information used for input into the Raynoise package consisted of: 1) the height above the floor of the noise source and the $\mathrm{X}$ and $\mathrm{Y}$ coordinates relative to the placement and location of the calibrated noise source; 2) the height above the floor relative to the bottom and top measurement points as shown in figure $6.12 ; 3$ ) the total length of the crosscut being examined; 4) the crosscut height and width at each measurement plane location and 5) the sound power output of the calibrated noise source in full-octave band format as displayed in table 6.1. Inputting the test conditions mentioned above, an equivalent Raynoise model was constructed (25). The structural information for the equivalent model was determined thru the development of an AutoCAD drawing of the crosscut and then inputted into the Raynoise package. The measurement points within the model are then defined utilizing the underground measurements collected relative to the height above the floor in relation to the top and bottom point measurements for input into the Raynoise model. The calibrated noise source is then placed in the position as performed for the underground measurements and the sound power output is set for input into the Raynoise model as shown in Figure 6.14 below. 


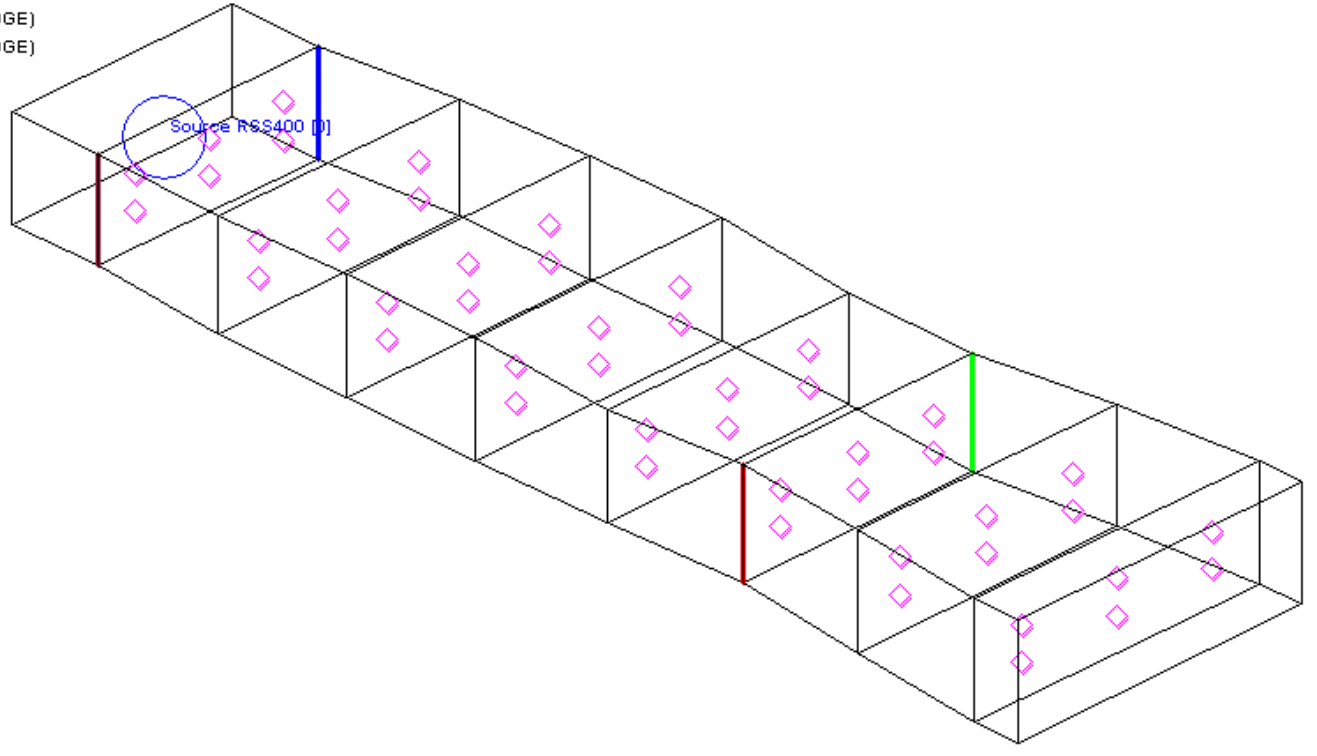

$\mathscr{L}_{Y}^{2}$

Figure 6.14 Test Layout for First Run in Raynoise Model

Due to the geometric underground measurements conducted in figure 6.12, a total of four diffraction edges were added to the model to account for the changing geometry of the crosscut measured underground. These edges are shown as $(\mathrm{F}) 1$ thru $(\mathrm{F}) 4$ shown in figure 6.14. An initial set of absorption coefficients, in which, are full-octave band based, were then inputted into the model relative to the underground mining environment. The first set of absorption coefficients inputted into the Raynoise model for the first run were selected from previous research conducted by Patterson, et.al (24) are shown in table 6.4 below. 
Table 6.4 Absorption Coefficients Utilized for First Run of Raynoise Model

\begin{tabular}{|c|c|}
\hline $\begin{array}{c}\text { Octave-band } \\
\text { (Hz) }\end{array}$ & $\begin{array}{c}\text { Absorption } \\
\text { Coefficient }\end{array}$ \\
\hline 63 & .035 \\
\hline 125 & .04 \\
\hline 250 & .17 \\
\hline 500 & .14 \\
\hline 1000 & .21 \\
\hline 2000 & .24 \\
\hline 4000 & .33 \\
\hline 8000 & .45 \\
\hline
\end{tabular}

The absorption coefficients were determined from a basic equation, where the volume, surface area and decay time are inputted as shown below:

$$
\alpha=0.05 * \mathrm{~V} / \mathrm{S} * 1 / \mathrm{T} 60
$$

where $\mathrm{V}$ represents the volume, $\mathrm{S}$ is the surface area and $\mathrm{T} 60$ represents the decay time. The decay time is determined by the amount of time it takes for sound to dissipate by $60 \mathrm{~dB}$ in each octave band for a given position.

A full-octave band test of the model, utilizing the absorption coefficients from table 6.4 was then processed utilizing the Raynoise program and Rayserve package, mentioned previously. For example, figure 6.15 displays graphically, the results for sound pressure levels experienced at the $1,000 \mathrm{~Hz}$ octave band relative to the absorption coefficients utilized in table 6.4. Seven additional plots for each of the other full-octave bands were processed and constructed, in which, were utilized for comparing the results from the actual underground testing displayed in table 6.3. 


$$
\text { प }
$$

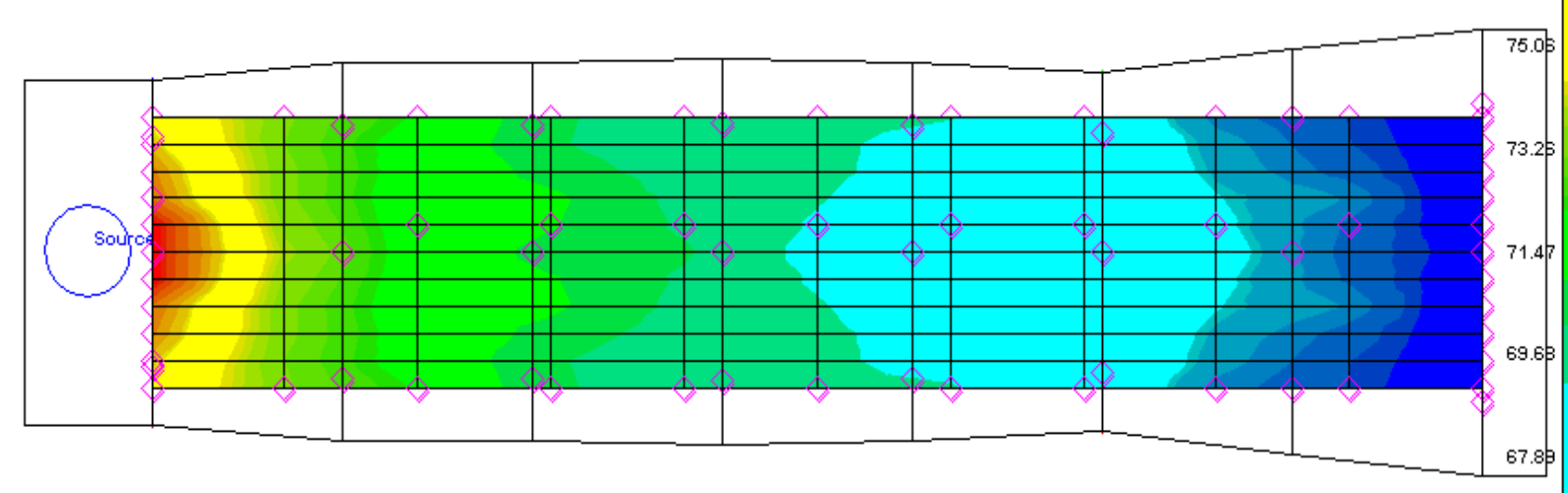

66.09 64.30

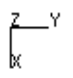

Figure 6.15 Sound Pressure Levels at 1,000 Hz Full-Octave Band

The linear sound pressure level information for each of the full-octave bands were also organized into a file and imported into Excel for comparing the calculated sound pressure level results to the measured sound pressure levels from table 6.3. The calculated sound pressure level results are shown in table 6.5 below. 
Table 6.5 Calculated Full-Octave Band Sound Pressure Levels - First Run of Model

\begin{tabular}{|c|c|c|c|c|c|c|c|c|c|}
\hline \multirow{2}{*}{$\begin{array}{c}\text { Point } \\
\text { Number }\end{array}$} & \multicolumn{8}{|c|}{ Octave Band (Hz) } & \multirow[b]{2}{*}{$\begin{array}{c}\text { Sound Pressure Level } \\
d B\end{array}$} \\
\hline & 63 & 125 & 250 & 500 & 1000 & 2000 & 4000 & 8000 & \\
\hline 1 & 70 & 74.1 & 73.5 & 74.1 & 75.9 & 75.9 & 73.2 & 70.2 & 82.9 \\
\hline 2 & 70.1 & 74.1 & 73.5 & 74.1 & 76 & 76 & 73.2 & 70.2 & 82.9 \\
\hline 3 & 72 & 76 & 76 & 76.5 & 78.6 & 78.8 & 76.4 & 73.8 & 85.5 \\
\hline 4 & 71.5 & 75.6 & 75.5 & 76 & 78.1 & 78.2 & 75.9 & 73.3 & 85.0 \\
\hline 5 & 70 & 74.1 & 73.5 & 74.1 & 75.9 & 75.9 & 73.2 & 70.2 & 82.9 \\
\hline 6 & 70.1 & 74.1 & 73.5 & 74.1 & 76 & 76 & 73.2 & 70.2 & 82.9 \\
\hline 7 & 66.8 & 70.9 & 69.9 & 70.6 & 72.2 & 72.2 & 69.1 & 65.7 & 79.2 \\
\hline 8 & 66.9 & 70.9 & 70 & 70.7 & 72.3 & 72.2 & 69.2 & 65.8 & 79.3 \\
\hline 9 & 67.3 & 71.3 & 70.4 & 71.1 & 72.7 & 72.7 & 69.7 & 66.2 & 79.7 \\
\hline 10 & 67.6 & 71.6 & 70.6 & 71.3 & 72.9 & 72.8 & 69.8 & 66.3 & 79.9 \\
\hline 11 & 66.8 & 70.9 & 69.9 & 70.6 & 72.2 & 72.2 & 69.1 & 65.7 & 79.2 \\
\hline 12 & 66.9 & 70.9 & 70 & 70.7 & 72.3 & 72.2 & 69.2 & 65.8 & 79.3 \\
\hline 13 & 65.8 & 69.8 & 68.3 & 69.1 & 70.4 & 70.2 & 66.8 & 62.9 & 77.5 \\
\hline 14 & 65.9 & 69.9 & 68.4 & 69.1 & 70.5 & 70.3 & 66.9 & 63 & 77.6 \\
\hline 15 & 65.9 & 69.9 & 68.4 & 69.2 & 70.6 & 70.4 & 67 & 63.1 & 77.7 \\
\hline 16 & 66.1 & 70.1 & 68.6 & 69.4 & 70.8 & 70.6 & 67.1 & 63.2 & 77.9 \\
\hline 17 & 65.8 & 69.8 & 68.3 & 69.1 & 70.4 & 70.2 & 66.8 & 62.9 & 77.5 \\
\hline 18 & 65.9 & 69.9 & 68.4 & 69.1 & 70.5 & 70.3 & 66.9 & 63 & 77.6 \\
\hline 19 & 65.1 & 69.1 & 67.1 & 68 & 69.1 & 68.8 & 65.1 & 60.9 & 76.3 \\
\hline 20 & 65.3 & 69.3 & 67.3 & 68.2 & 69.3 & 69 & 65.3 & 61 & 76.5 \\
\hline 21 & 65.8 & 69.8 & 67.9 & 68.8 & 69.9 & 69.6 & 65.9 & 61.6 & 77.1 \\
\hline 22 & 65.7 & 69.7 & 67.7 & 68.6 & 69.7 & 69.4 & 65.7 & 61.5 & 76.9 \\
\hline 23 & 65.1 & 69.1 & 67.1 & 68 & 69.1 & 68.8 & 65.1 & 60.9 & 76.3 \\
\hline 24 & 65.3 & 69.3 & 67.3 & 68.2 & 69.3 & 69 & 65.3 & 61 & 76.5 \\
\hline 25 & 65.3 & 69.2 & 67.2 & 68.1 & 69.1 & 68.8 & 65 & 60.5 & 76.4 \\
\hline 26 & 65.4 & 69.4 & 67.2 & 68.1 & 69.2 & 68.8 & 65 & 60.6 & 76.4 \\
\hline 27 & 64.9 & 68.8 & 66.5 & 67.5 & 68.4 & 68 & 64.2 & 59.7 & 75.7 \\
\hline 28 & 65 & 69 & 66.7 & 67.7 & 68.6 & 68.3 & 64.4 & 59.9 & 76.0 \\
\hline 29 & 65.3 & 69.2 & 67.2 & 68.1 & 69.1 & 68.8 & 65 & 60.5 & 76.4 \\
\hline 30 & 65.4 & 69.4 & 67.2 & 68.1 & 69.2 & 68.8 & 65 & 60.6 & 76.4 \\
\hline 31 & 64.4 & 68.4 & 66 & 67 & 67.9 & 67.5 & 63.5 & 58.9 & 75.2 \\
\hline 32 & 64.3 & 68.2 & 65.9 & 66.9 & 67.8 & 67.4 & 63.4 & 58.8 & 75.1 \\
\hline 33 & 64.3 & 68.3 & 66 & 66.9 & 67.8 & 67.4 & 63.5 & 59 & 75.2 \\
\hline 34 & 64.4 & 68.4 & 65.8 & 66.8 & 67.6 & 67.2 & 63.1 & 58.5 & 75.1 \\
\hline 35 & 64.4 & 68.4 & 66 & 67 & 67.9 & 67.5 & 63.5 & 58.9 & 75.2 \\
\hline 36 & 64.3 & 68.2 & 65.9 & 66.9 & 67.8 & 67.4 & 63.4 & 58.8 & 75.1 \\
\hline 37 & 62.3 & 66.3 & 63.8 & 64.8 & 65.6 & 65.1 & 61.1 & 56.4 & 73.0 \\
\hline 38 & 62.6 & 66.6 & 64.2 & 65.1 & 66 & 65.6 & 61.5 & 56.8 & 73.4 \\
\hline 39 & 62.5 & 66.5 & 64.3 & 65.2 & 66.2 & 65.8 & 61.9 & 57.4 & 73.5 \\
\hline 40 & 63.4 & 67.4 & 65.1 & 66 & 66.9 & 66.5 & 62.5 & 57.8 & 74.3 \\
\hline 41 & 62.3 & 66.3 & 63.8 & 64.8 & 65.6 & 65.1 & 61.1 & 56.4 & 73.0 \\
\hline 42 & 62.6 & 66.6 & 64.2 & 65.1 & 66 & 65.6 & 61.5 & 56.8 & 73.4 \\
\hline 43 & 61.2 & 65.1 & 62.5 & 63.6 & 64.3 & 63.8 & 59.7 & 54.9 & 71.7 \\
\hline 44 & 61 & 65 & 62.5 & 63.5 & 64.3 & 63.9 & 59.8 & 55 & 71.7 \\
\hline 45 & 61.2 & 65.2 & 62.9 & 63.8 & 64.8 & 64.4 & 60.6 & 56.1 & 72.1 \\
\hline 46 & 61.4 & 65.4 & 63.1 & 64 & 65 & 64.6 & 60.8 & 56.5 & 72.3 \\
\hline 47 & 61.2 & 65.1 & 62.5 & 63.6 & 64.3 & 63.8 & 59.7 & 54.9 & 71.7 \\
\hline 48 & 61 & 65 & 62.5 & 63.5 & 64.3 & 63.9 & 59.8 & 55 & 71.7 \\
\hline
\end{tabular}


Both files (measured and calculated) were then utilized to compare differences in sound pressure levels. Charts were generated plotting measured vs. calculated sound pressure level at each measurement point for each octave band $(63 \mathrm{~Hz}, 125 \mathrm{~Hz}, 250 \mathrm{~Hz}, 500 \mathrm{~Hz}, 1,000 \mathrm{~Hz}$, $2,000 \mathrm{~Hz}, 4,000 \mathrm{~Hz}$ and $8,000 \mathrm{~Hz}$ ) sound pressure level for comparison purposes as shown in figures 6.16 thru 6.23 below (25).

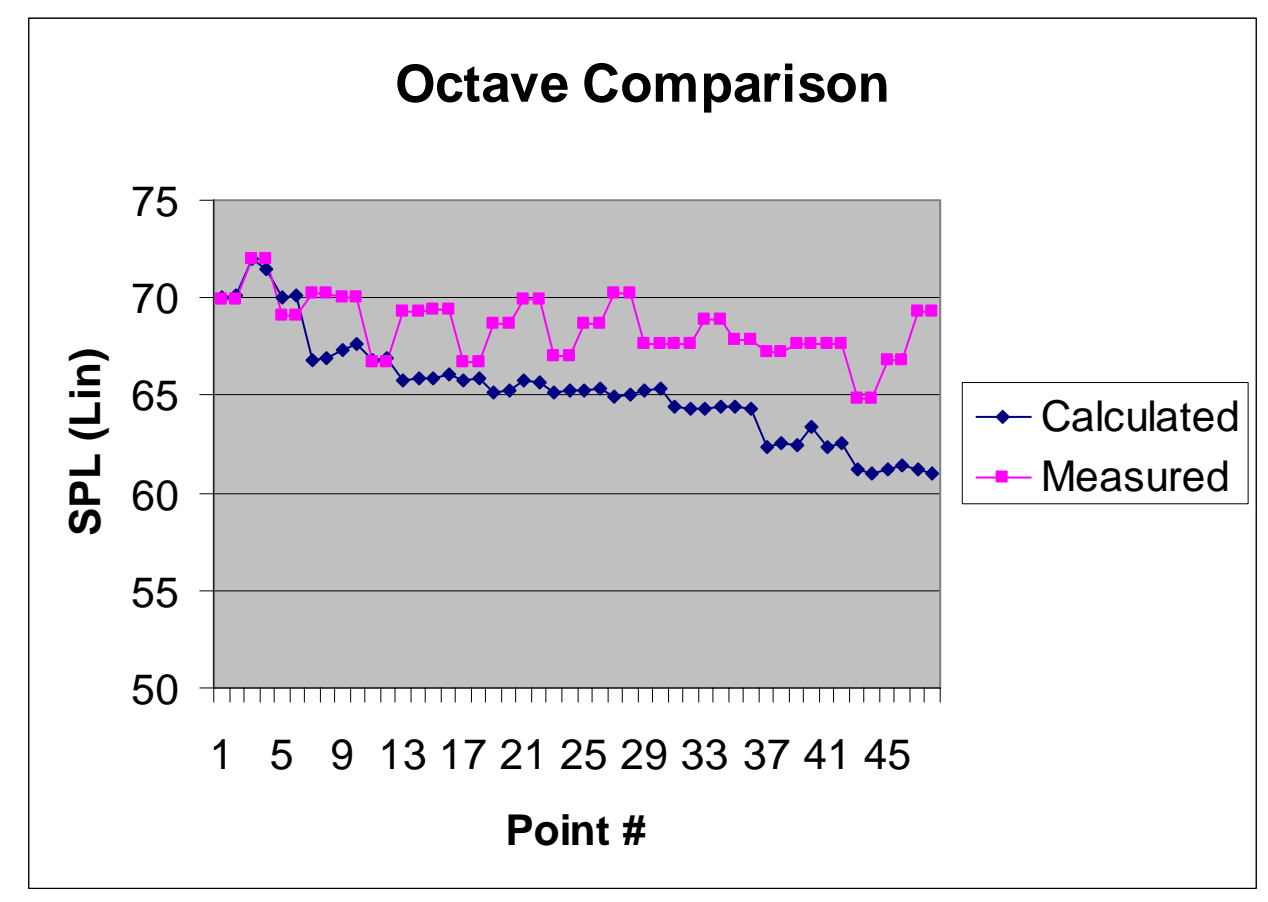

Figure 6.16 Comparing Calculated vs. Measured Sound Pressure Levels for $63-\mathrm{Hz}$ Octave Band. 


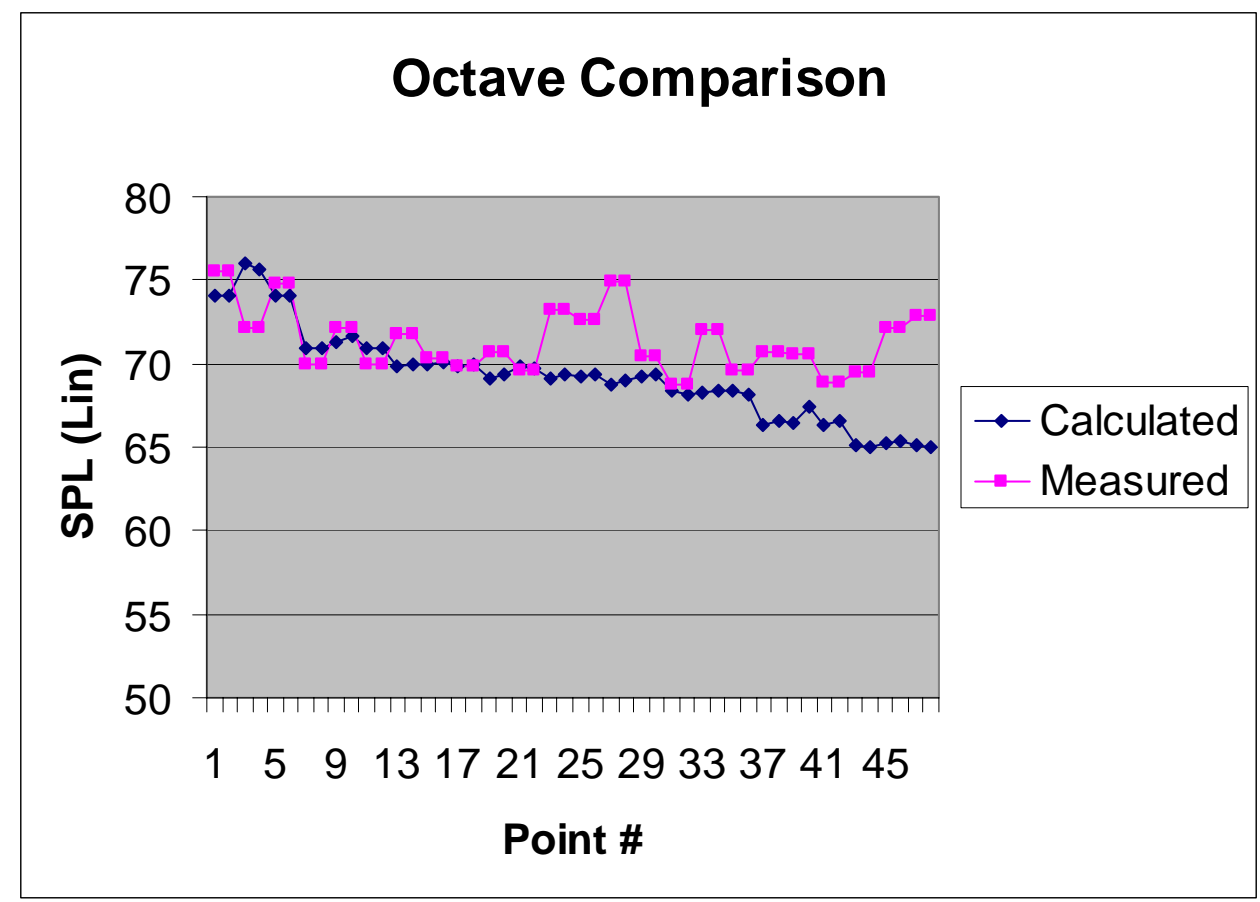

Figure 6.17 Comparing Calculated vs. Measured Sound Pressure Levels for $125-\mathrm{Hz}$ Octave Band.

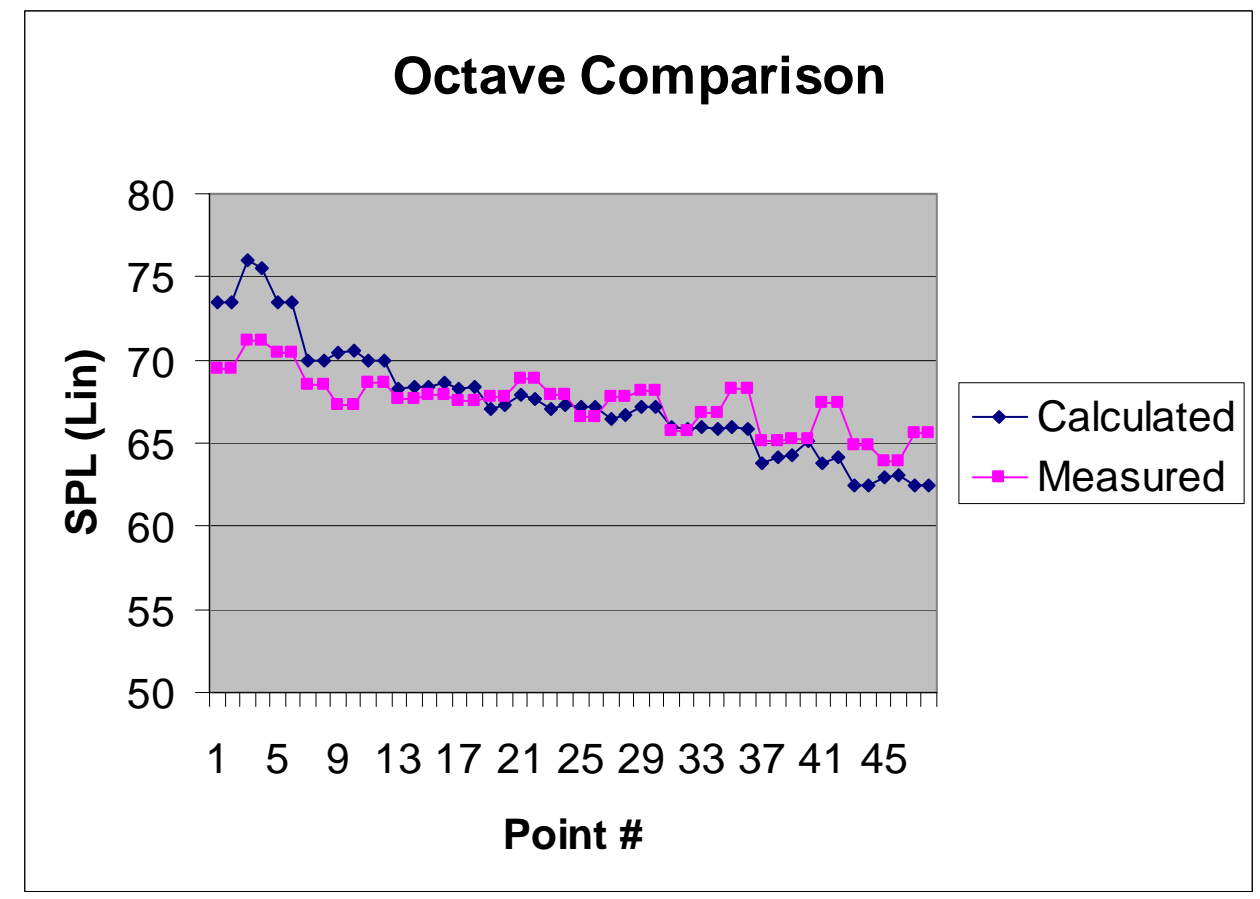

Figure 6.18 Comparing Calculated vs. Measured Sound Pressure Levels for 250-Hz Octave Band. 


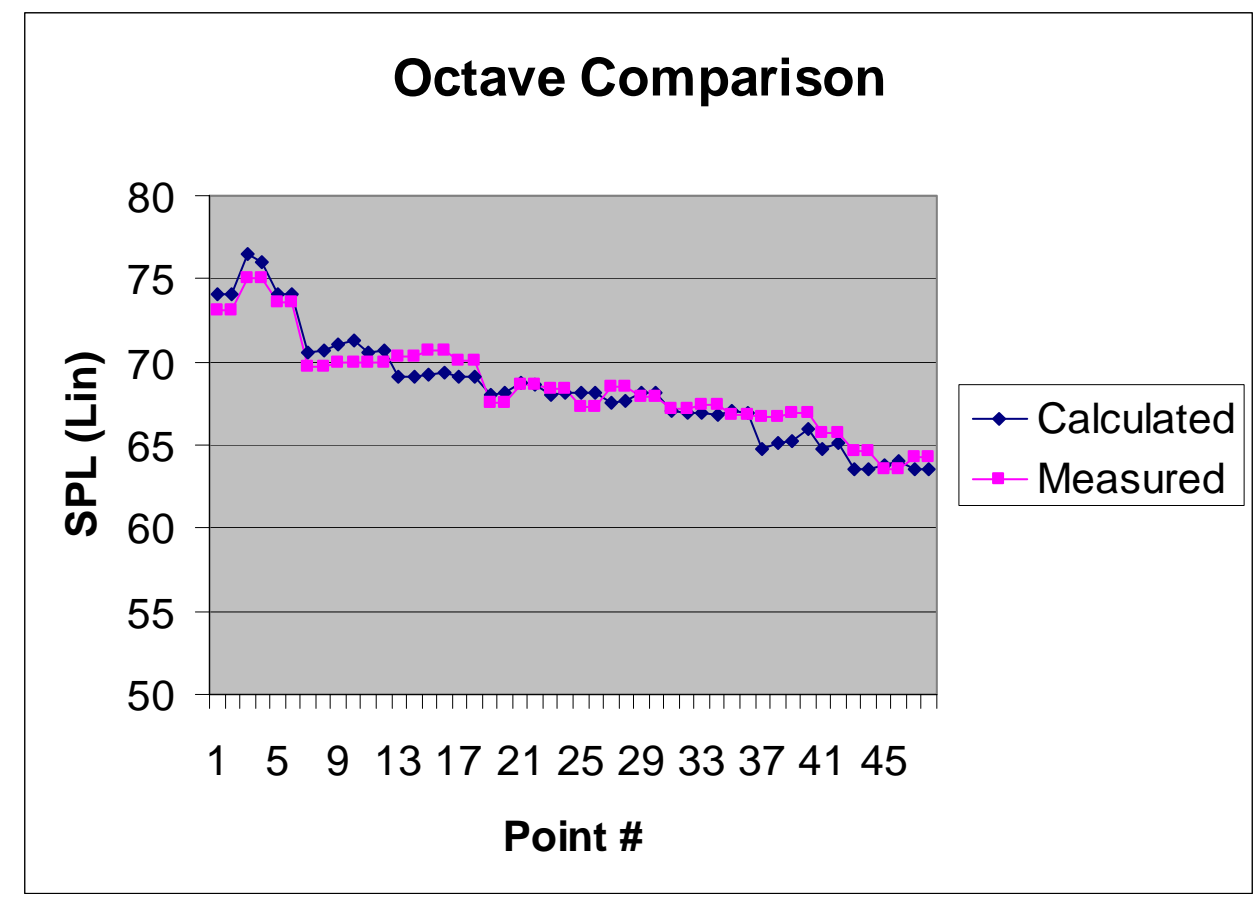

Figure 6.19 Comparing Calculated vs. Measured Sound Pressure Levels for 500-Hz Octave Band.

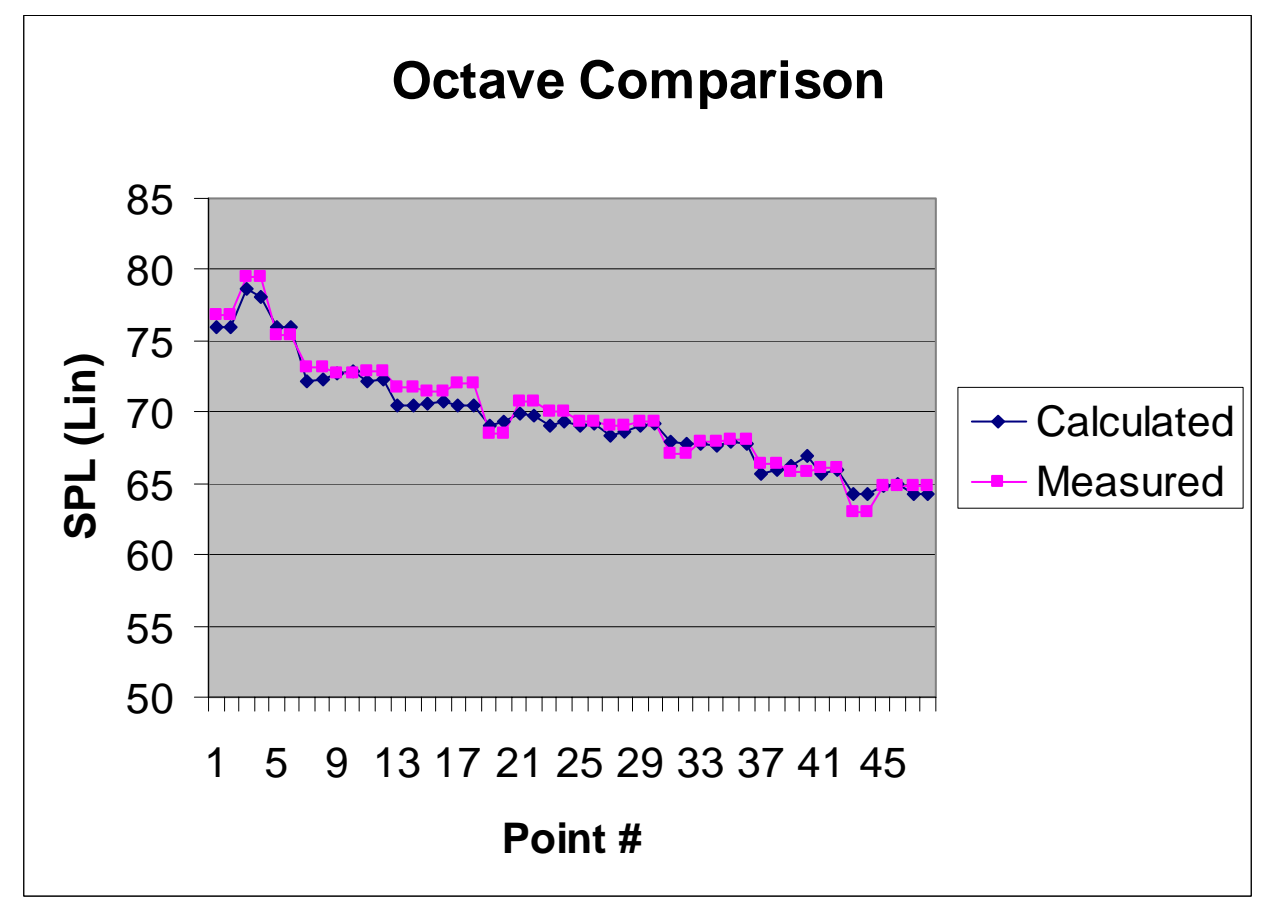

Figure 6.20 Comparing Calculated vs. Measured Sound Pressure Levels for 1,000-Hz Octave Band. 


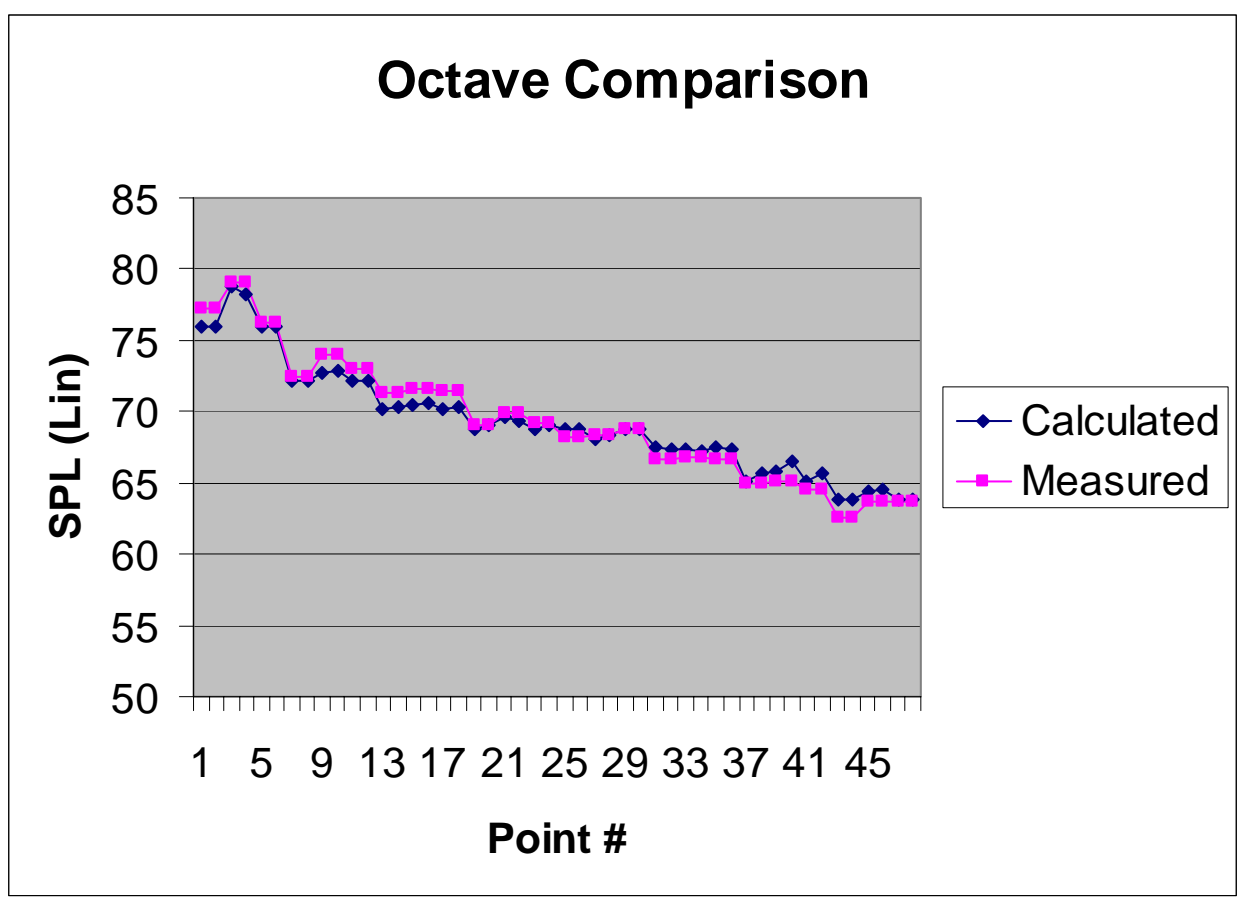

Figure 6.21 Comparing Calculated vs. Measured Sound Pressure Levels for 2,000-Hz Octave Band.

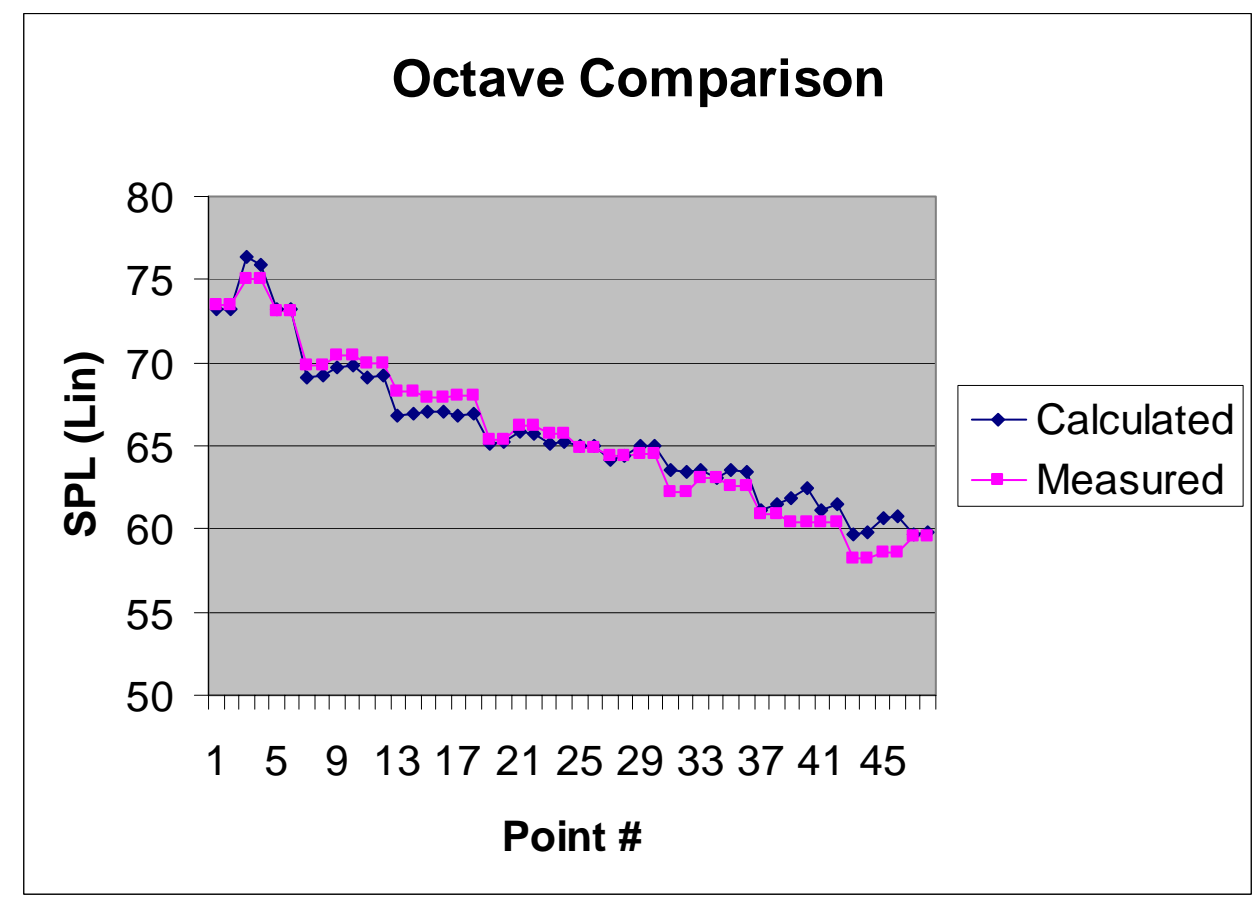

Figure 6.22 Comparing Calculated vs. Measured Sound Pressure Levels for 4,000-Hz Octave Band. 


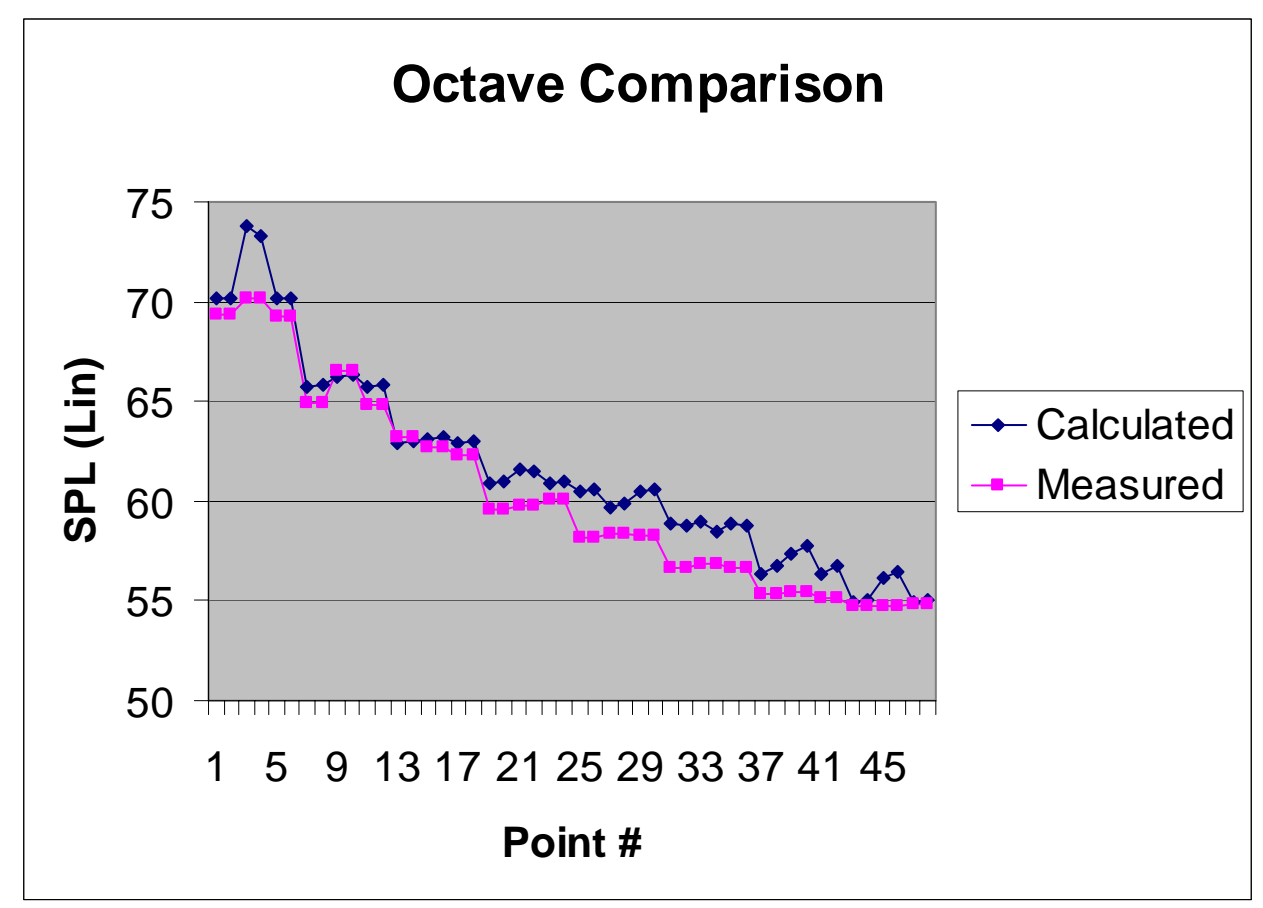

Figure 6.23 Comparing Calculated vs. Measured Sound Pressure Levels for 8,000-Hz Octave Band.

The calculated results at each of the eight full-octave bands were then compared to the measured results. The modeled absorption coefficients were then adjusted to bring the sound pressure level results closer to the measured sound pressure levels and the model was then processed again. Consequently, after five model runs, the error between the measured and calculated sound pressure levels were minimized and a set of full-octave band absorption coefficients for the mine cross-section were determined. Plots comparing the measured and calculated sound pressure levels for each of the eight full-octave bands are shown below in figures 6.24 thru 6.31. Additionally, table 6.6 displays the calculated sound pressure levels after the fifth model run in determining the absorption coefficients thru comparing sound pressure levels (measured and calculated). Table 6.7 provides the difference in $\mathrm{dB}$, between the measured and calculated sound pressure levels for all forty-eight monitoring points and full-octave band frequencies. 


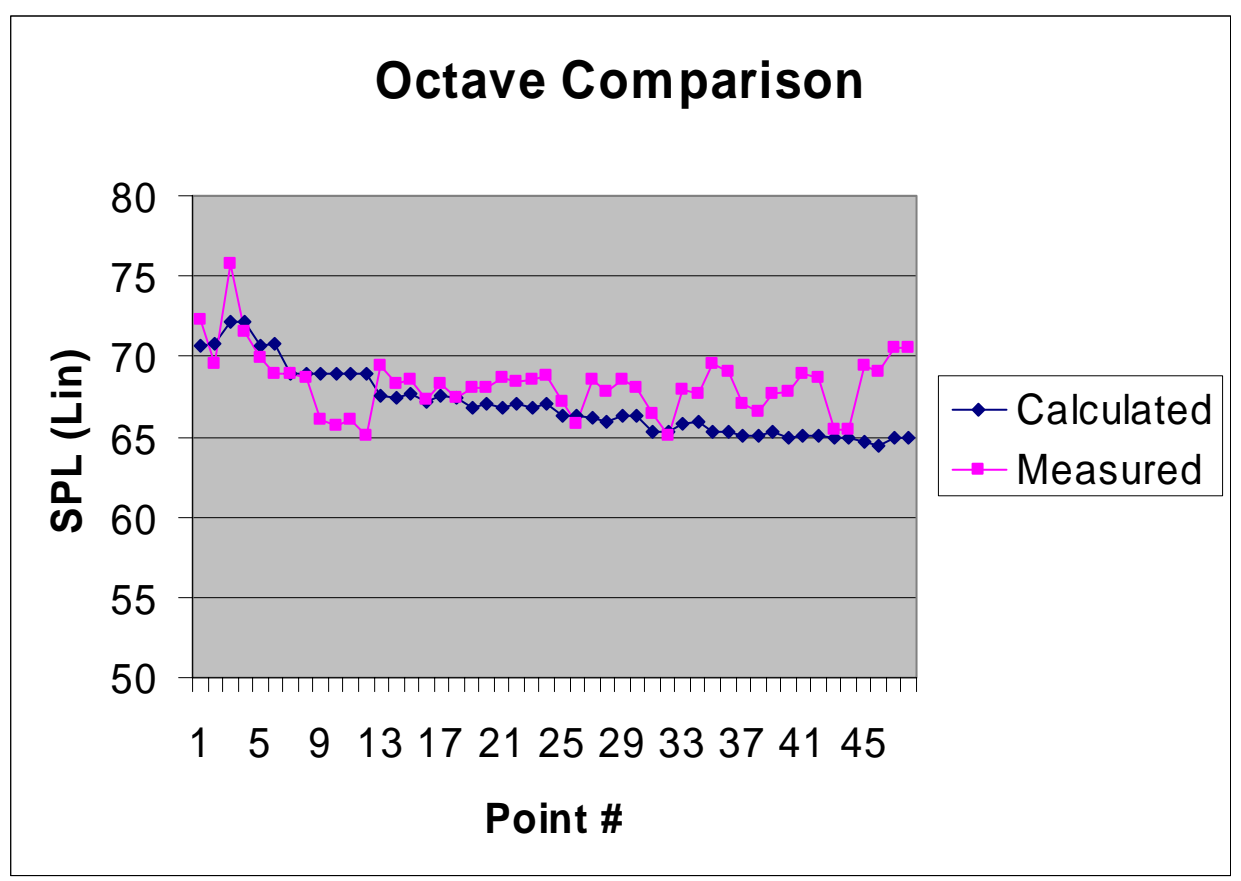

Figure 6.24 Comparing Calculated vs. Measured Sound Pressure Levels for 63-Hz Octave Band (Model Run 5)

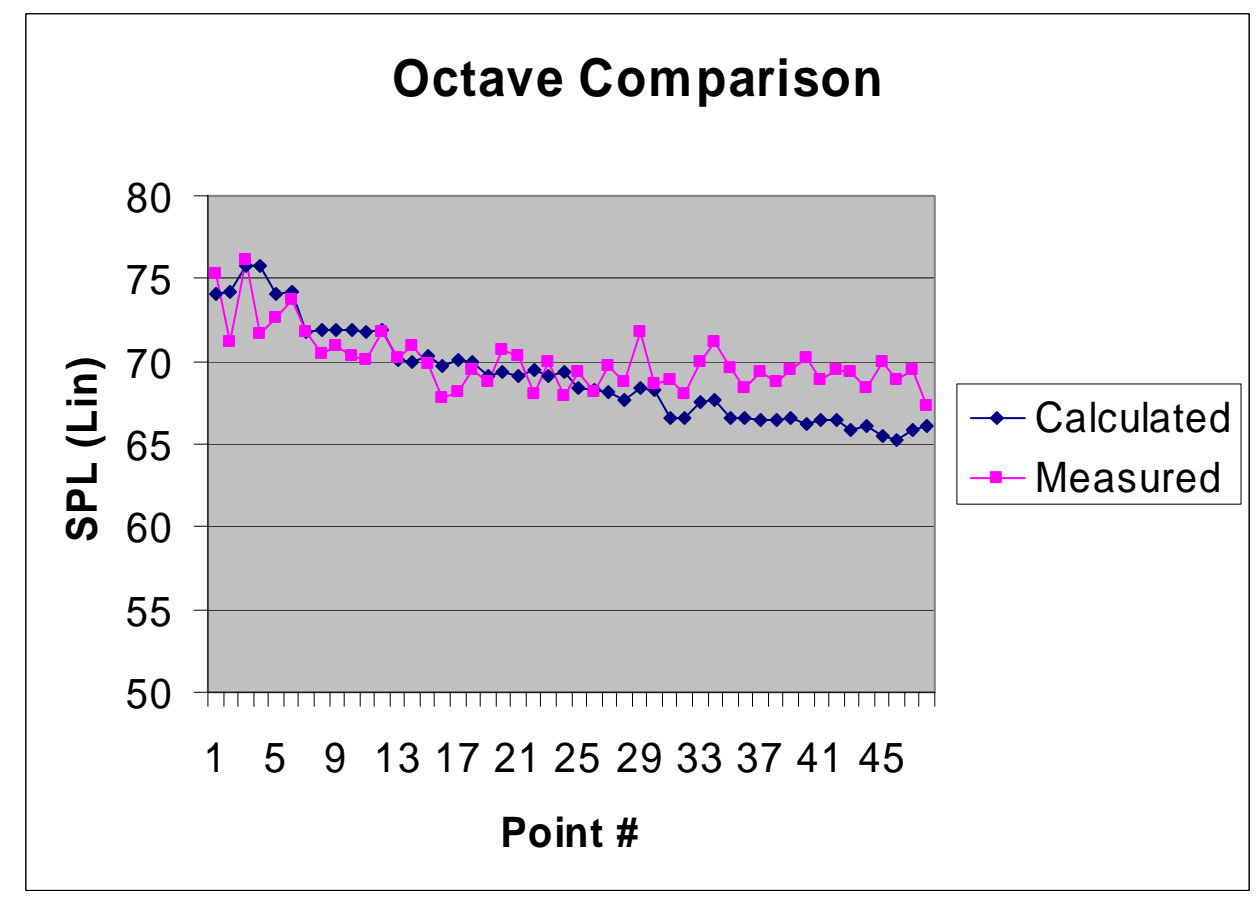

Figure 6.25 Comparing Calculated vs. Measured Sound Pressure Levels for $125-\mathrm{Hz}$ Octave Band (Model Run 5) 


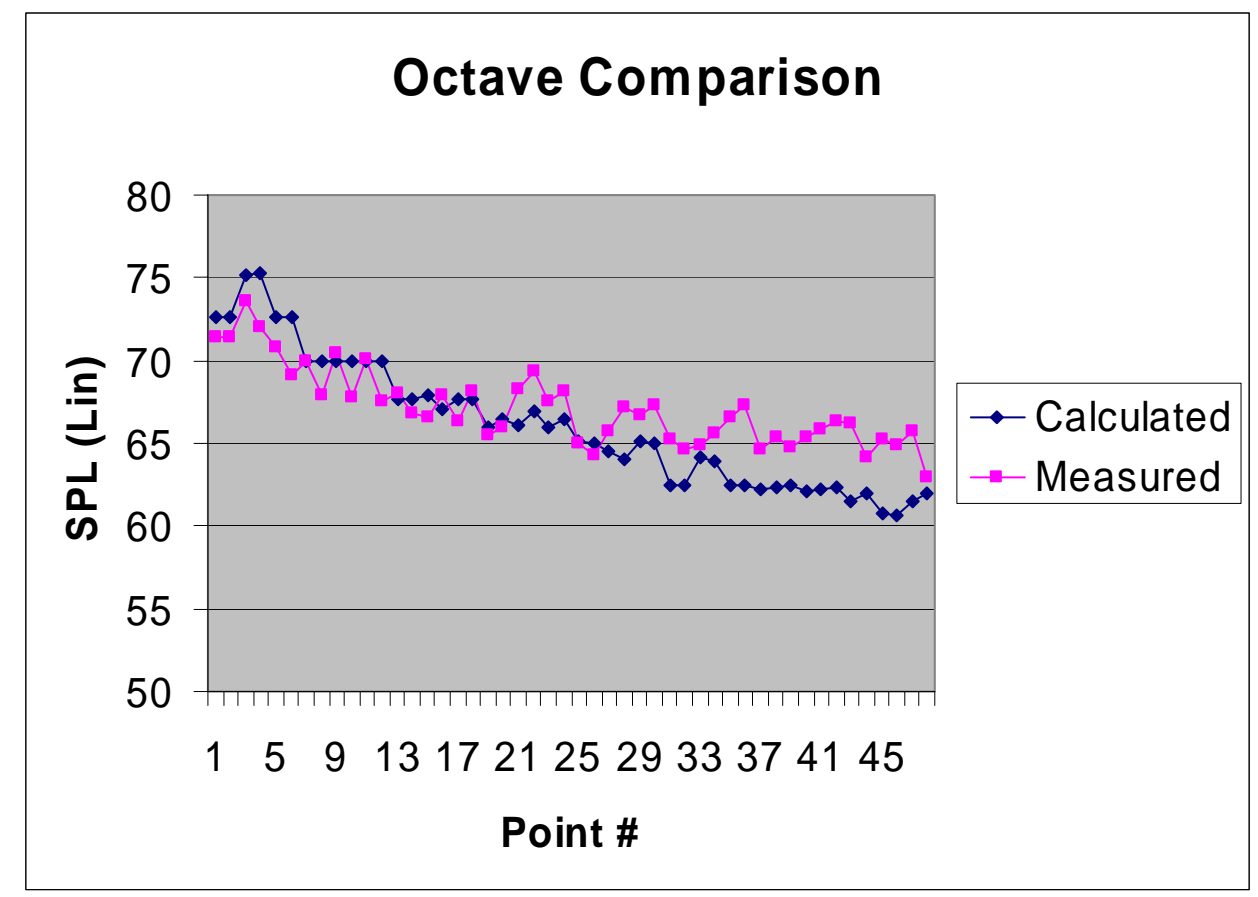

Figure 6.26 Comparing Calculated vs. Measured Sound Pressure Levels for $250-\mathrm{Hz}$ Octave Band (Model Run 5)

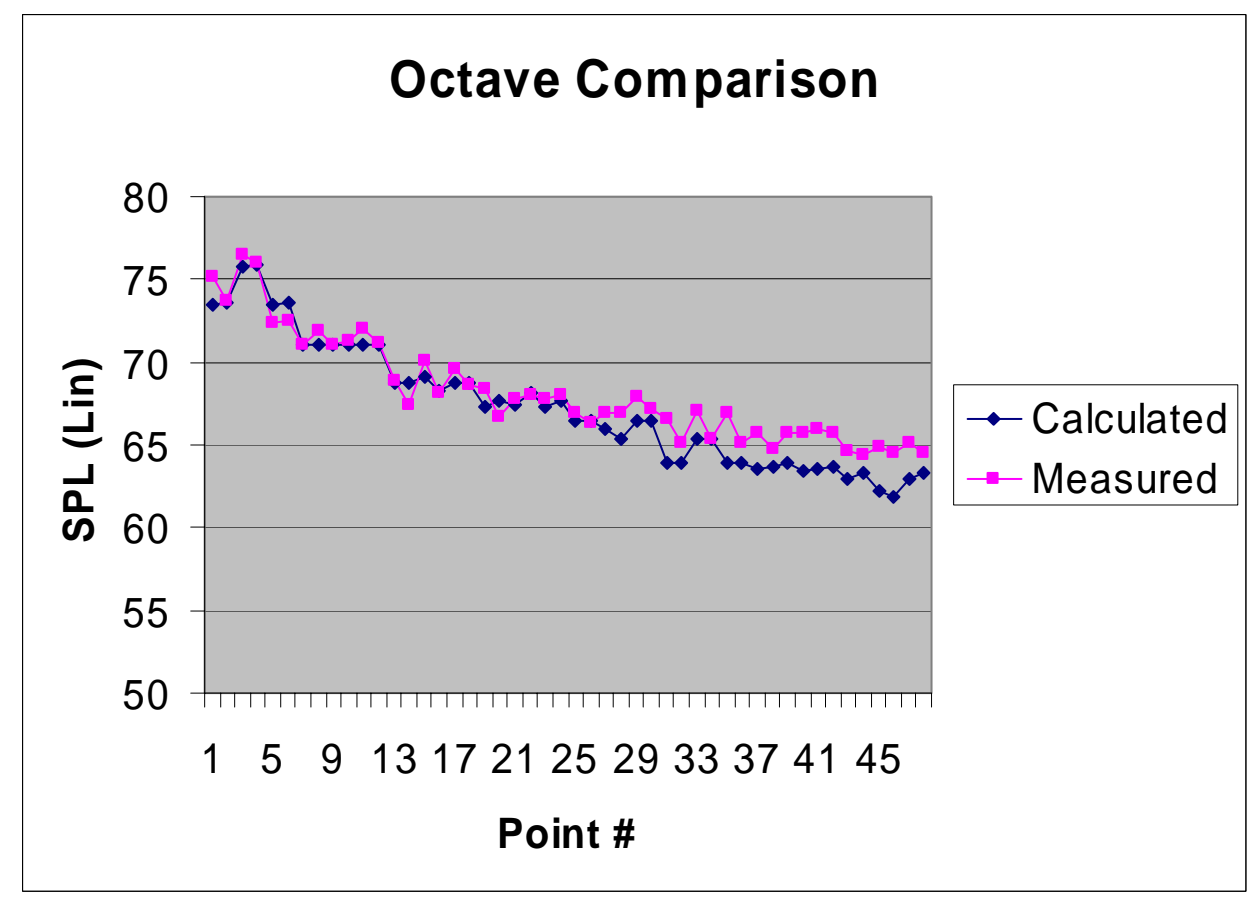

Figure 6.27 Comparing Calculated vs. Measured Sound Pressure Levels for 500-Hz Octave Band (Model Run 5) 


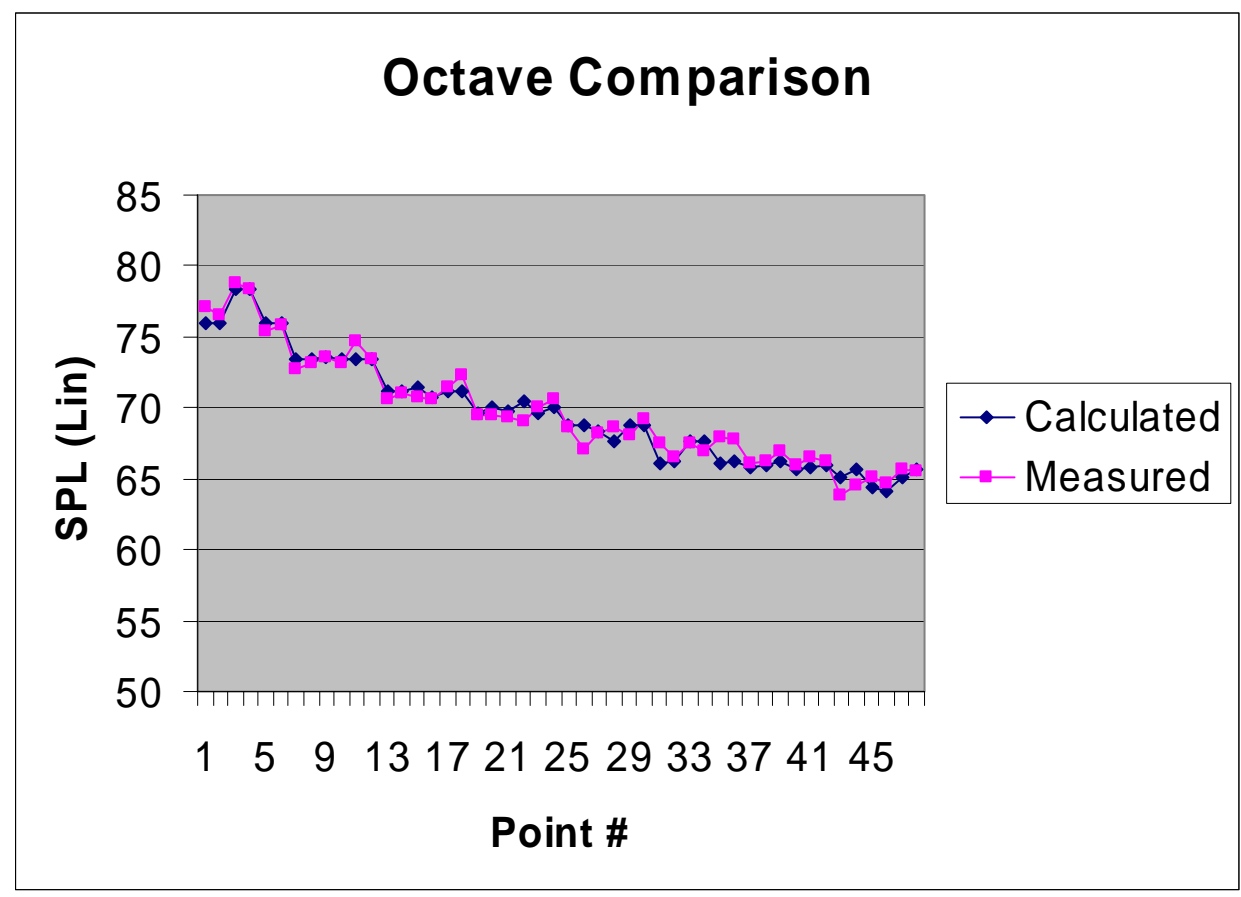

Figure 6.28 Comparing Calculated vs. Measured Sound Pressure Levels for 1,000-Hz Octave Band (Model Run 5)

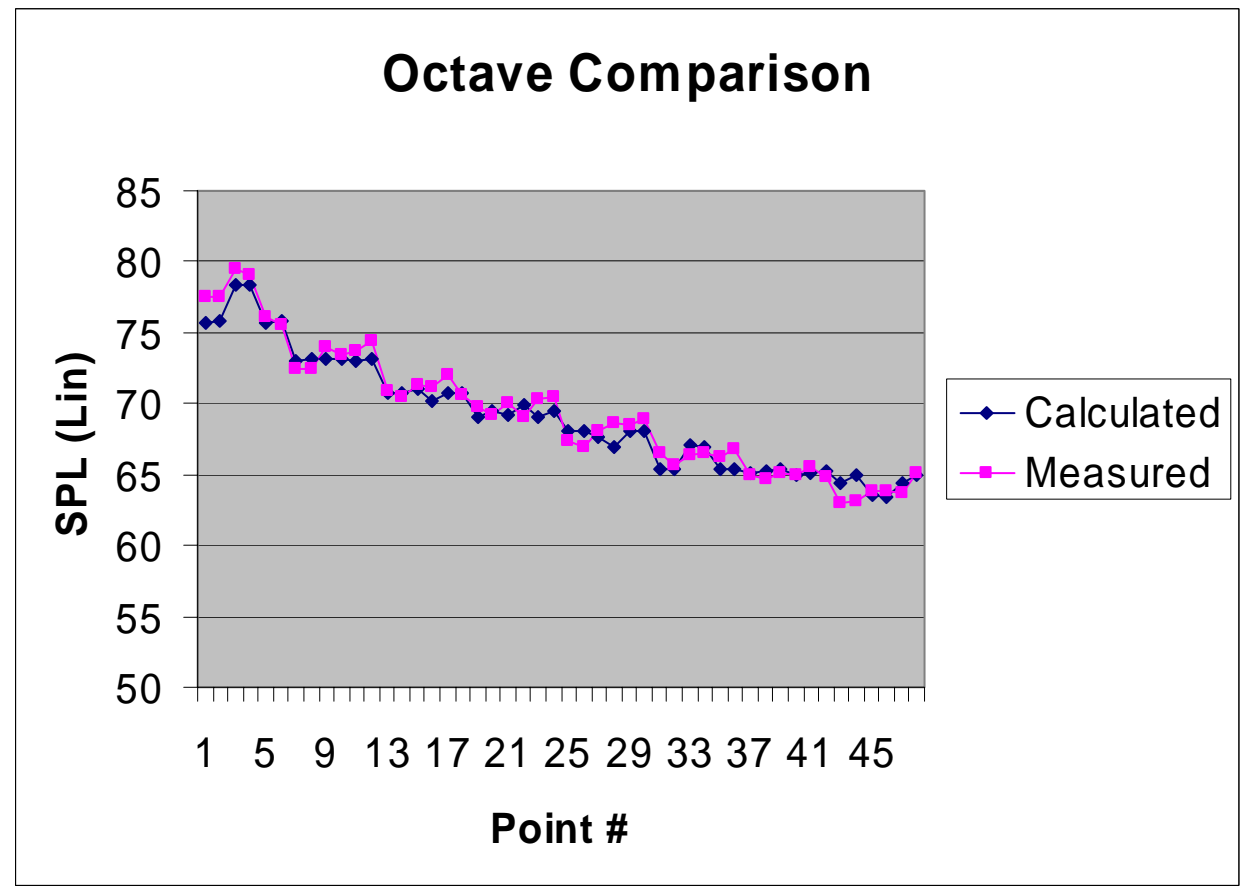

Figure 6.29 Comparing Calculated vs. Measured Sound Pressure Levels for 2,000-Hz Octave Band (Model Run 5) 


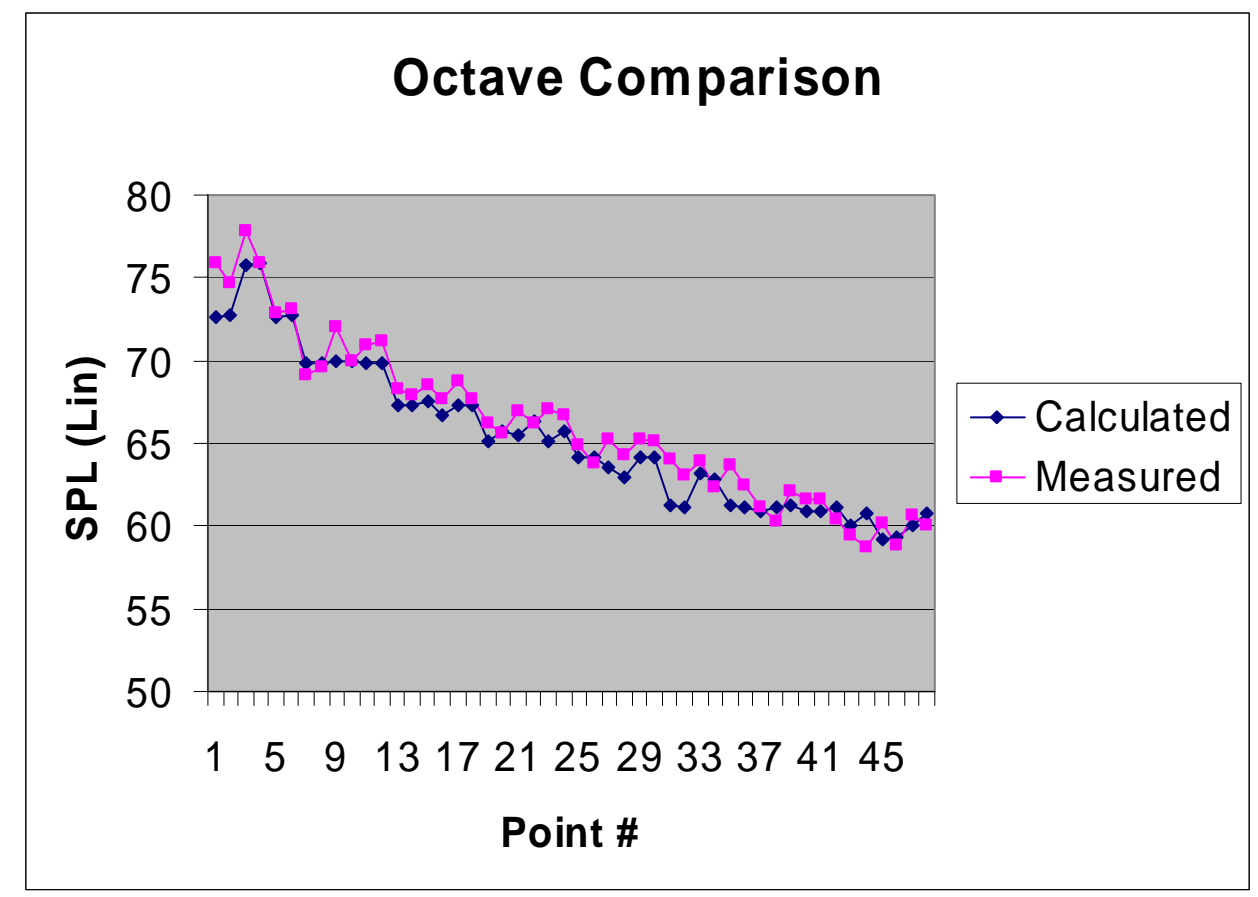

Figure 6.30 Comparing Calculated vs. Measured Sound Pressure Levels for 4,000-Hz Octave Band (Model Run 5)

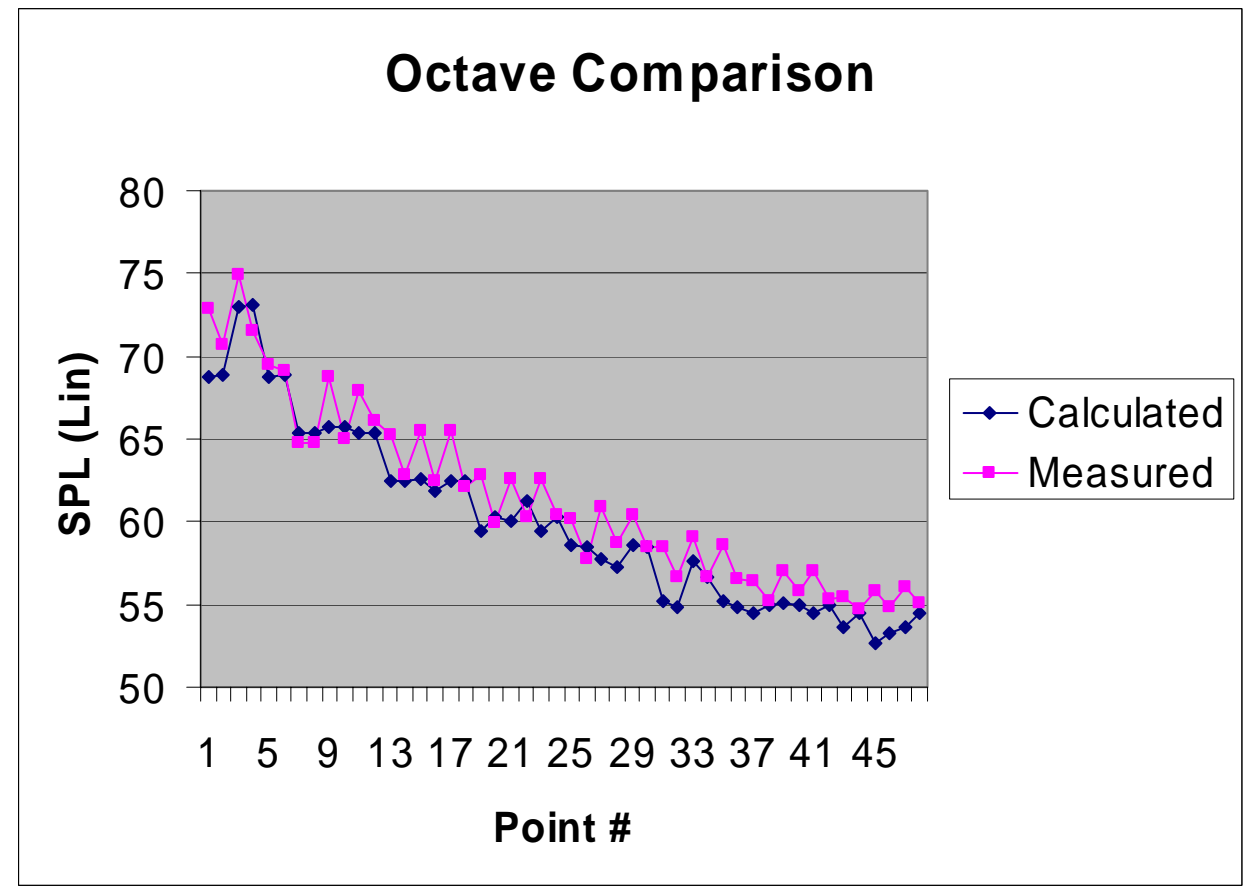

Figure 6.31 Comparing Calculated vs. Measured Sound Pressure Levels for 8,000-Hz Octave Band (Model Run 5) 
Table 6.6 Calculated Full-Octave Band Sound Pressure Levels - Fifth Run of Model

\begin{tabular}{|c|c|c|c|c|c|c|c|c|c|}
\hline & \multicolumn{8}{|c|}{ Full-Octave Band, $\mathrm{Hz}$} & \multirow[b]{2}{*}{ Sound Pressure Level, dB } \\
\hline Point Number & 63 & 125 & 250 & 500 & 1000 & 2000 & 4000 & 8000 & \\
\hline 1 & 70.7 & 74.1 & 72.6 & 73.5 & 75.9 & 75.7 & 72.6 & 68.8 & 82.5 \\
\hline 2 & 70.8 & 74.2 & 72.6 & 73.6 & 76 & 75.8 & 72.7 & 68.9 & 82.6 \\
\hline 3 & 72.2 & 75.8 & 75.2 & 75.8 & 78.3 & 78.3 & 75.8 & 73 & 85.0 \\
\hline 4 & 72.2 & 75.8 & 75.3 & 75.9 & 78.4 & 78.4 & 75.9 & 73.1 & 85.1 \\
\hline 5 & 70.7 & 74.1 & 72.6 & 73.5 & 75.9 & 75.7 & 72.6 & 68.8 & 82.5 \\
\hline 6 & 70.8 & 74.2 & 72.6 & 73.6 & 76 & 75.8 & 72.7 & 68.9 & 82.6 \\
\hline 7 & 68.9 & 71.8 & 69.9 & 71 & 73.4 & 73 & 69.8 & 65.4 & 80.0 \\
\hline 8 & 68.9 & 71.9 & 69.9 & 71 & 73.4 & 73.1 & 69.8 & 65.4 & 80.0 \\
\hline 9 & 68.9 & 71.9 & 70 & 71.1 & 73.5 & 73.2 & 70 & 65.7 & 80.1 \\
\hline 10 & 68.9 & 71.9 & 70 & 71 & 73.4 & 73.1 & 69.9 & 65.7 & 80.1 \\
\hline 11 & 68.9 & 71.8 & 69.9 & 71 & 73.4 & 73 & 69.8 & 65.4 & 80.0 \\
\hline 12 & 68.9 & 71.9 & 69.9 & 71 & 73.4 & 73.1 & 69.8 & 65.4 & 80.0 \\
\hline 13 & 67.5 & 70.1 & 67.7 & 68.8 & 71.2 & 70.8 & 67.3 & 62.5 & 77.9 \\
\hline 14 & 67.4 & 70 & 67.7 & 68.8 & 71.2 & 70.8 & 67.3 & 62.5 & 77.9 \\
\hline 15 & 67.7 & 70.3 & 67.9 & 69.1 & 71.4 & 71 & 67.5 & 62.6 & 78.1 \\
\hline 16 & 67.2 & 69.7 & 67.1 & 68.3 & 70.7 & 70.2 & 66.7 & 61.8 & 77.4 \\
\hline 17 & 67.5 & 70.1 & 67.7 & 68.8 & 71.2 & 70.8 & 67.3 & 62.5 & 77.9 \\
\hline 18 & 67.4 & 70 & 67.7 & 68.8 & 71.2 & 70.8 & 67.3 & 62.5 & 77.9 \\
\hline 19 & 66.8 & 69.1 & 66 & 67.3 & 69.6 & 69.1 & 65.1 & 59.4 & 76.4 \\
\hline 20 & 67 & 69.3 & 66.4 & 67.7 & 70 & 69.5 & 65.7 & 60.3 & 76.8 \\
\hline 21 & 66.8 & 69.1 & 66.1 & 67.4 & 69.7 & 69.2 & 65.5 & 60.1 & 76.5 \\
\hline 22 & 67.1 & 69.5 & 66.9 & 68.1 & 70.4 & 69.9 & 66.3 & 61.2 & 77.1 \\
\hline 23 & 66.8 & 69.1 & 66 & 67.3 & 69.6 & 69.1 & 65.1 & 59.4 & 76.4 \\
\hline 24 & 67 & 69.3 & 66.4 & 67.7 & 70 & 69.5 & 65.7 & 60.3 & 76.8 \\
\hline 25 & 66.3 & 68.4 & 65.1 & 66.4 & 68.7 & 68.1 & 64.2 & 58.6 & 75.6 \\
\hline 26 & 66.3 & 68.3 & 65 & 66.4 & 68.7 & 68.1 & 64.2 & 58.5 & 75.5 \\
\hline 27 & 66.2 & 68.2 & 64.5 & 66 & 68.3 & 67.6 & 63.5 & 57.7 & 75.2 \\
\hline 28 & 65.9 & 67.7 & 64 & 65.4 & 67.6 & 67 & 63 & 57.3 & 74.6 \\
\hline 29 & 66.3 & 68.4 & 65.1 & 66.4 & 68.7 & 68.1 & 64.2 & 58.6 & 75.6 \\
\hline 30 & 66.3 & 68.3 & 65 & 66.4 & 68.7 & 68.1 & 64.2 & 58.5 & 75.5 \\
\hline 31 & 65.3 & 66.6 & 62.5 & 63.9 & 66.1 & 65.4 & 61.3 & 55.2 & 73.3 \\
\hline 32 & 65.3 & 66.6 & 62.5 & 63.9 & 66.2 & 65.4 & 61.1 & 54.8 & 73.3 \\
\hline 33 & 65.8 & 67.6 & 64.1 & 65.4 & 67.7 & 67.1 & 63.2 & 57.6 & 74.7 \\
\hline 34 & 65.9 & 67.7 & 63.9 & 65.4 & 67.6 & 66.9 & 62.8 & 56.6 & 74.6 \\
\hline 35 & 65.3 & 66.6 & 62.5 & 63.9 & 66.1 & 65.4 & 61.3 & 55.2 & 73.3 \\
\hline 36 & 65.3 & 66.6 & 62.5 & 63.9 & 66.2 & 65.4 & 61.1 & 54.8 & 73.3 \\
\hline 37 & 65.1 & 66.4 & 62.2 & 63.6 & 65.8 & 65.1 & 60.9 & 54.5 & 73.0 \\
\hline 38 & 65.1 & 66.4 & 62.3 & 63.7 & 65.9 & 65.2 & 61.1 & 54.9 & 73.1 \\
\hline 39 & 65.3 & 66.6 & 62.5 & 63.9 & 66.2 & 65.4 & 61.2 & 55.1 & 73.3 \\
\hline 40 & 65 & 66.2 & 62.1 & 63.4 & 65.6 & 65 & 60.9 & 55 & 72.9 \\
\hline 41 & 65.1 & 66.4 & 62.2 & 63.6 & 65.8 & 65.1 & 60.9 & 54.5 & 73.0 \\
\hline 42 & 65.1 & 66.4 & 62.3 & 63.7 & 65.9 & 65.2 & 61.1 & 54.9 & 73.1 \\
\hline 43 & 64.9 & 65.9 & 61.5 & 62.9 & 65.1 & 64.4 & 60.1 & 53.6 & 72.5 \\
\hline 44 & 65 & 66.1 & 62 & 63.3 & 65.6 & 64.9 & 60.8 & 54.5 & 72.8 \\
\hline 45 & 64.7 & 65.5 & 60.8 & 62.2 & 64.4 & 63.6 & 59.2 & 52.7 & 71.9 \\
\hline 46 & 64.5 & 65.2 & 60.6 & 61.9 & 64.1 & 63.4 & 59.3 & 53.3 & 71.7 \\
\hline 47 & 64.9 & 65.9 & 61.5 & 62.9 & 65.1 & 64.4 & 60.1 & 53.6 & 72.5 \\
\hline 48 & 65 & 66.1 & 62 & 63.3 & 65.6 & 64.9 & 60.8 & 54.5 & 72.8 \\
\hline
\end{tabular}


Table 6.7 Differences Relative to the Measured and Calculated Sound Pressure Levels

\begin{tabular}{|c|c|c|c|c|c|c|c|c|}
\hline & \multicolumn{8}{|c|}{ Full-Octave Band, $\mathrm{Hz}$} \\
\hline Point Number & 63 & 125 & 250 & 500 & 1000 & 2000 & 4000 & 8000 \\
\hline 1 & 1.6 & 1.13 & -1.17 & 1.64 & 1.17 & 1.78 & 3.25 & 4.12 \\
\hline 2 & -1.3 & -3.02 & -1.13 & 0.07 & 0.58 & 1.79 & 1.99 & 1.81 \\
\hline 3 & 3.62 & 0.36 & -1.64 & 0.73 & 0.51 & 1.15 & 1.99 & 1.94 \\
\hline 4 & -0.61 & -4.1 & -3.27 & 0.14 & -0.03 & 0.74 & 0.04 & -1.57 \\
\hline 5 & -0.83 & -1.44 & -1.85 & -1.17 & -0.55 & 0.35 & 0.26 & 0.73 \\
\hline 6 & -1.91 & -0.47 & -3.53 & -1.14 & -0.22 & -0.19 & 0.44 & 0.22 \\
\hline 7 & 0 & 0 & 0 & 0 & -0.7 & -0.6 & -0.7 & -0.6 \\
\hline 8 & -0.28 & -1.51 & -2.05 & 0.94 & -0.32 & -0.65 & -0.16 & -0.7 \\
\hline 9 & -2.83 & -0.98 & 0.48 & -0.03 & 0.1 & 0.73 & 1.97 & 3.03 \\
\hline 10 & -3.25 & -1.62 & -2.24 & 0.35 & -0.25 & 0.27 & 0.1 & -0.7 \\
\hline 11 & -2.87 & -1.77 & 0.2 & 0.97 & 1.26 & 0.73 & 1.12 & 2.46 \\
\hline 12 & -3.8 & -0.15 & -2.33 & 0.13 & 0.06 & 1.32 & 1.41 & 0.73 \\
\hline 13 & 1.98 & 0.06 & 0.38 & 0.13 & -0.61 & 0.06 & 0.96 & 2.78 \\
\hline 14 & 0.92 & 0.89 & -0.83 & -1.35 & -0.14 & -0.29 & 0.56 & 0.37 \\
\hline 15 & 0.84 & -0.42 & -1.33 & 1.04 & -0.7 & 0.35 & 0.96 & 2.89 \\
\hline 16 & 0.15 & -1.89 & 0.79 & -0.11 & -0.07 & 1.01 & 1.02 & 0.67 \\
\hline 17 & 0.84 & -1.97 & -1.39 & 0.84 & 0.32 & 1.16 & 1.48 & 2.98 \\
\hline 18 & -0.02 & -0.55 & 0.43 & -0.13 & 1.14 & -0.22 & 0.31 & -0.41 \\
\hline 19 & 1.21 & -0.38 & -0.46 & 1.1 & -0.1 & 0.72 & 1.11 & 3.48 \\
\hline 20 & 1.01 & 1.39 & -0.44 & -0.97 & -0.49 & -0.31 & -0.14 & -0.43 \\
\hline 21 & 1.82 & 1.17 & 2.18 & 0.39 & -0.3 & 0.79 & 1.42 & 2.53 \\
\hline 22 & 1.35 & -1.49 & 2.49 & -0.02 & -1.36 & -0.78 & -0.06 & -0.91 \\
\hline 23 & 1.76 & 0.85 & 1.49 & 0.47 & 0.51 & 1.23 & 1.99 & 3.22 \\
\hline 24 & 1.74 & -1.34 & 1.7 & 0.35 & 0.59 & 0.91 & 1 & 0.14 \\
\hline 25 & 0.84 & 0.97 & -0.07 & 0.59 & -0.03 & -0.78 & 0.71 & 1.62 \\
\hline 26 & -0.48 & -0.14 & -0.75 & -0.08 & -1.59 & -1.18 & -0.45 & -0.71 \\
\hline 27 & 2.3 & 1.5 & 1.23 & 0.99 & -0.07 & 0.5 & 1.76 & 3.19 \\
\hline 28 & 1.94 & 1.02 & 3.18 & 1.53 & 1 & 1.62 & 1.31 & 1.4 \\
\hline 29 & 2.2 & 3.36 & 1.65 & 1.48 & -0.69 & 0.35 & 1.03 & 1.86 \\
\hline 30 & 1.81 & 0.28 & 2.31 & 0.77 & 0.5 & 0.77 & 0.9 & -0.02 \\
\hline 31 & 1.08 & 2.29 & 2.71 & 2.72 & 1.44 & 1.12 & 2.73 & 3.28 \\
\hline 32 & -0.28 & 1.42 & 2.14 & 1.24 & 0.29 & 0.32 & 1.92 & 1.8 \\
\hline 33 & 2.09 & 2.36 & 0.76 & 1.6 & -0.18 & -0.66 & 0.71 & 1.48 \\
\hline 34 & 1.79 & 3.41 & 1.75 & -0.05 & -0.66 & -0.38 & -0.42 & 0.03 \\
\hline 35 & 4.29 & 3.05 & 4.03 & 3.05 & 1.78 & 0.85 & 2.39 & 3.37 \\
\hline 36 & 3.74 & 1.74 & 4.83 & 1.22 & 1.6 & 1.35 & 1.4 & 1.76 \\
\hline 37 & 1.96 & 2.94 & 2.49 & 2.16 & 0.29 & -0.18 & 0.27 & 1.87 \\
\hline 38 & 1.44 & 2.32 & 3.09 & 1.04 & 0.29 & -0.47 & -0.82 & 0.31 \\
\hline 39 & 2.39 & 2.87 & 2.23 & 1.85 & 0.7 & -0.31 & 0.84 & 1.89 \\
\hline 40 & 2.79 & 4.04 & 3.22 & 2.28 & 0.29 & -0.11 & 0.72 & 0.78 \\
\hline 41 & 3.8 & 2.47 & 3.61 & 2.39 & 0.77 & 0.36 & 0.7 & 2.46 \\
\hline 42 & 3.58 & 3.06 & 4.04 & 2.07 & 0.31 & -0.35 & -0.65 & 0.45 \\
\hline 43 & 0.48 & 3.5 & 4.72 & 1.75 & -1.21 & -1.36 & -0.69 & 1.82 \\
\hline 44 & 0.42 & 2.32 & 2.18 & 1.04 & -1.07 & -1.75 & -2.12 & 0.27 \\
\hline 45 & 4.76 & 4.43 & 4.43 & 2.67 & 0.66 & 0.22 & 0.92 & 3.13 \\
\hline 46 & 4.54 & 3.7 & 4.29 & 2.64 & 0.55 & 0.48 & -0.51 & 1.49 \\
\hline 47 & 5.61 & 3.52 & 4.2 & 2.27 & 0.56 & -0.66 & 0.58 & 2.44 \\
\hline 48 & 5.49 & 1.24 & 0.94 & 1.26 & -0.12 & 0.2 & -0.75 & 0.58 \\
\hline
\end{tabular}


As shown in table 6.7 and figures 6.24 thru 6.27, the differences between the measured and calculated sound pressure levels for the $63 \mathrm{~Hz}, 125 \mathrm{~Hz}, 250 \mathrm{~Hz}$ and $500 \mathrm{~Hz}$ full-octave bands are typically larger as compared to the other full-octave bands. It should be noted that the measured and calculated sound pressure levels are displayed as linear values in the tables and figures. Once the data was filtered, utilizing an A-weighting of the data, the differences in the lower frequency bands was negligible due to the type of filtering. Additionally, the frequency bands of major interest relative to the drilling portion of a roof bolting machine are the $1,000 \mathrm{~Hz}$ to 4,000 Hertz full-octave bands. Therefore, the differences in measured and calculated sound pressure levels after the fifth run of the model relative to the full-octave bands of interest, provided a good fit and the final absorption coefficients determined from the model are shown in table 6.8 .

Table 6.8 Final Absorption Coefficients Determined from Model Runs

\begin{tabular}{|c|c|}
\hline $\begin{array}{c}\text { Octave-band } \\
\text { (Hz) }\end{array}$ & $\begin{array}{c}\text { Absorption } \\
\text { Coefficient }\end{array}$ \\
\hline 63 & .03 \\
\hline 125 & .04 \\
\hline 250 & .20 \\
\hline 500 & .14 \\
\hline 1000 & .15 \\
\hline 2000 & .19 \\
\hline 4000 & .28 \\
\hline 8000 & .45 \\
\hline
\end{tabular}

The absorption coefficients determined, were then inputted into the Raynoise program to predict sound pressure levels at the operator position of the roof bolting machine as described in the next section. 


\subsubsection{Predicting Sound Pressure Levels Underground Due to Drilling Cycle of Roof Bolting Machine}

Once the absorption coefficients were determined from section 6.3.4 and displayed in table 6.8, several other pieces of information were required for input into the model to determine or predict the sound pressure levels underground. Namely, the full-octave band sound power level information received from the laboratory testing for a specific test, the specific roof bolting machine characteristics designed from the drafting package, AutoCAD, the geometry of the section of the underground mine to be modeled and a measurement grid within the geometric section representing the point locations for determining the sound pressure levels.

\subsubsection{Full-Octave Band Sound Power Levels from Laboratory Testing}

Table 6.9, illustrated below, provides the one-third octave-band as well as full-octave band sound power levels as an example for input into the Raynoise modeling program for predicting sound pressure levels. This example illustrates the octave-band and one-third octave band information from one of the laboratory test conducted for high-compressive strength media ( $>20,000$ psi), using a 1.375-inch drill bit, round drill steel, a rotational speed of $600 \mathrm{rpm}$ and a thrust setting of 4,242 lbs. 
Table 6.9 Full-Octave and One-Third Octave Band Sound Power Levels From Laboratory Test (1.375-inch drill bit, round drill steel, rotational speed of $600 \mathrm{rpm}$ and thrust setting of 4,242 lbs.)

\begin{tabular}{|c|c|c|c|c|c|}
\hline & & dBA & & & dBA \\
\hline \multirow{25}{*}{ 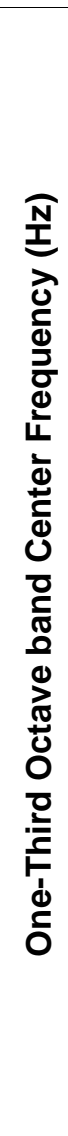 } & 50 & 78.4 & \multirow{9}{*}{ 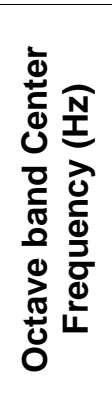 } & 63 & 81.6 \\
\hline & 63 & 76.9 & & 125 & 88.5 \\
\hline & 80 & 74.0 & & 250 & 96.5 \\
\hline & 100 & 87.0 & & 500 & 96.9 \\
\hline & 125 & 78.8 & & 1,000 & 96.1 \\
\hline & 160 & 81.0 & & 2,000 & 100.8 \\
\hline & 200 & 93.1 & & 4,000 & 105.9 \\
\hline & 250 & 93.0 & & 8,000 & 101.4 \\
\hline & 315 & 85.9 & & Overall & 109.0 \\
\hline & 400 & 90.2 & & & \\
\hline & 500 & 92.7 & & & \\
\hline & 630 & 93.1 & & & \\
\hline & 800 & 91.8 & & & \\
\hline & 1,000 & 89.8 & & & \\
\hline & 1,250 & 92.0 & & & \\
\hline & 1,600 & 93.8 & & & \\
\hline & 2,000 & 96.2 & & & \\
\hline & 2,500 & 97.3 & & & \\
\hline & 3,150 & 100.6 & & & \\
\hline & 4,000 & 102.0 & & & \\
\hline & 5,000 & 100.7 & & & \\
\hline & 6,300 & 98.9 & & & \\
\hline & 8,000 & 96.9 & & & \\
\hline & 10,000 & 90.4 & & & \\
\hline & Overall & 109.0 & & & \\
\hline
\end{tabular}

Therefore, the octave-band sound power levels from any of the tests conducted in the laboratory can be used as input for determining sound pressure levels utilizing the Raynoise modeling program.

\subsubsection{Specific Characteristics of the Roof Bolting Machine}

AutoCAD is a standard drafting package that is used to create the structural and machine models used to create testing environments for the Raynoise program. Due to input constraints with the Raynoise program, the drawings were limited to using the 3DPolyline entities to create the models (25). Objects with different material properties in a given model or structure drawing can be placed on different layers within AutoCAD and this can be read in as SET information by the Raynoise package where specific absorption, diffusion, transmission coefficients for each set 
can be assigned. Figures 6.32 and 6.33 listed below are drawings developed from the AutoCAD drafting package for two types of roof bolting machines. Figure 6.32 represents a Fletcher Roof Ranger II roof bolting machine and figure 6.33 illustrates a Fletcher HDDR roof bolting machine. Figures 6.32 and 6.33 were used as input to the Raynoise program relative to machine characteristics of the roof bolting machine.

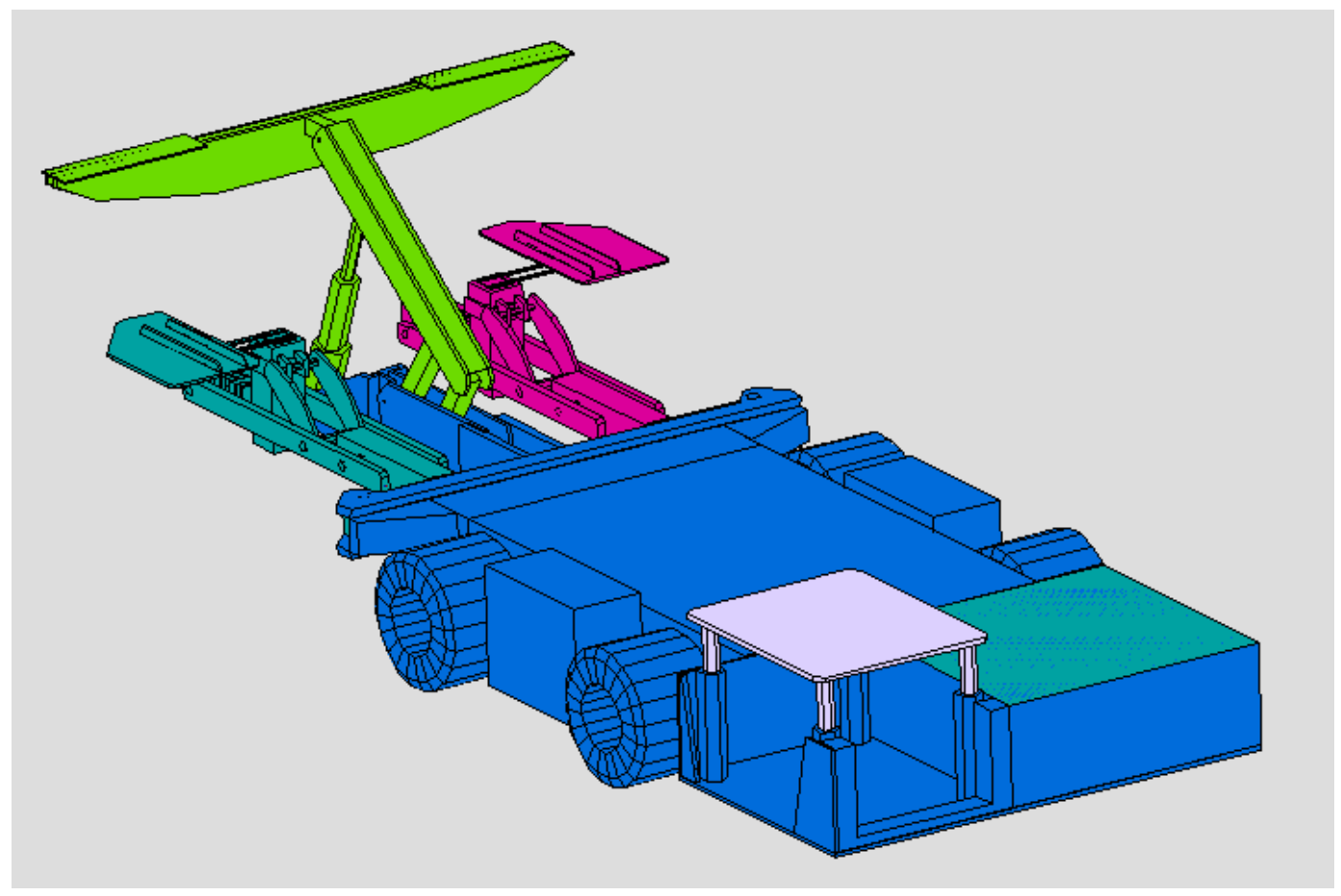

Figure 6.32 AutoCAD drawing of a Roof Ranger II Roof Bolting Machine 


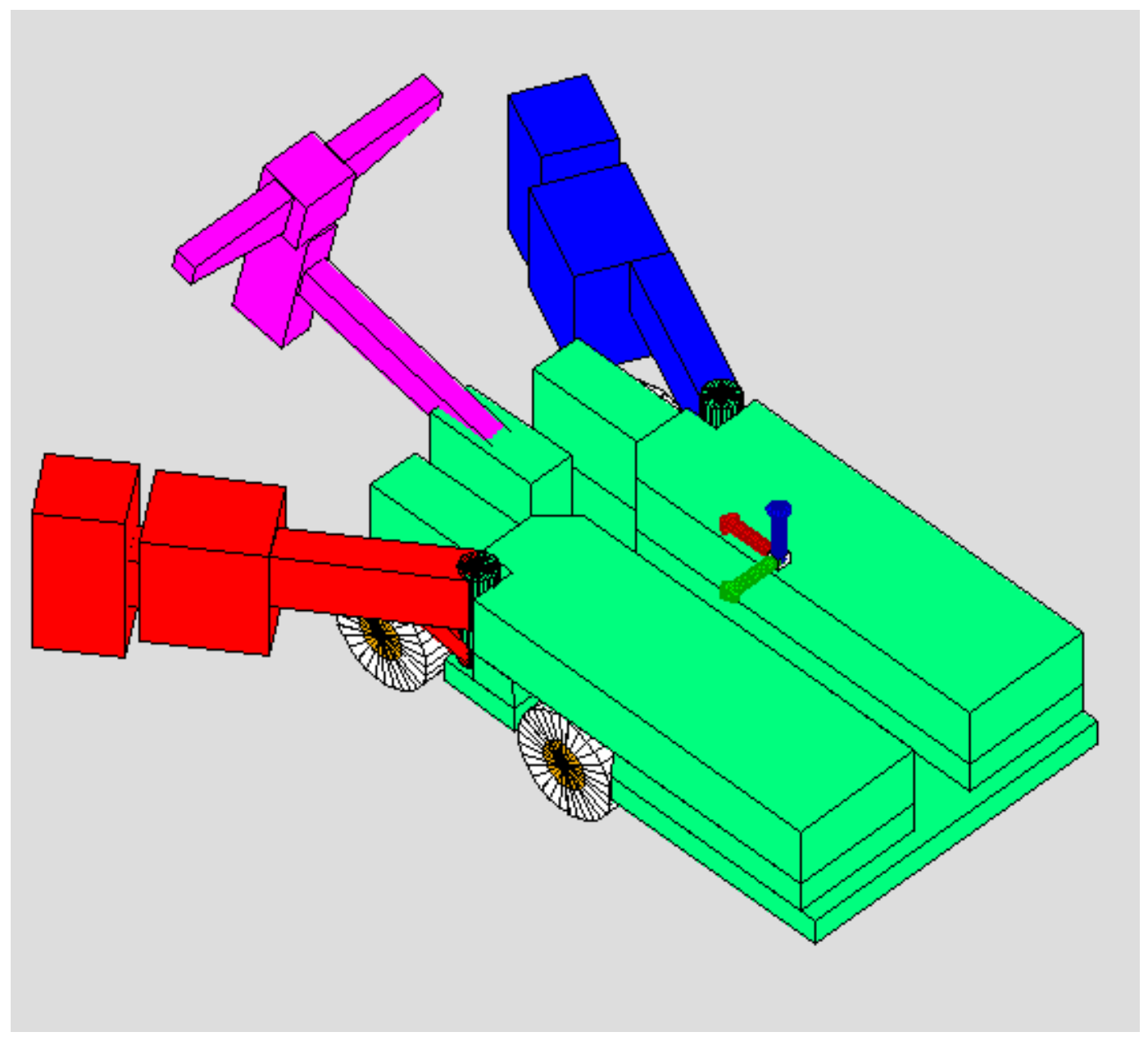

Figure 6.33 AutoCAD drawing of a HDDR Roof Bolting Machine

\subsubsection{Establishment of a Measurement Grid for the Underground Mine Section}

Section 6.3.4.3, discussed earlier, provided the geometric configuration of an underground mine section, which was developed from in-mine measurements. To determine or predict sound pressure levels at specific points within the underground mine section, a measurement grid or mesh was required to be constructed for input into the Raynoise program. The measurement grid was developed and the associated measuring points were determined. The grid was developed utilizing measuring points that were on one-meter centers relative to the width of the entry or crosscut and located five-feet above the floor surface. The height measurement of five-feet was selected because this distance, on average, represents the average 
ear-height of an individual. Figures 6.34 thru 6.36, shown below, illustrate the measurement grids developed for a roof bolting machine located at the working face, crosscut and intersection, respectively. Figures 6.34 thru 6.36 were generated and required for input into the Raynoise program.

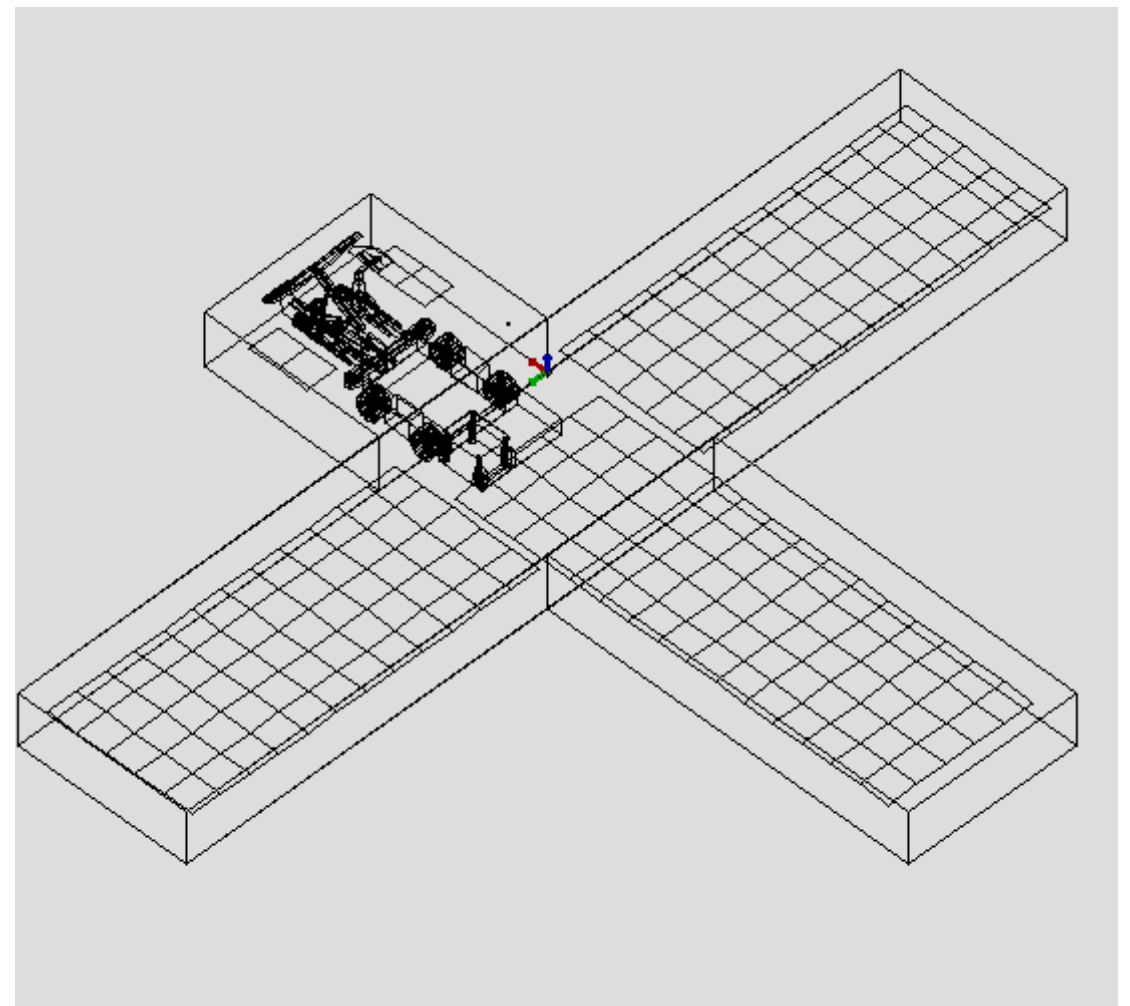

Figure 6.34 Measurement Grid Developed for a Roof Bolting at the Mine Face 


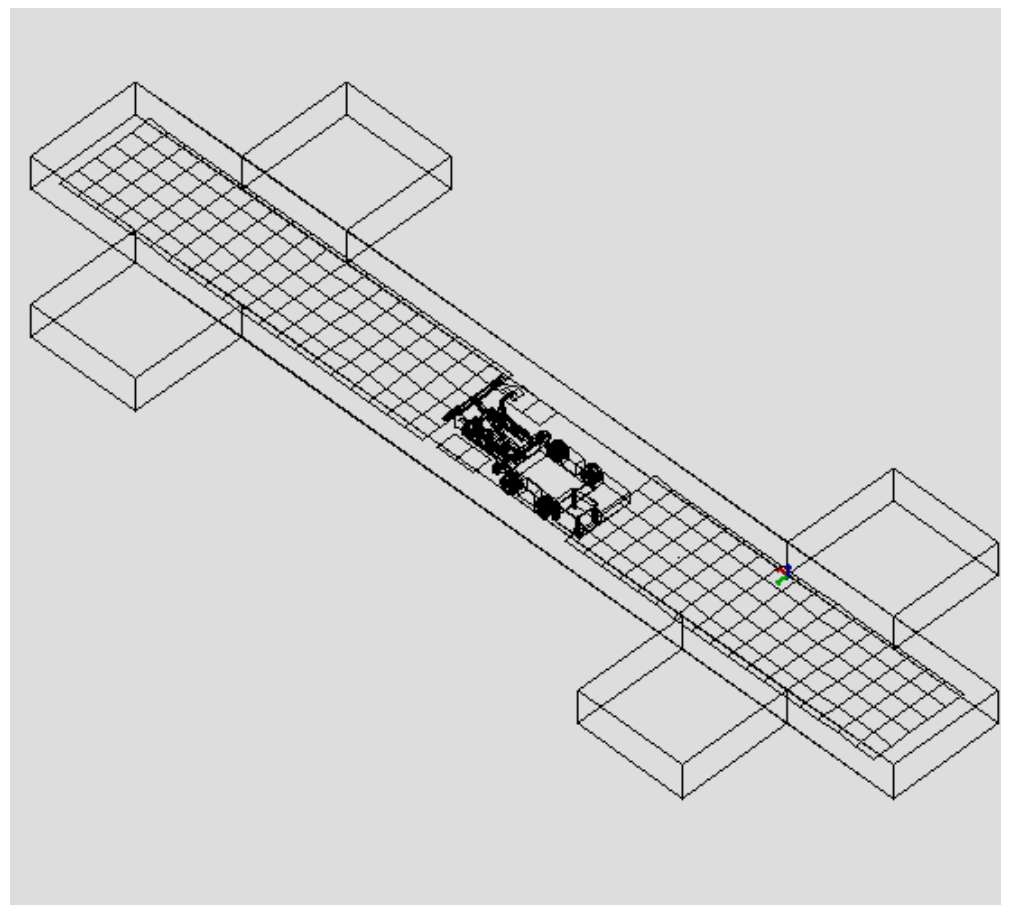

Figure 6.35 Measurement Grid Developed for a Roof Bolting Machine at a Crosscut

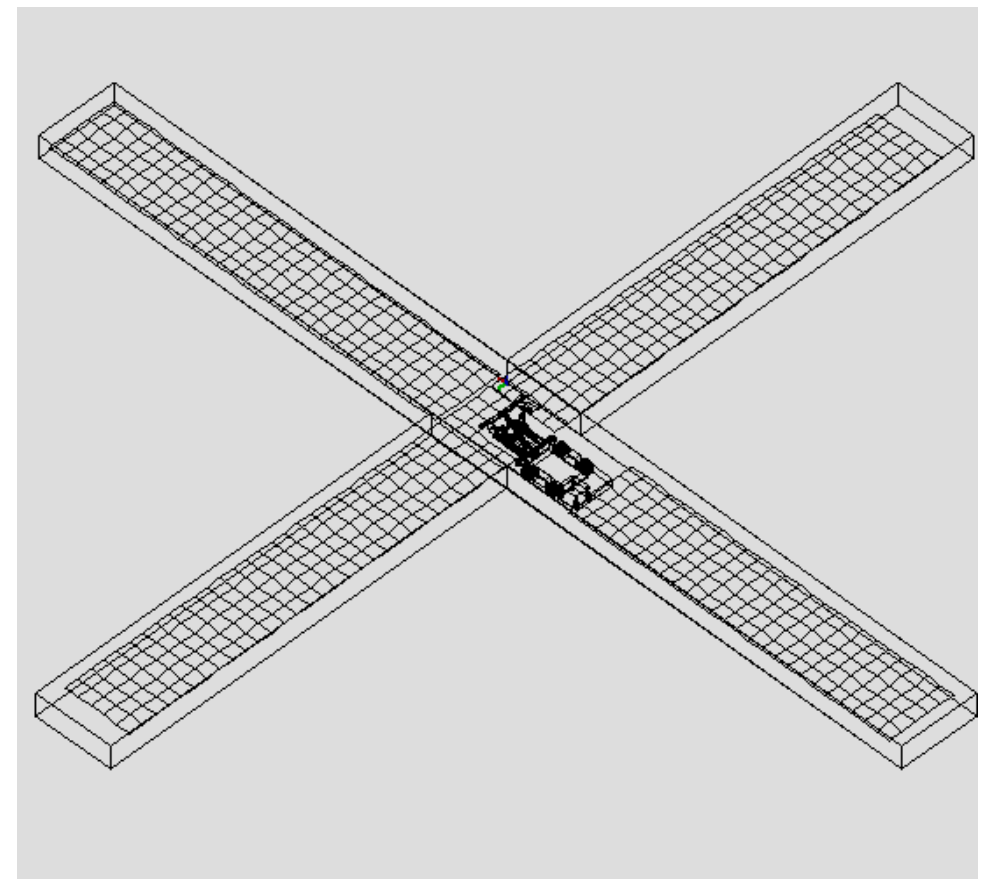

Figure 6.36 Measurement Grid Developed for a Roof Bolting Machine at an Intersection 


\subsubsection{Development of a Command File for Input into Raynoise Program}

The construction of a command file (CMD) is necessary for using the Raynoise program (25). The command file provided properties related to the sound power of the noise source or sources, the type of noise source, e.g. line source or point source and the absorption or sabine coefficients relative to the acoustic properties associated with the underground mine section, equipment, etc. A point source is defined as a single noise source at a given location and a line source is a group of point sources along a straight line with the same acoustical characteristics. Research results have shown the dominant noise sources of a roof bolting machine are the drill bit, the drill steel, and the drill chuck. These noise sources would correspond to three point sources on a line source extending from the bit to the chuck, with the drill bit/contact surface as one source, the drill steel another and the third source being the drill chuck. A line source was chosen from the drill chuck to the drill bit/contact surface for the model run. Figure 6.37, shown below, provides a screenshot of a typical command file for input into the Raynoise program. 


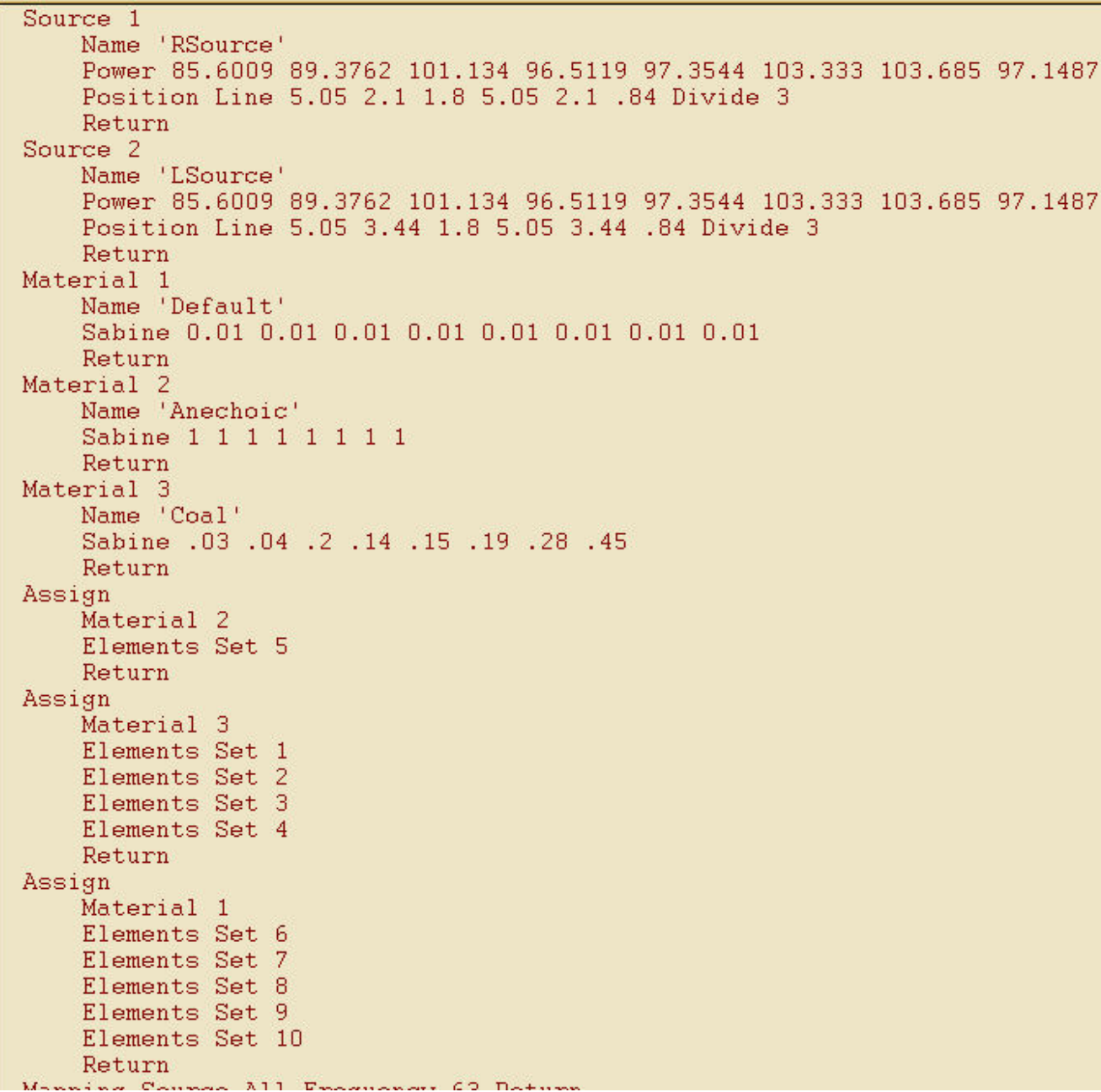

Figure 6.37 Screenshot of a Command File for Input into Raynoise Program 


\subsubsection{Sound Pressure Levels Determined from Raynoise Program}

Once all of the required input parameters for the Raynoise program are constructed, determined and entered as discussed in sections 6.3.5.1 thru 6.3.5.4, the predicted or determined underground sound pressure levels can then be determined and viewed using the Raynoise program. An example of this view is shown in Figure 6.38, displaying the sound pressure levels attributed to a Roof Ranger II roof bolting machine drilling a bolt hole at the face of 6-foot-high underground coal mine.

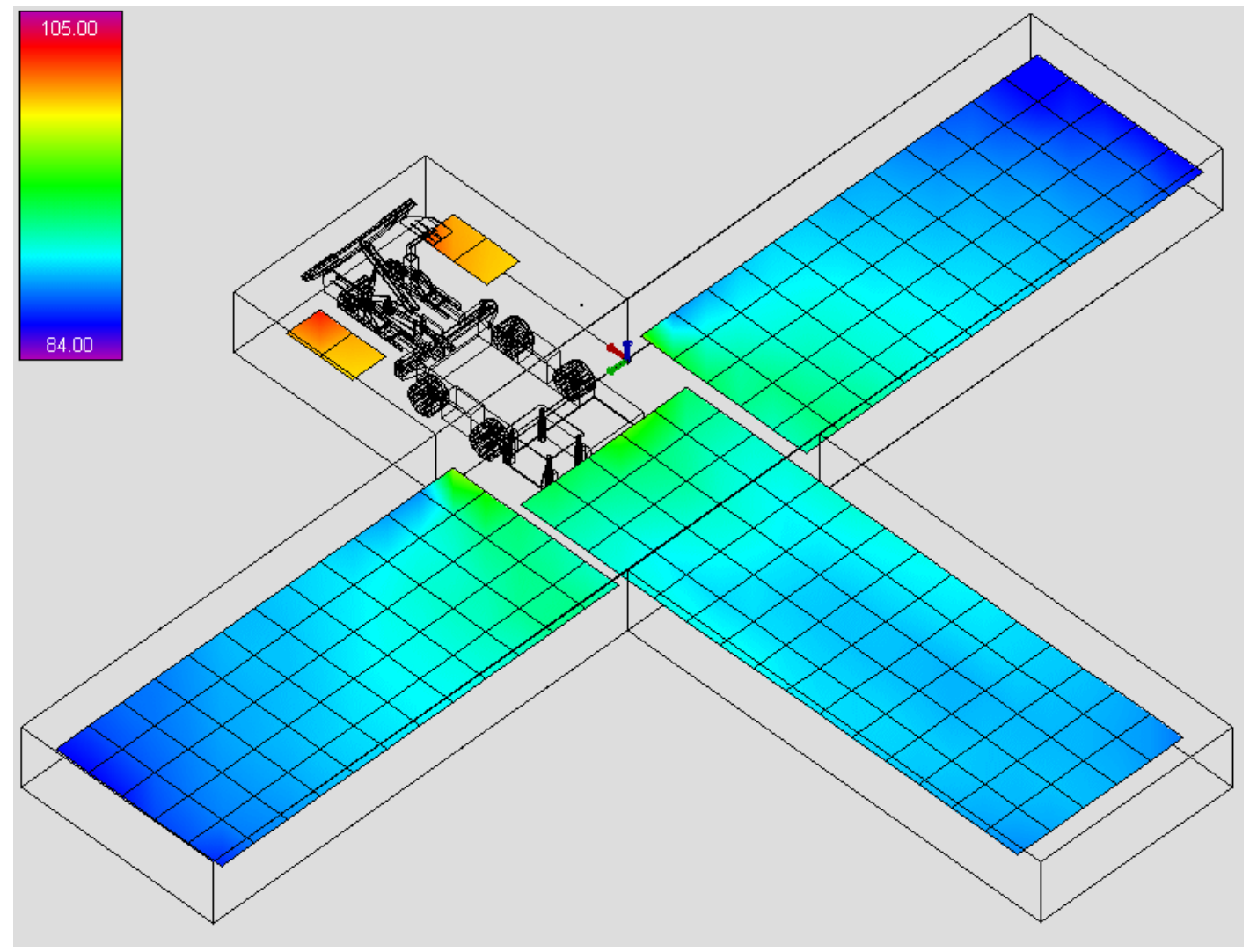

Figure 6.38 Determined Sound Pressure Level Contours in an Underground Coal Mine

The sound pressure levels can be viewed or displayed as contour plots, as shown in figure 6.38, or interpreted numerically as shown in figure 6.39 . 


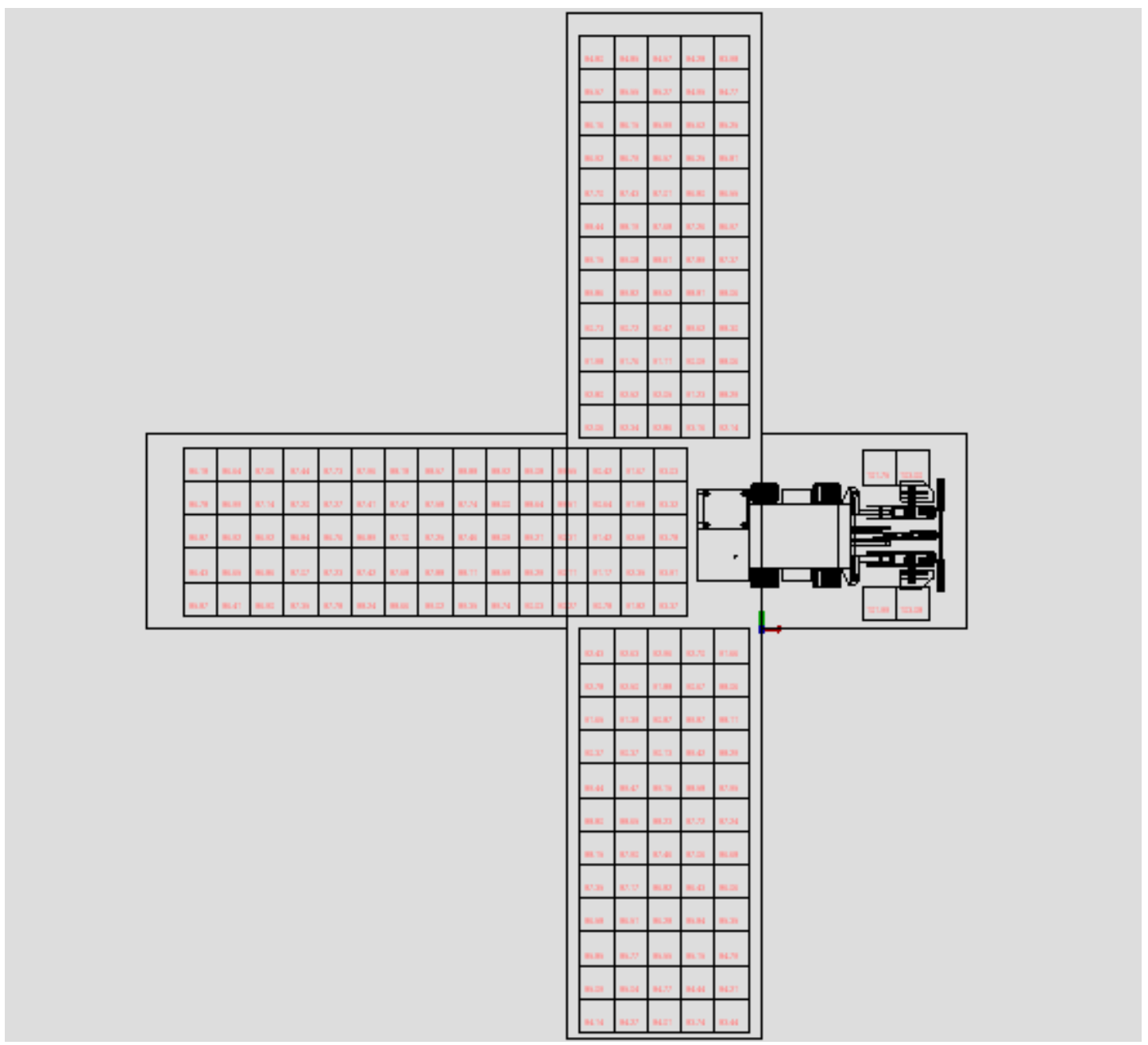

Figure 6.39 Determined Sound Pressure Levels (Numerical) in an Underground Coal Mine

Additionally, the program can provide a "zoom" view, relative to the determined sound pressure levels. Figure 6.40 shows a closer, or "zoom" view of the numerical sound pressure levels near and around a roof bolting machine. 


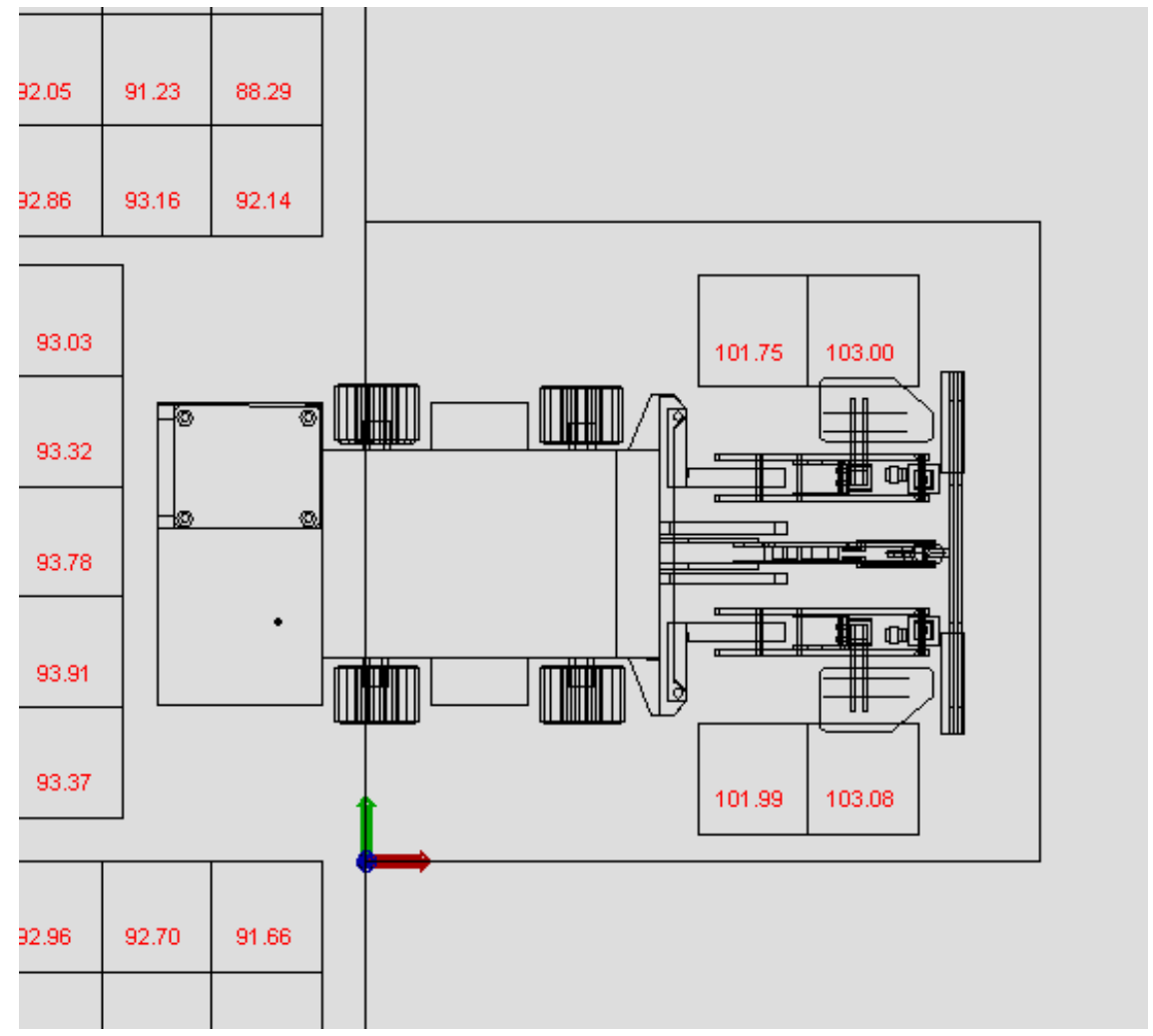

Figure 6.40 Zoom-view of Determined Sound Pressure Levels Near a Roof Bolting Machine 


\subsubsection{Comparing Sound Pressure Levels - Model Prediction vs. Underground Measurements}

Sound pressure level measurements were conducted at the operator position of a Roof Ranger II roof bolting machine in an underground coal mine. The underground mine height varied from approximately 4 to 5 feet and the thickness of the coal seam varied from 32-40 inches. The mine operator provided the opportunity to measure sound pressure levels relative to two bolting machines utilizing a vacuum system and mist system drilling method respectively. The roof bolting plan for the section is illustrated in figure 6.41 below.

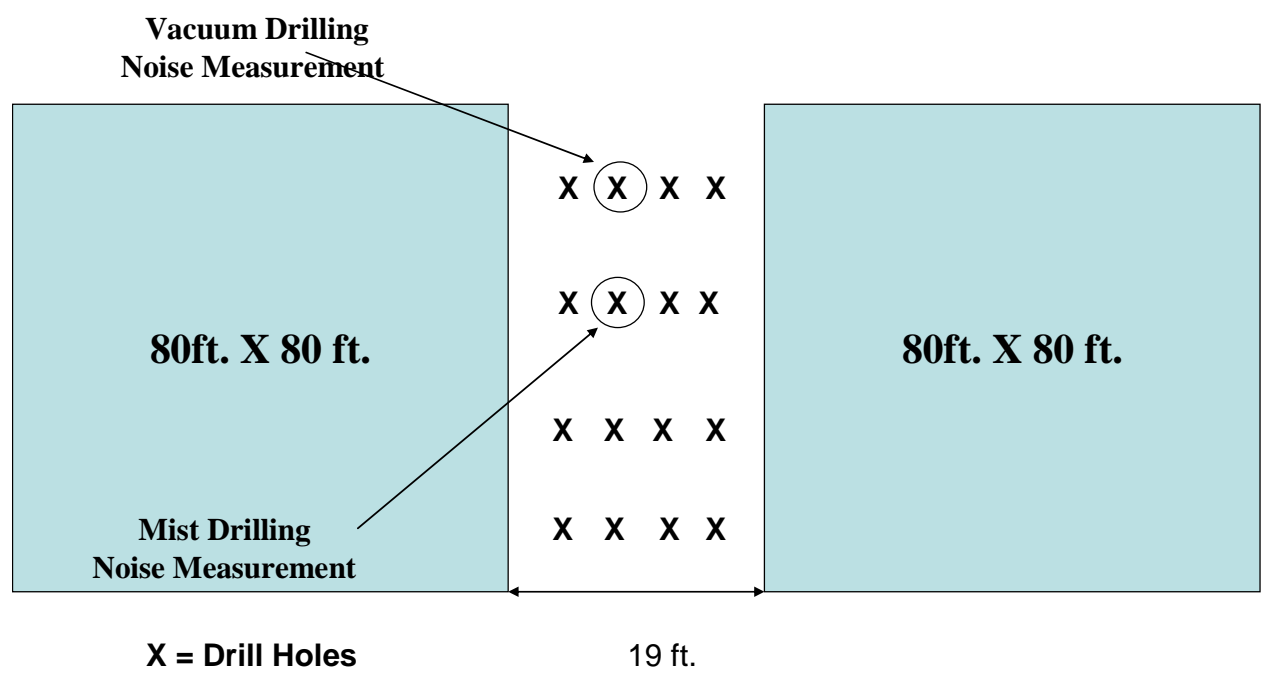

Figure 6.41 Roof Bolting Plan at the Underground Coal Mine

Each roof bolting machine utilized a 1-inch drill bit, hex drill steel and drilled to a depth of 5 feet into the immediate roof. The roof consisted of a highly fractured shale rock consistent of a rock type with a low compressive strength (approximately 6,000 psi). The drilling configurations for both machines were set at a rotational speed of $500 \mathrm{rpm}$ and a thrust of approximately $6,500 \mathrm{lbs}$. 
Sound pressure level measurements were conducted at the operator position of each machine.

Table 6.10, illustrated below provides the results of the sound pressure level testing.

Table 6.10 Sound Pressure Level Measurements at Operator Position of Roof Bolting Machine

\begin{tabular}{|c|c|c|}
\hline \hline $\begin{array}{c}\text { Operation of Roof } \\
\text { Bolting Machine }\end{array}$ & $\begin{array}{c}\text { Roof Ranger II } \\
\text { (Vacuum) } \\
\text { dBA }\end{array}$ & $\begin{array}{c}\text { Roof Ranger II } \\
\text { (Mist System) } \\
\text { dBA }\end{array}$ \\
\hline Idling & 82 & 82 \\
\hline $\begin{array}{c}\text { Mist System On } \\
\text { No drilling }\end{array}$ & NA & 88 \\
\hline Drilling & 101 & 96 \\
\hline
\end{tabular}

The sound pressure levels experienced at the operator position during drilling utilizing the vacuum system of drilling was $101 \mathrm{dBA}$. Utilizing a mist system type of drilling, the operator was exposed to a sound pressure level of $96 \mathrm{dBA}$, resulting in a $5 \mathrm{dBA}$ difference in sound pressure level.

The next step was to utilize the Raynoise program to compare the measured underground sound pressure level experienced at the operator position to the predicted sound pressure level determined thru the modeling approach. The first step was to characterize the geometric configuration of the mine layout in AutoCAD as shown in figure 6.41, secondly the specific characteristics of the roof bolting machine were then processed in AutoCAD and placed within the mine layout. A measurement mesh or grid was then developed to characterize sound pressure levels at specific locations within the mine section. Figure 6.42 displays the geometric configuration of the mine section, the location of the roof bolting machine and the measurement 
mesh used for predicting sound pressure levels. A total of 246 measurement locations within the mine section were selected and shown below.

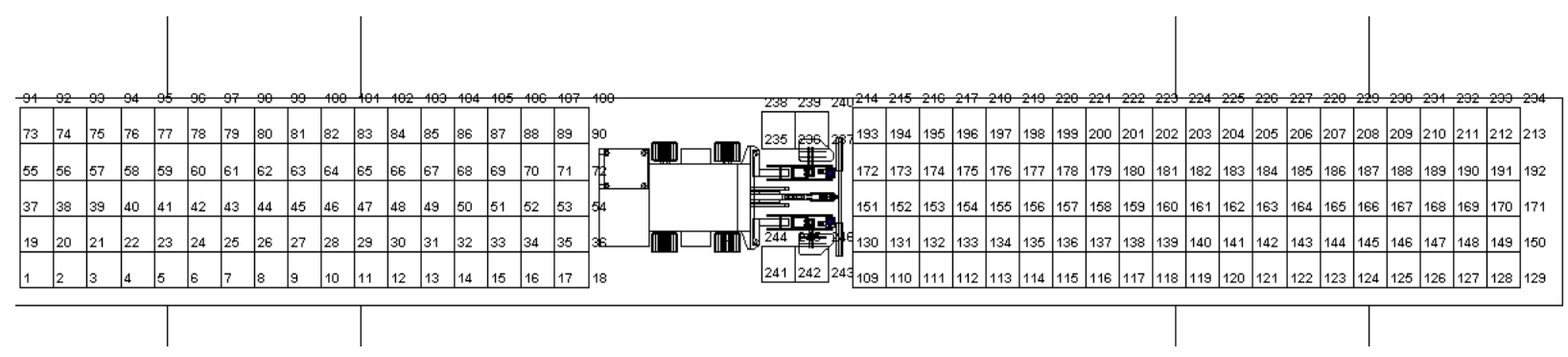

Figure 6.42 Model Simulation for Predicting Sound Pressure Levels

Additionally, full-octave band sound power levels, obtained from the reverberation room testing, were then utilized for input into the program. Table 6.11 below provides the full-octave band sound power levels based on a test in the reverberation room relative to a rock media with a compressive strength equal to $6,000 \mathrm{psi}$, a 1-inch drill bit, hex drill steel, a rotational speed of $500 \mathrm{rpm}$ and a thrust setting of $6,363 \mathrm{lbs}$. 
Table 6.11 Full-Octave Band Sound Power Levels - Compressive strength-6,000 psi, hex drill steel, 1-inch bit, rotational speed-500 rpm, and Thrust setting-6,363 lbs

\begin{tabular}{|c|c|}
\hline $\begin{array}{c}\text { Octave-band } \\
\text { (Hz) }\end{array}$ & $\begin{array}{c}\text { Sound Power Level } \\
\text { dBA }\end{array}$ \\
\hline 63 & 85.6 \\
\hline 125 & 89.4 \\
\hline 250 & 101.1 \\
\hline 500 & 96.5 \\
\hline 1000 & 97.4 \\
\hline 2000 & 103.3 \\
\hline 4000 & 103.7 \\
\hline 8000 & 97.1 \\
\hline
\end{tabular}

Therefore, the mine configuration or layout, the roof bolting machine characteristics, a measurement grid or mesh, the full-octave band sound power levels and the sabine or absorption coefficients determined from section 6.3.4 were then inputted into the Raynoise program for predicting or determining sound pressure levels within the mine section and at the operator position of the roof bolting machine. The results of the model run are displayed graphically, as sound pressure level contours, shown in figure 6.43 below. 


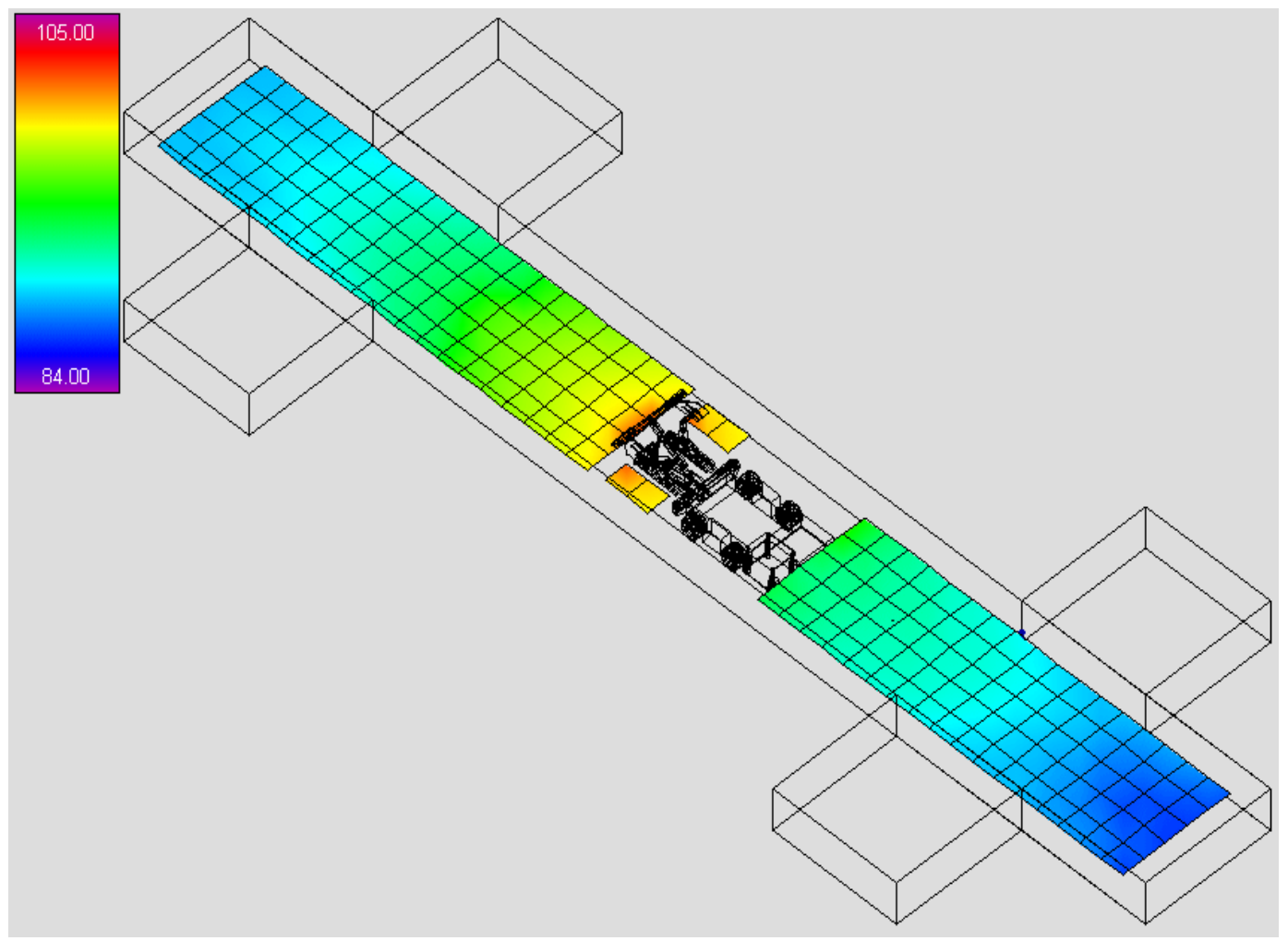

Figure 6.43 Sound Pressure Level Contours for Model Run

Furthermore, table 6.12 provides the results of the model run in numerical form for each of the 246 measurement positions as displayed in figure 6.42. The table provides the predicted or determined sound pressure levels for each full-octave band $(63 \mathrm{~Hz}, 125 \mathrm{~Hz}, 250 \mathrm{~Hz}, 500 \mathrm{~Hz}$, $1,000 \mathrm{~Hz}, 2,000 \mathrm{~Hz}, 4,000 \mathrm{~Hz}$ and $8,000 \mathrm{~Hz}$ ) relative to each of the 246 measurement positions. The table also provides the overall linear and a-weighted sound pressure level at each measurement position. 
Table 6.12 Sound Pressure Level Results (Numerically) of the Model Run

\begin{tabular}{|c|c|c|c|c|c|c|c|c|c|c|}
\hline Location & $63 \mathrm{~Hz}$ & $125 \mathrm{~Hz}$ & $250 \mathrm{~Hz}$ & $500 \mathrm{~Hz}$ & $1 \mathrm{kHz}$ & $2 \mathrm{kHz}$ & $4 \mathrm{kHz}$ & $8 \mathrm{kHz}$ & dBA & $\mathrm{dB}$ \\
\hline 1 & 65.3 & 68.8 & 77.4 & 74.0 & 74.6 & 79.8 & 78.5 & 69.0 & 84.1 & 84.7 \\
\hline 2 & 66.1 & 69.6 & 78.2 & 74.7 & 75.4 & 80.5 & 79.2 & 69.6 & 84.8 & 85.4 \\
\hline 3 & 66.6 & 70.2 & 78.7 & 75.3 & 75.9 & 81.1 & 79.8 & 70.2 & 85.4 & 86.0 \\
\hline 4 & 66.8 & 70.3 & 79.0 & 75.5 & 76.2 & 81.4 & 80.1 & 70.5 & 85.6 & 86.3 \\
\hline 5 & 67.1 & 70.7 & 79.3 & 75.8 & 76.5 & 81.7 & 80.4 & 70.8 & 85.9 & 86.6 \\
\hline 6 & 67.6 & 71.2 & 79.8 & 76.3 & 77.0 & 82.2 & 80.8 & 71.2 & 86.4 & 87.0 \\
\hline 7 & 67.6 & 71.2 & 79.9 & 76.4 & 77.0 & 82.3 & 80.9 & 71.4 & 86.5 & 87.1 \\
\hline 8 & 68.2 & 71.7 & 80.3 & 76.9 & 77.5 & 82.7 & 81.4 & 71.8 & 86.9 & 87.6 \\
\hline 9 & 68.8 & 72.4 & 81.1 & 77.6 & 78.2 & 83.4 & 82.1 & 72.7 & 87.7 & 88.3 \\
\hline 10 & 69.5 & 73.1 & 81.7 & 78.2 & 78.9 & 84.1 & 82.8 & 73.2 & 88.3 & 89.0 \\
\hline 11 & 70.4 & 73.9 & 82.5 & 79.1 & 79.7 & 84.9 & 83.6 & 74.1 & 89.1 & 89.8 \\
\hline 12 & 71.0 & 74.5 & 83.1 & 79.7 & 80.3 & 85.5 & 84.2 & 74.6 & 89.7 & 90.4 \\
\hline 13 & 71.4 & 74.9 & 83.7 & 80.2 & 80.8 & 86.1 & 84.8 & 75.3 & 90.3 & 91.0 \\
\hline 14 & 71.8 & 75.3 & 84.1 & 80.6 & 81.3 & 86.5 & 85.3 & 75.9 & 90.8 & 91.4 \\
\hline 15 & 72.2 & 75.7 & 84.7 & 81.1 & 81.8 & 87.0 & 85.9 & 76.6 & 91.3 & 91.9 \\
\hline 16 & 72.9 & 76.4 & 85.4 & 81.8 & 82.5 & 87.8 & 86.6 & 77.3 & 92.1 & 92.7 \\
\hline 17 & 73.6 & 77.2 & 86.3 & 82.7 & 83.4 & 88.7 & 87.6 & 78.4 & 93.0 & 93.6 \\
\hline 18 & 74.5 & 78.1 & 87.3 & 83.6 & 84.3 & 89.7 & 88.6 & 79.5 & 94.0 & 94.6 \\
\hline 19 & 65.0 & 68.6 & 77.2 & 73.7 & 74.4 & 79.6 & 78.2 & 68.7 & 83.8 & 84.4 \\
\hline 20 & 65.2 & 68.8 & 77.4 & 74.0 & 74.6 & 79.8 & 78.5 & 69.0 & 84.0 & 84.7 \\
\hline 21 & 65.5 & 69.1 & 77.8 & 74.3 & 75.0 & 80.2 & 78.9 & 69.5 & 84.4 & 85.1 \\
\hline 22 & 65.7 & 69.2 & 78.0 & 74.5 & 75.2 & 80.4 & 79.2 & 69.8 & 84.7 & 85.3 \\
\hline 23 & 66.1 & 69.7 & 78.6 & 75.0 & 75.7 & 80.9 & 79.7 & 70.4 & 85.2 & 85.8 \\
\hline 24 & 67.0 & 70.6 & 79.4 & 75.9 & 76.5 & 81.8 & 80.5 & 71.1 & 86.1 & 86.7 \\
\hline 25 & 67.9 & 71.5 & 80.3 & 76.7 & 77.4 & 82.6 & 81.4 & 72.0 & 86.9 & 87.5 \\
\hline 26 & 68.8 & 72.3 & 81.0 & 77.5 & 78.2 & 83.4 & 82.1 & 72.6 & 87.6 & 88.3 \\
\hline 27 & 69.7 & 73.3 & 81.9 & 78.4 & 79.1 & 84.3 & 83.0 & 73.3 & 88.5 & 89.2 \\
\hline 28 & 70.5 & 74.1 & 82.6 & 79.2 & 79.8 & 85.0 & 83.6 & 73.9 & 89.3 & 89.9 \\
\hline 29 & 71.2 & 74.7 & 83.3 & 79.8 & 80.5 & 85.7 & 84.3 & 74.6 & 89.9 & 90.5 \\
\hline 30 & 71.5 & 75.0 & 83.6 & 80.1 & 80.8 & 86.0 & 84.6 & 74.8 & 90.2 & 90.8 \\
\hline 31 & 71.7 & 75.3 & 83.8 & 80.4 & 81.0 & 86.2 & 84.8 & 75.1 & 90.4 & 91.1 \\
\hline 32 & 72.4 & 76.0 & 84.7 & 81.2 & 81.9 & 87.1 & 85.7 & 76.1 & 91.3 & 91.9 \\
\hline 33 & 72.6 & 76.1 & 84.9 & 81.4 & 82.0 & 87.3 & 86.0 & 76.5 & 91.5 & 92.2 \\
\hline 34 & 72.8 & 76.4 & 85.3 & 81.7 & 82.4 & 87.7 & 86.5 & 77.2 & 92.0 & 92.6 \\
\hline 35 & 73.5 & 77.0 & 86.2 & 82.5 & 83.2 & 88.6 & 87.5 & 78.5 & 92.9 & 93.5 \\
\hline 36 & 74.5 & 78.1 & 87.3 & 83.6 & 84.3 & 89.7 & 88.7 & 79.7 & 94.0 & 94.6 \\
\hline 37 & 64.7 & 68.3 & 77.0 & 73.5 & 74.2 & 79.4 & 78.1 & 68.5 & 83.6 & 84.3 \\
\hline 38 & 64.6 & 68.2 & 77.1 & 73.5 & 74.2 & 79.5 & 78.3 & 68.8 & 83.8 & 84.4 \\
\hline 39 & 64.6 & 68.2 & 77.3 & 73.7 & 74.3 & 79.6 & 78.5 & 69.2 & 84.0 & 84.5 \\
\hline 40 & 65.0 & 68.6 & 77.7 & 74.1 & 74.7 & 80.1 & 78.9 & 69.6 & 84.4 & 85.0 \\
\hline 41 & 65.6 & 69.1 & 78.2 & 74.6 & 75.2 & 80.5 & 79.4 & 70.0 & 84.8 & 85.4 \\
\hline 42 & 67.0 & 70.5 & 79.4 & 75.8 & 76.5 & 81.8 & 80.5 & 71.0 & 86.1 & 86.6 \\
\hline 43 & 67.8 & 71.4 & 80.1 & 76.6 & 77.3 & 82.5 & 81.2 & 71.5 & 86.7 & 87.4 \\
\hline 44 & 69.1 & 72.7 & 81.2 & 77.8 & 78.4 & 83.6 & 82.2 & 72.4 & 87.8 & 88.5 \\
\hline 45 & 70.1 & 73.6 & 82.0 & 78.6 & 79.3 & 84.4 & 82.9 & 73.0 & 88.6 & 89.2 \\
\hline 46 & 70.9 & 74.4 & 82.9 & 79.5 & 80.1 & 85.3 & 83.8 & 73.9 & 89.5 & 90.1 \\
\hline 47 & 71.5 & 75.0 & 83.6 & 80.1 & 80.8 & 85.9 & 84.5 & 74.8 & 90.2 & 90.8 \\
\hline
\end{tabular}




\begin{tabular}{|c|c|c|c|c|c|c|c|c|c|c|}
\hline Location & $63 \mathrm{~Hz}$ & $125 \mathrm{~Hz}$ & $250 \mathrm{~Hz}$ & $500 \mathrm{~Hz}$ & $1 \mathrm{kHz}$ & $2 \mathrm{kHz}$ & $4 \mathrm{kHz}$ & $8 \mathrm{kHz}$ & dBA & $\mathrm{dB}$ \\
\hline 48 & 71.8 & 75.4 & 83.8 & 80.4 & 81.1 & 86.2 & 84.8 & 74.9 & 90.4 & 91.1 \\
\hline 49 & 72.3 & 75.9 & 84.4 & 81.0 & 81.6 & 86.8 & 85.4 & 75.7 & 91.1 & 91.7 \\
\hline 50 & 72.5 & 76.1 & 84.8 & 81.3 & 81.9 & 87.2 & 85.8 & 76.2 & 91.4 & 92.0 \\
\hline 51 & 72.5 & 76.0 & 84.9 & 81.4 & 82.0 & 87.3 & 86.2 & 77.0 & 91.6 & 92.2 \\
\hline 52 & 73.0 & 76.6 & 85.6 & 82.0 & 82.7 & 88.0 & 86.9 & 77.7 & 92.3 & 92.9 \\
\hline 53 & 73.1 & 76.6 & 85.8 & 82.1 & 82.8 & 88.1 & 87.1 & 78.0 & 92.4 & 93.1 \\
\hline 54 & 73.8 & 77.4 & 86.7 & 83.0 & 83.7 & 89.1 & 88.1 & 79.2 & 93.4 & 94.0 \\
\hline 55 & 64.7 & 68.3 & 77.0 & 73.5 & 74.2 & 79.4 & 78.1 & 68.4 & 83.6 & 84.3 \\
\hline 56 & 64.9 & 68.5 & 77.3 & 73.8 & 74.4 & 79.7 & 78.4 & 68.9 & 83.9 & 84.6 \\
\hline 57 & 64.7 & 68.3 & 77.2 & 73.6 & 74.3 & 79.6 & 78.3 & 68.9 & 83.9 & 84.4 \\
\hline 58 & 65.2 & 68.8 & 77.7 & 74.1 & 74.8 & 80.0 & 78.8 & 69.4 & 84.4 & 84.9 \\
\hline 59 & 66.0 & 69.6 & 78.5 & 74.9 & 75.6 & 80.9 & 79.7 & 70.3 & 85.2 & 85.8 \\
\hline 60 & 66.7 & 70.2 & 79.1 & 75.5 & 76.2 & 81.5 & 80.2 & 70.8 & 85.8 & 86.4 \\
\hline 61 & 67.6 & 71.2 & 79.9 & 76.4 & 77.1 & 82.3 & 81.0 & 71.4 & 86.5 & 87.2 \\
\hline 62 & 68.5 & 72.1 & 80.7 & 77.3 & 77.9 & 83.1 & 81.8 & 72.2 & 87.3 & 88.0 \\
\hline 63 & 69.9 & 73.5 & 82.0 & 78.6 & 79.2 & 84.4 & 83.0 & 73.2 & 88.6 & 89.3 \\
\hline 64 & 70.9 & 74.4 & 82.8 & 79.5 & 80.1 & 85.2 & 83.8 & 73.8 & 89.5 & 90.1 \\
\hline 65 & 71.4 & 74.9 & 83.4 & 80.0 & 80.6 & 85.8 & 84.3 & 74.3 & 90.0 & 90.6 \\
\hline 66 & 71.8 & 75.3 & 83.8 & 80.4 & 81.0 & 86.2 & 84.7 & 74.8 & 90.4 & 91.0 \\
\hline 67 & 72.3 & 75.8 & 84.4 & 80.9 & 81.6 & 86.8 & 85.3 & 75.6 & 91.0 & 91.6 \\
\hline 68 & 72.3 & 75.9 & 84.5 & 81.0 & 81.7 & 86.9 & 85.5 & 75.9 & 91.1 & 91.7 \\
\hline 69 & 72.6 & 76.2 & 84.9 & 81.4 & 82.1 & 87.3 & 86.0 & 76.5 & 91.6 & 92.2 \\
\hline 70 & 72.9 & 76.5 & 85.4 & 81.8 & 82.5 & 87.8 & 86.6 & 77.3 & 92.1 & 92.7 \\
\hline 71 & 72.9 & 76.5 & 85.5 & 81.9 & 82.6 & 87.9 & 86.7 & 77.4 & 92.2 & 92.8 \\
\hline 72 & 73.5 & 77.1 & 86.1 & 82.5 & 83.2 & 88.5 & 87.3 & 77.8 & 92.8 & 93.4 \\
\hline 73 & 65.4 & 68.9 & 77.3 & 73.9 & 74.6 & 79.7 & 78.3 & 68.5 & 84.0 & 84.6 \\
\hline 74 & 65.4 & 69.0 & 77.4 & 74.0 & 74.6 & 79.8 & 78.4 & 68.7 & 84.0 & 84.7 \\
\hline 75 & 65.7 & 69.2 & 77.9 & 74.4 & 75.1 & 80.3 & 79.0 & 69.4 & 84.5 & 85.2 \\
\hline 76 & 65.8 & 69.3 & 78.2 & 74.6 & 75.3 & 80.5 & 79.3 & 69.9 & 84.8 & 85.4 \\
\hline 77 & 66.1 & 69.7 & 78.6 & 75.0 & 75.7 & 81.0 & 79.8 & 70.5 & 85.3 & 85.9 \\
\hline 78 & 66.8 & 70.4 & 79.3 & 75.8 & 76.4 & 81.7 & 80.5 & 71.2 & 86.0 & 86.6 \\
\hline 79 & 67.4 & 71.0 & 79.8 & 76.3 & 77.0 & 82.2 & 81.0 & 71.6 & 86.5 & 87.1 \\
\hline 80 & 68.3 & 71.9 & 80.6 & 77.1 & 77.7 & 83.0 & 81.7 & 72.2 & 87.2 & 87.9 \\
\hline 81 & 69.3 & 72.8 & 81.4 & 77.9 & 78.6 & 83.8 & 82.4 & 72.8 & 88.0 & 88.6 \\
\hline 82 & 70.3 & 73.8 & 82.4 & 79.0 & 79.6 & 84.8 & 83.5 & 73.8 & 89.0 & 89.7 \\
\hline 83 & 71.2 & 74.7 & 83.3 & 79.9 & 80.5 & 85.7 & 84.3 & 74.6 & 89.9 & 90.6 \\
\hline 84 & 71.7 & 75.3 & 83.9 & 80.4 & 81.0 & 86.2 & 84.9 & 75.2 & 90.5 & 91.1 \\
\hline 85 & 71.9 & 75.5 & 84.1 & 80.6 & 81.3 & 86.5 & 85.1 & 75.4 & 90.7 & 91.3 \\
\hline 86 & 72.1 & 75.6 & 84.4 & 80.9 & 81.5 & 86.7 & 85.4 & 75.9 & 91.0 & 91.6 \\
\hline 87 & 72.4 & 75.9 & 84.7 & 81.2 & 81.9 & 87.1 & 85.8 & 76.2 & 91.3 & 92.0 \\
\hline 88 & 72.8 & 76.4 & 85.3 & 81.7 & 82.4 & 87.7 & 86.5 & 77.2 & 92.0 & 92.6 \\
\hline 89 & 73.4 & 77.0 & 86.2 & 82.5 & 83.2 & 88.5 & 87.4 & 78.3 & 92.8 & 93.4 \\
\hline 90 & 74.0 & 77.6 & 86.8 & 83.1 & 83.8 & 89.1 & 88.0 & 78.8 & 93.4 & 94.0 \\
\hline 91 & 65.0 & 68.5 & 77.1 & 73.6 & 74.3 & 79.5 & 78.1 & 68.5 & 83.7 & 84.3 \\
\hline 92 & 65.8 & 69.3 & 77.9 & 74.4 & 75.1 & 80.3 & 78.9 & 69.3 & 84.5 & 85.1 \\
\hline 93 & 66.3 & 69.9 & 78.5 & 75.0 & 75.7 & 80.9 & 79.6 & 70.0 & 85.1 & 85.8 \\
\hline 94 & 66.5 & 70.1 & 78.8 & 75.3 & 76.0 & 81.2 & 79.9 & 70.4 & 85.5 & 86.1 \\
\hline 95 & 66.7 & 70.3 & 79.0 & 75.5 & 76.1 & 81.4 & 80.1 & 70.5 & 85.6 & 86.3 \\
\hline 96 & 67.7 & 71.2 & 79.8 & 76.3 & 77.0 & 82.2 & 80.8 & 71.1 & 86.4 & 87.0 \\
\hline
\end{tabular}




\begin{tabular}{|c|c|c|c|c|c|c|c|c|c|c|}
\hline Location & $63 \mathrm{~Hz}$ & $125 \mathrm{~Hz}$ & $250 \mathrm{~Hz}$ & $500 \mathrm{~Hz}$ & $1 \mathrm{kHz}$ & $2 \mathrm{kHz}$ & $4 \mathrm{kHz}$ & $8 \mathrm{kHz}$ & dBA & $\mathrm{dB}$ \\
\hline 97 & 67.5 & 71.1 & 79.7 & 76.2 & 76.9 & 82.1 & 80.8 & 71.3 & 86.3 & 87.0 \\
\hline 98 & 67.8 & 71.4 & 80.1 & 76.6 & 77.3 & 82.5 & 81.2 & 71.8 & 86.7 & 87.4 \\
\hline 99 & 68.5 & 72.1 & 80.8 & 77.3 & 78.0 & 83.2 & 82.0 & 72.6 & 87.5 & 88.1 \\
\hline 100 & 69.4 & 73.0 & 81.7 & 78.2 & 78.9 & 84.1 & 82.8 & 73.3 & 88.3 & 89.0 \\
\hline 101 & 70.5 & 74.1 & 82.7 & 79.3 & 79.9 & 85.1 & 83.8 & 74.2 & 89.3 & 90.0 \\
\hline 102 & 71.0 & 74.5 & 83.2 & 79.7 & 80.4 & 85.6 & 84.3 & 74.7 & 89.8 & 90.5 \\
\hline 103 & 71.4 & 75.0 & 83.7 & 80.2 & 80.8 & 86.1 & 84.7 & 75.1 & 90.3 & 90.9 \\
\hline 104 & 71.6 & 75.2 & 83.9 & 80.4 & 81.1 & 86.3 & 85.0 & 75.6 & 90.6 & 91.2 \\
\hline 105 & 72.1 & 75.7 & 84.6 & 81.0 & 81.7 & 87.0 & 85.8 & 76.6 & 91.3 & 91.9 \\
\hline 106 & 72.6 & 76.1 & 85.2 & 81.6 & 82.3 & 87.6 & 86.5 & 77.3 & 91.9 & 92.5 \\
\hline 107 & 73.1 & 76.7 & 85.9 & 82.3 & 82.9 & 88.3 & 87.3 & 78.2 & 92.6 & 93.2 \\
\hline 108 & 73.9 & 77.5 & 86.7 & 83.0 & 83.7 & 89.1 & 88.1 & 79.1 & 93.4 & 94.0 \\
\hline 109 & 79.2 & 82.8 & 92.6 & 88.7 & 89.4 & 94.9 & 94.2 & 86.0 & 99.4 & 99.9 \\
\hline 110 & 78.3 & 81.9 & 91.3 & 87.5 & 88.2 & 93.7 & 92.8 & 84.3 & 98.1 & 98.6 \\
\hline 111 & 77.6 & 81.1 & 90.4 & 86.7 & 87.4 & 92.7 & 91.8 & 83.2 & 97.1 & 97.7 \\
\hline 112 & 76.8 & 80.4 & 89.5 & 85.8 & 86.5 & 91.8 & 90.8 & 81.9 & 96.1 & 96.8 \\
\hline 113 & 76.3 & 79.8 & 88.7 & 85.1 & 85.8 & 91.1 & 90.0 & 80.9 & 95.4 & 96.0 \\
\hline 114 & 75.8 & 79.4 & 88.1 & 84.6 & 85.2 & 90.5 & 89.3 & 80.1 & 94.8 & 95.4 \\
\hline 115 & 75.4 & 78.9 & 87.6 & 84.1 & 84.7 & 89.9 & 88.7 & 79.4 & 94.2 & 94.8 \\
\hline 116 & 75.0 & 78.5 & 87.2 & 83.7 & 84.3 & 89.5 & 88.3 & 79.1 & 93.8 & 94.4 \\
\hline 117 & 74.4 & 78.0 & 86.4 & 83.0 & 83.6 & 88.8 & 87.5 & 78.1 & 93.1 & 93.7 \\
\hline 118 & 73.9 & 77.4 & 85.9 & 82.5 & 83.1 & 88.3 & 86.9 & 77.5 & 92.5 & 93.2 \\
\hline 119 & 73.0 & 76.5 & 85.0 & 81.6 & 82.2 & 87.4 & 86.1 & 76.8 & 91.7 & 92.3 \\
\hline 120 & 71.9 & 75.5 & 84.1 & 80.6 & 81.2 & 86.4 & 85.2 & 75.9 & 90.7 & 91.3 \\
\hline 121 & 71.0 & 74.5 & 83.1 & 79.6 & 80.2 & 85.5 & 84.2 & 74.9 & 89.7 & 90.4 \\
\hline 122 & 70.1 & 73.6 & 82.1 & 78.7 & 79.3 & 84.5 & 83.2 & 73.8 & 88.8 & 89.4 \\
\hline 123 & 69.6 & 73.1 & 81.7 & 78.2 & 78.9 & 84.1 & 82.8 & 73.6 & 88.3 & 89.0 \\
\hline 124 & 69.3 & 72.9 & 81.6 & 78.0 & 78.7 & 83.9 & 82.7 & 73.6 & 88.2 & 88.8 \\
\hline 125 & 68.6 & 72.1 & 80.9 & 77.4 & 78.0 & 83.3 & 82.0 & 72.8 & 87.6 & 88.2 \\
\hline 126 & 68.3 & 71.8 & 80.6 & 77.0 & 77.7 & 82.9 & 81.7 & 72.4 & 87.2 & 87.8 \\
\hline 127 & 68.1 & 71.6 & 80.3 & 76.8 & 77.4 & 82.7 & 81.4 & 72.0 & 86.9 & 87.6 \\
\hline 128 & 67.7 & 71.2 & 79.9 & 76.4 & 77.0 & 82.2 & 81.0 & 71.6 & 86.5 & 87.1 \\
\hline 129 & 67.5 & 71.0 & 79.6 & 76.2 & 76.8 & 82.0 & 80.8 & 71.5 & 86.3 & 86.9 \\
\hline 130 & 80.0 & 83.6 & 93.9 & 89.8 & 90.5 & 96.1 & 95.8 & 88.2 & 100.7 & 101.3 \\
\hline 131 & 78.7 & 82.3 & 92.1 & 88.1 & 88.9 & 94.4 & 93.8 & 85.7 & 98.9 & 99.5 \\
\hline 132 & 77.9 & 81.5 & 91.0 & 87.2 & 87.9 & 93.3 & 92.5 & 84.1 & 97.7 & 98.3 \\
\hline 133 & 77.1 & 80.7 & 89.9 & 86.2 & 86.9 & 92.3 & 91.4 & 82.7 & 96.7 & 97.3 \\
\hline 134 & 76.8 & 80.3 & 89.5 & 85.8 & 86.5 & 91.8 & 90.8 & 82.1 & 96.2 & 96.8 \\
\hline 135 & 76.1 & 79.7 & 88.6 & 85.0 & 85.6 & 90.9 & 89.8 & 80.8 & 95.2 & 95.8 \\
\hline 136 & 75.4 & 79.0 & 87.7 & 84.1 & 84.8 & 90.1 & 88.9 & 79.8 & 94.4 & 95.0 \\
\hline 137 & 75.0 & 78.6 & 87.1 & 83.7 & 84.3 & 89.5 & 88.3 & 79.0 & 93.8 & 94.4 \\
\hline 138 & 74.6 & 78.1 & 86.6 & 83.2 & 83.8 & 89.0 & 87.7 & 78.3 & 93.2 & 93.9 \\
\hline 139 & 74.3 & 77.8 & 86.3 & 82.8 & 83.5 & 88.7 & 87.3 & 78.0 & 92.9 & 93.6 \\
\hline 140 & 73.8 & 77.3 & 85.7 & 82.3 & 83.0 & 88.1 & 86.8 & 77.3 & 92.4 & 93.0 \\
\hline 141 & 73.0 & 76.5 & 85.1 & 81.6 & 82.2 & 87.4 & 86.1 & 76.7 & 91.7 & 92.3 \\
\hline 142 & 72.1 & 75.7 & 84.3 & 80.8 & 81.5 & 86.7 & 85.4 & 76.1 & 91.0 & 91.6 \\
\hline 143 & 71.2 & 74.8 & 83.5 & 80.0 & 80.6 & 85.9 & 84.7 & 75.4 & 90.2 & 90.8 \\
\hline 144 & 70.3 & 73.9 & 82.7 & 79.1 & 79.8 & 85.0 & 83.8 & 74.7 & 89.3 & 89.9 \\
\hline 145 & 69.5 & 73.0 & 81.9 & 78.3 & 79.0 & 84.3 & 83.1 & 74.0 & 88.6 & 89.2 \\
\hline
\end{tabular}




\begin{tabular}{|c|c|c|c|c|c|c|c|c|c|c|}
\hline Location & $63 \mathrm{~Hz}$ & $125 \mathrm{~Hz}$ & $250 \mathrm{~Hz}$ & $500 \mathrm{~Hz}$ & $1 \mathrm{kHz}$ & $2 \mathrm{kHz}$ & $4 \mathrm{kHz}$ & $8 \mathrm{kHz}$ & dBA & dB \\
\hline 146 & 68.7 & 72.3 & 81.1 & 77.6 & 78.2 & 83.5 & 82.4 & 73.3 & 87.8 & 88.4 \\
\hline 147 & 68.2 & 71.8 & 80.5 & 77.0 & 77.6 & 82.9 & 81.7 & 72.6 & 87.2 & 87.8 \\
\hline 148 & 68.0 & 71.5 & 80.1 & 76.7 & 77.3 & 82.5 & 81.2 & 72.0 & 86.8 & 87.4 \\
\hline 149 & 67.8 & 71.4 & 79.9 & 76.5 & 77.1 & 82.3 & 81.0 & 71.6 & 86.5 & 87.2 \\
\hline 150 & 67.7 & 71.3 & 79.7 & 76.3 & 76.9 & 82.1 & 80.7 & 71.3 & 86.3 & 87.0 \\
\hline 151 & 82.5 & 86.2 & 97.1 & 92.8 & 93.6 & 99.4 & 99.4 & 92.4 & 104.1 & 104.6 \\
\hline 152 & 79.4 & 83.0 & 93.1 & 89.1 & 89.8 & 95.4 & 94.9 & 87.1 & 99.9 & 100.5 \\
\hline 153 & 78.4 & 82.0 & 91.6 & 87.7 & 88.5 & 93.9 & 93.3 & 85.1 & 98.4 & 99.0 \\
\hline 154 & 77.5 & 81.1 & 90.5 & 86.7 & 87.4 & 92.8 & 92.0 & 83.5 & 97.2 & 97.8 \\
\hline 155 & 77.0 & 80.5 & 89.7 & 86.0 & 86.7 & 92.0 & 91.1 & 82.4 & 96.4 & 97.0 \\
\hline 156 & 76.3 & 79.9 & 88.9 & 85.2 & 85.9 & 91.2 & 90.2 & 81.3 & 95.5 & 96.2 \\
\hline 157 & 75.9 & 79.5 & 88.3 & 84.7 & 85.4 & 90.6 & 89.5 & 80.5 & 95.0 & 95.6 \\
\hline 158 & 75.4 & 78.9 & 87.6 & 84.1 & 84.8 & 90.0 & 88.8 & 79.7 & 94.3 & 94.9 \\
\hline 159 & 75.0 & 78.5 & 87.1 & 83.6 & 84.3 & 89.5 & 88.3 & 79.0 & 93.8 & 94.4 \\
\hline 160 & 74.4 & 77.9 & 86.4 & 83.0 & 83.6 & 88.8 & 87.5 & 78.2 & 93.1 & 93.7 \\
\hline 161 & 74.0 & 77.5 & 86.0 & 82.5 & 83.2 & 88.4 & 87.0 & 77.6 & 92.6 & 93.3 \\
\hline 162 & 73.3 & 76.9 & 85.4 & 81.9 & 82.6 & 87.8 & 86.4 & 77.0 & 92.0 & 92.7 \\
\hline 163 & 72.4 & 76.0 & 84.6 & 81.1 & 81.8 & 87.0 & 85.7 & 76.4 & 91.3 & 91.9 \\
\hline 164 & 71.2 & 74.8 & 83.5 & 80.0 & 80.7 & 85.9 & 84.7 & 75.5 & 90.2 & 90.8 \\
\hline 165 & 70.5 & 74.0 & 82.9 & 79.3 & 80.0 & 85.2 & 84.1 & 75.0 & 89.6 & 90.2 \\
\hline 166 & 70.0 & 73.5 & 82.4 & 78.8 & 79.5 & 84.8 & 83.6 & 74.5 & 89.1 & 89.7 \\
\hline 167 & 69.4 & 73.0 & 81.8 & 78.3 & 78.9 & 84.2 & 83.0 & 73.9 & 88.5 & 89.1 \\
\hline 168 & 68.8 & 72.4 & 81.2 & 77.7 & 78.3 & 83.6 & 82.5 & 73.4 & 87.9 & 88.5 \\
\hline 169 & 68.5 & 72.0 & 80.8 & 77.3 & 77.9 & 83.2 & 82.0 & 72.8 & 87.5 & 88.1 \\
\hline 170 & 68.0 & 71.6 & 80.3 & 76.8 & 77.4 & 82.7 & 81.5 & 72.2 & 87.0 & 87.6 \\
\hline 171 & 67.7 & 71.3 & 79.9 & 76.4 & 77.1 & 82.3 & 81.0 & 71.7 & 86.5 & 87.2 \\
\hline 172 & 82.5 & 86.2 & 97.1 & 92.8 & 93.5 & 99.3 & 99.3 & 92.3 & 104.0 & 104.6 \\
\hline 173 & 79.4 & 83.1 & 93.1 & 89.1 & 89.8 & 95.4 & 94.9 & 87.1 & 99.9 & 100.5 \\
\hline 174 & 78.4 & 82.0 & 91.7 & 87.8 & 88.5 & 94.0 & 93.3 & 85.2 & 98.5 & 99.0 \\
\hline 175 & 77.5 & 81.1 & 90.5 & 86.7 & 87.4 & 92.8 & 92.0 & 83.5 & 97.2 & 97.8 \\
\hline 176 & 76.9 & 80.4 & 89.6 & 85.9 & 86.6 & 91.9 & 91.0 & 82.2 & 96.3 & 96.9 \\
\hline 177 & 76.3 & 79.9 & 88.8 & 85.2 & 85.9 & 91.2 & 90.1 & 81.3 & 95.5 & 96.1 \\
\hline 178 & 75.9 & 79.4 & 88.2 & 84.7 & 85.3 & 90.6 & 89.4 & 80.4 & 94.9 & 95.5 \\
\hline 179 & 75.4 & 78.9 & 87.6 & 84.1 & 84.7 & 90.0 & 88.8 & 79.6 & 94.3 & 94.9 \\
\hline 180 & 74.9 & 78.5 & 87.1 & 83.6 & 84.2 & 89.5 & 88.2 & 79.0 & 93.7 & 94.4 \\
\hline 181 & 74.5 & 78.0 & 86.5 & 83.1 & 83.7 & 88.9 & 87.6 & 78.3 & 93.2 & 93.8 \\
\hline 182 & 74.0 & 77.5 & 86.0 & 82.5 & 83.2 & 88.3 & 87.0 & 77.5 & 92.6 & 93.2 \\
\hline 183 & 73.3 & 76.8 & 85.3 & 81.9 & 82.5 & 87.7 & 86.4 & 76.9 & 92.0 & 92.6 \\
\hline 184 & 72.4 & 75.9 & 84.6 & 81.1 & 81.7 & 87.0 & 85.7 & 76.4 & 91.2 & 91.9 \\
\hline 185 & 71.3 & 74.9 & 83.6 & 80.1 & 80.7 & 86.0 & 84.8 & 75.5 & 90.3 & 90.9 \\
\hline 186 & 70.5 & 74.1 & 82.9 & 79.3 & 80.0 & 85.2 & 84.1 & 74.9 & 89.6 & 90.2 \\
\hline 187 & 69.8 & 73.4 & 82.2 & 78.6 & 79.3 & 84.5 & 83.3 & 74.2 & 88.8 & 89.4 \\
\hline 188 & 69.3 & 72.8 & 81.6 & 78.1 & 78.7 & 84.0 & 82.8 & 73.6 & 88.3 & 88.9 \\
\hline 189 & 68.7 & 72.2 & 81.0 & 77.5 & 78.2 & 83.4 & 82.3 & 73.2 & 87.7 & 88.3 \\
\hline 190 & 68.3 & 71.8 & 80.6 & 77.0 & 77.7 & 83.0 & 81.8 & 72.6 & 87.3 & 87.9 \\
\hline 191 & 68.0 & 71.5 & 80.2 & 76.7 & 77.4 & 82.6 & 81.4 & 72.2 & 86.9 & 87.5 \\
\hline 192 & 67.5 & 71.1 & 79.7 & 76.2 & 76.8 & 82.0 & 80.8 & 71.5 & 86.3 & 86.9 \\
\hline 193 & 80.0 & 83.6 & 93.9 & 89.8 & 90.5 & 96.2 & 95.9 & 88.3 & 100.8 & 101.3 \\
\hline 194 & 78.7 & 82.3 & 92.0 & 88.1 & 88.8 & 94.3 & 93.7 & 85.5 & 98.8 & 99.4 \\
\hline
\end{tabular}




\begin{tabular}{|c|c|c|c|c|c|c|c|c|c|c|}
\hline Location & $63 \mathrm{~Hz}$ & $125 \mathrm{~Hz}$ & $250 \mathrm{~Hz}$ & $500 \mathrm{~Hz}$ & $1 \mathrm{kHz}$ & $2 \mathrm{kHz}$ & $4 \mathrm{kHz}$ & $8 \mathrm{kHz}$ & dBA & dB \\
\hline 195 & 77.9 & 81.5 & 90.9 & 87.1 & 87.8 & 93.2 & 92.4 & 83.9 & 97.6 & 98.2 \\
\hline 196 & 77.2 & 80.7 & 89.9 & 86.2 & 86.9 & 92.3 & 91.3 & 82.7 & 96.7 & 97.2 \\
\hline 197 & 76.7 & 80.3 & 89.3 & 85.7 & 86.4 & 91.7 & 90.7 & 81.8 & 96.0 & 96.6 \\
\hline 198 & 76.1 & 79.6 & 88.5 & 84.9 & 85.6 & 90.8 & 89.7 & 80.7 & 95.1 & 95.8 \\
\hline 199 & 75.5 & 79.1 & 87.8 & 84.2 & 84.9 & 90.1 & 88.9 & 79.8 & 94.4 & 95.0 \\
\hline 200 & 75.1 & 78.6 & 87.2 & 83.7 & 84.4 & 89.6 & 88.3 & 79.1 & 93.8 & 94.5 \\
\hline 201 & 74.7 & 78.2 & 86.7 & 83.3 & 83.9 & 89.1 & 87.8 & 78.4 & 93.3 & 94.0 \\
\hline 202 & 74.3 & 77.8 & 86.3 & 82.8 & 83.5 & 88.7 & 87.3 & 78.0 & 92.9 & 93.6 \\
\hline 203 & 73.7 & 77.3 & 85.7 & 82.3 & 82.9 & 88.1 & 86.7 & 77.3 & 92.4 & 93.0 \\
\hline 204 & 72.8 & 76.4 & 84.9 & 81.4 & 82.1 & 87.3 & 86.0 & 76.6 & 91.5 & 92.2 \\
\hline 205 & 71.9 & 75.5 & 84.1 & 80.6 & 81.3 & 86.5 & 85.2 & 75.9 & 90.7 & 91.4 \\
\hline 206 & 71.0 & 74.5 & 83.2 & 79.7 & 80.3 & 85.6 & 84.4 & 75.1 & 89.9 & 90.5 \\
\hline 207 & 70.0 & 73.6 & 82.3 & 78.8 & 79.4 & 84.6 & 83.4 & 74.2 & 88.9 & 89.5 \\
\hline 208 & 69.2 & 72.8 & 81.5 & 78.0 & 78.6 & 83.8 & 82.6 & 73.5 & 88.2 & 88.7 \\
\hline 209 & 68.5 & 72.0 & 80.7 & 77.2 & 77.8 & 83.1 & 81.9 & 72.7 & 87.4 & 88.0 \\
\hline 210 & 68.1 & 71.7 & 80.3 & 76.8 & 77.4 & 82.7 & 81.4 & 72.2 & 86.9 & 87.6 \\
\hline 211 & 68.0 & 71.5 & 80.0 & 76.6 & 77.2 & 82.4 & 81.1 & 71.9 & 86.7 & 87.3 \\
\hline 212 & 67.9 & 71.4 & 79.9 & 76.5 & 77.1 & 82.3 & 81.0 & 71.6 & 86.5 & 87.2 \\
\hline 213 & 68.0 & 71.5 & 80.0 & 76.5 & 77.2 & 82.4 & 81.0 & 71.6 & 86.6 & 87.3 \\
\hline 214 & 79.4 & 83.0 & 92.8 & 88.9 & 89.6 & 95.1 & 94.5 & 86.3 & 99.6 & 100.2 \\
\hline 215 & 78.4 & 82.0 & 91.5 & 87.7 & 88.4 & 93.8 & 93.0 & 84.5 & 98.2 & 98.8 \\
\hline 216 & 77.6 & 81.2 & 90.5 & 86.7 & 87.4 & 92.8 & 91.9 & 83.2 & 97.2 & 97.8 \\
\hline 217 & 76.9 & 80.5 & 89.5 & 85.9 & 86.6 & 91.9 & 90.9 & 82.0 & 96.2 & 96.8 \\
\hline 218 & 76.3 & 79.9 & 88.8 & 85.2 & 85.9 & 91.2 & 90.1 & 81.0 & 95.5 & 96.1 \\
\hline 219 & 75.7 & 79.3 & 88.0 & 84.5 & 85.2 & 90.4 & 89.2 & 80.0 & 94.7 & 95.3 \\
\hline 220 & 75.3 & 78.8 & 87.5 & 84.0 & 84.6 & 89.9 & 88.6 & 79.3 & 94.1 & 94.8 \\
\hline 221 & 74.9 & 78.4 & 87.0 & 83.5 & 84.2 & 89.4 & 88.1 & 78.8 & 93.6 & 94.3 \\
\hline 222 & 74.3 & 77.9 & 86.4 & 82.9 & 83.6 & 88.8 & 87.4 & 78.0 & 93.0 & 93.7 \\
\hline 223 & 73.8 & 77.3 & 85.7 & 82.3 & 83.0 & 88.1 & 86.8 & 77.3 & 92.4 & 93.0 \\
\hline 224 & 72.6 & 76.1 & 84.6 & 81.1 & 81.8 & 87.0 & 85.7 & 76.3 & 91.2 & 91.9 \\
\hline 225 & 71.2 & 74.7 & 83.2 & 79.8 & 80.4 & 85.6 & 84.2 & 74.9 & 89.8 & 90.5 \\
\hline 226 & 70.5 & 74.1 & 82.5 & 79.1 & 79.7 & 84.9 & 83.6 & 74.2 & 89.1 & 89.8 \\
\hline 227 & 69.8 & 73.4 & 81.9 & 78.4 & 79.1 & 84.3 & 83.0 & 73.7 & 88.5 & 89.2 \\
\hline 228 & 69.4 & 72.9 & 81.5 & 78.0 & 78.7 & 83.9 & 82.6 & 73.4 & 88.2 & 88.8 \\
\hline 229 & 69.4 & 73.0 & 81.6 & 78.1 & 78.8 & 84.0 & 82.8 & 73.6 & 88.3 & 88.9 \\
\hline 230 & 68.4 & 72.0 & 80.8 & 77.2 & 77.9 & 83.2 & 82.0 & 72.8 & 87.5 & 88.1 \\
\hline 231 & 68.3 & 71.9 & 80.7 & 77.1 & 77.8 & 83.1 & 81.9 & 72.7 & 87.4 & 88.0 \\
\hline 232 & 68.1 & 71.7 & 80.4 & 76.9 & 77.5 & 82.8 & 81.5 & 72.3 & 87.1 & 87.7 \\
\hline 233 & 67.7 & 71.2 & 80.0 & 76.5 & 77.1 & 82.4 & 81.2 & 71.9 & 86.7 & 87.3 \\
\hline 234 & 67.3 & 70.9 & 79.6 & 76.1 & 76.7 & 82.0 & 80.8 & 71.6 & 86.3 & 86.9 \\
\hline 235 & 79.5 & 83.1 & 93.1 & 89.1 & 89.9 & 95.4 & 94.9 & 86.8 & 99.9 & 100.5 \\
\hline 236 & 80.3 & 83.9 & 94.2 & 90.1 & 90.9 & 96.5 & 96.1 & 88.3 & 101.0 & 101.6 \\
\hline 237 & 82.3 & 86.0 & 96.8 & 92.5 & 93.3 & 99.1 & 99.0 & 91.7 & 103.7 & 104.3 \\
\hline 238 & 78.9 & 82.5 & 92.4 & 88.5 & 89.2 & 94.8 & 94.1 & 85.9 & 99.2 & 99.8 \\
\hline 239 & 79.6 & 83.3 & 93.4 & 89.4 & 90.1 & 95.7 & 95.3 & 87.3 & 100.3 & 100.8 \\
\hline 240 & 79.8 & 83.4 & 93.7 & 89.6 & 90.3 & 95.9 & 95.5 & 87.6 & 100.5 & 101.0 \\
\hline 241 & 78.8 & 82.4 & 92.3 & 88.4 & 89.1 & 94.6 & 94.1 & 85.9 & 99.1 & 99.7 \\
\hline 242 & 79.3 & 82.9 & 93.1 & 89.0 & 89.8 & 95.3 & 94.9 & 86.9 & 99.9 & 100.4 \\
\hline 243 & 79.6 & 83.2 & 93.4 & 89.3 & 90.1 & 95.7 & 95.3 & 87.5 & 100.2 & 100.8 \\
\hline
\end{tabular}




\begin{tabular}{|c|c|c|c|c|c|c|c|c|c|c|}
\hline Location & $\mathbf{6 3} \mathbf{~ H z}$ & $\mathbf{1 2 5} \mathbf{~ H z}$ & $\mathbf{2 5 0} \mathbf{~ H z}$ & $\mathbf{5 0 0} \mathbf{~ H z}$ & $\mathbf{1 ~} \mathbf{~ H z}$ & $\mathbf{2} \mathbf{~ k H z}$ & $\mathbf{4} \mathbf{~} \mathbf{H z}$ & $\mathbf{8} \mathbf{~ k H z}$ & $\mathbf{d B A}$ & $\mathbf{d B}$ \\
\hline 244 & 79.6 & 83.2 & 93.3 & 89.3 & 90.0 & 95.6 & 95.1 & 87.0 & 100.1 & 100.7 \\
\hline 245 & 80.3 & 83.9 & 94.3 & 90.2 & 91.0 & 96.6 & 96.3 & 88.6 & 101.2 & 101.7 \\
\hline 246 & 82.5 & 86.1 & 97.1 & 92.7 & 93.5 & 99.3 & 99.3 & 92.2 & 104.0 & 104.5 \\
\hline
\end{tabular}

In determining the validity of the model approach relative to comparing the actual underground measurements to the predicted or determined sound pressure levels when utilizing the model approach, measurement positions 235 thru 237, shown in figure 6.42, were examined to provide the predicted or determined sound pressure levels at the operator position of the roof bolting machine. Figure 6.44 displays a "snapshot" of the sound pressure level contours, along with the A-weighted sound pressure levels at measuring points 235 thru 237 of the model.

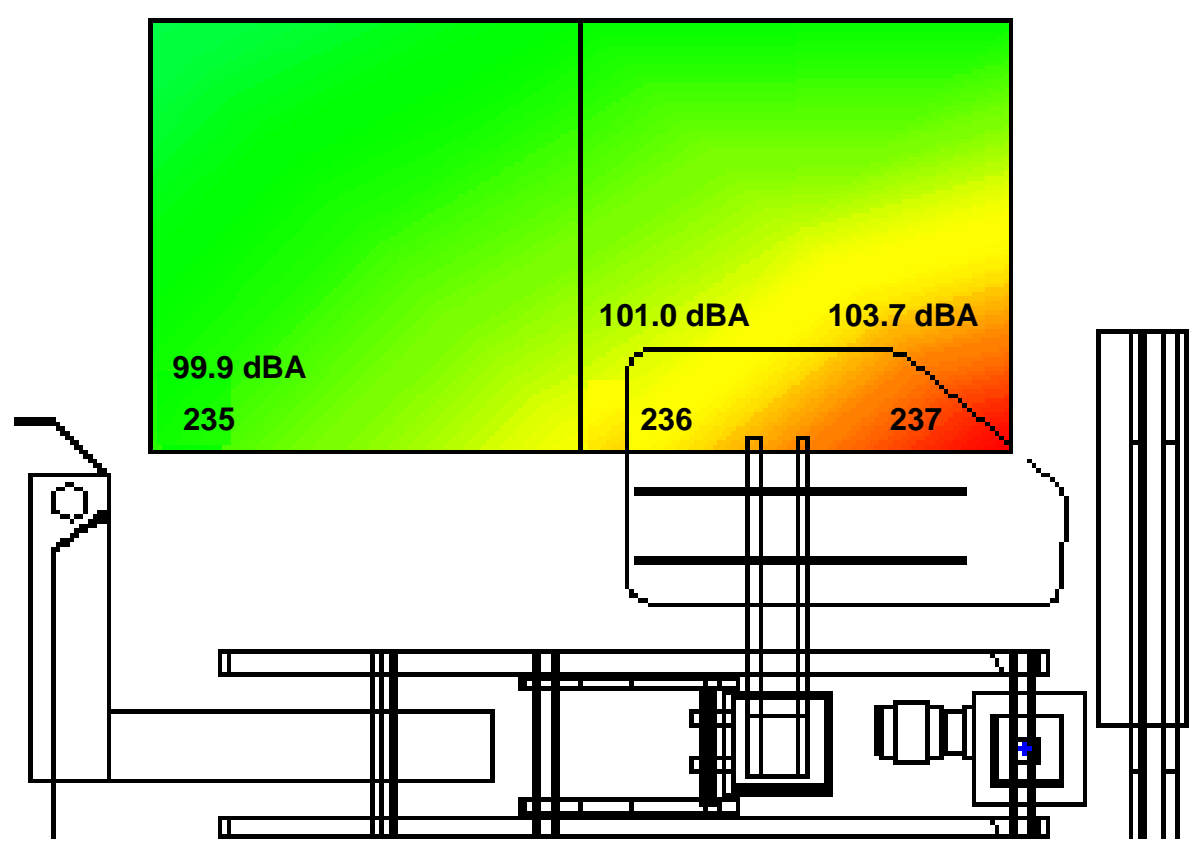

Figure 6.44 A-Weighted Sound Pressure Levels Near Operator Position of Roof Bolting Machine 
Table 6.10 provided a sound pressure level of $101 \mathrm{dBA}$ at the operator position of the roof bolting machine from underground measurements. The location of the measurement underground was the same location as measuring point number 236 utilized for the model approach. The determined or predicted sound pressure level using the modeling approach was $101 \mathrm{dBA}$, the same sound pressure level as measured underground. It should be noted, in order for model validation, data was collected in an actual underground mine environment. Due to mine accessibility, characterization of the acoustic environment, along with measuring sound pressure levels associated operators of roof bolting machines occurred in a mine with low compressive strength rock media during drilling operations. However, the research effort has proven that measuring laboratory sound power level results of the roof bolting machine given any compressive strength rock media, along with proper characterization of the acoustic and geological environment underground, one could predict the sound pressure level experienced by a roof bolting machine operator with confidence.

Therefore, this section provided the mining community with an approach, which utilizes sound power levels acquired from laboratory tests and measured absorption coefficients from underground testing to accurately predict or determine sound pressure levels, at any location in a mine section. The approach as compared to the modeling approach in section 6.2 , provides a more reliable and accurate determination of sound pressure level at any position or location within a mine section without the limitations relative to absorption coefficients and near-field limitations as discussed in section 6.2. Section 6.3.6 below will demonstrate and provide an approach for determining the noise dosage of a roof bolting machine operator utilizing the predicted or determined sound pressure levels obtained from the modeling approach addressed from this section. 
6.3.6 Determining Noise Dosage of a Roof Bolter Operator from Predicted Sound Pressure $\underline{\text { Levels }}$

The noise dosage a worker receives can be expressed by the following equation:

$$
\text { Dose } \%=(100 / T C)\left[\int_{0}^{R T i m e} 2^{(L S-C L) / E R} d t\right]
$$

and

$$
\text { Dose } \%=(100 / T C)\left(2^{(L S-C L) / E R}\right)\left[\int_{0}^{R T i m e} d t\right]
$$

therefore $\quad D o s e \%=(100 / T C)\left(2^{(L S-C L) / E R}\right)($ RTime $)$

where

$$
\begin{aligned}
& \text { Dose } \%=\text { workers } ' \text { noise dosage, percent } \\
& \text { TC }=\text { criterion time, } 8 \text { hours or } 28,800 \text { seconds } \\
& \text { LS }=\text { Sound pressure level, dBA } \\
& \mathrm{CL}=\text { Criterion level, dBA } \\
& \text { ER }=\text { Exchange rate, dBA } \\
& \text { RTime }=\text { Run time, seconds }
\end{aligned}
$$

Using equation (12) above, with a predicted or determined sound pressure level at the operator position of a roof bolting machine, the machine operators' noise dosage could then be determined. For instance, if we use the example illustrated above in section 6.3.5.6, where the compressive strength of the rock media was $6,000 \mathrm{psi}$ and the roof bolting machine operator utilized the vacuum drilling method, with a 1-inch bit, hex drill steel, a rotational speed of 500 rpm and a thrust setting of $6,363 \mathrm{lbs}$, the measured and validated predicted sound pressure level was determined to be $101 \mathrm{dBA}$ at the operator position of the machine. Using equation (12), the mining community can then determine the operators' noise dosage, relative to the MSHAPermissible Exposure Limit (MSHA-PEL) (90 decibels, A-weighted, as an 8-hour time-weighted 
average [90 dBA as an 8-hr TWA]), with a $5 \mathrm{dBA}$ exchange rate) or the NIOSH-Recommended Exposure Limit (NIOSH-REL) (85 decibels, A-weighted, as an 8-hour time-weighted average [85 $\mathrm{dBA}$ as an 8-hr TWA]), with a $3 \mathrm{dBA}$ exchange rate (26) received per drilling an individual hole during the drilling cycle of the roof bolting machine as shown below.

$$
\text { Dose } \%=(100 / T C)\left(2^{(L S-C L) / E R}\right)(\text { RTime })
$$

where

$\mathrm{TC}=28,800$ seconds

$\mathrm{LS}=101 \mathrm{dBA}$

$\mathrm{CL}=90 \mathrm{dBA}$

$\mathrm{ER}-5 \mathrm{dBA}$

RTime $=50$ seconds (based on a penetration rate of 1.2 inches $/$ second and a hole depth of $5 \mathrm{ft}$ ) therefore, the dose percentage of the roof bolter operator for this particular example would be:

$$
\text { Dose } \%=(100 / 28,800)\left(2^{(101-90) / 5}\right)(50)=(.00347)(4.59)(50)=0.80 \%
$$

Additionally, assuming similar rock media (compressive strength of 6,000 psi) and the operator of the roof bolting machine drilling 78 drill holes per shift for installation of roof bolts, the operator's noise dosage relative to only utilizing the roof bolting machine for drilling would be:

$0.8 \% \times(78$ drill holes $)=62.4 \%$ of the MSHA-PEL of $100 \%$

In comparison, the NIOSH-REL noise dosage for the same situation mentioned above would be $546 \%$, based on a criterion level of $85 \mathrm{dBA}$ and an exchange rate of $3 \mathrm{dBA}$. Table 6.13 below, provides the noise dosage of a roof bolter operator (per hole and per shift), relative to a respective sound pressure level and based on a run time of each hole consisting of 50 seconds and assuming the operator will drill 78 holes per his working shift. 
Table 6.13 Noise Dosage (MSHA and NIOSH) of Roof Bolting Machine Operator

\begin{tabular}{|c|c|c|c|c|c|c|}
\hline $\begin{array}{c}\text { Sound } \\
\text { Pressure Level } \\
\text { dBA }\end{array}$ & $\begin{array}{c}\text { Run Time } \\
\text { (per hole) } \\
\text { (sec) }\end{array}$ & $\begin{array}{c}\text { MSHA-Dose } \\
\text { (per hole) } \\
\text { (\%) }\end{array}$ & $\begin{array}{c}\text { NIOSH-Dose } \\
\text { (per hole) } \\
\text { (\%) }\end{array}$ & $\begin{array}{c}\text { Drill Holes } \\
\text { (per shift) }\end{array}$ & $\begin{array}{c}\text { MSHA-Dose } \\
\text { (per shift) } \\
\text { (\%) }\end{array}$ & $\begin{array}{c}\text { NIOSH-Dose } \\
\text { (per shift) } \\
\text { (\%) }\end{array}$ \\
\hline 80 & 50 & 0.0 & 0.1 & 78 & 3.4 & 4.3 \\
\hline 82 & 50 & 0.1 & 0.1 & 78 & 4.5 & 6.8 \\
\hline 85 & 50 & 0.1 & 0.2 & 78 & 6.8 & 13.5 \\
\hline 86 & 50 & 0.1 & 0.2 & 78 & 7.8 & 17.1 \\
\hline 87 & 50 & 0.1 & 0.3 & 78 & 8.9 & 21.5 \\
\hline 88 & 50 & 0.1 & 0.3 & 78 & 10.3 & 27.1 \\
\hline 89 & 50 & 0.2 & 0.4 & 78 & 11.8 & 34.1 \\
\hline 90 & 50 & 0.2 & 0.6 & 78 & 13.5 & 43.0 \\
\hline 91 & 50 & 0.2 & 0.7 & 78 & 15.6 & 54.2 \\
\hline 92 & 50 & 0.2 & 0.9 & 78 & 17.9 & 68.2 \\
\hline 93 & 50 & 0.3 & 1.1 & 78 & 20.5 & 86.0 \\
\hline 94 & 50 & 0.3 & 1.4 & 78 & 23.6 & 108.3 \\
\hline 95 & 50 & 0.3 & 1.7 & 78 & 27.1 & 136.5 \\
\hline 96 & 50 & 0.4 & 2.2 & 78 & 31.1 & 172.0 \\
\hline 97 & 50 & 0.5 & 2.8 & 78 & 35.7 & 216.7 \\
\hline 98 & 50 & 0.5 & 3.5 & 78 & 41.1 & 273.0 \\
\hline 99 & 50 & 0.6 & 4.4 & 78 & 47.2 & 343.9 \\
\hline 100 & 50 & 0.7 & 5.6 & 78 & 54.2 & 433.3 \\
\hline 101 & 50 & 0.8 & 7.0 & 78 & 62.2 & 546.0 \\
\hline 102 & 50 & 0.9 & 8.8 & 78 & 71.5 & 687.9 \\
\hline 103 & 50 & 1.1 & 11.1 & 78 & 82.1 & 866.7 \\
\hline 104 & 50 & 1.2 & 14.0 & 78 & 94.3 & 1091.9 \\
\hline 105 & 50 & 1.4 & 17.6 & 78 & 108.3 & 1375.7 \\
\hline 106 & 50 & 1.6 & 22.2 & 78 & 124.4 & 1733.3 \\
\hline
\end{tabular}

Chapter 6 has provided the mining community with proven approaches to predict sound pressure levels, with relative certainty, at the operator position of a roof bolting machine and at differing locations within a mine section, utilizing laboratory testing results relative to the roof bolting machine. Additionally, the mining community was presented with an approach to characterize the noise dosage a roof bolting machine operator will receive, based on laboratory results. These approaches provide the mining industry with the opportunity to predict sound pressure levels and noise dosage to machine operators without the laborious effort of conducting numerous underground measurements. 


\section{CHAPTER 7 \\ CONCLUSIONS}

The evaluation of differing noise control technologies relative to a roof bolting machine was possible utilizing the acoustically controlled reverberation room at the Pittsburgh Research Laboratory, along with installing thrust, rotational speed and penetration sensors on the machine as discussed in Chapter 4 . Chapter 5 of the research effort provided testing results related to using differing drilling configurations (thrust, rotational speed, penetration rate, bit size, type of drill steel) and drilling methods (vacuum or dry, wet, mist) in high compressive strength rock media (>20,000 psi) relative to sound power levels measured from the roof bolting machine. When comparing round and hex drill steel, round drill steel should be used when utilizing the vacuum type of drilling method and hex drill steel should be utilized when performing the wet or mist type of drilling method. While increasing the thrust does yield an increased sound power level for both of the round and hex drill steel, the differences are negligible. When comparing rotational speed affect relative to round or hex drill steel, the round drill steel, during vacuum type drilling, provides a lower sound power level than similar hex drill steel tests. For the wet or mist system type of drilling, there appears to be no difference between the one-inch and 1.375-inch round and hex drill steel. Upon comparing penetration rates relative to round or hex drill steel in relation to thrust or rotational speed, their appears to be minimal affect attributed to thrust or rotational speeds.

When comparing the one-inch diameter bits to the 1.375-inch diameter bits, the oneinch diameter drill bits are slightly quieter than the 1.375-inch diameter drill bits. The penetration rates relative to the one-inch drill bits are noticeably higher than the 1.375-inch 
bits, on an order of two to three times higher. When comparing the 1-inch bit to the 1.375inch bit relative to rotational speed, the one-inch bit performed significantly better than the 1.375-inch bit. For optimal performance and lower sound power levels, rotational speeds in the range of 200-400 rpm performed better and were quieter.

When comparing the different types of drilling methods, specifically vacuum, wet and mist drilling, penetration rates utilizing a wet or mist system drilling technique were much higher than using a dry or vacuum type drilling method. Additionally, utilizing a wet or mist system proved to emit less noise than similar tests conducted under vacuum or dry conditions. Much of the difference is attributable to the lubricating affect of the water or mist, which attenuates the higher frequency noise during the drilling process.

The individual test data collected (approximately 500 tests) from the research effort was then compiled, summarized and statistically correlated for drilling into a highcompressive strength media (>20,000 psi) by developing one equation, in which, could be used to determine or predict overall sound power levels given any type of drilling method (vacuum, wet or mist) and using varying types of drilling parameters or configurations related to thrust, rotational speed, bit size and type of drill steel. The statistical model equation, provided the mining community with a simple and reliable approach to predict a sound power level for a roof bolting machine during the drilling operation in high compressive strength rock media, given any type of drilling method (vacuum, wet or mist) and drilling parameter configuration (thrust, rotational speed, bit size and type of drill steel). The coefficient of determination for the test data, $\mathrm{R}^{2}$, or the measure of the goodness of fit of a linear model, was equal to .849 , indicating the statistical model to be a good fit or a representation of the data set. Furthermore, the residuals of the data set (laboratory minus 
model values of sound power) provided an excellent correlation with each other. Five residuals out of 486 , were determined to be plus or minus 3.5 to $4.0 \mathrm{dBA}$ and nine residuals at plus or minus 3.0 to $3.5 \mathrm{dBA}$. The remaining 472 residuals all fell within plus or minus 0 to $3.0 \mathrm{dBA}$. Therefore, $97 \%$ of the data fell within a residual of 0 to $3.0 \mathrm{dBA}$ and would be well received within the acoustical community, particularly during prediction exercises.

Chapter 6 then offered the mining community with two different approaches in predicting sound pressure levels at the operator position of a roof bolting machine. One method of prediction, utilized overall sound power levels either measured from laboratory tests or determined (predicted) from the statistical model equation. The other approach, a more sophisticated and reliable approach, predicted sound pressure levels at the operator position of the roof bolting machine as well as other locations within the underground mining section, using full-octave band frequency measurements obtained from laboratory testing for input into a computer model for simulating and predicting sound pressure levels from sound power level measurements. This approach, predicted the same sound pressure level at the operator position of a roof bolting machine, when compared to the actual sound pressure level from underground measurements. The approach, proved especially reliable, utilizing: 1) underground measurements to characterize the acoustic properties of an underground coal mine section in determining the correct sabine or absorption coefficients; 2) laboratory testing in the reverberation room to determine full-octave band sound power levels of the roof bolting machine and 3) the use of an acoustical ray-tracing computer model program for predicting sound pressure levels from the required input data as mentioned above. 
The research effort has provided the mining community with: 1) an understanding on how differing drilling configurations and drilling methods attribute to the sound power levels generated from a roof bolting machine while drilling into a high compressive rock media; 2) optimal drilling configurations and drilling methods in reducing sound power levels of the roof bolting machine; 3) a statistically valid equation for determining sound power levels of a roof bolting machine given differing drilling configurations and drilling methods; 4) a method for predicting sound pressure levels at the operator position and multiple locations in an underground mine related to the drilling cycle of a roof bolting machine and 5) a method for determining an operators' noise dosage relative to a roof bolting machine given any type of drilling configuration or drilling method utilized. 


\section{CHAPTER 8}

\section{RECOMMENDATIONS FOR FUTURE RESEARCH}

This research effort has provided the mining industry with: 1) a complete understanding on how differing drilling configurations and drilling methods attribute to the sound power levels generated from a roof bolting machine while drilling into a high compressive rock media; 2) optimal drilling configurations and drilling methods in reducing sound power levels of the roof bolting machine; 3) a statistically valid equation for determining sound power levels of a roof bolting machine given differing drilling configurations and drilling methods; 4) a method for predicting sound pressure levels at the operator position and multiple locations in an underground mine related to the drilling cycle of a roof bolting machine and 5) a method for determining an operators' noise dosage relative to a roof bolting machine given any type of drilling configuration or drilling method utilized.

Initially, this research program focused on the related sound power and sound pressure levels attributed to roof bolting machines when drilling into high compressive strength rock media (>20,000 psi). Additional research efforts should be performed to characterize sound power and sound pressure level emissions of roof bolting machines when drilling into either low or medium compressive strength rock media. A similar testing plan should be developed and performed comparable to the plan conducted for determining sound power levels while drilling into high compressive strength rock media (>20,000 psi). Sound power levels should be determined in the laboratory relative to utilizing differing drilling parameters (thrust, rotational speed, drill bit size and type of drill steel) and drilling methods (vacuum, wet or mist) while drilling into low or medium 
compressive strength rock media. Additionally, the data collected from each individual test in the laboratory should then be compiled and analyzed for comparing sound power levels relative to the differing drilling parameters and drilling methods. Furthermore, a statistical analysis should be conducted on the collected data to determine if a statistically valid equation could then be developed, in which, will provide the mining community with a reliable and valid equation for predicting overall sound power levels relative to differing drilling parameters and methods used in low or medium compressive strength rock media.

Secondly, further research should be conducted to continue to characterize and define the acoustical properties related to differing geometrical configurations in underground coal mines. The research program presented, only characterized underground coal mines with roof to floor heights of five and six feet, mine heights lower than five feet and greater than six feet should be investigated to verify if differing mine heights have an affect on the acoustical properties in underground coal mines, as well as examining the affect shotcrete or rock dust usage might have relative to the acoustical properties in underground coal mines.

Additionally, research efforts relative to absorption coefficient determination should span outside the underground coal industry into underground metal and non-metal operations. Eventually, the results of the research effort could possibly be a handbook, in which, would provide the mining industry with the appropriate absorption coefficients relative to the mine type, geometry and geological characteristics for predicting and determining sound power and sound pressure levels underground. 
Finally, the research presented here only focused on the drilling cycle of the roof bolting machine, additional research should be conducted to characterize and monitor the sound power and sound pressure levels attributed to the bolting cycle of the machine and the corresponding noise dosage to the operator. Obtaining this information, would provide the mining industry with a complete understanding relative to the overall noise dosage presented to the operator of the roof bolting machine relative to both, the drilling and bolting cycle of the machine. Acquiring this additional information, would provide extremely useful in the development of engineering noise controls during the bolting cycle of the machine, thereby, reducing the noise exposure to the operator. 


\section{References}

1. Federal Register, Rules and Regulations. Volume 64, Number 176. September 13, 1999.

2. Franks, J.R. Analysis of Audiograms for a Large Cohort of Noise-Exposed Miners. National Institute for Occupational Safety and Health, Internal Report, 1996, pp. $1-7$.

3. International Standard ISO 1999.2 [1990]. Acoustics - determination of occupational noise exposure and estimation of noise-induced hearing impairment. Geneva, Switzerland.

4. Mine Safety and Health Administration. Health Standards for Occupational Noise Exposure; Final Rule, 30 CFR Parts 56, 57, 62, 70, and 71; 64 Federal Register pp. 49548-49634.

5. Seiler, J.P., and Giardino, D.A. The Effect of Threshold on Noise Dosimeter Measurements and Interpretation of Their Results. U.S. Dept. of Labor, Mine Safety and Health Administration, Informational Report, IR 1224, 1994.

6. Title 30 CFR Part 62, 2000-2002, U.S. Department of Labor, Mine Safety and Health Administration, Information

7. Bartholomae, R.C. Mining Machinery Noise Control Guidelines. United States Department of the Interior, Bureau of Mines, 1983, 87pp.

8. Bauer, E.R. Internal Communication. National Institute for Occupational Safety and Health (NIOSH), 2003.

9. Bobick, T.G. and Giardino, D.A. The Noise Environment of the Underground Coal Mine. United States Department of the Interior, Mine Enforcement and Safety Administration, Informational Report, No.1034.

10. Lesage, C., Oddo, R., Champoux, Y. and Attalla, N. Experimental Characterization of the Noise Generation Mechanism of Percussion Drill Rods. CIM Bulletin, v. 90, n. 1010, 1997, pp. 65-69.

11. Champoux, Y., Oddo, R., Guigou, C., and Atalla, N. On the Noise of Percussion Drill Steel Rods. Proceedings, National Conference on Noise Control Engineering, 1994, pp. 169-174.

12. Ogreen, J. A Dynamic Photoelastic Study of Flexural Wave Generation in a Model of Percussive Drilling. Journal of Sound and Vibration, Volume 86 (2), 1983.

13. Stein, R and Aljoe, W. Concentric Drill Steels for Noise Reduction of Percussive Drilling. Proceedings, Inter-Noise, Cambridge, MA, 1986, pp. 333-336. 
14. Visnapsu, A. and Jensen, J. Noise Reduction of a Pneumatic Rock Drill. U.S. Department of the Interior, Bureau of Mines, Report of Investigations, 8082, 1975, 23p.

15. Bartholomae, R. Small Diameter In-the-Hole Percussion Drilling Tool for Percussion Drill Noise Control. Proceedings, National Conference on Noise Control Engineering, 1994, pp. 175-180.

16. Paraszczak, J. and Planeta, S. Evaluation of the Potential of Mining with WaterPowered Jackleg Drills. Journal, Mining Engineering, Volume 48, Number 3, 1996. pp. 68-72.

17. Hurel, A. and Cagnioncle, G. Rotary Drilling Assisted by High Pressure Water Jets. Proceedings, Seventh International Conference on Coal Research, Volume 2, 1985, pp. 261-272.

18. Peterson, J.S. Personal Communication. National Institute for Occupational Safety and Health. Pittsburgh Research Laboratory.

19. International Standard ISO 3743-2. Acoustics-Determination of sound power levels of noise sources using sound pressure-Engineering methods for small, movable sources in reverberant fields. International Organization for Standardization, Case Postale 56, CH-1211, Geneva 20, Switzerland.ISO.

20. International Standard ISO 6926. Acoustics - Requirements for the performance and calibration of reference sound sources used for the determination of sound power levels. International Organization for Standardization, Geneva 20, Switzerland.ISO.

21. Yantek, D.S. Personal Communication. National Institute for Occupational Safety and Health. Pittsburgh Research Laboratory.

22. International Standard ISO/CD 7849. Acoustics-Estimation of airborne noise emitted by machinery using vibration measurements. International Organization for Standardization, Geneva 20, Switzerland.ISO.

23. Peterson, J.S., Kovalchik, P.G. and R.J. Matetic. A Sound Power Level Study of a Roof Bolter, SME Preprint No. 05-72, 2005 SME Conference, Salt Lake City, Utah, 2005, 8 pp.

24. Patterson, W., Huggins, G. and Galaitsis, A. Noise of Diesel-Powered Underground Mining Equipment: Impact, Prediction, and Control. Report No. 2979, Contract No. H0346046, United States Bureau of Mines, March 21, 1975.

25. Cole, G.P. Personal Communication. National Institute for Occupational Safety and Health. Pittsburgh Research Laboratory. 
26. Department of Health and Human Services (NIOSH) Publication No. 98-126. Criteria for a Recommended Standard. Occupational Noise Exposure. June 1998. 122pp. 